
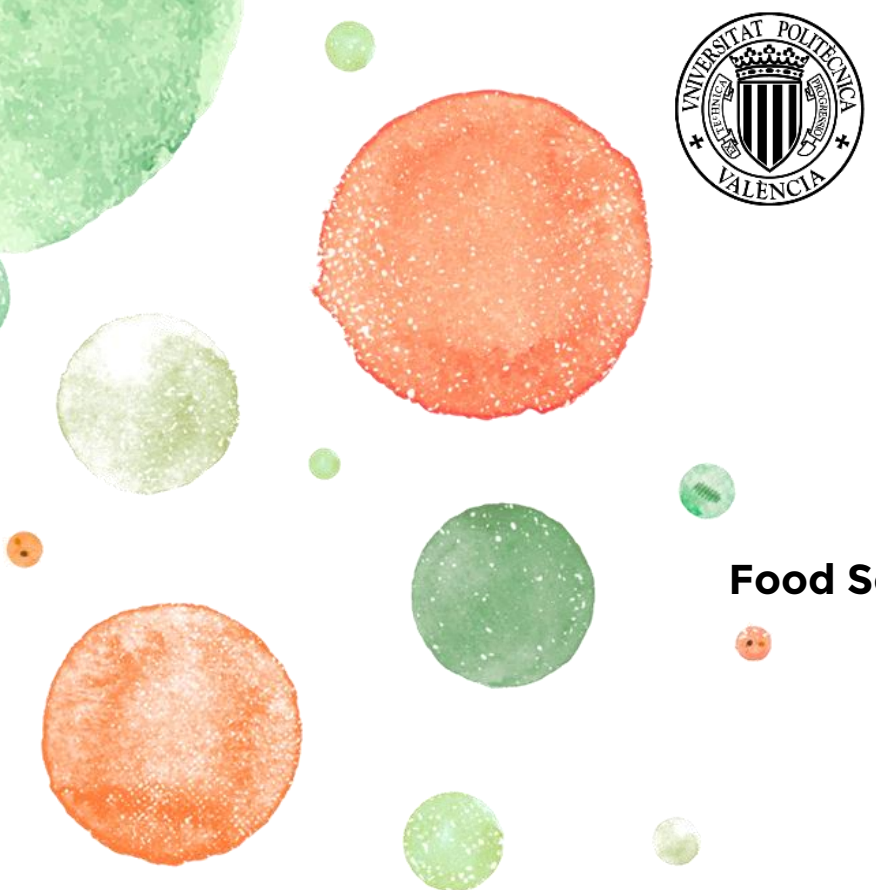

UNIVERSITAT POLITĖCNICA DE VALÈNCIA

PhD Programme in Food Science, Technology and Management

MICROALGAE AS NOVEL INGREDIENTS FOR THE FORMULATION OF FOOD PRODUCTS

Author

Zaida Natalia Uribe Wandurraga

Supervisors

Prof. Dr. Javier Martínez Monzó Prof. Dr. Purificación García Segovia 



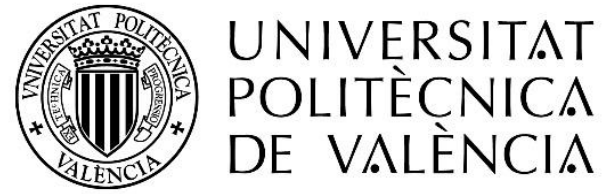

PhD Programme in

Food Science, Technology and Management

\title{
MICROALGAE AS NOVEL INGREDIENTS FOR THE FORMULATION OF FOOD PRODUCTS
}

\author{
Author \\ Zaida Natalia Uribe Wandurraga \\ Supervisors \\ Prof. Dr. Javier Martínez Monzó \\ Prof. Dr. Purificación García Segovia
}

Valencia, October 2020 
Cover design: Diana Trujillo Neme Oிin

Zaida Natalia Uribe Wandurraga

Thanks to Arthur Kuipers for contributing to the idea

Layout: Zaida Natalia Uribe Wandurraga 


\title{
PhD Thesis
}

\section{"MICROALGAE AS NOVEL INGREDIENTS FOR THE FORMULATION OF FOOD PRODUCTS"}

\section{EXAMINERS THESIS COMMITTEE}

\author{
Dr. Ana Paula dos Santos Batista \\ Institut National de Recherche pour l'agriculture, \\ I'alimentation et l'environnement (France) \\ Prof. Dr. Ángel Darío González Delgado \\ Universidad de Cartagena (Colombia) \\ Prof. Dr. Víctor Manuel Palacios Macías \\ Universidad de Cádiz (Spain)
}

\author{
DEFENSE THESIS COMMITTEE \\ Dr. Ana Paula dos Santos Batista \\ Institut National de Recherche pour l'agriculture, \\ I'alimentation et l'environnement (France) \\ Prof. Dr. Nuria Martínez Navarrete \\ Universitat Politècnica de València (Spain) \\ Prof. Dr. Atze Jan van der Goot \\ Wageningen University \& Research (The Netherlands)
}

Valencia, October 2020 



\title{
cuinค
}

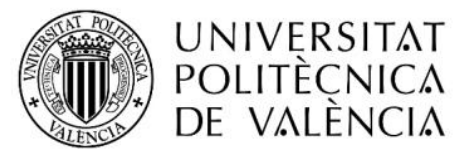

Dr. Javier Martínez Monzó and Dr. Purificación García Segovia, Professors in the Food Technology Department at the Universitat Politècnica de València

\author{
CERTIFY
}

That the $\mathrm{PhD}$ Thesis entitled "Microalgae as novel ingredients for the formulation of food products" has been developed by Zaida Natalia Uribe Wandurraga under our supervision at the Food Innovation and Investigation (CUINA) group in the Food Technology Department at the Universitat Politècnica de València, in order to obtain the PhD degree in Food Science, Technology and Management at the Universitat Politècnica de València.

Valencia, October 2020

Prof. Dr. Javier Martínez Monzó

Prof. Dr. Purificación García Segovia 

In honor of my mom

In memory of my dad 



\section{Table of contents}

Abstract, Resumen and Resum 11

Chapter 1. Introduction, research objectives and thesis outline 19

Chapter 2. Effect of microalgae addition on mineral content, colour 53 and mechanical properties of breadsticks

Chapter 3. In vitro bioaccessibility of minerals from microalgae- 73 enriched cookies

Chapter 4. Microalgae fortification of low-fat oil-in-water food 95 emulsions: an evaluation of the physicochemical and rheological properties

Chapter 5. Influence of microalgae addition in formulation on colour, texture, and extrusion parameters of corn snacks

Chapter 6. $\quad$ Effect of microalgae (Arthrospira platensis and Chlorella 139 vulgaris) addition on 3D printed cookies

Chapter 7. Printability and physicochemical properties of microalgae169 enriched 3D-printed snacks

$\begin{array}{lll}\text { Chapter 8. General discussion } & 201\end{array}$

$\begin{array}{lll}\text { Chapter 9. Conclusions } & 215\end{array}$

$\begin{array}{ll}\text { Acknowledgements } & 221\end{array}$

About the author 



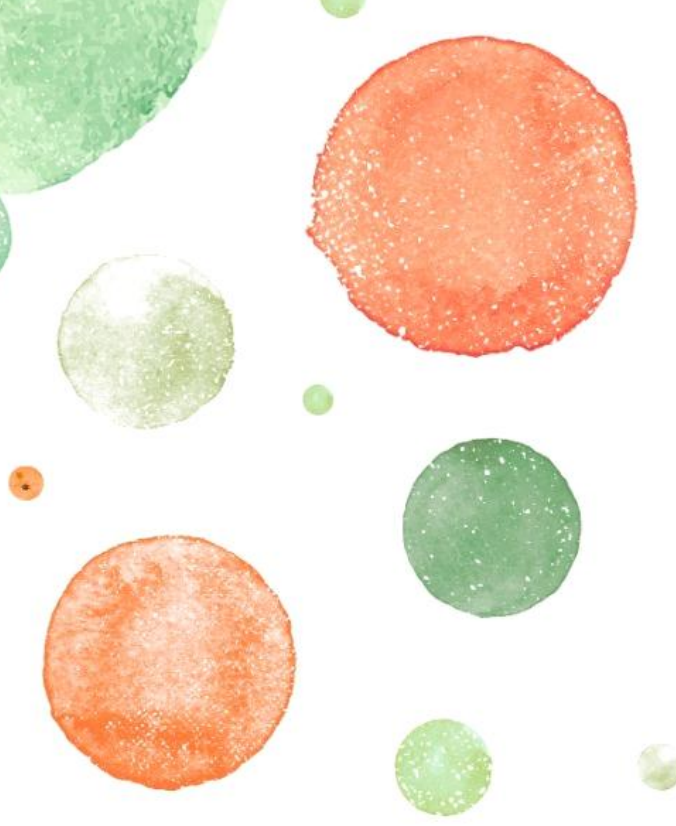

(2) Resumen

\section{and Resum}





\section{Abstract}

Microalgae are microscopic unicellular and photosynthetic organisms that can be found in a wide variety of environments. These microorganisms are very efficient when transforming solar energy into biomass, due to their cellular structure, which is completely submerged in an aqueous medium, forming an adequate surface for the exchange of nutrients and gases.

Microalgae compounds are now known to exhibit cardioprotective, immunomodulatory, antiproliferative, anti-inflammatory, cognitive, neurobehavioral and antimicrobial properties, amongst others. Researchers have shown possible benefits of the incorporation of microalgae in the diet so far. The most common way to consume microalgae is as a dietary supplement in the form of tablets, capsules or powder. The incorporation of microalgae biomass in traditional products has faced the challenge of the appearance of strong green colours, as well as its powdery consistency that can affect the texture and perception of the product. All these aspects constitute the main areas for improvement the development of microalgae-based products, and they are the challenges faced of this project.

The main objective of this $\mathrm{PhD}$ Thesis was the development of novel food products incorporating the nutritional properties of microalgae biomass, thereby increasing or improving the nutritional properties of the original food matrix. To achieve this goal, the effect of the addition of different species of microalgae (Arthrospira platensis (Spirulina), Chlorella vulgaris (Chlorella), Dunaliella salina (Dunaliella) and Nannochloropsis gaditana (Nannochloropsis)) on the physicochemical, rheological and textural properties of different food matrices (baked products (breadsticks, cookies and snacks), emulsions and extrudates) was evaluated. Furthermore, the effect of the incorporation of microalgae using different technologies such as 3D printing or extrusion to obtain food products was studied. In addition, how the incorporation of microalgae affects the nutritional aspects of the food products in terms of the contribution of minerals and their bioavailability was also evaluated.

The rheological properties of doughs, batters and emulsions enriched with microalgae (Spirulina, Chlorella and Dunaliella) indicated that their viscoelastic behaviour was modified and improved, showing characteristics suitable for this type of products. The addition of microalgae (Spirulina and Chlorella) to the doughs and batters used for the 3D printing of cookies and snacks, allowed a better extrusion or printing behaviour. This allowed obtaining 
cylindrical 3D printed samples, more precise in terms of their dimensions with respect to the designed cylindrical structure. In addition, the 3D microalgae-printed sample structures presented greater stability and resistance, before and after the baking process compared to the control sample. For baked products, both for breadsticks and 3D printed snacks, the addition of microalgae (Spirulina and Chlorella) allowed greater stability in terms of texture. Slight changes in the physicochemical and expansion parameters were produced by the addition of Spirulina and Chlorella in the extruded products. In addition, the extrudates enriched with Nannochloropsis, showed similar parameters to those of the control sample.

Microalgae-enriched obtained products showed bright colours with appealing appearances. Doughs, batters, baked goods and emulsions presented different and stable hue colours, green for Spirulina and Chlorella, and yellow for Dunaliella. For extrudates, the addition of microalgae (Spirulina, Chlorella and Nannochloropsis) produced a change in luminosity from translucent to opaque.

Regarding minerals, an increase in $\mathrm{P}, \mathrm{K}, \mathrm{Ca}, \mathrm{Na}, \mathrm{Mg}$, Fe and Se was observed with the addition of Spirulina and Chlorella, along the increase of concentration of microalgae addition. Following the regulations on nutrition labelling for food stuffs, breadstick enrichment with microalgae are a food "high in iron (Fe)" In the same way, breadsticks and cookies enriched with microalgae can be considered a "high in selenium (Se)" food. Going a step further, Spirulina and Chlorella vulgaris incorporation in cookie formulations allowed for greater bioaccessibility of $\mathrm{P}, \mathrm{K}, \mathrm{Ca}, \mathrm{Mg}, \mathrm{Fe}, \mathrm{Zn}$, and Se content for absorption in the body than control cookies. 


\section{Resumen}

Las microalgas son organismos unicelulares fotosintéticos microscópicos que se encuentran en una gran variedad de ambientes. Estos microorganismos son muy eficientes a la hora de transformar la energía solar en biomasa, ya que su estructura celular es sencilla y se encuentran completamente sumergidas en un medio acuoso, conformando toda su superficie como un área de intercambio de nutrientes y gases.

Los estudios realizados hasta el momento hacen referencia a posibles beneficios de la incorporación de microalgas en la dieta, por la mejora del sistema cardiovascular, las propiedades adelgazantes y energizantes, capacidad antioxidante, o la reducción del colesterol y los triglicéridos. La forma más habitual de consumir las microalgas es como suplemento dietético en forma de tabletas, cápsulas o polvo. La incorporación de biomasa de microalgas en productos tradicionales se ha enfrentado al reto de la aparición de colores verdes fuertes, así como su consistencia pulverulenta que puede afectar la textura y percepción del producto. Todos estos aspectos constituyen las principales áreas de mejora para conseguir un mayor grado de aceptación de productos con microalgas, y son la base del reto de este proyecto.

El objetivo de la presente tesis doctoral fue el desarrollo de nuevos productos alimentarios incorporando las propiedades nutricionales de la biomasa de microalgas, incrementando o mejorando con ello, las propiedades nutricionales del alimento original. Para conseguir este objetivo se evaluaron a nivel fisicoquímico, reológico y textural, la incorporación de diferentes especies de microalgas (Arthrospira platensis (Spirulina), Chlorella vulgaris (Chlorella), Dunaliella salina (Dunaliella) y Nannochloropsis gaditana (Nannochloropsis)) en distintas matrices alimentarias (productos horneados (rosquilletas, galletas y snacks), emulsiones y extrusionados). Por otra parte, se evaluó y caracterizó la incorporación de las microalgas utilizando diferentes tecnologías como la impresión 3D o la extrusión. Además de cómo afecta la incorporación de las microalgas a los productos obtenidos, se evaluaron los aspectos nutricionales de su incorporación, en cuanto al aporte de minerales y su biodisponibilidad.

Las propiedades reológicas de las masas y emulsiones enriquecidas con microalgas (Spirulina, Chlorella y Dunaliella) indicaron que su comportamiento viscoelástico fue 
modificado y mejorado, mostrando características aptas para este tipo de productos. La adición de microalgas (Spirulina y Chlorella) a las masas utilizadas para la impresión 3D de galletas y snacks, permitió una mejor extrusión o impresión de éstas, obteniendo muestras impresas en 3D de forma cilíndrica, más precisas en cuanto a sus dimensiones con respecto a la estructura cilíndrica diseñada. Además, las muestras impresas presentaron mayor estabilidad y resistencia, antes y después del proceso de horneado comparadas con la muestra control. Para los productos horneados, tanto para las rosquilletas como los snacks impresos en 3D, la adición de microalgas (Spirulina y Chlorella) permitió mayor estabilidad en términos de textura. Ligeros cambios en los parámetros fisicoquímicos y de expansión se produjeron por la adición de Spirulina y Chlorella en los productos extrusionados. Además, los extrusionados enriquecidos con Nannochloropsis, mostraron parámetros similares a los de la muestra de control.

Todos los productos presentaron colores luminosos y apariencias innovadoras y atractivas. Las masas, los productos horneados y las emulsiones presentaron diferentes tonalidades estables, verdes para Spirulina y Chlorella y amarillo para Dunaliella. En el caso de los extrusionados, la adición de microalgas (Spirulina, Chlorella y Nannochloropsis) produjo un cambio de luminosidad de translúcidas a opacas.

En cuanto a los minerales, se observó un aumento de $\mathrm{P}, \mathrm{K}, \mathrm{Ca}, \mathrm{Na}, \mathrm{Mg}$, Fe y Se con la adición de Spirulina y Chlorella, junto con el aumento de la concentración adicionada de microalgas. Siguiendo la normativa sobre etiquetado nutricional de los alimentos, el enriquecimiento con microalgas en rosquilletas se puede clasificar como un alimento "rico en hierro (Fe)". De igual forma, las rosquilletas y galletas enriquecidas con microalgas pueden considerarse un alimento "alto en selenio (Se)". Además, la incorporación de Spirulina y Chlorella en las formulaciones de galletas, permitió una mayor bioaccesibilidad del contenido de $\mathrm{P}, \mathrm{K}, \mathrm{Ca}, \mathrm{Mg}, \mathrm{Fe}, \mathrm{Zn}$ y Se para la absorción en el cuerpo comparado con las muestras control. 


\section{Resum}

Les microalgues són organismes unicel-lulars fotosintètics microscòpics que es poden trobar en una gran varietat d'ambients. Aquests microorganismes són molt eficients a l'hora de transformar l'energia solar en biomassa pel fet que tenen una estructura cel'lular simple i es troben completament submergits en un mitjà aquós, de manera que tota la seua superfície queda com una àrea d'intercanvi de nutrients i gasos.

Els estudis realitzats fins ara fan referència a possibles beneficis de la incorporació de microalgues en la dieta per produir una millora del sistema cardiovascular, per presentar propietats per aprimar i donar energia, per mostrar capacitat antioxidant o per afavorir una reducció del colesterol i els triglicèrids. La forma més habitual de consumir microalgues és com a suplement dietètic en forma de tauleta, càpsula o en pols. La incorporació de biomassa de microalgues en productes tradicionals s'ha afrontat al repte de l'aparició d'un color verd fosc i d'una consistència polsosa que pot afectar a la textura i, per tant, a la percepció del producte. Aquests aspectes constituïxen les principals àrees de millora per aconseguir un major grau d'acceptació de productes amb microalgues i són la base del repte d'aquest projecte.

L'objectiu d'aquesta tesi doctoral és el desenvolupament de nous productes alimentaris que incorporen les propietats nutricionals de la biomassa de microalgues, de manera que s'incrementen o es milloren les propietats nutricionals de l'aliment original. Per aconseguir aquest objectiu s'avaluaren a escala fisicoquímica, reològica i de textura la incorporació de diferents espècies de microalgues (Arthrospira platensis (Spirulina), Chlorella vulgaris (Chlorella), Dunaliella salina (Dunaliella) i Nannochloropsis gaditana (Nannochloropsis)) en diferents matrius alimentàries (productes fornejats (rosquilletes, galetes i snacks), emulsions i extrudits). D'altra banda, s'avaluà i caracteritzà la incorporació de les microalgues utilitzant diferents tecnologies com la impressió en 3D o l'extrusió. A banda de valorar com afecta la incorporació de microalgues als productes elaborats, s'avaluaren els aspectes nutricionals, pel que fa a l'aportació i biodisponibilitat de minerals.

Les propietats reològiques de les masses i emulsions enriquides amb microalgues (Spirulina, Chlorella i Dunaliella) indicaren que el seu comportament viscoelàstic fou modificat i millorat, de tal manera que mostrà característiques aptes per aquest tipus de productes. 
L'addició de microalgues (Spirulina i Chlorella) en les masses utilitzades per a la impressió $3 \mathrm{D}$ de galetes i snacks permeté una millor impressió, ja que s'obtingueren mostres impreses de forma cilíndrica amb unes dimensions més precises respecte a l'estructura cilíndrica dissenyada. A més, les mostres impreses presentaren una major estabilitat i resistència abans i després del procés de fornejat en comparació amb la mostra control. Respecte als productes fornejats, l'addició de microalgues (Spirulina i Chlorella) a les rosquilletes i els snacks impresos en 3D permeté una major estabilitat en termes de textura. Lleugers canvis als paràmetres fisicoquímics i d'expansió es produïren per l'addició d'Spirulina i Chlorella en els productes extrudits. A més, els extrudits que foren enriquits amb Nannochloropsis mostraren paràmetres similars als de la mostra control.

Tots els productes presentaren colors lluminosos i aparences innovadores i atractives. Les masses, els productes fornejats i les emulsions presentaren diferents tonalitats estables: verdes per a Spirulina i Chlorella i grogues per a Dunaliella. Respecte als productes extrudits, l'addició de les microalgues (Spirulina, Chlorella i Nannochloropsis) produí un canvi de lluminositat fent que aquests passaren de translúcid a opac.

Pel que fa als minerals, s'observà un augment de $\mathrm{P}, \mathrm{K}, \mathrm{Ca}, \mathrm{Na}, \mathrm{Mg}$, Fe i Se quan s'afegí Spirulina i Chlorella, directament relacionat amb l'augment de la concentració de microalgues. Seguint la normativa sobre etiquetatge nutricional dels aliments, l'enriquiment amb microalgues en rosquilletes ens permet classificar-les com a aliment "ric en ferro (Fe)". De la mateixa manera, les rosquilletes i galetes enriquides amb microalgues poden considerar-se un aliment "alt en seleni (Se)". A més a més, la incorporació de Spirulina i Chlorella en les formulacions de galetes, permeté una major bioaccessibiltat del contingut de $\mathrm{P}, \mathrm{K}, \mathrm{Ca}, \mathrm{Mg}, \mathrm{Fe}, \mathrm{Zn}$ i Se comparat amb les mostres control. 


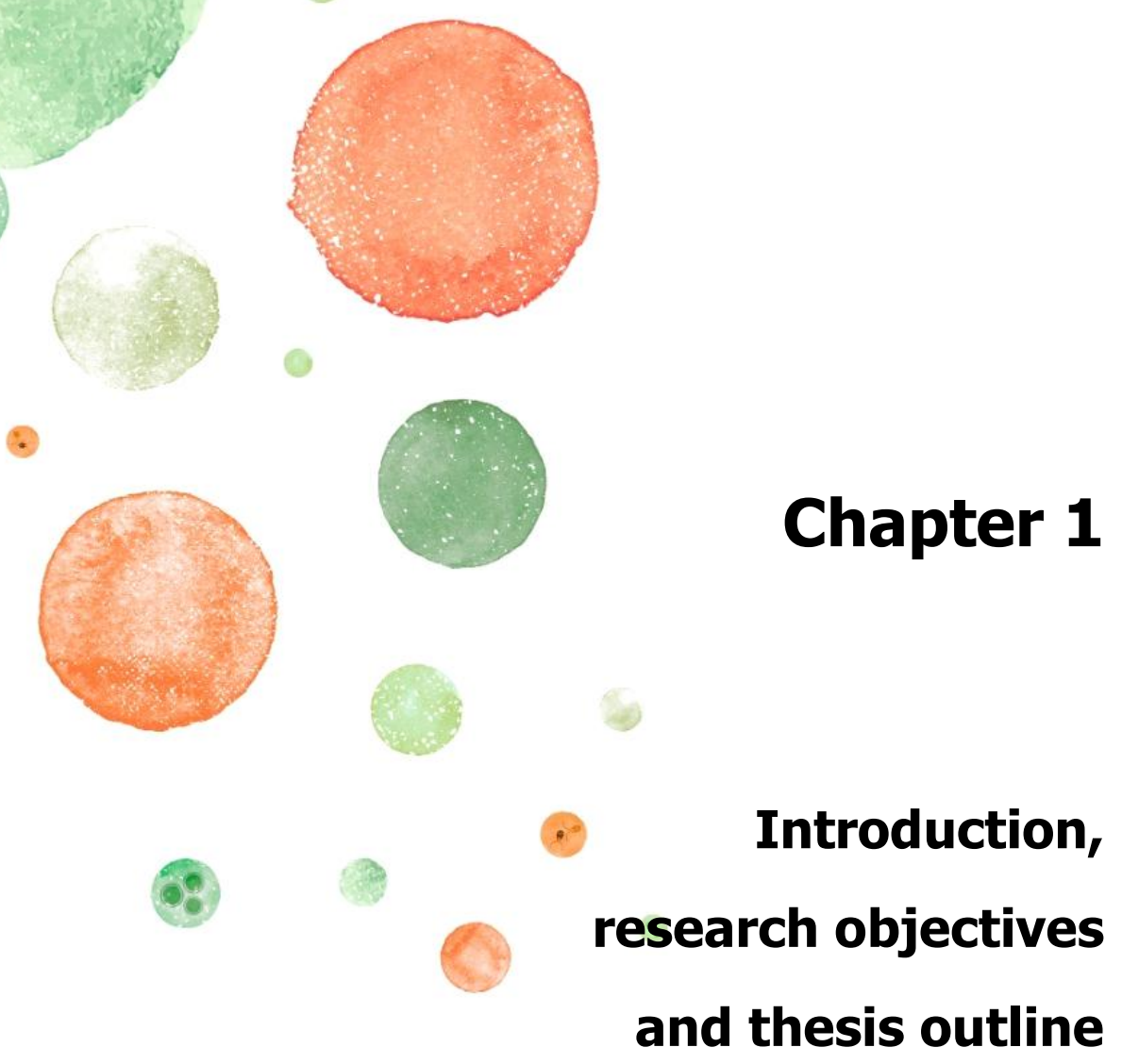





\section{Novel ingredients for food products formulation}

In recent years, the demand for foods with improved nutritional and functional properties has increased (Kraus et al., 2017; Temesi et al., 2019), which is driven by consumer's demand to strengthen their health system and prevent disease. They seek and try to incorporate these foods with ingredients or functional compounds into their diet. Thus, an increasing number of consumers is aware of the importance of a balanced diet and, in addition, adequate physical activity and the repercussions that improper diet and physical activity can have on long-term health (Neuhouser, 2019).

Within the healthy food categories, functional foods are perhaps most recognized by the population. Functional foods are defined as "foods that have the same appearance as conventional foods, but that in their composition have some characteristics that can contribute to improving the health status of a habitual consumer" (Vicentini et al., 2016; Granato et al., 2020).

The increasing trend towards convenience foods, due to current hectic lifestyles and the tendency to seek novel ready-to-eat or easy-to-eat food products, is directing the food industry towards the development of new functional foods, with extra added value (Thienhirun et al., 2018; Dror et al., 2020). It is not only worth it to reduce the amount of sugar or fats, or increase the amount of fibre, but formulating or reformulating (new) products with high antioxidant capacity, immunomodulatory potential, anticancerogenic, hepato-protective, and anticoagulant activities among others is of high interest as well (Suleria et al., 2016; Chakdar et al., 2017; Novovesk et al., 2019).

To achieve this goal, scientific advances in the development of ingredients and formulations have been as important as emerging technologies for food production, maintaining their functional value. However, the challenge for the food industry lies not only in the design of new functional products, but in using the results of research for improving the potential benefit for health. It must also ensure that these new foods have a sensory quality or a personalized nutritional design that meets (new) consumer's expectations (Brennan et al., 2013; Sun et al., 2015). In the search for natural ingredients and compounds that could contribute to this growing demand for developing healthy and/or functional foods, microalgae have emerged as a highly valuable source. 
Over the last two decades, the compounds and bioactive molecules produced by microalgae have been investigated in order to determine their health-promoting properties, which has resulted in promising results applicable to the fields of bioenergy, food, pharmacy and biomedicine (Ruiz et al., 2016). Therefore, studying the addition of microalgae to different matrix food products is of high interest.

\section{Microalgae}

Microalgae and cyanobacteria are currently of interest to scientific and research communities among the world owing to their infinite availability and promising role in biotechnological prospects specifically in the field of food, feed and applied biotechnology (Figure 1).

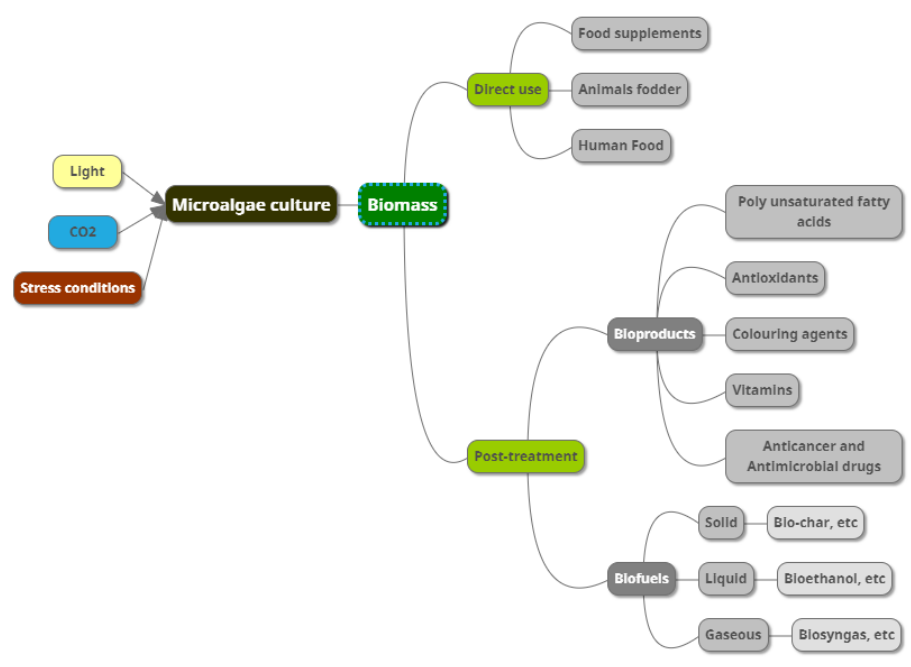

Figure 1. Microalgae uses.

Microalgae are ancestral organisms that constitute the basis of aquatic food chains. They can be found in almost all environments and habitats on earth (fresh water, seawater, salt lakes, soil, rocks and trees, among others) from the polar regions to the equator. They become visible in water bodies, when they grow out rapidly and in large quantities. They are a group of relatively basic plant-like organisms, which depend on light as the energy source for their metabolic processes. Light capture is mediated via chloroplasts, which use light energy to convert $\mathrm{CO}_{2}$ and nutrients into sugars to produce the chemical energy required for 
their development and oxygen as one of the end products. Due to their abundance in Earth's water bodies, this process contributes to global oxygen production (between 50 to 87\%) (Enzing et al., 2014; Borowitzka, 2018; Deviram et al., 2020).

Microalgae are a diverse group of unicellular organisms comprising prokaryotic (Cyanobateria (blue-green algae)), and eukaryotic photosynthetic (Cyanophyta (blue-green algae), Pyrophyta (dinoflagellates), Chrysophyta (diatoms and golden brown algae) and Chlorophyta (microscopic green algae)) microorganisms. Prokaryotes are organisms made up of cells that lack a cell nucleus or any membrane-encased organelles. Eukaryotes are organisms made up of cells that possess a membrane-bound nucleus that holds genetic material as well as membrane-bound organelles (Javed et al., 2019). Although cyanobacteria lack organized chloroplast, their photosynthetic apparatus is remarkably similar in functional, structural, and molecular respects when compared to chloroplast of higher plants and algae (Wehr et al., 2014). In fact, cyanobacteria are believed to be the first life forms responsible for oxygenating early earth atmosphere, and their microfossil record obtained from the Precambrian rocks near Alice Springs in Australia evidenced their existence from 3.5 billion years ago (Chapman et al., 1973). Although cyanobacteria belong to the domain of bacteria, being photosynthetic prokaryotes, often they are considered microalgae (Brodie et al., 2007).

Microalgae are autotrophic organisms that are able to use solar energy to convert inorganic forms of carbon ( $\mathrm{CO}_{2}$, carbonate, or bicarbonate) into organic forms of carbon. In contrast, some species of microalgae are heterotrophic, using the chemical energy of organic forms of carbon (acetate or glucose) for their metabolic activities. Therefore, eukaryotic microalgae can be either autotrophic or heterotrophic. However, eukaryotic microalgae combine plant systems and bacterial systems for their fast growth, rapid transformation cycles, scalability and capacity for mixotrophic growth. Mixotrophic cultivation is the growth mode where microalgae simultaneously perform photosynthesis and catabolise exogenous organic nutrients (Wijffels et al., 2013). Nevertheless, some species are not bona fide mixotrophs, but have the ability of switching between phototrophic and heterotrophic metabolisms, depending on environmental conditions (Perez-Garcia et al., 2011). 


\section{Bioactive composition of microalgae}

Many marine molecules have been determined as possessing a variety of biological effects which vary considerably between species and seasonality as well as geographical location (Barkia et al., 2019). Microalgae are well-known for their unique chemical composition including components with proven health benefits, making them valuable as nutrientenhancing ingredients for foods (Borowitzka, 2018; Wang et al., 2020). Microalgal bioactive compounds such as minerals, fibres, vitamins, polyphenols, starch and pigments depend on the species and the accumulated under stress conditions which include nutrient deprivation, changes in pH, light intensity, temperature and salinity (Hamed, 2016; Batista et al., 2017).

\section{Pigments}

One of the most obvious and arresting characteristic of microalgae is their colour. In general, each phylum has its own particular combination of pigments, essentially molecules that absorb light from the visible spectrum. The wavelength which is not absorbed by these molecules is caught by the human eye resulting in unique colours (Gouveia et al., 2009; Koyande et al., 2019). Chlorophylls, carotenoids (carotenes and xanthophylls) and phycobiliproteins are the three major classes of photosynthetic pigments in microalgae and are green, yellow and brown to red, respectively. Different spectral proportions of light such as red:far red, blue:red, green:red, and blue:green affect the relative pigment composition. Thus, the productivity of microalgae is affected by the individual light regimen (Kianianmomeni et al., 2014). Chlorophylls and carotenoids are generally fat-soluble molecules, whereas phycobiliproteins are water soluble (Begum et al., 2016). These pigments have health-promoting properties by acting as vitamin precursors, antioxidants immune enhancers or anti-inflammatory agents (Mazumder et al., 2014; Christaki et al., 2015; Suleria et al., 2016; Chakdar et al., 2017).

\section{Chlorophylls}

Chlorophyll, present in all higher plants, is a bioactive constituent that can be extracted from microalgal biomass. It is a green pigment that is ubiquitous in nature because it is responsible for the photosynthetic process due to its critical "light harvesting" role. There are several kinds of chlorophylls in microalgae (chlorophylls $a, b, c, d$ and $f$ ) which have some small differences in their absorption spectra and consequently their tonality. Chlorophyll $a$ has a blue-green colour, chlorophyll $b$ is a brilliant green, chlorophyll $c$ is 
yellow-green, chlorophyll $d$ is a brilliant/forest green, and chlorophyll $f$ is emerald green. Chlorophyll $a$, which is the major light-harvesting pigment, appears in all photosynthetic organisms. Chlorophyll $b$ appears exclusive to chlorophyta and their descendants, whereas chlorophyll $c$ appears exclusive to rhodophyta (Halim et al., 2010; Safi et al., 2014; Christaki et al., 2015).

\section{Carotenoids}

Carotenoids have been traditionally used in food and feed production due to their colour and nutritional properties. Carotenoids are considered safe natural dyes and, as such, are added to a variety of products to enhance their colour. Chemically, carotenoids can be divided into two groups: the carotenes (hydrocarbons; e.g., a-carotene, $\beta$-carotene, lycopene) and the xanthophylls (oxygenated molecules; e.g., astaxanthin, lutein, canthaxanthin). Primary carotenoids, such as $\alpha$-carotene, $\beta$-carotene and lutein, are directly involved in photosynthesis and they are essential for cellular survival. Secondary carotenoids, especially astaxanthin and canthaxanthin, accumulate when exposed to specific environmental stimuli (carotenogenesis) (Zhang et al., 2014). As antioxidants, carotenoids neutralise free radicals and therefore prevent or slow down chronic disease progression, cellular damage and aging. In addition, carotenoids may reduce the risk of inflammation, heart disease, cancer, type 2 diabetes, chronic eye and macular diseases, obesity, Alzheimer's disease, Parkinson's disease, amyotrophic lateral sclerosis (ALS) and mental diseases (Sathasivam et al., 2018; Novovesk et al., 2019). $\beta$-carotene is an important carotenoid pigment because it is the precursor of vitamin $A$ and therefore added to multivitamin supplements and tablets. $\beta$ carotene is also applied as food colour in cheese, butter and margarine (Kendrick, 2016). Recently, studies have shown that $\beta$-carotene production can be enhanced by manipulating the culture conditions to high salinity, high light intensity, lower nutrient content and extreme temperature (Koyande et al., 2019; Sathasivam et al., 2019).

\section{Phycobiliproteins}

Phycobiliproteins (phycocyanin, phycoerythrin and allophycocyanin) are a family of coloured proteins that are solely present in cyanobacteria strains. These molecules are water soluble and highly fluorescent. They are light harvesting pigment proteins, which are recognized for their antioxidant, anti-inflammatory, hepato, and neuro protective effects (Manirafasha et al., 2016). Due to their bright natural colour, these can be a nontoxic alternative to synthetic dyes and are predominantly used in products like chocolates, chewing gums, 
beverages, sweet decorations and ice creams (Sigamani et al., 2016; Ledermann et al., 2017).

\section{Protein}

Proteins are made of long chains of amino acids; essential and non-essential amino acids (EEAs and NEAAs, respectively). NEAAs can be produced by the human body. However, EAAs cannot be synthesized de-novo in human body and need to be consumed externally as food items. Common sources of these EAAs are eggs, poultry meat, red meat, dairy, soy/tofu, and fish. Microalgae dry biomass consists of $50-70 \%$ protein of which a high percentage is EAAs. Thus, compared with those traditional protein sources, microalgae are considered a viable source of protein for food and feed industry (Bleakley et al., 2017; Koyande et al., 2019).

\section{Fatty Acids}

Microalgae are a rich source of polyunsaturated fatty acids (PUFAs) omega-3 ( $\omega-3)$ series, especially eicosapentaenoic acid (EPA), docosahexaenoic acid (DHA), linoleic acid (LA), $\alpha$ linolenic acid (ALA) and arachidonic acid (AA). Therefore, extraction and purification of those acids from algal strains are emerging steeply to nourish the nutritional needs of the population. Lipids are constituents of all microalgae cells and their main biological functions include storing energy, signalling and acting as structural components of cell membranes. Depending on species and environmental culture conditions, the total lipid content of microalgae can vary considerably. Amounts as high as $70-85 \%$ of dry matter have been reported for microalgae, although between 20 and 50\% are more typical (Alishah et al., 2019). As a consequence of their vital structural and metabolic functions, PUFAs are responsible for a number of health effects. Dietary long-chain PUFAs are now known to exhibit cardioprotective, immunomodulatory, anti-proliferative, anti-inflammatory, cognitive, neurobehavioral, anti-cancer and antimicrobial properties, amongst others. Hence, PUFA play a significant role preventing inflammatory and chronic disorders including obesity, type 2 diabetes mellitus, rheumatoid arthritis, Alzheimer's disease and inflammatory bowel disease (Adkins et al., 2010; Boucher et al., 2011; Cuellar-Bermudez et al., 2015; Blondeau et al., 2015). 


\section{Polysaccharides}

Polysaccharides (PSs) are polymeric carbohydrate macromolecules with complex structures, and have various functional activities. They can store energy in the form of starch, glucose, sugar and glycogen and act as structural components in the cell wall of plants and microalgae. PSs produced by microalgae are of increasing interest due to their potential biological activity and therapeutic application (e.g., antitumor, infection preventive agent, antiviral, antibacterial, prevention of tumour cell growth, anti-proliferative, anti-adhesive and anti-metastatic) (Filomena et al., 2014; Matos, 2017; Chanda et al., 2019).

\section{Vitamins and minerals}

Microalgae also contain an abundant supply of trace minerals and vitamins important for human nutrition. Microalgae are especially rich in B complex vitamins, a class of watersoluble vitamins. In general, the concentrations of the various vitamins are comparable between the different microalgae as well as in higher plants. In addition to the vitamin $B$ complex, other vitamins such as vitamin C, vitamin A and isomers of tocopherol (vitamin E), as well as a balanced mineral content (e.g., $\mathrm{Na}, \mathrm{K}, \mathrm{Ca}, \mathrm{Mg}, \mathrm{Fe}, \mathrm{Zn}$ and trace minerals) can be found in almost all microalgae (Fox et al., 2018; Wang et al., 2020).

\section{Microalgae cultivation for food production}

Microalgae can be cultured by different methods under diverse conditions. Mostly, they need light as an energy source to convert the absorbed water and $\mathrm{CO}_{2}$ into biomass through photosynthesis. Photosynthetic products accumulate in various forms, such as cell components or storage materials, and vary from 20 to $50 \%$ of total biomass (Khan et al., 2018). Due to their enormous biodiversity as well as biochemical and molecular strategies for dealing with stress, microalgae can synthesize various bioactive chemicals (Singh et al., 2013).

The use of microalgae biomass as food is a traditional practice of several ancient people, especially in Asia, Africa and North America. For example, Spirulina sp. has been used as food for indigenous people in Mexico and Chad since ancient times (Vaz et al., 2016). Around the 1950s, microalgae were considered a promising candidate for protein supply in the human food chains. Commercial cultures of microalgae were started in the early 1960s 
in Japan, where Chlorella sp. was used as a food additive, followed by Spirulina sp. in the 1970s. However, only over the last 30 years, microalgae biotechnology has been developed and diversified significantly (Costa et al., 2011). First, the single-cell protein was the main product that targeted the industry, with applications directed to food and prophylactic use. Later, in the 1980s, pigment production emerged through the cultivation of the Dunaliella sp. with a focus on $\beta$-carotene and astaxanthin, due to their orange and red colours, respectively, as food additive and animal feed. More recently, in the early 1990s, the production of polyunsaturated fatty acids with a focus on DHA and EPA was started for use in enrichment of nutritional products. Today, commercial facilities for microalgae production are scattered worldwide. Research and demonstration programs are being carried out to develop the technology needed to expand microalgal production from a craft or lab scale to a pilot scale or a major industrial process (Wijffels et al., 2010; Sigamani et al., 2016).

The cultivation of microalgae can be performed in open-culture systems (e.g., lakes, lagoons and artificial ponds) and highly controlled closed-culture systems (photobioreactors) (Yew et al., 2019). Microalgae biomass harvesting is a costly process because microalgae cells are relatively small and a high percentage of the culture system consists of water. Therefore, the fact that microalgae can be cultivated without using arable terrain and freshwater makes them a sustainable alternative to the current practices of food production (Ruiz et al., 2016). Researchers and companies have been exploring different ways to reduce production costs, showing that the commercial production cost of microalgae products can be significantly reduced by increasing production scales and choosing a suitable production location using wastewater. In addition, some studies have shown that the optimum microalgal biomass production scenario is to employ natural light/dark regime and harvest the biomass around late exponential phase (Sui et al., 2020; Leite et al., 2020).

Harvesting methods for microalgae include sedimentation, flotation, filtration, flocculation, and centrifugation, which are applied in either a single or a combined process. Harvested biomass contains high moisture and it leads to the damage of the quality of biomass slurry in room temperature within a few hours. Thus upon harvesting, it is necessary to dry the biomass immediately to make it stable and storable for further use. Different methods are applied like solar, oven, microwave, spray, freeze, cross flow air-drying, and incinerator (Alam et al., 2017). 
Taiwan, Japan, The United States (USA), China, Brazil, Spain, Israel, Germany and Myanmar are the main producers of the microalgal biomass and derived products. The annual production of dry microalgal biomass is about 19000 tons. The current combined productions add up to ca. 5000, 2500 and 220 tons of dry biomass per year for Spirulina sp., Chlorella sp. and Dunaliella sp, respectively, and those have contributed to address the so-called "protein gap" defined as "the inequitable high quality protein problem in relation to the world food supply" (FAO, 2018; Ferdouse et al., 2018; Camacho et al., 2019).

\section{Nutritional Quality Standard and Regulations}

In recent years, consumer concerns regarding health and safety issues on the consumption of processed foods have increased. They are demanding high quality food and also information about what they are eating. As a response, the food market recognises the importance of communicating nutrition and safety information to consumers through product packaging. Thus, the food industry has been implementing within their production processes and supply chain all the manufacturing practices and standards as well as the printed information in their packaging. Likewise, the competent authorities have developed mechanisms to detect whether an ingredient or food is suitable for human consumption.

Products from microalgae that are intended for human or animal nutrition must be subject to a range of specific regulations and standards. International level food safety is governed by Codex Alimentarius Commission (CAC), which was created by the Food and Agriculture Organization (FAO) and the World Health Organization (WHO). The CAC is a collection of internationally recognized standards, codes of practice, guidelines and other recommendations related to food production and food safety (FAO and WHO, 2019). In the case of food additives and novel foods, which include nutraceuticals and functional foods, laws and regulations may vary from country to country or region but most adhere to The United States of America (USA) and/or European Union (EU) regulations. In the USA, the Food and Drug Administration (FDA) has the primary responsibility for regulating new food ingredients, whereas the EU through the European Food Safety Authority (EFSA) has regulations for food additives, novel foods and genetically modified organisms (European Parliament and Council, 2002). In January 2011, the Food Safety Modernization Act was signed into law in USA by the FDA. This means that the manufacturers may seek approval 
for a new ingredient by filing a food additive petition with the FDA to (a) make a Generally Recognized As Safe (GRAS) determination or (b) request a formal pre-market review (Burdock et al., 2004). In addition, for many markets, including the microalgae industry, Good Manufacturing Practice (GMP) certification and the ISO 9001/2000 standard (Wilkinson et al., 2010) are essential to conform to guidelines recommended by agencies that control authorization and licensing for manufacturing of products. In the case of food and related industries, a Hazard Analysis and Critical Control Points (HACCP) methodology is highly recommended as well (ICMSF, 2005; Yanniotis et al., 2013; Spiegel et al., 2013).

In EU, novel foods and novel food ingredients are those that have not been used to a significant degree for human consumption within the European Union before 15th May 1997. Hence, 'Novel Food' can be newly developed, innovative food, food produced using new technologies and production processes, as well as food which is or has been traditionally eaten outside of the EU. With the Regulation (EU) 2015/2283 on novel foods which replaced Regulation (EC) No 258/97 and Regulation (EC) No 1852/2001, through the EFSA, novel foods and novel food ingredients including microalgae products, are subjected to a safety assessment through a unified procedure to protect public health (Regulation (EU) 2015/2283 on novel foods, 2015).

\section{Microalgae Food Products Applications}

Food intake was originally intended to respond to hunger, and thus provide nutrients needed for human survival. According to the United Nation (UN), the global population is expected to increase from 7.7 billion in 2019 to 9.7 billion in 2050 (United Nations Department of Economic and Social Affairs Population Division, 2019). Not only will the required amount of food increase, but the type of foods sought and their relative contribution to diet(s) will change as well. Consequently, the use of microalgae biomass or components as an ingredient, allows for enrichment of current or novel food products in order to provide some of the nutrients needed for the health of the population. In fact, incorporation of microalgal biomass into processed food products has actually been proven an effective and sustainable strategy (Sun et al., 2018). Since the trend in the food industry is using natural ingredients, microalgae could fit in well with this trend. 
This $\mathrm{PhD}$ thesis is part of several projects related to the research of microalgae biomass, which our research group has been working together with different companies for the last few years.

The microalgae species used in this thesis were selected due to their potential as functional food ingredients and include Arthrospira platensis (Spirulina), Chlorella vulgaris and Nannochloropsis gaditana supplied by the company Algaenergy S.A. (Madrid, Spain) and Dunaliella Salina, by Algalimento S.L. (Gran Canaria, Spain). These types of microalgae contain interesting nutritional profiles for the human health and were incorporated to several formulations as freeze-dried microalgae biomass (Figure 2). These biomasses have been accepted or authorized under the European Novel Food Regulation and the FDA, or applications have been studied and submitted by industry and research centres (Tang et al., 2011; Batista et al., 2013; Rodríguez De Marco et al., 2018).
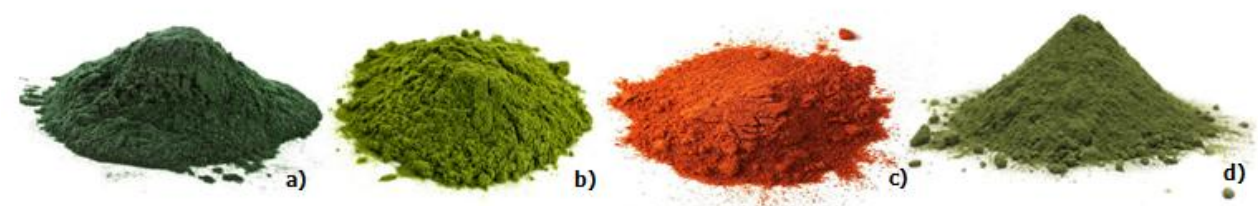

Figure 2. Biomass freeze-dried powders. a)Arthrospira platensis (Spirulina), b) Chlorella vulgaris, c) Dunaliella salina and, d) Nannochloropsis gaditana.

Arthrospira platensis (Spirulina) is a blue-green cyanobacteria, also considered a microalgae. Because of its high protein, fatty acids, mineral and vitamin content it is considered of high nutritional value, which has gained worldwide popularity as a food supplement. The protein content of Spirulina (50-70\% dry weight) contains all essential amino acids particularly leucine, valine and isoleucine, exhibiting high digestibility (83-90\%) and it contains a considerable amount of essential fatty acids and ALA. Moreover, it is a rich natural source of vitamins $A, B_{1}, B_{2}$ and $B_{12}$ as well as pigments, including carotenoids such as $\beta$-carotene (provitamin $A$ ), xanthophylls, chlorophyll and phycocyanin with antioxidant properties. In addition, Spirulina is rich in minerals such as iron, calcium, chromium, copper, magnesium, manganese, phosphorus, potassium, sodium and zinc (Soni et al., 2017; de la Jara et al., 2018; Barkallah et al., 2019). 
Chlorella vulgaris has a total protein content of $43-58 \%$ and the lipid profile ranges from 5 to $58 \%$ of its dry weight depending on growth conditions. However, it produces more lipids (60-68\%) when it is cultivated under mixotrophic conditions. The most abundant polysaccharide in C. vulgaris is starch, which is made up of amylose and amylopectin, followed by the polysaccharide cellulose, which is found in the cell wall. C. vulgaris can potentially mass-produce chlorophyll, reaching up to $1-2 \%$ of its dry weight and also it is a rich source of carotenoids (astaxanthin, lutein, $\beta$-carotene, lycopene and canthaxanthin). It contains vitamin A, B, C and $E$, and minerals such as calcium, potassium, magnesium and zinc (Hamedi et al., 2016; Tiong et al., 2020).

Dunaliella salina is characterized by its unique feature of hypercarotenogenesis, a process leading to the production of $14 \%$ (dry-weight) $\beta$-carotene. It is one of the first commercial high-value products from microalgae and is mostly used for human and animal nutrition, food colouring, and cosmetics due to its antioxidant effect. In addition, it contains violaxanthin, neoxanthin, astaxanthin, zeaxanthin, chlorophylls a and $\beta$, lutein and the dried biomass of Dunaliella comprises between 50 and $80 \%$ of protein and between 5 and $17 \%$ of lipids (Zhang et al., 2014; Rajauria et al., 2015; Elleuch et al., 2019; Sui et al., 2020).

Nannochloropsis gaditana (Nannochloropsis) is an oleaginous microalgae which is adapted to the climatological conditions of the Bay of Cadiz, in the south of Spain, where it was isolated for the first time. This microalgae is commercially cultivated for numerous purposes, including biofuel production, aquaculture and for use as a food additive. The main interest for production of Nannochloropsis is its considerable amount of lipids that ranges between 25 and $48 \%$ of biomass dry weight depending on growth conditions (Mitra et al., 2015), which indicates the superiority of Nannochloropsis as a potential oleaginous microalgae. The main fatty acids accumulated comprise of C16:0 (palmitic acid) and C16:1 (palmitoleic acid). In addition, Nannochloropsis is a good photoautotrophic producer of EPA, a high-value fatty acid with numerous health benefits (Ma et al., 2016; Castejón et al., 2019). Nannochloropsis produces carotenoids such as violaxanthin and vaucheraxanthin (Mitra et al., 2015). As an emerging application, extracts of Nannochloropsis may be useful in cosmetics considering their skin protection activity against induced oxidative stress (Letsiou et al., 2017; Wijffels et al., 2017; Menegol et al., 2019). 
The feasibility of incorporating microalgal biomass in conventional or innovative food preparations is dependent on the processing type, the nature of the food matrix (e.g., emulsion, gel and aerated dough systems) and the interactions with other food components (e.g. proteins, polysaccharides, lipids and sugars). Continuous research of the ingredients used for the food production is of great importance for the food industry, and even more so, when they have a great nutritional contribution. In addition, introducing microalgal ingredients in food systems can cause significant changes in the physical properties of food (Buono et al., 2014).

In this thesis, the researches in Chapter $\mathbf{2}$ and Chapter $\mathbf{3}$ were carried out in collaboration with Alga Energy S.A. (using Spirulina andCh/orella) and supported by the Ignacio H. de Larramendi Research grant from the Mapfre Foundation (FUDHALGAE Project). Chapter 4 was carried out in collaboration with Algaenergy S.A. and Algalimento S.L (using Spirulina, Chlorella and Dunaliella) and Jumel Alimentaria S.A. (company who produces emulsions, jams and marmalades) as a part of the $\mu$ ALGAVITAE project (funded by The Ministerio de Ciencia, Innovación y Universidades (CDTI) and Fondo Europeo de Desarrollo Regional (FEDER)). Chapter 5 was carried out in collaboration with Algaenergy S.A. (using Spirulina, Chlorella and Nannochloropsis). Finally, Chapter 6 and Chapter 7 were carried out in collaboration with Algaenergy S.A. (using Spirulina and Chlorella).

Chlorella and Spirulina were taken as reference to define the level of microalgae biomass use because they are recognized as GRAS as an ingredient in food in a level of use of $1.35 \mathrm{~g}$ (dairy intake) for Chlorella, and 0.5-3 g/serving (30 g per serving) for Spirulina (USFDA, 2011; USFDA, 2012). In all formulated food products, the amounts of microalgae added is below or within the values established by the regulation.

In this way, by using the biomass of two currently unregulated species of microalgae (Dunaliella and Nannochloropsis) and comparing them with control samples (no microalgae addition) and the two other species that are already authorized and regulated (Spirulina and Chlorella), it allows a better understanding of the properties at a technological level that they can contribute to production processes and the final product. Thus, companies will be aided in acquiring approval for the use of these microalgae as food additives. 
Thus, we studied the feasibility of adding microalgal biomass to different food formulations like baked goods, emulsions and extrudates in terms of their physicochemical, textural and rheological properties. To this end, we applied various preparative methods such as heating, baking, mixing and more novel techniques such as extrusion and 3D food printing. Studying as well some parameters related to the techniques like extrusion parameters for extrusion and the printability in terms of dimensional properties and the use of coaxial nozzle for 3D food printing.

\section{Baked goods}

Bakery and cereal products are an important part of the diet of today's consumer, because of their relatively cheap production costs and ease of production. In addition, they are ready-to-eat and easy-to-eat trending products and are versatile when combined with other food products. These are mainly prepared from refined wheat flour and because of their importance in today's diet $25 \%$ of the total production of wheat is used in the manufacturing of bakery products (Shewry et al., 2015). Bakery products range in complexity and include items such as bread, cakes, biscuits (crackers and cookies), where wheat flour as the main ingredient provides bulk and structure (Martins et al., 2017).

Cookies, breadsticks and snacks, commonly named, baked goods, are widely consumed food products (Figure 3 ). The process employed for their production can vary a lot, providing different textures and sensory characteristics to the final products. The main common operations in the production of baked goods are ingredient metering, dough mixing, shape forming, baking, cooling, and packaging. Each of the aforementioned processing steps is of equal importance in determining the final characteristics of this food product category. The quality of baked goods is generally

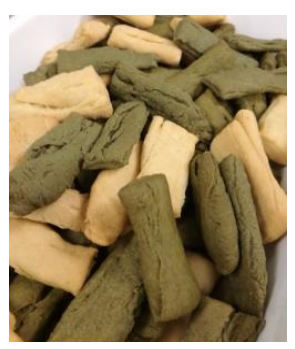

Figure 3. Example of baked goods: breadsticks. based on their appearance, texture, colour, taste, and aroma (Romani et al., 2016). The addition of natural ingredients, exhibiting functional properties and providing specific health benefits beyond traditional nutrients, to baked goods is a very attractive way to design new food products. This niche market presently shows pronounced growth, making research into this field of value (Beckley et al., 2007; Uribe-Wandurraga et al., 2019). 


\section{Oil-in-Water Emulsions}

An emulsion is a temporarily stable mixture of immiscible fluids, such as oil and water, achieved by finely dividing one phase into very small droplets. Oil-in-water (o/w) emulsions are colloidal dispersions containing small droplets of an oily disperse phase distributed throughout a watery continuous phase (Figure 4). They are found in a broad range of beverages, milk, infant formulas and other dairy-based

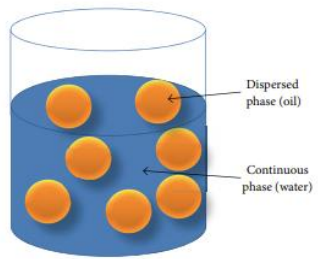

Figure 4. Concept of oilin-water emulsion. products, mayonnaise, dressings and sauces (Berton-Carabin et al., 2019). Although the taste and texture of mayonnaise is appreciated by many consumers, local markets often value different sensory properties. The development of coloured oil-in-water emulsions using natural sources, especially from microalgal origin, is an interesting field to investigate. The attainment of appealing and stable colourations is an important innovation for these types of products (Gouveia et al., 2008). Due to the antioxidant properties that most natural pigments present it is also possible to improve nutritional properties.

\section{Extrudates}

Extrusion process of cereals is a very important process in food industry, because of its involvement in the production of a wide range of products such as snack-foods, babyfoods, breakfast cereals, noodle, pasta and cereals based blends (Morsy et al., 2014). Extrusion is defined as "a system of pushing mixed ingredients out through a small opening, called a die, to form and shape materials" (Figure 5) (Gu et al., 2017). It is a system that encompasses multiple unit operations such as mixing, kneading, cooking, forming, and cutting all into a single piece of equipment. This results in having a relatively simple process with high efficiency and low cost compared to other processing methods (Gu et al., 2017). The formed products are then referred to as extrudates.

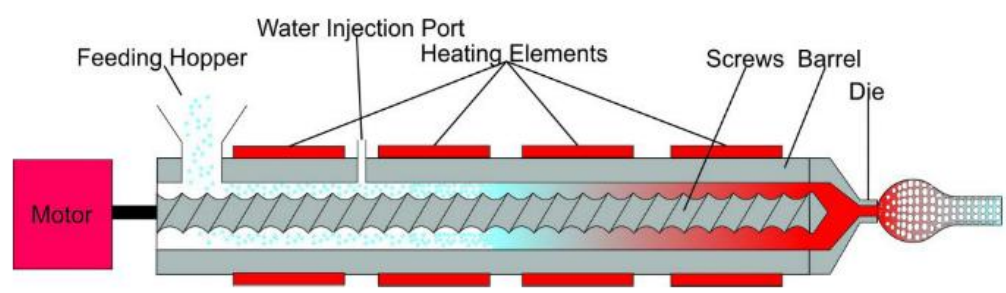

Figure 5. A schematic of extrusion processing, showing the transformation of raw ingredient to finished product. Source: Gu et al. (2017). 
The extrusion process used in snacks production has advantages such as rapid processing, lower cost and greater flexibility, leading to minimal degradation of nutrients and inactivation of undesirable compounds (Anton et al., 2009). Extruded snack products are predominantly made from cereal flour because of their good expansion characteristics where corn has been extensively used (Riaz, 2016) (Figure

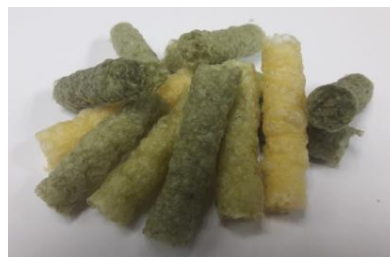

Figure 6. Extruded snacks. $6)$.

\section{D Food printing}

Additive manufacturing, also known as $3 \mathrm{D}$ printing is an up-and-coming production technology characterized by a layer by layer material deposition mode based directly from a pre-designed file to reproduce a computer-generated 3D design (Pinna et al., 2016). Additive manufacturing is a collective term used for a variety of technologies, such as fused deposition modelling (FDM), inkjet printing (IJP), powder bed printing (PBP), and selective laser sintering (SLS). Fused deposition modelling (FDM), an extrusion-based technology, is the most commonly used 3D printing manner for food fabrications (Kim et al., 2017) (Figure 7). Owing to the unique opportunities it provides for flexible manufacturing of items based on digital designs, 3D printing has found many applications in a variety of industries, including automotive, aerospace, medical, pharmacy, dental and, more recently, food production (Noort et al., 2017).
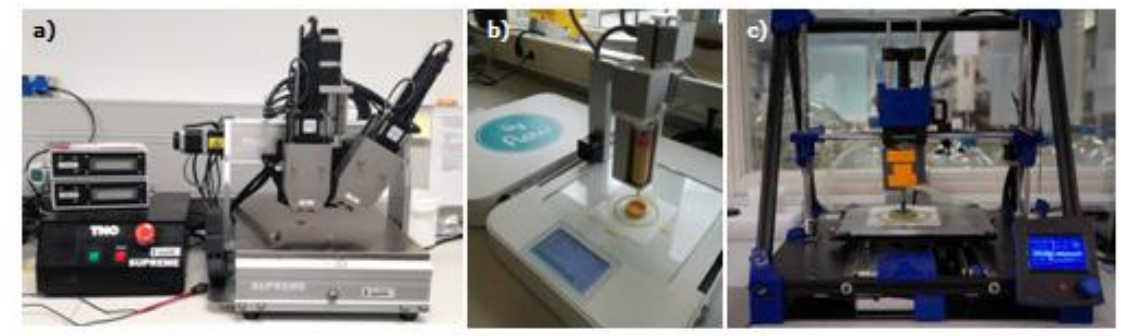

Figure 7. Examples of 3D Food Printers. a) TNO Supreme, b) byFlow and, c) $3 B C N$.

There are many potential advantages of 3D printing technology when applied to the food sector, such as customised food designs, personalised and digitalised nutrition, simplifying the supply chain and broadening the source of available food material. Using this 
technology, some complex food designs which cannot be achieved by manual labour or conventional moulds can be produced by ordinary people based on predetermined data files that comprise culinary knowledge and artistic skills from chefs, nutrition experts, and food designers (Figure 8) (Liu et al., 2017).
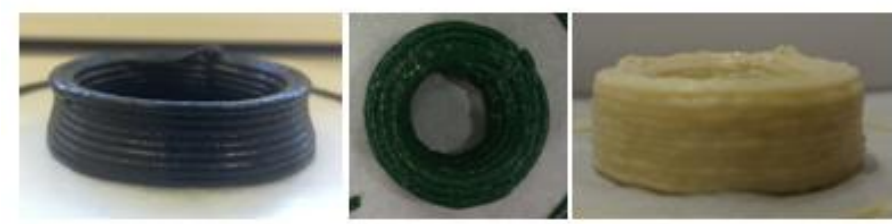

Figure 8. 3D Cookie-doughs printed structures.

\section{Trends in biocompounds bioaccessibility of microalgae-enriched products}

When bioactive compounds are used for consumption, three different concepts need to be considered: bioaccessibility, bioavailability, and bioactivity. The bioaccessibility, usually evaluated by in vitro tests, represents the fraction of a compound released from the food matrix becoming available for absorption. Afterwards, the fraction of compounds that reaches the systemic circulation and is being utilised is referred to as bioavailability and can be determined by in vivo tests. Finally, the bioactivity of a compound describes the physiological response (e.g., antioxidative, antihypertensive or anticancerogenic activities). The bioactivity can be evaluated in vivo, ex vivo, and in vitro. Based on these definitions, a compound can be considered bioaccessible, but not necessarily bioactive (Carbonell-Capella et al., 2014; Caporgno et al., 2018).

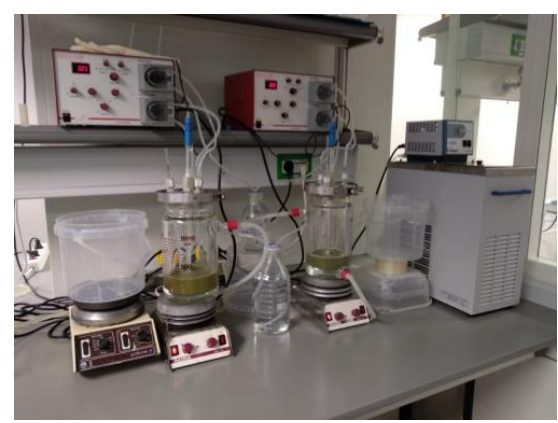

Figure 9. In vitro digestion equipment. 
Recently, the bioaccessibility of microalgal biomass and its bioactive compounds have been studied. In vitro digestion models are widely used to study the structural changes, digestibility and release of food components under simulated gastrointestinal conditions (Figure 9). The most frequently used digestive enzymes (pancreatin, pepsin, trypsin, chymotrypsin, peptidase, a-amylase and lipase) are of porcine, rabbit or human origin, or derive from bile salts and mucin (Boisen et al., 1997; Minekus et al., 2014). These in vitro digestion models have already been adopted to evaluate the digestibility of microalgal biomasses (Niccolai et al., 2019; Bernaerts et al., 2020) and for different food products such as bread, wheat pasta (Rodríguez De Marco et al., 2014), cookies (Batista et al., 2017; Uribe-Wandurraga et al., 2020) and baked goods (Lafarga et al., 2019). 


\section{Research objectives and thesis outline}

Microalgae have recently attracted considerable attention due to their ability to increase the nutritional and technological value of food products. Therefore, the overall objective of this thesis is to provide deeper understanding of the effect of the microalgae biomass addition on the physicochemical, textural and rheological properties of different food products, using different techniques to obtain these products.

In Chapter 2, we studied the possibility of improving the quality and nutritional content of breadsticks by the addition of two types of microalgae biomass, Arthrospira platensis and Chlorella vulgaris. To this end, mineral content, colour, textural and rheological properties of breadsticks, and the colour, texture and rheology of doughs were studied.

The increasing use of microalgae as nutritive ingredient in food, and the lack of knowledge on digestibility of minerals from microalgae-enriched food make it an interesting topic to study. Because cookies are a trending product in the worldwide market as are breadsticks, in Chapter 3, we evaluated the mineral content of cookies enriched with Arthrospira platensis and Chlorella vulgaris, at different levels of addition. In addition, we studied the in vitro digestibility and mineral bioaccessibility of one representative sample, using an in vitro static system that simulates the first part of the digestive process.

Starting from traditional techniques to obtain food products as breadsticks and cookies and knowing that microalgae contribute to enhance their properties, we further explored the addition of microalgae in other types of products, emulsions and corn extrudates. The results would provide theoretical guidance to produce new products with microalgae fortification, especially due to their innovative colour and appearance. In these chapters, in addition to the use of Arthrospira platensis and Chlorella vulgaris, we studied two other types of microalgae, Dunaliella salina and Nannochloropsis gaditana. In Chapter 4, we studied the effect of three types of microalgal biomass, Arthrospira platensis, Chlorella vulgaris and Dunaliella salina, on water activity, $\mathrm{pH}$, colour, texture, and rheological properties of low-fat oil-in-water food emulsions.

As a follow up to studying the benefits of microalgae addition to breadsticks, cookies and low-fat oil-in-water emulsions, we put forward another food processing technique, 
extrusion. The aim in Chapter 5 was to obtain corn extrudates enriched with different concentration levels of Arthrospira platensis, Chlorella vulgaris, and Nannochloropsis gaditana biomass and to compare their expansion and compositional parameters and physicochemical properties with control corn extrudates.

$3 \mathrm{D}$ food printing is gaining more popularity and it was therefore of high interest to study the feasibility of adding microalgae to 3D-printed food. The last two chapters explore the effect of microalgae addition to 3D-printed foods. The feasibility of microalgae as a novel ingredient for 3D-printed cookies is described in Chapter 6. The aim of this study was to investigate the printability in terms of dimensional properties (variation in width, height and internal diameter) of 3D printed cookie doughs containing different microalgae concentration levels of Arthrospira platensis and Chlorella vulgaris. The effect of microalgae biomass on rheology and texture of doughs plus colour of the final product was studied. Furthermore, cookie doughs and cookies were evaluated for changes in shape and dimensions of the 3D printed structures based on layer height and filament diameter, with increasing microalgae incorporation. In addition, the results acquired from this study can give us knowledge regarding the effect of microalgae-enriched cookie dough in 3D printing and their effects on post-processing of 3D printed foods.

In Chapter 7, in addition to investigate how the addition of microalgal biomass, Arthrospira platensis and Chlorella vulgaris, affects the rheological properties, printability (in terms of extrusion behaviour and shear modulus) and physicochemical properties (shape, textural, and colour properties) of 3D-printed batter snacks; we further investigated the possibilities of 3D food printing with microalgae-enriched doughs by manipulating the food structure at smaller dimensional scales making use of a 3D Food printer equipped with a coaxial extrusion nozzle. By making use of such a nozzle we were able to evaluate the possibility of 'hiding' microalgae fortified batter in the interior of the product. These results contribute to development of innovative food products containing microalgae which are attractive to consumers by means on 3D food printing technology.

The results of this thesis are combined and discussed in Chapter 8. In addition, general recommendations for future research are given. Finally, conclusions are written in Chapter 9. 


\section{References}

Adkins, Y., \& Kelley, D. S. (2010). Mechanisms underlying the cardioprotective effects of omega-3 polyunsaturated fatty acids. The Journal of Nutritional Biochemistry, 21(9), 781-792. doi: https://doi.org/10.1016/j.jnutbio.2009.12.004

Alam, M. A., Wang, Z., \& Yuan, Z. (2017). Generation and Harvesting of Microalgae Biomass for Biofuel Production. In B. N. Tripathi \& D. Kuma (Eds.), Prospects and Challenges in Algal Biotechnology (pp. 89-111). Singapore: Springer. doi: 10.1007/978-981-10-1950-0_4

Alishah Aratboni, H., Rafiei, N., Garcia-Granados, R., Alemzadeh, A., \& Morones-Ramírez, J. R. (2019). Biomass and lipid induction strategies in microalgae for biofuel production and other applications. Microbial Cell Factories, 18(1), 1-17. doi: 10.1186/s12934-019-1228-4

Anton, A. A., Fulcher, R. G., \& Arntfield, S. D. (2009). Physical and nutritional impact of fortification of corn starch-based extruded snacks with common bean (Phaseolus vulgaris L.) flour: Effects of bean addition and extrusion cooking. Food Chemistry, 113(4), 989996. doi: 10.1016/j.foodchem.2008.08.050

Barkallah, M., Atitallah, A. Ben, Hentati, F., Dammak, M., Hadrich, B., Fendri, I., Ayadi, M. A., Michaud, P., \& Abdelkafi, S. (2019). Effect of Spirulina platensis biomass with high polysaccharides content on quality attributes of common Carp (Cyprinus carpio) and Common Barbel (Barbus barbus) fish burgers. Applied Sciences (Switzerland), 9(11). doi: 10.3390/app9112197

Barkia, I., Saari, N., \& Manning, S. R. (2019). Microalgae for high-value products towards human health and nutrition. Marine Drugs, 17(5), 1-29. doi: 10.3390/md17050304

Batista, A. P., Gouveia, L., Bandarra, N. M., Franco, J. M., \& Raymundo, A. (2013). Comparison of microalgal biomass profiles as novel functional ingredient for food products. Algal Research, 2(2), 164-173. doi: 10.1016/j.algal.2013.01.004

Batista, A. P., Niccolai, A., Fradinho, P., Fragoso, S., Bursic, I., Rodolfi, L., Biondi, N., Tredici, M. R., Sousa, I., \& Raymundo, A. (2017). Microalgae biomass as an alternative ingredient in cookies: Sensory, physical and chemical properties, antioxidant activity and in vitro digestibility. Algal Research, 26(March), 161-171. doi: 10.1016/j.algal.2017.07.017

Beckley, J. H., Foley, M. M., Topp, E. J., Huang, J. C., \& Prinyawiwatkul, W. (2007). Accelerating New Food Product Design and Development. In Accelerating New Food Product Design and Development. doi: 10.1002/9780470277621

Begum, H., Yusoff, F. M. D., Banerjee, S., Khatoon, H., \& Shariff, M. (2016). Availability and Utilization of Pigments from Microalgae. Critical Reviews in Food Science and Nutrition, 56(13), 2209-2222. doi: 10.1080/10408398.2013.764841

Bernaerts, T. M. M., Verstreken, H., Dejonghe, C., Gheysen, L., Foubert, I., Grauwet, T., \& Van 
Loey, A. M. (2020). Cell disruption of Nannochloropsis sp. improves in vitro bioaccessibility of carotenoids and W3-LC-PUFA. Journal of Functional Foods, 65, 103770. doi: 10.1016/J.JFF.2019.103770

Berton-Carabin, C., \& Schroën, K. (2019). Towards new food emulsions: designing the interface and beyond. Current Opinion in Food Science, 27, 74-81. doi: 10.1016/J.COFS.2019.06.006

Bleakley, S., \& Hayes, M. (2017). Algal Proteins: Extraction, Application, and Challenges Concerning Production. Foods, 6(5), 33. doi: 10.3390/foods6050033

Blondeau, N., Lipsky, R. H., Bourourou, M., Duncan, M. W., Gorelick, P. B., \& Marini, A. M. (2015). Alpha-linolenic acid: An omega-3 fatty acid with neuroprotective properties - Ready for use in the stroke clinic? BioMed Research International, 2015(Figure 1). doi: $10.1155 / 2015 / 519830$

Boisen, S., \& Fernández, J. A. (1997). Prediction of the total tract digestibility of energy in feedstuffs and pig diets by in vitro analyses. Animal Feed Science and Technology, 68(3-4), 277-286. doi: 10.1016/S0377-8401(97)00058-8

Borowitzka, M. A. (2018). Biology of Microalgae. In I. A. Levine \& J. B. T. Fleurence (Eds.), Microalgae in Health and Disease Prevention (pp. 23-72). Academic Press. doi: https://doi.org/10.1016/B978-0-12-811405-6.00003-7

Boucher, O., Burden, M. J., Muckle, G., Saint-Amour, D., Ayotte, P., Dewailly, E., Nelson, C. A., Jacobson, S. W., \& Jacobson, J. L. (2011). Neurophysiologic and neurobehavioral evidence of beneficial effects of prenatal omega-3 fatty acid intake on memory function at school age. American Journal of Clinical Nutrition, 93(5), 1025-1037. doi: 10.3945/ajcn.110.000323

Brennan, M. A., Derbyshire, E., Tiwari, B. K., \& Brennan, C. S. (2013). Ready-to-eat snack products: The role of extrusion technology in developing consumer acceptable and nutritious snacks. International Journal of Food Science and Technology, 48(5), 893-902. doi: 10.1111/ijfs.12055

Brodie, J., \& Lewis, J. (Eds.). (2007). Unravelling the algae: the past, present, and future of algal systematics (Systematic). Boca raton: CRC Press.

Buono, S., Langellotti, A. L., Martello, A., Rinna, F., \& Fogliano, V. (2014). Functional ingredients from microalgae. Food and Function, 5(8), 1669-1685. doi: 10.1039/c4fo00125g

Burdock, G. A., \& Carabin, I. G. (2004). Generally recognized as safe (GRAS): History and description. Toxicology Letters, 150(1), 3-18. doi: 10.1016/j.toxlet.2003.07.004

Camacho, F., Macedo, A., \& Malcata, F. (2019). Potential industrial applications and commercialization of microalgae in the functional food and feed industries: A short review. Marine Drugs, 176). doi: 10.3390/md17060312

Caporgno, M. P., \& Mathys, A. (2018). Trends in Microalgae Incorporation Into Innovative Food 
Products With Potential Health Benefits. Frontiers in Nutrition, 5(July), 1-10. doi: 10.3389/fnut.2018.00058

Carbonell-Capella, J. M., Buniowska, M., Barba, F. J., Esteve, M. J., \& Frígola, A. (2014). Analytical methods for determining bioavailability and bioaccessibility of bioactive compounds from fruits and vegetables: A review. Comprehensive Reviews in Food Science and Food Safety, 13(2), 155-171. doi: 10.1111/1541-4337.12049

Castejón, N., \& Señoráns, F. J. (2019). Simultaneous extraction and fractionation of omega-3 acylglycerols and glycolipids from wet microalgal biomass of Nannochloropsis gaditana using pressurized liquids. Algal Research, 37, 74-82. doi: 10.1016/J.ALGAL.2018.11.003

Chakdar, H., \& Pabbi, S. (2017). Algal Pigments for Human Health and Cosmeceuticals. In R. P. Rastogi \& A. Pandey (Eds.), Algal Green Chemistry: Recent Progress in Biotechnology (pp. 171-188). Elsevier B.V. doi: 10.1016/B978-0-444-63784-0.00009-6

Chanda, M. joan, Merghoub, N., \& EL Arroussi, H. (2019). Microalgae polysaccharides: the new sustainable bioactive products for the development of plant bio-stimulants? World Journal of Microbiology and Biotechnology, 35(11), 1-10. doi: 10.1007/s11274-019-2745-3

Chapman, V. J., \& Chapman, D. J. (1973). Fossil Algae. In The Algae (pp. 309-327). Palgrave, London. doi: 10.1007/978-1-349-27910-4_13

Christaki, E., Bonos, E., \& Florou-Paneri, P. (2015). Innovative Microalgae Pigments as Functional Ingredients in Nutrition. In Handbook of Marine Microalgae (pp. 233-243). Boca raton: Academic Press. doi: 10.1016/B978-0-12-800776-1.00014-5

Costa, J. A. V., \& de Morais, M. G. (2011). The role of biochemical engineering in the production of biofuels from microalgae. Bioresource Technology, 102(1), 2-9. doi: 10.1016/J.BIORTECH.2010.06.014

Cuellar-Bermudez, S. P., Aguilar-Hernandez, I., Cardenas-Chavez, D. L., Ornelas-Soto, N., Romero-Ogawa, M. A., \& Parra-Saldivar, R. (2015). Extraction and purification of highvalue metabolites from microalgae: Essential lipids, astaxanthin and phycobiliproteins. Microbial Biotechnology, 8(2), 190-209. doi: 10.1111/1751-7915.12167

de la Jara, A., Ruano-Rodriguez, C., Polifrone, M., Assunçao, P., Brito-Casillas, Y., Wägner, A. M., \& Serra-Majem, L. (2018). Impact of dietary Arthrospira (Spirulina) biomass consumption on human health: main health targets and systematic review. Journal of Applied Phycology, 30(4), 2403-2423. doi: 10.1007/s10811-018-1468-4

Deviram, G., Mathimani, T., Anto, S., Ahamed, T. S., Ananth, D. A., \& Pugazhendhi, A. (2020). Applications of microalgal and cyanobacterial biomass on a way to safe, cleaner and a sustainable environment. Journal of Cleaner Production, 253, 119770. doi: 10.1016/J.JCLEPRO.2019.119770

Dror, Y., Rimon, E., \& Vaida, R. (2020). The Ready-to-Eat Cereals (RTEC) BT - Whole-Wheat 
Bread for Human Health. In Y. Dror, E. Rimon, \& R. Vaida (Eds.), Whole-Wheat Bread for Human Health (pp. 389-394). Cham: Springer International Publishing. doi: 10.1007/9783-030-39823-1_21

Elleuch, F., Hlima, H. Ben, Barkallah, M., Baril, P., Abdelkafi, S., Pichon, C., \& Fendri, I. (2019). Carotenoids overproduction in Dunaliella sp:: Transcriptional changes and new insights through lycopene cyclase regulation. Applied Sciences (Switzerland), 9(24). doi: 10.3390/app9245389

Enzing, C., Ploeg, M., Barbosa, M., \& Sijtsma, L. (2014). Microalgae-based products for the food and feed sector: an outlook for Europe. In JRC Scientific and Policy Reports. European Comission. doi: 10.2791/3339

European Parliament and Council. (2002). Regulation (EC) N 178/2002 of 28 January 2002 laying down the general principles and requirements of food law, establishing the European Food Safety Authority and laying down procedures in matters of food safety. In Official Journal of the European Communities (Vol. L31). doi: 2004R0726 - v.7 of 05.06.2013

FAO. (2018). The future of food and agriculture - Alternative pathways to 2050. Rome. Retrieved from http://www.fao.org/3/I8429EN/i8429en.pdf

FAO/WHO. (2019). Codex Alimentarius Commission - Procedural Manual twenty-seventh edition.

Ferdouse, F., Holdt, S. L., Smith, R., Murúa, P., \& Yang, Z. (2018). The global status of seaweed production, trade and utilization. In FAO Globefish Research Programme (Vol. 124). Italy, Rome. Retrieved from http://www.fao.org/in-action/globefish/publications/detailspublication/en/c/1154074/

Filomena, M., Raposo, D. J., Maria, A., Bernardo, M., Manuel, R., \& Costa, S. (2014). Bioactivity and Applications of Polysaccharides from Marine Microalgae. In M. J. Ramawat K. (Ed.), Polysacharides: Bioactivity and Biotechnology (1st ed., pp. 1-38). Cham, Switzerland: Springer International Publishing. doi: 10.1007/978-3-319-03751

Fox, J. M., \& Zimba, P. V. (2018). Minerals and Trace Elements in Microalgae. Microalgae in Health and Disease Prevention, 177-193. doi: 10.1016/b978-0-12-811405-6.00008-6

Gouveia, L., Batista, A. P., Sousa, I., Raymundo, A., \& Bandarra, N. M. (2008). Microalgae in novel food products. In K. N. Papadopoulos (Ed.), Food Chemistry Research Developments (pp. 1-36). Nova Science Publishers, Inc.

Granato, D., Barba, F. J., Bursać Kovačević, D., Lorenzo, J. M., Cruz, A. G., \& Putnik, P. (2020). Functional Foods: Product Development, Technological Trends, Efficacy Testing, and Safety. Annual Review of Food Science and Technology, 11(1), 93-118. doi: 10.1146/annurev-food-032519-051708

Gu, B., Kowalski, R. J., \& Ganjyal, G. (2017). Food Extrusion Processing :An Overview. WSU Peer Reviewed, 1-8. 
Halim, R., Hosikian, A., Lim, S., \& Danquah, M. K. (2010). Chlorophyll extraction from microalgae: A review on the process engineering aspects. International Journal of Chemical Engineering, 2010. doi: 10.1155/2010/391632

Hamed, I. (2016). The Evolution and Versatility of Microalgal Biotechnology: A Review. Comprehensive Reviews in Food Science and Food Safety, 15(6), 1104-1123. doi: $10.1111 / 1541-4337.12227$

Hamedi, S., Mahdavi, M. A., \& Gheshlaghi, R. (2016). Improved lipid and biomass productivities in Chlorella vulgaris by differing the inoculation medium from the production medium. Biofuel Research Journal, 3(2), 410-416. doi: 10.18331/BRJ2016.3.2.6

ICMSF. (2005). Microbial ecology of food commodities. In Micro-organisms in foods 6 (2nd ed.). New York: Kluwer Academic / plenum Publishers. doi: 10.1007/978-1-4615-6095-1

Javed, M. R., Bilal, M. J., Ashraf, U. F., Waqar, A., \& Mehmood, M. A. (2019). Microalgae as a Feedstock for Biofuel Production: Current Status and Future Prospects. In Top 5 Contributions in Energy Research and Development (Issue December, pp. 1-39). Avid Science.

Kendrick, A. (2016). Coloring Aqueous Food Types. In Handbook on Natural Pigments in Food and Beverages (pp. 163-177). Woodhead Publishing. doi: 10.1016/B978-0-08-1003718.00007-5

Khan, M. I., Shin, J. H., \& Kim, J. D. (2018). The promising future of microalgae: Current status, challenges, and optimization of a sustainable and renewable industry for biofuels, feed, and other products. Microbial Cell Factories, 171), 1-21. doi: 10.1186/s12934-018-0879-x

Kianianmomeni, A., \& Hallmann, A. (2014). Algal photoreceptors: In vivo functions and potential applications. Planta, 239(1), 1-26. doi: 10.1007/s00425-013-1962-5

Kim, H. W., Bae, H., \& Park, H. J. (2017). Classification of the printability of selected food for 3D printing: Development of an assessment method using hydrocolloids as reference material. Journal of Food Engineering, 215, 23-32. doi: 10.1016/J.JFOODENG.2017.07.017

Koyande, A. K., Chew, K. W., Rambabu, K., Tao, Y., Chu, D. T., \& Show, P. L. (2019). Microalgae: A potential alternative to health supplementation for humans. Food Science and Human Wellness, 8(1), 16-24. doi: 10.1016/J.FSHW.2019.03.001

Kraus, A., Annunziata, A., \& Vecchio, R. (2017). Sociodemographic Factors Differentiating the Consumer and the Motivations for Functional Food Consumption. Journal of the American College of Nutrition, 36(2), 116-126. doi: 10.1080/07315724.2016.1228489

Lafarga, T., Mayre, E., Echeverria, G., Viñas, I., Villaró, S., Acién-Fernández, F. G., Castellari, M., \& Aguiló-Aguayo, I. (2019). Potential of the microalgae Nannochloropsis and Tetraselmis for being used as innovative ingredients in baked goods. LWT - Food Science and Technology, 115(May), 108439. doi: 10.1016/j.Iwt.2019.108439 
Ledermann, B., Aras, M., \& Frankenberg-Dinkel, N. (2017). Biosynthesis of Cyanobacterial LightHarvesting Pigments and Their Assembly into Phycobiliproteins. In Modern Topics in the Phototrophic Prokaryotes: Metabolism, Bioenergetics, and Omics (pp. 305-340). Cham, Switzerland: Springer International Publishing. doi: 10.1007/978-3-319-51365-2_6

Leite, L. de S., dos Santos, P. R., \& Daniel, L. A. (2020). Microalgae harvesting from wastewater by $\mathrm{pH}$ modulation and flotation: Assessing and optimizing operational parameters. Journal of Environmental Management, 254(May 2019), 109825. doi: 10.1016/j.jenvman.2019.109825

Letsiou, S., Kalliampakou, K., Gardikis, K., Mantecon, L., Infante, C., Chatzikonstantinou, M., Labrou, N. E., \& Flemetakis, E. (2017). Skin protective effects of Nannochloropsis gaditana extract on $\mathrm{H}_{2} \mathrm{O}_{2}$-stressed human dermal fibroblasts. Frontiers in Marine Science, 4(JUL), 115. doi: $10.3389 /$ fmars.2017.00221

Liu, Z., Zhang, M., Bhandari, B., \& Wang, Y. (2017). 3D printing: Printing precision and application in food sector. Trends in Food Science \& Technology, 69, 83-94. doi: 10.1016/J.TIFS.2017.08.018

Ma, X., Chen, T., Yang, B., Liu, J., \& Chen, F. (2016). Lipid Production from Nannochloropsis. Marine drugs, 14(4):61. doi: 10.3390/md14040061

Manirafasha, E., Ndikubwimana, T., Zeng, X., Lu, Y., \& Jing, K. (2016). Phycobiliprotein: Potential microalgae derived pharmaceutical and biological reagent. Biochemical Engineering Journal, 109, 282-296. doi: 10.1016/J.BEJ.2016.01.025

Martins, Z. E., Pinho, O., \& Ferreira, I. M. P. L. V. O. (2017). Food industry by-products used as functional ingredients of bakery products. Trends in Food Science and Technology, 67, 106-128. doi: 10.1016/j.tifs.2017.07.003

Matos, Â. P. (2017). The Impact of Microalgae in Food Science and Technology. JAOCS, Journal of the American Oil Chemists' Society, 94(11), 1333-1350. doi: 10.1007/s11746-017-30507

Mazumder, A., Prabuthas, P., Giri, A., \& Mishra, H. N. (2014). Major food grade pigments from microalgae and their health benefits- A review. Indian Food Industry Magazine, 33(January 2016), 19-30.

Menegol, T., Romero-Villegas, G. I., López-Rodríguez, M., Navarro-López, E., López-Rosales, L., Chisti, Y., Cerón-García, M. C., \& Molina-Grima, E. (2019). Mixotrophic production of polyunsaturated fatty acids and carotenoids by the microalga Nannochloropsis gaditana. Journal of Applied Phycology, 31(5), 2823-2832. doi: 10.1007/s10811-019-01828-3

Minekus, M., Alminger, M., Alvito, P., Ballance, S., Bohn, T., Bourlieu, C., Carrière, F., Boutrou, R., Corredig, M., Dupont, D., Dufour, C., Egger, L., Golding, M., Karakaya, S., Kirkhus, B., Le Feunteun, S., Lesmes, U., Macierzanka, A., Mackie, A., \& Brodkorb, A. (2014). A 
standardised static in vitro digestion method suitable for food - an international consensus. Food Funct., 5(6), 1113-1124. doi: 10.1039/C3FO60702]

Mitra, M., Patidar, S. K., George, B., Shah, F., \& Mishra, S. (2015). A euryhaline Nannochloropsis gaditana with potential for nutraceutical (EPA) and biodiesel production. Algal Research, 8 , 161-167. doi: 10.1016/J.ALGAL.2015.02.006

Morsy, O. M., Sharoba, A. M., Bahlol, H., \& Abdel-mawla, E. (2014). Production and evaluation of extruded food products by using Spirulina algae. Annals of Agric. Sci., Moshtohor, 52(4), 329-342.

Neuhouser, M. L. (2019). The importance of healthy dietary patterns in chronic disease prevention. Nutrition Research, 70, 3-6. doi: 10.1016/j.nutres.2018.06.002

Niccolai, A., Chini Zittelli, G., Rodolfi, L., Biondi, N., \& Tredici, M. R. (2019). Microalgae of interest as food source: Biochemical composition and digestibility. Algal Research, 42, 101617. doi: 10.1016/J.ALGAL.2019.101617

Noort, M., Van Bommel, K., \& Renzetti, S. (2017). 3D-printed cereal foods. Cereal Foods World, 62(6), 272-277. doi: 10.1094/CFW-62-6-0272

Novovesk, L., Ross, M. E., Stanley, M. S., Pradelles, R., Wasiolek, V., \& Sassi, J. (2019). Microalgal Carotenoids: A Review of Production, Current Markets, Regulations, and Future Direction. 1-21.

Perez-Garcia, O., Escalante, F. M. E., de-Bashan, L. E., \& Bashan, Y. (2011). Heterotrophic cultures of microalgae: Metabolism and potential products. Water Research, 45(1), 11-36. doi: 10.1016/J.WATRES.2010.08.037

Pinna, C., Ramundo, L., Sisca, F. G., Angioletti, C. M., Taisch, M., \& Terzi, S. (2016). Additive Manufacturing applications within food industry: An actual overview and future opportunities. Proceedings of the Summer School Francesco Turco, 13-15-Sept, 18-24.

Rajauria, G., Cornish, L., Ometto, F., Msuya, F. E., \& Villa, R. (2015). Identification and selection of algae for food, feed, and fuel applications. In Seaweed Sustainability: Food and NonFood Applications (pp. 315-345). Elsevier Inc. doi: 10.1016/B978-0-12-418697-2.00012-X

Regulation (EU) 2015/2283 on novel foods. Official Journal of the European Union 1 (2015).

Riaz, M. N. (2016). Snack Foods, Processing. In Reference Module in Food Science. Elsevier. doi: https://doi.org/10.1016/B978-0-08-100596-5.00160-8

Rodríguez De Marco, E., Steffolani, M. E., Martínez, C. S., \& León, A. E. (2014). Effects of Spirulina biomass on the technological and nutritional quality of bread wheat pasta. $L W T$ Food Science and Technology, 58(1), 102-108. doi: 10.1016/j.Iwt.2014.02.054

Rodríguez De Marco, E., Steffolani, M. E., Martínez, M., \& León, A. E. (2018). The use of Nannochloropsis sp. as a source of omega-3 fatty acids in dry pasta: chemical, technological and sensory evaluation. International Journal of Food Science and 
Technology, 53(2), 499-507. doi: 10.1111/ijfs.13609

Romani, S., \& Rodriguez-Estrada, M. T. (2016). Bakery Products and Electronic Nose. In Electronic Noses and Tongues in Food Science. Elsevier Inc. doi: 10.1016/B978-0-12800243-8.00005-6

Ruiz, J., Olivieri, G., De Vree, J., Bosma, R., Willems, P., Reith, J. H., Eppink, M. H. M., Kleinegris, D. M. M., Wijffels, R. H., \& Barbosa, M. J. (2016). Towards industrial products from microalgae. Energy and Environmental Science, $9(10), 3036-3043$. doi: $10.1039 /$ c6ee01493c

Safi, C., Zebib, B., Merah, O., Pontalier, P. Y., \& Vaca-Garcia, C. (2014). Morphology, composition, production, processing and applications of Chlorella vulgaris: A review. Renewable and Sustainable Energy Reviews, 35, 265-278. doi: 10.1016/J.RSER.2014.04.007

Sathasivam, R., \& Ki, J. S. (2018). A review of the biological activities of microalgal carotenoids and their potential use in healthcare and cosmetic industries. Marine Drugs, 16(1). doi: $10.3390 /$ md16010026

Sathasivam, R., Radhakrishnan, R., Hashem, A., \& Abd-Allah, E. F. (2019). Microalgae metabolites: A rich source for food and medicine. Saudi Journal of Biological Sciences, 26(4), 709-722. doi: 10.1016/j.sjbs.2017.11.003

Shewry, P. R., \& Hey, S. J. (2015). The contribution of wheat to human diet and health. Food and Energy Security, 4(3), 178-202. doi: 10.1002/FES3.64

Sigamani, S., Ramamurthy, D., \& Natarajan, H. (2016). A review on potential biotechnological applications of microalgae. Journal of Applied Pharmaceutical Science, 6(8), 179-184. doi: 10.7324/JAPS.2016.60829

Singh, B., Liu, Y., \& Sharma, Y. C. (2013). Synthesis of biodiesel/bio-oil from microalgae. Biotechnological Applications of Microalgae: Biodiesel and Value-Added Products, 6(126), 99-112. doi: 10.1201/b14920

Soni, R. A., Sudhakar, K., \& Rana, R. S. (2017). Spirulina - From growth to nutritional product: A review. Trends in Food Science and Technology, 69, 157-171. doi: 10.1016/j.tifs.2017.09.010

Spiegel, M. van der, Noordam, M. Y., \& Fels-Klerx, H. J. van der. (2013). Safety of Novel Protein Sources (Insects, Microalgae, Seaweed, Duckweed, and Rapeseed) and Legislative Aspects for Their Application in Food and Feed Production. Comprehensive Reviews in Food Science and Food Safety, 12(6), 662-678. Retrieved from https://edepot.wur.nl/279490

Sui, Y., Jiang, Y., Moretti, M., \& Vlaeminck, S. E. (2020). Harvesting time and biomass composition affect the economics of microalgae production. Journal of Cleaner Production, 259, 120782. doi: 10.1016/j.jclepro.2020.120782 
Sui, Y., \& Vlaeminck, S. E. (2020). Forum Dunaliella Microalgae for Nutritional Protein: An Undervalued Asset. Trends in Biotechnology, 38(1), 10-12. doi: 10.1016/j.tibtech.2019.07.011

Suleria, H. A. R., Gobe, G., Masci, P., \& Osborne, S. A. (2016). Marine bioactive compounds and health promoting perspectives; innovation pathways for drug discovery. Trends in Food Science and Technology, 50, 44-55. doi: 10.1016/j.tifs.2016.01.019

Sun, H., Zhao, W., Mao, X., Li, Y., Wu, T., \& Chen, F. (2018). High-value biomass from microalgae production platforms: Strategies and progress based on carbon metabolism and energy conversion. Biotechnology for Biofuels, 11(1), 1-23. doi: 10.1186/s13068-018$1225-6$

Sun, J., Zhou, W., Huang, D., Fuh, J. Y. H., \& Hong, G. S. (2015). An Overview of 3D Printing Technologies for Food Fabrication. Food and Bioprocess Technology, 8, 1605-1615. doi: $10.1007 / \mathrm{s} 11947-015-1528-6$

Tang, G., \& Suter, P. M. (2011). Vitamin A, nutrition, and health values of Algae: Spirulina, Chlorella, and Dunaliella. Journal of Pharmacy and Nutrition Sciences, 1(2), 111-118. doi: 10.6000/1927-5951.2011.01.02.04

Temesi, Á., Bacsó, Á., Grunert, K. G., \& Lakner, Z. (2019). Perceived correspondence of health effects as a new determinant influencing purchase intention for functional food. Nutrients, 11(4), 130-131. doi: 10.3390/nu11040740

Thienhirun, S., \& Chung, S. (2018). Consumer Attitudes and Preferences toward Cross-Cultural Ready-To-Eat (RTE) Food. Journal of Food Products Marketing, 24(1), 56-79. doi: 10.1080/10454446.2016.1266544

Tiong, I., Ru, K., Sung, Y. Y., Jusoh, M., Abdul, M. E., \& Nagappan, T. (2020). Chlorella vulgaris: a perspective on its potential for combining high biomass with high value bioproducts. Applied Phycology, OO(00), 1-10. doi: 10.1080/26388081.2020.1715256

United Nations Department of Economic and Social Affairs Population Division. (2019). World population prospects 2019. In Department of Economic and Social Affairs. World Population Prospects 2019. (Issue 141). Retrieved from http://www.ncbi.nlm.nih.gov/pubmed/122832

Uribe-Wandurraga, Z. N., Igual, M., García-Segovia, P., \& Martínez-Monzó, J. (2019). Effect of microalgae addition on mineral content, colour and mechanical properties of breadsticks. Food \& Function, 10(8), 4685-4692. doi: 10.1039/c9fo00286c

Uribe-Wandurraga, Z. N., Igual, M., García-Segovia, P., \& Martínez-Monzó, J. (2020). In vitro bioaccessibility of minerals from microalgae-enriched cookies. Food \& Function, 11, 21862194. doi: $10.1039 / \mathrm{c} 9 \mathrm{fo} 02603 \mathrm{~g}$

USFDA. (2011). Agency response letter GRAS notice no. GRN 000394. Dried biomass of Arthrospira platensis, also known as Spirulina. Retrieved from http://wayback.archive- 
it.org/7993/20171031045652/https://www.fda.gov/downloads/Food/IngredientsPackagingL abeling/GRAS/NoticeInventory/UCM269772.pdf

USFDA. (2012). Agency response letter GRAS notice no. GRN 000396. Chlorella vulgaris as an ingredient in foods. Retrieved from https://wayback.archiveit.org/7993/20171031011011/https://www.fda.gov/Food/IngredientsPackagingLabeling/GR AS/NoticeInventory/ucm320210.htm

Vaz, B. da S., Moreira, J. B., Morais, M. G. de, \& Costa, J. A. V. (2016). Microalgae as a new source of bioactive compounds in food supplements. Current Opinion in Food Science, 7 , 73-77. doi: 10.1016/J.COFS.2015.12.006

Vicentini, A., Liberatore, L., \& Mastrocola, D. (2016). Functional Foods: Trends and Development. Italian Journal of Food Science, 28, 338-352.

Wang, A., Yan, K., Chu, D., Nazer, M., Lin, N. T., Samaranayake, E., \& Chang, J. (2020). Microalgae as a Mainstream Food Ingredient: Demand and Supply Perspective. In M. A. Alam, J.-L. Xu, \& Z. Wang (Eds.), Microalgae Biotechnology for Food, Health and High Value Products (pp. 29-80). Singapore: Springer Nature Singapore Pte Ltd. doi: 10.1007/978-981-15-0169-2

Wehr, J. D., Sheath, R. G., \& Kociolek, J. P. (Eds.). (2014). Introduction to the Freshwater Algae. In Freshwater Algae of North America (2nd Editio, pp. 1-11). Academic Press. doi: 10.1016/B978-0-12-385876-4.00001-3

Wijffels, H., Bolla, S., Kiron, V., \& Hulatt, C. J. (2017). Production of Fatty Acids and Protein by Nannochloropsis in Flat-Plate Photobioreactors. PLOS ONE, 12(1), 1-17. doi: 10.1371/journal.pone.0170440

Wijffels, R. H., \& Barbosa, M. J. (2010). An outlook on microalgal biofuels. Science, 329(5993), 796-799. doi: 10.1126/science.1189003

Wijffels, R. H., Kruse, O., \& Hellingwerf, K. J. (2013). Potential of industrial biotechnology with cyanobacteria and eukaryotic microalgae. Current Opinion in Biotechnology, 24(3), 405413. doi: $10.1016 /$ J.COPBIO.2013.04.004

Wilkinson, G., \& Dale, B. G. (2010). An examination of the ISO 9001: 2000 standard and its influence on the integration of management systems An examination of the ISO 9001 : 2000 standard and its influence on the integration of management systems. 7287. doi: $10.1080 / 0953728011008636$

Yanniotis, S., Taoukis, P., Stoforos, N., \& Karathanos, V. (2013). Advances in Food Process Engineering Research and Applications. In G. V. Barbosa-Cánovas (Ed.), Food Engineering Series. Athens: Springer. doi: 10.1201/b16696-2

Yew, G. Y., Lee, S. Y., Show, P. L., Tao, Y., Law, C. L., Nguyen, T. T. C., \& Chang, J.-S. (2019). Recent advances in algae biodiesel production: From upstream cultivation to downstream 
processing. Bioresource Technology Reports, 7, 100227. doi: 10.1016/J.BITEB.2019.100227

Zhang, J., Sun, Z., Sun, P., Chen, T., \& Chen, F. (2014). Microalgal carotenoids: Beneficial effects and potential in human health. Food and Function, 5(3), 413-425. doi: $10.1039 / c 3 f 060607 d$ 



\section{Chapter 2}

\section{Effect of microalgae addition on mineral content, colour and mechanical properties of breadsticks}

This chapter has been published as:

Uribe-Wandurraga, Z. N., Igual, M., García-Segovia, P., \& MartínezMonzó, J. (2019). Effect of microalgae addition on mineral content, colour and mechanical properties of breadsticks. Food \& Function, 10(8), 4685-4692. doi: 10.1039/c9fo00286c 



\section{Abstract}

Microalgae have recently attracted considerable attention due to its potential as a high source of proteins, lipids, vitamins, minerals and phytochemicals. Hence, it can be a useful ingredient intended to increase the nutritional and technological value of food products. The aim of the present study was to evaluate the effect of the addition of microalgae biomass, Chlorella vulgaris and Arthrospira platensis (Spirulina) on mineral content, colour and mechanical properties of breadsticks, and the colour, texture and rheology of doughs. Microalgae were shown to affect texture and rheology in doughs showing greater hardness values, although, a decrease in hardness, toughness, crispiness and brittleness parameters was seen in breadsticks. The main effects observed with microalgae addition were changes in dough colour, with visual colour perception, in all cases, of distinguished green colour tones. Breadstick colour was evaluated over 15 days of storage and showed colour stability. Furthermore, the mineral content of breadsticks increased, specifically, iron and selenium, both important compounds involved in human body functions. The incorporation of Chlorella or Spirulina in the formulation allows for the production of breadsticks classed as "high in iron and selenium food" and more stable in colour and texture. 


\section{Introduction}

Microalgae are unicellular microorganisms and are commonly found in fresh and salt water and vary in shape and size, with lengths or diameters ranging, approximately, between 3-10 $\mu \mathrm{m}$ (de Morais et al., 2015). Microalgae have gained more attention from researchers due to their rich source of biochemicals, namely protein, vitamins, minerals, pigments, plus many more (Volk, 2008; Ibañez et al., 2013). The first commercialised microalgae were Chlorella vulgaris and Arthrospira platensis (Spirulina), being two important microalgae used in food applications, and were promoted as health foods in Japan, Taiwan and Mexico (Borowitzka, 2013). Chlorella vulgaris is a green microalga belonging to the Chlorophyta group, having important nutritional value and consumed worldwide (Priyadarshani et al., 2012). Chlorella contains high amounts of chlorophyll, proteins, polysaccharides, vitamins, minerals and essential amino acids (Borowitzka, 2013). Spirulina is filamentous in nature and is a microscopic blue-green microalgae type, which is found intensively in alkaline waters (Ak et al., 2016). Spirulina has a high content of micro and macronutrients. Its dry weight chemical composition includes proteins (60-70\% dry weight), carbohydrates, vitamins and minerals (iron, calcium, chromium, copper, magnesium, manganese, phosphorus, potassium, sodium and zinc) (Soni et al., 2017). Therefore, microalgae, due to its phenomenal composition, is a novel healthy food ingredient with biologically active compounds (Batista et al., 2013) and when used in food production, those such foods are determined functional (Batista et al., 2012).

Functional foods can be defined as foods that are similar in appearance to conventional foods, are consumed as part of a regular diet, and can contribute to increase the health condition of a person to a higher degree of that expected from regular nutritional intake from a common food source (Chacón-Lee et al., 2010). Currently, bakery products are the most widely consumed foods in the world and have great potential for delivery of macroalgae and microalgae functional ingredients (Kadam et al., 2010; Roohinejad et al., 2017). In recent years, the demand for snacks with improved nutritional and functional properties has increased (Potter et al., 2013), due to the high practicality, convenience and acceptability of these foods, especially among children (Potter et al., 2013; Shahbazizadeh et al., 2015). 
The present study aimed to evaluate the effect of the addition of two microalgae biomass, Chlorella vulgaris and Arthrospira platensis (Spirulina) on mineral content, colour, textural and rheological properties of breadsticks. It should be noted that breadsticks are traditionally baked snacks in the Valencian Community, Spain, although they are also widely consumed in other Mediterranean countries and the world. For this, doughs and breadsticks were evaluated to study and improve the quality and nutritional content of the bakery product upon the incorporation of microalgae. Considering that, the formulation was varied with the type of microalgae while retaining the same level of concentration.

\section{Material and methods}

\section{Raw materials}

Freeze dried Arthrospira platensis (Spirulina) and Chlorella vulgaris were supplied from AlgaEnergy S.A., Madrid, Spain. Wheat flour, salt, yeast and sunflower oil were purchased from a local supermarket (Alcampo, Valencia, Spain).

\section{Dough formulation and breadstick preparation}

Three dough samples of $60 \mathrm{~g}$ were prepared by mixing microalgae and wheat flour, the ratio was calculated by percentage; control dough (CD) contains $0 \%$ microalgae and $100 \%$ wheat flour; Spirulina dough (SD), 1.5\% Arthrospira platensis and 98.5\% wheat flour, and Chlorella dough (CHD), $1.5 \%$ of Chlorella vulgaris and $98.5 \%$ wheat flour. The other components of the dough were $14 \mathrm{~g}$ of sunflower oil, $7 \mathrm{~g}$ of fresh yeast, $0.4 \mathrm{~g}$ of salt and $18.6 \mathrm{~g}$ of water.

The ingredients were mixed in a food processor (Kenwood chef classic, KM400/99 plus, Kenwood Corporation, Tokyo, Japan), kneading for $15 \mathrm{~min}$ at low speed. Dough samples were fermented for 1 hour at $33^{\circ} \mathrm{C}$ in a controlled temperature oven (Convotherm OES 6.06 mini CC, Convotherm Elektrogeräte GMBH, Eglfing, Germany). The breadsticks were shaped by hand into $10 \mathrm{~cm}$ length and $10 \mathrm{~g}$ weighted sticks and fermented once again for $30 \mathrm{~min}$ at $33^{\circ} \mathrm{C}$. After the second fermentation, samples were baked on rectangular baking sheets at $180{ }^{\circ} \mathrm{C}$ for $28 \mathrm{~min}$ in a steamer oven (Convotherm OES $6.06 \mathrm{mini} \mathrm{CC}$, Convotherm Elektrogeräte GMBH, Eglfing, Germany). Breadsticks were cooled for $2 \mathrm{~h}$ and placed in heatresistant polyethylene plastic pouches (Cryovac $($ HT3050) to be stored at room temperature $\left(25^{\circ} \mathrm{C}\right)$ for 15 days. 


\section{Analysis}

\section{Water content}

Water content (g water/100 g sample) was determined by vacuum oven drying at $105^{\circ} \mathrm{C}$ until constant weight (AOAC, 2005) both for dough and for breadstick samples. Samples were analysed in triplicate.

\section{Colour Measurement}

The colour of dough and breadstick samples were measured instrumentally using a Konica Minolta CM-700d colourimeter (Konica Minolta CM-700d/600d series, Tokyo, Japan) with standard illuminant D65 and a visual angle of $10^{\circ}$.

For dough colour, three breadstick shaped doughs were measured at three equidistant points for each formulation. For breadstick colour, three breadsticks of each formulation were measured on each side, bottom and top, at three equidistant points, at day 0 and day 15 of storage. The results were expressed in terms of $L^{*}$ (brightness: $L^{*}=0$ (black), $L^{*}=$ 100 (white) $), a^{*}\left(-a^{*}=\right.$ greenness,$+a^{*}=$ redness $)$, and $b^{*}\left(-b^{*}=\right.$ blueness,$+b^{*}=$ yellowness), according to the CIELab system (CIE, 1986). Chroma, C* ${ }_{a b}$ (saturation) and hue angle, $\mathrm{h}_{\mathrm{ab}}^{\circ}$, were also calculated, defined by: $\mathrm{C}^{*}{ }_{\mathrm{ab}}=\left[\left(\mathrm{a}^{2}+\mathrm{b}^{* 2}\right)\right]^{1 / 2} ; \mathrm{h}_{\mathrm{ab}}^{\circ}=\arctan$ $\left(b^{*} / a^{*}\right)$. The total colour difference $(\Delta E)$ between samples with and without microalgae, and of both doughs and breadsticks, was determined using $\mathrm{L}^{*} \mathrm{a} * \mathrm{~b} *$ values according to: $\Delta \mathrm{E}=$ $\left[\left(\Delta \mathrm{L}^{*}\right)^{2}+(\Delta \mathrm{a} *)^{2}+\left(\Delta \mathrm{b}^{*}\right)^{2}\right]^{1 / 2}$. For breadstick samples, $\Delta \mathrm{E}$ measurements between positions (top and bottom) were calculated, as well as between 0 and 15 days of storage.

\section{Rheological Measurements}

The rheological behaviour of doughs was studied using a Kinexus pro+ rotational rheometer (Malvern Instruments, Worcestershire, UK) and rSpace software. The rheometer was equipped with a parallel plate geometry ( $25 \mathrm{~mm}$ diameter) set to a $2 \mathrm{~mm}$ gap. Prior to oscillatory testing, dough samples were loaded onto the geometry plate and rested for $300 \mathrm{~s}$ before measurement. Dynamic rheological characterisation of the samples was subsequently performed. Firstly, the linear viscoelastic region was determined, followed by oscillatory stress sweeps at $20{ }^{\circ} \mathrm{C}$ with a frequency range of $0.1-10 \mathrm{~Hz}$ for each sample using a constant strain of $0.5 \%$. Values of elastic modulus ( $\left.\mathrm{G}^{\prime}[\mathrm{Pa}]\right)$, viscous modulus $\left(\mathrm{G}^{\prime \prime}[\mathrm{Pa}]\right)$ and 
$\tan \delta\left(G^{\prime \prime} / G^{\prime}\right)$ were obtained for different frequency values $(\omega[\mathrm{Hz}])$. Samples were analysed in triplicate.

\section{Textural properties}

The texture of doughs and breadsticks was measured using a TA-XT2 Texture Analyser (Stable Micro Systems Ltd, Godalming, UK) and software Texture Exponent (version 6.1.12.0). A dough piece (60 g) was placed in a standard size back extrusion container (50 $\mathrm{mm}$ diameter) immediately after the second dough fermentation. An extrusion disc (35 mm diameter) attached to a $50 \mathrm{~kg}$ load cell was positioned centrally over the container compressing the sample to a thickness of $5 \mathrm{~mm}$ at pre-test and test speeds of $1 \mathrm{~mm} \mathrm{~s}^{-1}$ and post-test speed of $10 \mathrm{~mm} \mathrm{~s}^{-1}$. Six samples were measured from each blend at day 0 , and the results were averaged. The parameters analysed were a maximum force $(N)$, the gradient of force-time ( $\mathrm{N} / \mathrm{s})$ and area under the curve force-time $(\mathrm{N} \mathrm{s})$.

A snap test was used to evaluate the textural properties of the breadsticks and observe any changes which occurred during storage. The texture analyser was equipped with a $50 \mathrm{~kg}$ load cell and a three-point bending rig (HDP/3PB). The two adjustable supports of the base plate were set $20 \mathrm{~mm}$ apart, and the sample was placed centrally over the supports just prior to testing. The upper blade moved downwards at a pre-test and test speeds of $1 \mathrm{~mm}$ $\mathrm{s}^{-1}$ and, $3 \mathrm{~mm} \mathrm{~s}^{-1}$, respectively. Hardness, toughness, crispiness and brittleness, an index of breadstick break strength was measured with six breadsticks per batch. The test was performed on days 0 and 15 of storage.

\section{Ash and mineral content}

Total ash content was determined following method 930.05 of AOAC procedures (AOAC, 2005). A sample of $500 \mathrm{mg}$ was incinerated with high pressure in a microwave oven (Muffle P Selecta Mod.367PE) for $24 \mathrm{~h}$ at $550{ }^{\circ} \mathrm{C}$, and ash was gravimetrically quantified. The residue of incineration was extracted with $\mathrm{HCl}$ (hydrochloric acid) $(50 \% \mathrm{v} / \mathrm{v})$ and $\mathrm{HNO}_{3}$ (nitric acid) (50\% v/v) and made up to an appropriate volume with distilled water (Fernández-Ruiz et al., 2011), also minerals were measured using standard solutions for calibration purposes.

The multi-mineral determination was performed by using inductively coupled plasma optical emission spectrometer, model 700 Series ICP-OES from Agilent Technologies (Santa Clara, 
United States), with axial viewing and a charge coupled device detector. The instrumental parameters used for the multi-element determination were as follows: RF generator of 40 $\mathrm{MHz}$, a power of $1 \mathrm{~kW}$, plasma gas flow rate of $15 \mathrm{~L} \mathrm{~min}^{-1}$, auxiliary gas flow rate of $1.5 \mathrm{~L}$ $\mathrm{min}^{-1}$ and nebuliser gas (One Neb 2) pressure of $200 \mathrm{kPa}$. The elements and the analytical spectral lines (nm) used were: P (214.914), K (766.491), Ca (317.933), Na (589.592), Mg (285.213), Fe (238.204), Zn (213.857), Cu (327.395), Mn (259.372), and Se (196.026). Mineral composition (macro and microelements) were expressed as mg/100 g. Samples were analysed in triplicate.

\section{Statistical analysis}

Analysis of variance (ANOVA), with a confidence level of $95 \%(p<0.05)$, using Statgraphics Centurion XVII Software, version 17.2.04, was applied to evaluate the differences among breadstick samples. Furthermore, a correlation analysis among the rheological and textural properties of doughs studied, and the textural properties of breadsticks produced in the study, with a 95\% significance level, was carried out (Statgraphics Centurion XVII). A factor analysis was applied to the values of rheological and textural parameters of doughs studied, using SPSS program version 16.0.

\section{Results and discussion}

\section{Dough properties}

Doughs obtained according to section 2.2 were evaluated with regards to water content, rheological and textural properties, and colour. The water content of three doughs was similar $(\approx 28 \%)$ without significant $(p>0.05)$ differences among them.

Dough rheological behaviour is considered the predominant characteristic for the effective production of bakery products, therefore rheological properties of dough significantly influence the final quality of baked products (Devi et al., 2016). Dough rheological parameters are shown in Figure 1 and Table 1. In all cases, storage modulus (G') was greater than loss modulus ( $\left.\mathrm{G}^{\prime \prime}\right)$ throughout the frequency range $(0.1$ to $10 \mathrm{~Hz})$, which shows a predominant solid viscoelastic behaviour of all the breadstick doughs studied (Inglett et al., 2015). Additionally, the loss factor ( $\tan \delta=\mathrm{G}^{\prime \prime} / \mathrm{G}^{\prime}$ ) represents the relationship between loss modulus and storage modulus, where a high value of $\tan \delta$ corresponds to materials 
with predominant viscous behaviour. The mean values of $\mathrm{G}^{\prime}, \mathrm{G}^{\prime \prime}$ and $\tan \delta$ at $1 \mathrm{~Hz}$ are presented in Table 1.

The cyanobacterium Spirulina is well recognised as a potential food supplement for humans because of its high levels of protein (60-70\% of dry weight) (Buono et al., 2014). Chlorella, also containing elevated levels of protein is a potential food supplement (Batista et al., 2013), along with Spirulina. Protein addition increases $\mathrm{G}^{\prime}$ and was observed when wheat flour was substituted for flours with a higher protein content in cookies formulations (Mancebo et al., 2016). Other authors (Graça et al., 2018) suggest that content up to $3.0 \mathrm{~g}$ of Chlorella per $100 \mathrm{~g}$ wheat flour showed higher $\mathrm{G}^{\prime}$ values, indicating a possible strengthening effect of the dough structure, believed to be due to a reinforcement of the viscoelastic protein matrix from the addition of microalgae, with high protein content. Microalgae addition increased $\mathrm{G}^{\prime}$ values (Figure 1) when compared with the control sample without significant differences $(p>0.05$ ), and when values were compared at $1 \mathrm{~Hz}$ (Table 1). Relating to tan $\delta$, the values observed in Table 1 show that samples with microalgae are significantly lower $(p<0.05)$, indicating a greater elastic behaviour.

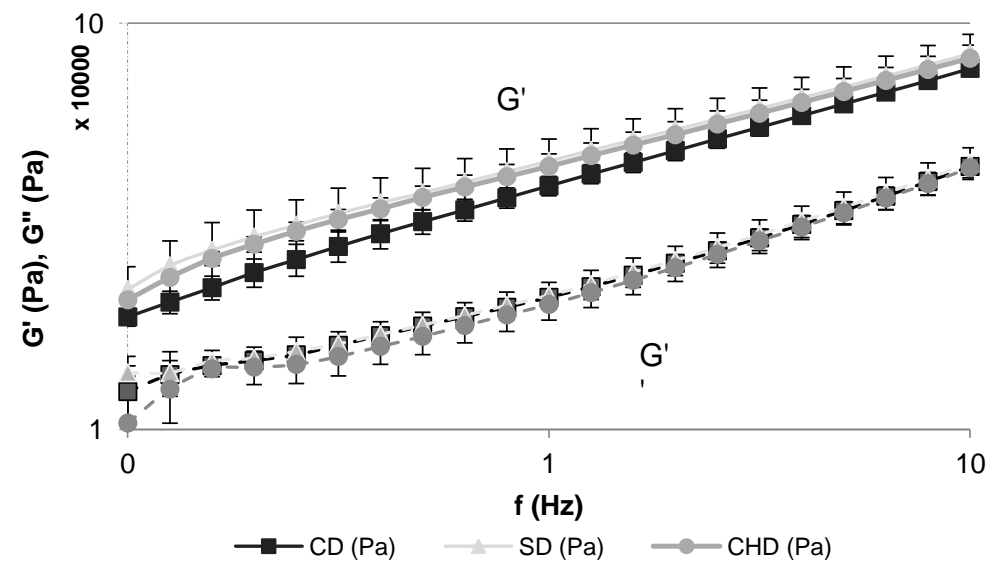

Figure 1. Frequency sweeps of doughs. Storage modulus $\left(\mathrm{G}^{\prime}\right)$ with a continuous line and loss modulus $\left(\mathrm{G}^{\prime \prime}\right)$ with a dotted line of studied doughs. $\mathrm{CD}$ : control dough; SD: dough with Spirulina (1.5\%); CHD: Dough with Chlorella (1.5\%). 
The textural properties of doughs were determined in terms of maximum force $(\mathrm{N})$, the gradient of force-time ( $\mathrm{N} / \mathrm{s}$ ) and area under the curve force-time ( $\mathrm{N} \mathrm{s}$ ) (Table 1 ). The addition of microalgae biomass contributed to a significant increase $(p<0.05)$ on the textural characteristics of the doughs studied. Therefore, doughs with microalgae showed a greater hardness in comparison with control doughs, with SD being the hardest sample.

Table 1. Mean values (and standard deviations) of storage modulus $\left(\mathrm{G}^{\prime}\right)$, loss modulus $\left(\mathrm{G}^{\prime \prime}\right)$ values and $\tan \delta$ at $1 \mathrm{~Hz}$ obtained from rheological measurements and maximum force $\left(\mathrm{F}_{\max }\right)$, area and gradient as textural properties of studied doughs.

\begin{tabular}{ccccccc}
\hline \multirow{2}{*}{ Sample } & $\begin{array}{c}\mathbf{G}^{\prime} \\
\mathbf{P a}\end{array}$ & $\begin{array}{c}\mathbf{G}^{\prime \prime} \\
\mathbf{( P a})\end{array}$ & $\tan \mathbf{\delta}$ & $\begin{array}{c}\text { Gradient } \\
\mathbf{( N / s )}\end{array}$ & $\begin{array}{c}\mathbf{F}_{\max } \\
\mathbf{( N )}\end{array}$ & $\begin{array}{c}\text { Area } \\
(\mathbf{N . s})\end{array}$ \\
\hline CD & $39777(2180)^{\mathrm{a}}$ & $21143(238)^{\mathrm{a}}$ & $0.53(0.02)^{\mathrm{a}}$ & $4.64(0.18)^{\mathrm{b}}$ & $25.7(0.6)^{\mathrm{c}}$ & $72(3)^{\mathrm{c}}$ \\
SD & $45780(6067)^{\mathrm{a}}$ & $21390(1626)^{\mathrm{a}}$ & $0.47(0.03)^{\mathrm{b}}$ & $5.44(0.15)^{\mathrm{a}}$ & $39.9(0.6)^{\mathrm{a}}$ & $81(2)^{\mathrm{a}}$ \\
CHD & $44395(3260)^{\mathrm{a}}$ & $20305(1718)^{\mathrm{a}}$ & $0.457(0.005)^{\mathrm{b}}$ & $5.2(0.2)^{\mathrm{a}}$ & $28.4(0.8)^{\mathrm{b}}$ & $77(3)^{\mathrm{b}}$ \\
\hline
\end{tabular}

The same letter in superscript within column indicates homogeneous groups established by ANOVA $(p<$ 0.05).

A factor analysis (Figure 2) was used to explore the relationships between rheological and textural parameters of doughs studied, as well as the links between them. The first two factors showed eigenvalues higher than 1 and the consideration of both factors accounted for $95.40 \%$ of the total variability. The first factor (F1), explaining $67.05 \%$ of the variability, was associated with maximum force $(r=0.97)$, area $(r=0.97)$, $\tan \delta(r=0.95)$ and gradient ( $r=0.94$ ) values. The second factor (F2) accounted for $28.35 \%$ of the variability and was mainly associated with $G^{\prime}(r=0.98)$ and $G^{\prime \prime}(r=0.82)$ values. F1 separated CD and dough from microalgae on the left-hand side, because of their lower values of $F_{\text {max }}$ area, gradient and their higher values of $\tan \delta$. This analysis clearly separates the doughs depending on the use of microalgae in their formulation, as ingredient affecting higher resistance and hardness as well as elasticity. F2 shows higher viscoelastic behaviour in SD, in comparison with the other samples. The results from current analysis confirm that the addition of microalgae in dough reinforces their elastic behaviour. 


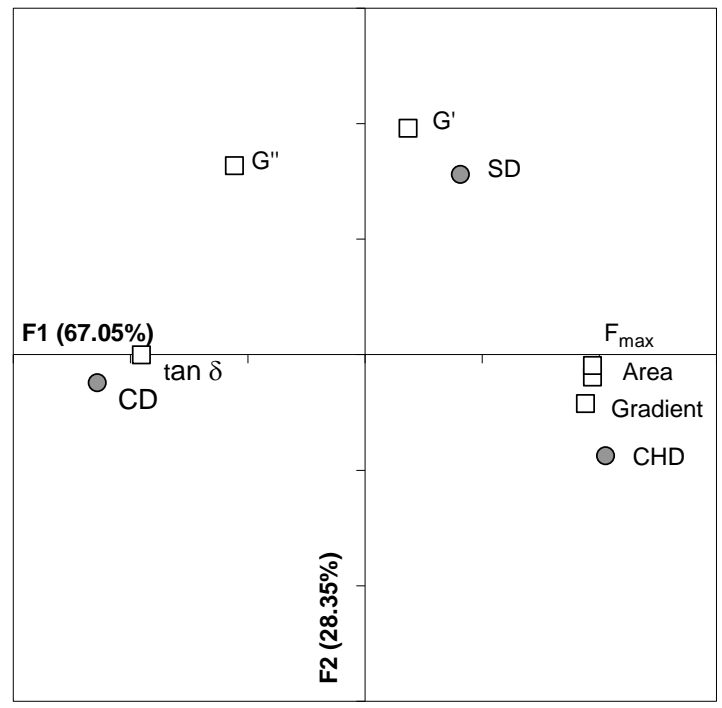

Figure 2. Factor analysis plot for studied dough: rheological and textural parameters.

The results obtained for the dough colour parameters, lightness $\left(L^{*}\right)$, green/red $\left(a^{*}\right)$, blue/yellow $\left(\mathrm{b}^{*}\right)$, hue $\left(\mathrm{h}_{\mathrm{ab}}^{\circ}\right)$ and chroma $\left(\mathrm{C}^{*}{ }_{\mathrm{ab}}\right)$ are presented in Table 2 . The evaluation of parameter $L^{*}$ shows that lightness decreased significantly $(p<0.05)$ with microalgae addition. Also, for both microalgae doughs (Chlorella and Spirulina) at the same concentration $(1.5 \%)$ significant $(p<0.05)$ differences were found between them, with the addition of Spirulina resulting in darker dough than Chlorella. Parameter a* (red) and b* (yellow) showed significant differences $(p<0.05)$ and microalgae addition significantly $(p<$ 0.05 ) increased the doughs green colour (negative a* values) compared with control dough.

Table 2. Mean values (and standard deviation) of colour parameters of dough samples.

\begin{tabular}{cccccccc}
\hline Sample & $\mathbf{L}^{*}$ & $\mathbf{a}^{*}$ & $\mathbf{b}^{*}$ & $\mathbf{h}_{\mathrm{ab}}$ & $\mathbf{C}^{*}{ }_{\mathrm{ab}}$ & $\mathbf{\Delta E}_{\mathbf{1}}$ & $\mathbf{\Delta E}_{\mathbf{2}}$ \\
\hline $\mathrm{CD}$ & $58.5(1.2)^{\mathrm{a}}$ & $1.8(0.4)^{\mathrm{a}}$ & $20.0(1.4)^{\mathrm{a}}$ & $84.9(0.9)^{\mathrm{c}}$ & $20.1(1.4)^{\mathrm{a}}$ & - & - \\
$\mathrm{SD}$ & $35.1(1.3)^{\mathrm{c}}$ & $-4.1(0.8)^{\mathrm{c}}$ & $7.383(0.997)^{\mathrm{c}}$ & $119.1(1.7)^{\mathrm{a}}$ & $8.5(1.2)^{\mathrm{c}}$ & $27.3(1.3)^{\mathrm{a}}$ & - \\
$\mathrm{CHD}$ & $36.6(1.4)^{\mathrm{b}}$ & $-0.4(0.3)^{\mathrm{b}}$ & $10.9(1.7)^{\mathrm{b}}$ & $92.139(1.096)^{\mathrm{b}}$ & $10.9(1.8)^{\mathrm{b}}$ & $23.9(1.9)^{\mathrm{b}}$ & $5.874(1.112)$ \\
\hline
\end{tabular}

The same letter in superscript within columns indicates homogeneous groups established by the ANOVA $(p<0.05)$. Colour differences of doughs as compared to control $\left(\Delta \mathrm{E}_{1}\right)$ and compared amongst Spirulina and Chlorella doughs $\left(\Delta \mathrm{E}_{2}\right)$. 
$\Delta \mathrm{E}$ values show perceptible colour differences when comparing the control dough to both doughs with microalgae $(\Delta \mathrm{E} 1)$, and when comparing Spirulina and Chlorella doughs $(\Delta \mathrm{E} 2)$ together. A value of $\Delta \mathrm{E}>3$ implies perceptible colour difference for a consumer (Bodart et al., 2008). However, the visual colour perception in all cases is very pleasant, as can be observed in Figure 3.

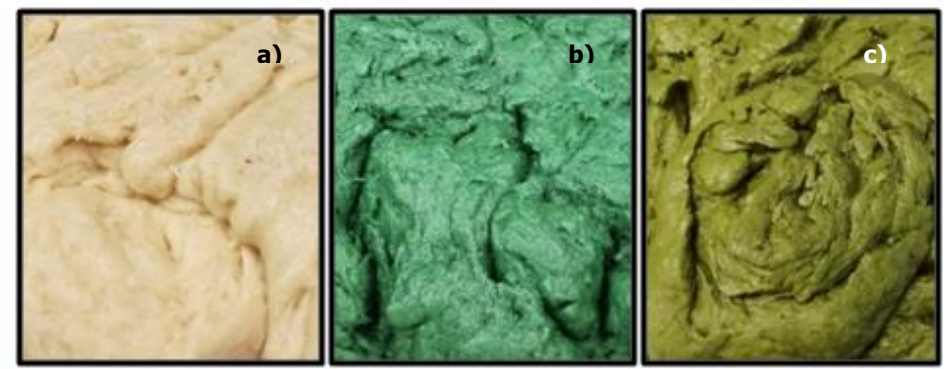

Figure 3. Visual colour differences among the three studied doughs: a) CD: Control dough, b) SD: Spirulina dough and c) CHD: Chlorella dough.

\section{Breadstick characterisation}

Breadsticks produced were evaluated according to water and ash content, textural and optical properties, and mineral content. All breadsticks presented water content values ranging from 0.45 to $0.65 \%$ without significant differences $(p>0.05)$, which is typical for this type of dried foods. No significant changes $(p>0.05)$ were observed in the breadsticks' ash content upon microalgae addition (0.89-1.12\%).

Table 3 shows the mean values of hardness, brittleness, area, toughness and crispiness of breadsticks studied at 0 and after 15 storage days. In general, the addition of microalgae provokes a decrease in all textural parameters studied in breadsticks. In the same way as Shahbazizadeh et al. (2015), who reported that the firmness of cookies generally decreased by enhancing microalgal biomass content, as a consequence of the formation of weaker gels when Spirulina biomass was added to the batter (Gouveia et al., 2007). However, after 15 storage days, breadsticks with microalgae were harder and presented higher areas than the control breadsticks. While the control's hardness and area were decreasing, these parameters in breadsticks with microalgae were increasing (SB) or maintaining (CHB). Other authors observed this trend in cookies enriched with $2 \%$ of Spirulina, after eight weeks of storage (Batista et al., 2017). 
Table 3. Mean values (and standard deviations) of Hardness (N), Brittleness (mm), Area (N.s), Toughness (N.s) and Crispiness (N) as textural properties of studied breadsticks.

\begin{tabular}{|c|c|c|c|c|c|c|}
\hline $\begin{array}{c}\text { Time } \\
\text { (days) }\end{array}$ & Sample & $\begin{array}{c}\text { Hardness } \\
\text { (N) }\end{array}$ & $\begin{array}{c}\text { Brittleness } \\
(\mathrm{mm})\end{array}$ & $\begin{array}{l}\text { Area } \\
\text { (N.s) }\end{array}$ & $\begin{array}{c}\text { Toughness } \\
\text { (N.s) }\end{array}$ & $\begin{array}{c}\text { Crispiness } \\
\text { (N) }\end{array}$ \\
\hline \multirow{4}{*}{0} & $\mathrm{CB}$ & $40.6(4.6)^{\mathrm{aA}}$ & $1.3(0.2)^{\mathrm{aA}}$ & $9.7(2.2)^{\mathrm{aA}}$ & $1.1(0.5)^{\mathrm{aA}}$ & $2.67(1.03)^{a A}$ \\
\hline & SB & $32.7(2.8)^{\mathrm{bB}}$ & $0.89(0.06)^{\mathrm{bB}}$ & $5.0(0.6)^{\mathrm{bB}}$ & $0.36(0.04)^{\mathrm{bB}}$ & $1.33(0.82)^{\mathrm{bA}}$ \\
\hline & $\mathrm{CHB}$ & $35.11(3.11)^{\mathrm{bA}}$ & $1.1(0.2)^{\mathrm{abA}}$ & $6.4(1.9)^{\mathrm{bA}}$ & $0.7(0.5)^{\mathrm{abA}}$ & $2.0(1.3)^{\mathrm{abA}}$ \\
\hline & $\mathrm{CB}$ & $29.3(1.9)^{\mathrm{CB}}$ & $0.93(0.05)^{\mathrm{aB}}$ & $4.8(0.6)^{\mathrm{b} B}$ & $1.1(0.5)^{\mathrm{abA}}$ & $2 . \overline{(1.6)^{\mathrm{aA}}}$ \\
\hline \multirow[t]{2}{*}{15} & SB & $41.8(4.7)^{\mathrm{aA}}$ & $1.06(0.10)^{\mathrm{aA}}$ & $7.6(1.6)^{\mathrm{aA}}$ & $0.52(0.08)^{\mathrm{bA}}$ & $2.33(1.03)^{\mathrm{aA}}$ \\
\hline & $\mathrm{CHB}$ & $34.0(2.9)^{\mathrm{bA}}$ & $1.0(0.3)^{\mathrm{aA}}$ & $5.9(2.5)^{\mathrm{abA}}$ & $2.1(1.7)^{\mathrm{aA}}$ & $2.3(1.4)^{\mathrm{aA}}$ \\
\hline
\end{tabular}

For each storage time ( 0 or 15 days), the same small letter in superscript within column indicates homogeneous groups established by ANOVA $(p<0.05)$ comparing breadstick formulation. For each breadstick (CB, SB or CHB), the same capital letter in superscript within column indicates homogeneous groups established by ANOVA ( $p<0.05)$ comparing storage time ( 0 or 15 days).

To explain the relationship of the rheological and textural properties of doughs studied with the textural properties of breadsticks produced, correlation statistical analyses were performed (Table 4). Textural properties of doughs ( $F_{\max }$ area and gradient) showed negative Pearson's correlation coefficients with textural properties of breadsticks. Doughs with microalgae put up more resistance; nevertheless, the related breadsticks were less hard. In general, there is a negative relationship between area and maximum force of doughs and breadstick hardness. On the other hand, the highest significant $(p<0.05)$ correlation was observed between tan $\delta$ and area of dough and crispiness in breadsticks. Dough with high $\tan \delta(C D)$ showed high values of area and crispiness in the breadsticks samples (CB).

Table 4. Pearson correlation coefficients between rheological and textural properties of doughs and textural properties of breadsticks.

\begin{tabular}{|l|ccccc|}
\cline { 2 - 6 } \multicolumn{1}{c|}{} & \multicolumn{5}{c|}{ Breadsticks } \\
\cline { 2 - 6 } \multicolumn{1}{c|}{} & Hardness & Brittleness & Area & Toughness & Crispiness \\
\hline F & $-0.7355^{*}$ & $-0.609^{*}$ & $-0.6900^{*}$ & $-0.7042^{*}$ & -0.4055 \\
Area & $-0.7639 *$ & $-0.6346^{*}$ & $-0.7082^{*}$ & $-0.6816^{*}$ & $-0.5177^{*}$ \\
Gradient & $-0.5714^{*}$ & $-0.4427^{*}$ & $-0.5804^{*}$ & $-0.6276^{*}$ & $-0.5227^{*}$ \\
G' & -0.1495 & -0.3117 & -0.2418 & 0.0445 & -0.3526 \\
G" & 0.3796 & 0.2328 & 0.391 & 0.4422 & 0.2764 \\
Tan $\delta$ & $0.7063^{\prime}$ & $0.7014^{*}$ & $0.8264 *$ & 0.5062 & $0.7906^{*}$ \\
\hline
\end{tabular}

${ }^{*}$ Correlation is significant at the 0.05 level. 
Colour is an important characteristic of baked products because together with texture, it contributes to consumer preference (Cox et al., 2013). Mean values of colour parameters of breadstick samples were shown in Table 5. The degradation of microalgae pigments such as chlorophyll and carotenoids due to heat contributes to colour changes in samples with microalgae (García-Segovia et al., 2017). This fact can be observed comparing Table 2 (dough colour) and Table 5 (breadstick colour). The typical green colour of microalgae dough (Table 2) was lost after baking and the addition of microalgae decreased luminosity significantly $(p<0.05)$, when compared to the control, that caused darkening of the breadstick. The values for $\mathrm{a}^{*}$ and $\mathrm{b}^{*}$ also decreased significantly $(p<0.05)$ in samples with microalgae. This behaviour was observed by other authors (Cervejeira Bolanho et al., 2014) in cookies because of Spirulina biomass addition. Comparing the colour measurement position (top and bottom) in Table 5 , there were no significant $(p>0.05)$ differences in total colour differences between the types of microalgae added $\left(\Delta \mathrm{E}_{2}\right)$. Chroma values for the three samples were significantly $(p<0.05)$ different according to the colour measurement position, both top and bottom positions for chroma values of samples were ordered as $\mathrm{CB}>$ $\mathrm{CHB}>\mathrm{SB}$.

Table 5. Mean values (and standard deviation) of colour parameters of breadstick samples.

\begin{tabular}{cccc|ccc}
\hline \multirow{2}{*}{ Sample } & \multicolumn{3}{c|}{ TOP } & \multicolumn{3}{c}{ BOTTOM } \\
\cline { 2 - 7 } & $\mathbf{C B}$ & $\mathbf{S B}$ & $\mathbf{C H B}$ & $\mathbf{C B}$ & $\mathbf{S B}$ & $\mathbf{C H B}$ \\
\hline $\mathbf{L}^{*}$ & $61(2)^{\mathrm{aB}}$ & $42.6(1.3)^{\mathrm{bB}}$ & $39.8(1.7)^{\mathrm{CB}}$ & $63.8(1.4)^{\mathrm{aA}}$ & $44.2(1.2)^{\mathrm{bA}}$ & $44.2(0.9)^{\mathrm{bA}}$ \\
$\mathbf{a}^{*}$ & $5.3(0.6)^{\mathrm{aA}}$ & $1.0(0.2)^{\mathrm{CB}}$ & $1.8(0.2)^{\mathrm{bA}}$ & $5.32(1.06)^{\mathrm{aA}}$ & $1.6(0.3)^{\mathrm{bA}}$ & $1.9(0.2)^{\mathrm{bA}}$ \\
$\mathbf{b}^{*}$ & $26.7(0.7)^{\mathrm{aB}}$ & $13.72(1.02)^{\mathrm{CA}}$ & $14.4(1.5)^{\mathrm{bB}}$ & $27.7(1.4)^{\mathrm{aA}}$ & $14.48(1.13)^{\mathrm{cA}}$ & $17.47(1.06)^{\mathrm{bA}}$ \\
$\mathbf{h}_{\mathbf{a b}}$ & $78.7(1.2)^{\mathrm{CA}}$ & $85.7(0.9)^{\mathrm{aA}}$ & $82.9(0.8)^{\mathrm{bB}}$ & $79.2(1.6)^{\mathrm{bA}}$ & $83.55(1.06)^{\mathrm{aB}}$ & $83.7(0.5)^{\mathrm{aA}}$ \\
$\mathbf{C}^{*}{ }_{\mathbf{a b}}$ & $27.2(0.7)^{\mathrm{aB}}$ & $13.759(1.015)^{\mathrm{CB}}$ & $14.7(1.5)^{\mathrm{bB}}$ & $28.3(1.5)^{\mathrm{aA}}$ & $14.58(1.15)^{\mathrm{CA}}$ & $17.57(1.07)^{\mathrm{bA}}$ \\
$\mathbf{\Delta E}_{\mathbf{1}}$ & - & $22.8(2.3)^{\mathrm{aA}}$ & $24.5(2.4)^{\mathrm{aA}}$ & - & $24(1.3)^{\mathrm{aA}}$ & $22.5(1.3)^{\mathrm{bB}}$ \\
$\boldsymbol{\Delta E}_{\mathbf{2}}$ & - & - & $4.2(1.5)^{\mathrm{A}}$ & - & - & $3.5(1.4)^{\mathrm{A}}$ \\
\hline
\end{tabular}

For each measurement position (top or bottom), the same small letter in superscript within rows indicates homogeneous groups established by ANOVA $(p<0.05)$ comparing breadstick formulation. For each breadstick $(C B, S B$ or $C H B)$, the same capital letter in superscript within rows indicates homogeneous groups established by ANOVA $(p<0.05)$ comparing top and bottom.

$L^{*}, a^{*}$ and $b^{*}$ variation of storage time and the total colour differences observed for stored breadstick samples are showed in Table 6. There are no significant $(p>0.05)$ differences of $L^{*}, a *$ and $b^{*}$ colour coordinates over storage. These trends were also observed by Gouveia et al. (2007) in cookies enrichment with Chlorella. Samples total colour difference due to 
storage on the top position were below the perceptible sensory limit ( $\Delta E>3$ ) according to Bodart et al. (2008). Nevertheless, on the bottom position, the control's total colour differences, due to storage, were significantly $(p<0.05)$ higher than the rest of the samples. These differences were higher than 3 units, so were perceptible by the human eye (Bodart et al., 2008). In short, breadstick enrichment with Chlorella or Spirulina was more stable in colour terms.

Table 6. Mean values (and standard deviation) of $L^{*}, a^{*}$ and $b^{*}$ variation for storage and total colour differences for storage of breadstick samples.

\begin{tabular}{cccc|ccc}
\hline \multirow{2}{*}{ Sample } & \multicolumn{3}{c|}{ TOP } & \multicolumn{3}{c}{ BOTTOM } \\
\cline { 2 - 7 } & $\mathbf{C B}$ & $\mathbf{S B}$ & $\mathbf{C H B}$ & $\mathbf{C B}$ & $\mathbf{S B}$ & $\mathbf{C H B}$ \\
\hline $\boldsymbol{\Delta} \mathbf{L}_{\mathbf{1 5 - 0}}$ & $-0.4(2.6)^{\mathrm{aA}}$ & $0.8(1.8)^{\mathrm{aA}}$ & $0.9(1.9)^{\mathrm{aA}}$ & $-1.4(2.9)^{\mathrm{aA}}$ & $0.1(1.8)^{\mathrm{aA}}$ & $-0.01(1.13)^{\mathrm{aA}}$ \\
$\boldsymbol{\Delta}_{\mathbf{1 5}-\mathbf{0}}$ & $0.1(0.8)^{\mathrm{aA}}$ & $0.1(0.3)^{\mathrm{aA}}$ & $-0.1(0.2)^{\mathrm{aA}}$ & $0.1(1.9)^{\mathrm{aA}}$ & $-0.1(0.4)^{\mathrm{aA}}$ & $-0.1(0.3)^{\mathrm{aA}}$ \\
$\boldsymbol{\Delta}_{\mathbf{1 5}-\mathbf{0}}$ & $0.313(0.998)^{\mathrm{aA}}$ & $1.2(1.5)^{\mathrm{aA}}$ & $0.9(1.6)^{\mathrm{aA}}$ & $-0.3(2.8)^{\mathrm{aA}}$ & $0.4(1.4)^{\mathrm{aA}}$ & $-0.2(1.2)^{\mathrm{aA}}$ \\
$\boldsymbol{\Delta E}_{15-0}$ & $2.3(1.7)^{\mathrm{aB}}$ & $2.4(1.2)^{\mathrm{aA}}$ & $2.2(1.7)^{\mathrm{aA}}$ & $4.2(1.9)^{\mathrm{aA}}$ & $1.8(1.5)^{\mathrm{bA}}$ & $1.4(0.7)^{\mathrm{bA}}$ \\
\hline
\end{tabular}

For each measurement position (top or bottom), the same small letter in superscript within rows indicates homogeneous groups established by ANOVA $(p<0.05)$ comparing breadstick formulation. For each breadstick (CB, SB or $\mathrm{CHB})$, the same capital letter in superscript within rows indicates homogeneous groups established by ANOVA $(p<0.05)$ comparing top and bottom.

Figure 4 shows the mineral content of the studied breadsticks. All samples presented similar macronutrient composition (Figure $4 \mathrm{a}$ ), however potassium content (K) in breadsticks with Chlorella was significantly $(p<0.05)$ higher than the rest of the samples. Potassium, along with sodium and calcium, are present as salts in body fluids, where these have the physiological function of maintaining osmotic pressure (Latham, 2002). Also, the addition of microalgae results in a significant increase $(p<0.05)$ in iron $(\mathrm{Fe})$ and selenium $(\mathrm{Se})$, as can be observed in Figure $4 b$, however, without significant differences $(p>0.05)$ between Spirulina and Chlorella. Other authors (Ak et al., 2016) also observed a significant increase of iron content in bread when they added Spirulina in its formulations. This fact is an important benefit to the enrichment of breadsticks with microalgae since one of the most important minerals in human nutrition is iron according to Latham (2002). Iron is an essential element for almost all living organisms as it participates in a wide variety of metabolic processes, including oxygen transport, deoxyribonucleic acid synthesis, and electron transport (Abbaspour et al., 2014). 

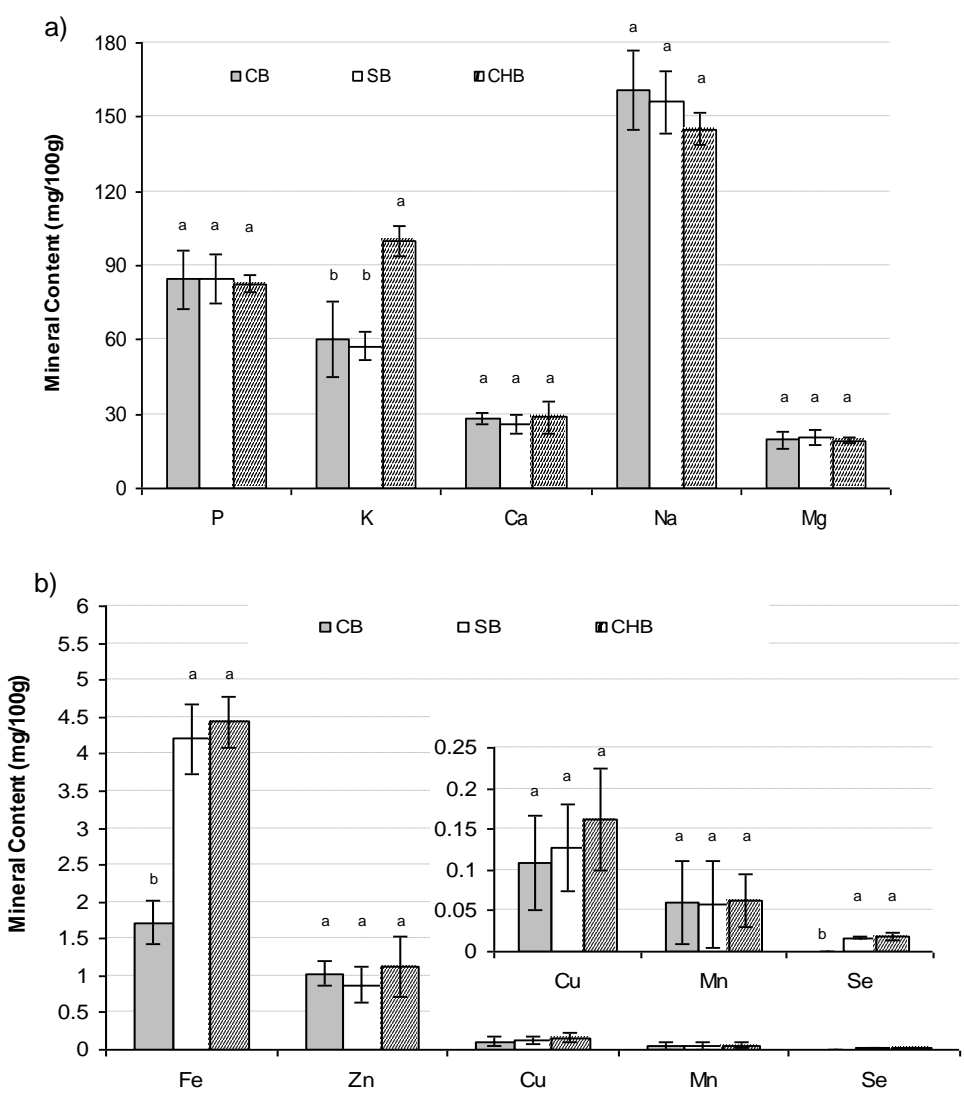

Figure 4. Mean values and standard deviation of macrominerals (a) and microminerals (b) content of each formulation (CB, SB and CHB). Letters indicate homogeneous groups established by the ANOVA ( $p$ $<0.05)$ for each mineral.

World Health Organization (WHO) estimates that two billion people are anaemic worldwide and attribute approximately $50 \%$ of all anaemia to iron deficiency (World Health Organization, 2001). On the other hand, the essential trace mineral, selenium, is of fundamental importance to human health. As a constituent of selenoproteins, selenium has structural and enzymic roles, best-known as an antioxidant and catalyst to produce active thyroid hormone. Selenium is needed for a properly functioning immune system and appears to be a key nutrient in counteracting the development of virulence and inhibiting HIV progression to AIDS. It is required for sperm motility and may reduce the risk of 
miscarriage. Deficiency has been linked to adverse mood states. Furthermore, selenium is presented both as an antioxidant and anti-inflammatory agent (Rayman, 2000).

The iron dietary needs are approximately ten times the physiological requirements of the body, if a healthy man or post-menopausal woman requires $1 \mathrm{mg}$ of iron per day, due to iron losses, the dietary needs are around $10 \mathrm{mg}$ per day (Latham, 2002). The Council directive on the 24 September 1990, on nutrition labelling for foodstuffs (Council of the European Union, 1990), in the annex, specify that the recommended daily allowance of iron is $14 \mathrm{mg}$. According to this directive and the regulation No. 1924/2006 of the European Parliament and of the Council of 20 December 2006 on nutrition and health claims made in foods (European Parliament and Council of the European Union, 2006), breadstick enrichment with Chlorella or Spirulina are a food "high in iron". With respect to selenium, the intake of this micromineral required to achieve plateau concentrations of plasma is 55 $\mu \mathrm{g}$ per day for both men and women (Rayman, 2000). In the same way as iron, breadsticks enriched with Chlorella or Spirulina can be considered as a "high in selenium" food. Subsequently, the content of other studied microminerals was not affected by the microalgae incorporation and do not need classification.

\section{Conclusions}

Breadsticks are a carbohydrate-based snack, which are consumed widely in Mediterranean countries. Breadstick enrichment with Chlorella and Spirulina are foods classed "high in iron and selenium". In addition, this study found microalgae dough presents an attractive and innovative appearance with tonalities close to green. However, the effects of baking provoke changes in colour toward brown tonalities, but the incorporation of Chlorella or Spirulina in the formulation allows for the production of breadsticks, more stable in colour and texture. 


\section{References}

Abbaspour, N., Hurrell, R., \& Kelishadi, R. (2014). Review on iron and its importance for human health. Journal of Research in Medical Sciences: The Official Journal of Isfahan University of Medical Sciences, 19(2), 164-174.

Ak, B., Avşaroğlu, E., Işık, O., Özyurt, G., Kafkas, E., Etyemez, M., \& Uslu, L. (2016). Nutritional and Physicochemical Characteristics of Bread Enriched with Microalgae Spirulina platensis. Int. Journal of Engineering Research and Application, 6(12), 30-38.

AOAC. (2005). Official Methods of Analysis of AOAC International. Association of Official Analysis Chemists International.

Batista, A. P., Gouveia, L., Bandarra, N. M., Franco, J. M., \& Raymundo, A. (2013). Comparison of microalgal biomass profiles as novel functional ingredient for food products. Algal Research, 2(2), 164-173. doi: 10.1016/j.algal.2013.01.004

Batista, A. P., Niccolai, A., Fradinho, P., Fragoso, S., Bursic, I., Rodolfi, L., Biondi, N., Tredici, M. R., Sousa, I., \& Raymundo, A. (2017). Microalgae biomass as an alternative ingredient in cookies: Sensory, physical and chemical properties, antioxidant activity and in vitro digestibility. Algal Research, 26(March), 161-171. doi: 10.1016/j.algal.2017.07.017

Batista, A. P., Nunes, M. C., Fradinho, P., Gouveia, L., Sousa, I., Raymundo, A., \& Franco, J. M. (2012). Novel foods with microalgal ingredients - Effect of gel setting conditions on the linear viscoelasticity of Spirulina and Haematococcus gels. Journal of Food Engineering, $110(2), 182-189$. doi: 10.1016/j.jfoodeng.2011.05.044

Bodart, M., de Peñaranda, R., Deneyer, A., \& Flamant, G. (2008). Photometry and colorimetry characterisation of materials in daylighting evaluation tools. Building and Environment. doi: 10.1016/j.buildenv.2007.12.006

Borowitzka, M. A. (2013). High-value products from microalgae-their development and commercialisation. Journal of Applied Phycology, 25(3), 743-756. doi: 10.1007/s10811013-9983-9

Buono, S., Langellotti, A. L., Martello, A., Rinna, F., \& Fogliano, V. (2014). Functional ingredients from microalgae. Food and Function, 5(8), 1669-1685. doi: 10.1039/c4fo00125g

Cervejeira Bolanho, B., Buranelo Egea, M., Morocho Jácome, A. L., Campos, I., Monteiro de Carvalho, J. C., \& Godoy Danesi, E. D. (2014). Antioxidant and nutritional potential of cookies enriched with Spirulina platensis and sources of fibre. Journal of Food and Nutrition Research, 53(2), 171-179. doi: 10.1093/humrep/deq166

Chacón-Lee, T. L., \& González-Mariño, G. E. (2010). Microalgae for "Healthy" Foods-Possibilities and Challenges. Comprehensive Reviews in Food Science and Food Safety, 9(6), 655-675. doi: $10.1111 / j .1541-4337.2010 .00132 . x$

Council of the European Union. (1990). COUNCIL DIRECTIVE of 24 September 1990 on nutrition labelling for foodstuffs. In Official Journal of the European Communities (Vol. 276, Issue 
(90/496/EEC)).

Cox, S., \& Abu-Ghannam, N. (2013). Incorporation of Himanthalia elongata seaweed to enhance the phytochemical content of breadsticks using response surface methodology (RSM). International Food Research Journal, 20(4), 1537-1545. doi: 10.21427/D7DS5R

de Morais, M. G., da Silva Vaz, B., Etiele Greque, de M., \& Vieira Costa, J. A. (2015). Review Article Biologically Active Metabolites Synthesized by Microalgae. BioMed Research International, 2015, 1-15. doi: 10.1155/2015/835761

Devi, A., \& Khatkar, B. S. (2016). Physicochemical, rheological and functional properties of fats and oils in relation to cookie quality: a review. Journal of Food Science and Technology, 53(10), 3633-3641. doi: 10.1007/s13197-016-2355-0

European Parliament and Council of the European Union. (2006). Regulation (EC) No 1924/2006 of the European Parliament and of the Council of 20 December 2006 on nutrition and health claims made on foods. In Official Journal of the European Union (Issue 404).

Fernández-Ruiz, V., Olives, A. I., Cámara, M., Sánchez-Mata, M. D. C., \& Torija, M. E. (2011). Mineral and trace elements content in 30 accessions of tomato fruits (Solanum lycopersicum L.,) and wild relatives (Solanum pimpinellifolium L., Solanum cheesmaniae L. Riley, and Solanum habrochaites S. Knapp \& D.M. Spooner). Biological Trace Element Research, 141(1-3), 329-339. doi: 10.1007/s12011-010-8738-6

García-Segovia, P., Pagán-Moreno, M. J., Lara, I. F., \& Martínez-Monzó, J. (2017). Effect of microalgae incorporation on physicochemical and textural properties in wheat bread formulation. Food Science and Technology International, 23(5), 437-447. doi: $10.1177 / 1082013217700259$

Gouveia, L., Batista, A. P., Miranda, A., Empis, J., \& Raymundo, A. (2007). Chlorella vulgaris biomass used as colouring source in traditional butter cookies. Innovative Food Science and Emerging Technologies, 8(3), 433-436. doi: 10.1016/j.ifset.2007.03.026

Graça, C., Fradinho, P., Sousa, I., \& Raymundo, A. (2018). Impact of Chlorella vulgaris on the rheology of wheat flour dough and bread texture. LWT - Food Science and Technology, 89(November 2017), 466-474. doi: 10.1016/j.Iwt.2017.11.024

Ibañez, E., \& Cifuentes, A. (2013). Benefits of using algae as natural sources of functional ingredients. Journal of the Science of Food and Agriculture, 93(4), 703-709. doi: 10.1002/jsfa.6023

Inglett, G. E., Chen, D., \& Liu, S. X. (2015). Physical properties of gluten-free sugar cookies made from amaranth-oat composites. LWT - Food Science and Technology, 63(1), 214-220. doi: 10.1016/j.lwt.2015.03.056

Kadam, S. U., \& Prabhasankar, P. (2010). Marine foods as functional ingredients in bakery and pasta products. Food Research International, 43(8), 1975-1980. doi: 10.1016/j.foodres.2010.06.007

Latham, M. C. (2002). Minerales. In Nutrición humana en el mundo en desarrollo. Ithaca, Nueva York: FAO. 
Mancebo, C. M., Rodriguez, P., \& Gómez, M. (2016). Assessing rice flour-starch-protein mixtures to produce gluten free sugar-snap cookies. LWT - Food Science and Technology, 67, 127132. doi: $10.1016 /$ j.Iwt.2015.11.045

Potter, R., Stojceska, V., \& Plunkett, A. (2013). The use of fruit powders in extruded snacks suitable for Children's diets. LWT - Food Science and Technology, 51(2), 537-544. doi: 10.1016/j.Iwt.2012.11.015

Priyadarshani, I., \& Rath, B. (2012). Commercial and industrial applications of micro algae - A review. Journal of Algal Biomass Utilization, 3(4), 89-100.

Rayman, M. P. (2000). The importance of selenium to human health. The Lancet, 356(9225), 233-241. doi: 10.1016/S0140-6736(00)02490-9

Roohinejad, S., Koubaa, M., Saljoughian, S., Amid, M., \& Greiner, R. (2017). Application of seaweeds to develop new food products with enhanced shelf-life, quality and health-related beneficial properties. Food Research International, 99, 1066-1083. doi: 10.1016/J.FOODRES.2016.08.016

Shahbazizadeh, S., Khosravi-Darani, K., \& Sohrabvandi, S. (2015). Fortification of Iranian Traditional Cookies with Spirulina platensis. Annual Research \& Review in Biology, 73), 144-154. doi: 10.9734/ARRB/2015/13492

Soni, R. A., Sudhakar, K., \& Rana, R. S. (2017). Spirulina - From growth to nutritional product: A review. Trends in Food Science and Technology, 69, 157-171. doi: 10.1016/j.tifs.2017.09.010

Volk, R. B. (2008). A newly developed assay for the quantitative determination of antimicrobial (anticyanobacterial) activity of both hydrophilic and lipophilic test compounds without any restriction. Microbiological Research, 163(2), 161-167. doi: 10.1016/j.micres.2006.03.015

World Health Organization. (2001). Iron deficiency anaemia: assessment, prevention and control. Geneva, Switzerland: WHO/UNICEF/UNU. 


\section{$0^{\circ}$}
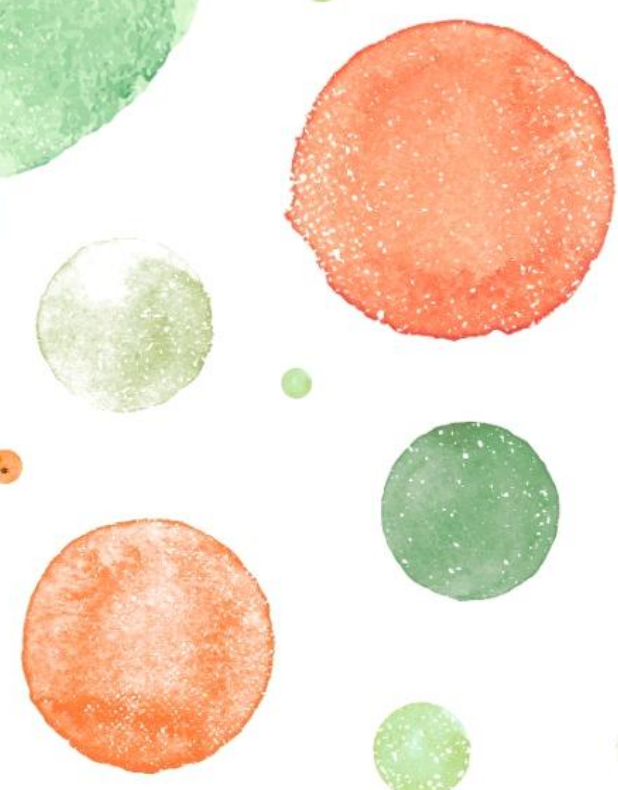

\section{Chapter 3}

\section{In vitro bioaccessibility of minerals from microalgae-enriched cookies}

This chapter has been published as:

Uribe-Wandurraga, Z. N., Igual, M., García-Segovia, P., \& MartínezMonzó, J. (2020). In vitro bioaccessibility of minerals from microalgae-enriched cookies. Food \& Function, 11, 2186-2194. doi: 



\section{Abstract}

Microalgae have several biologically active constituents such as pigments, fatty acids, vitamins, and minerals, among others. Nowadays, there are numerous commercial applications for microalgae in food and animal feed. Minerals have many functions in the human body, from structural to metabolic function; as mineral absorption by the human body is important, its study is also key because of anti-nutritional factors responsible for lowering the bioaccessibility of these minerals. The aim of this work was to evaluate the mineral bioaccessibility in cookies, enriched with Arthrospira platensis (Spirulina) and Chlorella vulgaris, using in vitro static systems that simulate digestive processes. Using microalgae as an ingredient to enrich cookies with minerals was a good alternative because cookies presented a higher content in minerals compared to control samples. When the microalgae concentration in formulation increased (within studied range), higher $\mathrm{P}, \mathrm{Se}, \mathrm{Na}$, and $\mathrm{Mg}$ amounts were observed in cookies. Cookies enrichment with 1.5 or $2 \%$ Chlorella or Spirulina are foods classed as "high in selenium". Incorporating A. platensis and C. vulgaris in cookie formulations, therefore, allowed greater accessibility of $\mathrm{P}, \mathrm{K}, \mathrm{Ca}, \mathrm{Mg}, \mathrm{Fe}, \mathrm{Zn}$, and Se for absorption in the body, compared with control cookies. 


\section{Introduction}

Minerals have many functions in the human body. Sodium $(\mathrm{Na})$ and potassium $(\mathrm{K})$ are present as salts in body fluids, having the physiological function of maintaining osmotic pressure. Minerals are part of the tissues' structure; for example, calcium and phosphorus (P) in the bones are key functional components of the skeleton. In addition, they are important in metabolic functions, such as muscle function, nerve stimulation, enzymatic and hormonal activities, and oxygen transport. Magnesium ( $\mathrm{Mg}$ ) is an essential mineral which is found in bones and human tissues (Latham, 2002). Iron (Fe), an essential element for almost all living organisms, participates in a wide variety of metabolic processes. In the human body, Fe mainly exists in complex forms bound to protein (haemoprotein) such as haem compounds (haemoglobin and myoglobin), haem enzymes, and non-haem compounds (flavin-iron enzymes, transferrin, and ferritin) (McDowel, 2003). The body requires Fe for the synthesis of its oxygen transport proteins, in particular haemoglobin and myoglobin, and for the formation of haem enzymes along with other iron-containing enzymes, involved in electron transfer and oxidation reductions (Hurrell, 1997; McDowel, 2003). Zinc ( $\mathrm{Zn}$ ) is essential for a normal growth and development of the human body, because it plays an important role in gene expression, regulation of cellular growth, and differentiation (Hambidge, 2000), beside to development of the immune response. Zinc has a recognised action on over 300 enzymes implied in the metabolism of nucleic acids, carbohydrates, and proteins; participating as a cofactor (Salgueiro et al., 2002). Selenium (Se) is another element, which is an essential trace mineral of fundamental importance to human health. As a constituent of selenoproteins, Se has structural and enzymatic roles, best known as an antioxidant and catalyst, producing active thyroid hormones. Selenium is needed for a functioning immune system and appears to be a key nutrient in counteracting the development of virulence and inhibiting HIV progression to AIDS; it is also required for sperm motility and may reduce the risk of miscarriage.

Deficiency in Se has been linked to adverse mood states, while selenium is presented, both, as an antioxidant and anti-inflammatory agent (Rayman, 2000). Among mineral insufficiencies, deficiencies in $\mathrm{Fe}$ and $\mathrm{Zn}$ are reported as highly prevalent nutritional problems around the world, affecting mostly developing countries ranking 9 and 11 , respectively, in the list of the major risk factors for global burden of disease. Iron deficiency has been related to health and productivity of adults and to impairment of cognitive 
development in infants and young children. Zinc deficiency may lead to retarded skeletal development and immunodeficiency disorders (Darnton-Hill et al., 2005; Lachat et al., 2006). Interventions targeting mineral deficiencies include dietary variation and/or supplementation. However, the enrichment of food with a naturally high mineral content matrix, such as microalgae, can be useful in avoiding the use of supplementation.

Microalgae have biologically active constituents such as pigments, fatty acids, vitamins, and minerals, among others (Volk, 2008). Nowadays, there are numerous commercial applications for microalgae in food and animal feed. For example, in food, microalgae can enhance the nutritional value of pasta (Fradique et al., 2010), cookies (Batista et al., 2017), and breadsticks (Uribe-Wandurraga et al., 2019). In addition, mineral absorption by the human body is a key item for study, because there are anti-nutritional factors responsible for lowering the bioaccessibility of these minerals (Hotz et al., 2007). The observed effects of the temperature-time combinations of heat treatment will influence the levels of the antinutritional factors and bioaccessibility of minerals. During heat treatment, minerals are not destroyed owing to their heat stability. Depending on the heat treatment, the endogenous (and bacterial) enzymes will be, in most cases, inactivated. This implies that endogenous enzymes such as phytase, cellulase, and pectinase will not contribute further to the improvement of the mineral bioaccessibility. However, heat treatments will reduce the content of the antinutritional factors such as phytic acid, tannins, and phenolic compounds, up to $40 \%$, as reported for legumes or pulses (Rehman et al., 2005; Hemalatha et al., 2007).

Bioavailability is a term used to describe the proportion of a nutrient in foods that can be used for normal bodily functions. Many quantification techniques have been proposed for bioavailability; the most reliable methods for bioavailability studies are in vivo measurement of absorption in humans, with or without using a labelling technique (Promchan et al., 2005). Still, human in vivo studies are time-consuming, high-priced, complex, and produce variable results. In vitro methods are being extensively used at present since these are quick, safe, and do not have the ethical restrictions of in vivo methods. In vitro methods either simulate the digestion and absorption processes (for bioavailability) or only the digestion process (for bioaccessibility), while the concentration of a nutrient, in some type of final extract, is the response measured (Parada et al., 2007). The in vitro method proposed by the COST INFOGEST network is a general standardised and practical static digestion 
method based on relevant conditions that can be applied for various purposes (Minekus et al., 2014).

The objective of this consortium was to harmonise in vitro static systems that simulate digestive processes by defining key parameters and conditions. Due to the important of mineral in the human body, the increasing use of microalgae as nutritive ingredient in food, and the lack of knowledge on digestibility of minerals from microalgae-enriched food, the aim of this work was to evaluate the mineral bioaccessibility in cookies enriched with Spirulina and Chlorella, comparing with control cookies.

\section{Material and methods}

\section{Raw materials}

Commercial wheat pastry flour, salt, granulated sugar, and butter were purchased from a local supermarket (Alcampo, Valencia, Spain). Freeze-dried Arthrospira platensis (Spirulina) and Chlorella vulgaris were supplied by AlgaEnergy (S.A., Madrid, Spain).

\section{Dough formulation and cookies preparation}

Three kinds of cookie doughs were formulated; with Spirulina, Chlorella, and a control sample without microalgae. Water (25\%), butter (18\%), granulated sugar (13\%), and salt $(0.2 \%)$ were the basic ingredients. Spirulina dough and Chlorella dough contain binomial microalgae-wheat:pastry-flour combinations at different levels of concentrations: 0.5\%:43.3\%; 1.0\%:42.8\%; 1.5\%:42.3\%, and 2.0\%:41.8\%.

Butter and sugar were manually mixed until a fluffy texture was achieved. Salt, microalgae, and wheat pastry flour were gradually added into the formulation and mixed with a dough hook in a food processor (Kenwood chef classic, KM400/99 plus, Kenwood Corporation, Tokyo, Japan), kneading for $5 \mathrm{~min}$ at a low speed and ambient temperature. After mixing, cookies were shaped into cylinders, were frozen at $-18{ }^{\circ} \mathrm{C}$ for $90 \mathrm{~min}$ in a fast freezing blast chiller (SINCOLD, A.T.O. SRL, Treviso, Italy), then were baked at $140{ }^{\circ} \mathrm{C}$ for $55 \mathrm{~min}$ on a stainless steel plate covered with baking paper, in a steamer oven (Convotherm OES 6.06 mini CC, Convotherm Elektrogeräte GMBH, Eglfing, Germany). Baked cookies were named: Control Cookie (CC), Spirulina Cookie (SC), and Chlorella Cookie (CHC). 


\section{In vitro digestion}

Sample in vitro digestibility was assessed by the standardised static in vitro digestion method suitable for food (COST INFOGEST network) proposed by Minekus et al. (2014). The in vitro digestion protocol is summarised in Figure 1, where four steps have been followed: oral phase, mixing the sample and simulate salivary fluid (SSF) (1:1) with amylase at $\mathrm{pH} 7$ for 2 min; gastric phase, mixing the oral bolus and simulate gastric fluid (SGF) (1:1) with pepsin at $\mathrm{pH} 3$ for $2 \mathrm{~h}$; intestinal phase, mixing the gastric chyme and simulate intestinal fluid (SIF) (1:1) with enzymes at $\mathrm{pH} 7$ for $2 \mathrm{~h}$; and filtration, centrifuging at 4500 rpm for $30 \mathrm{~min}$ and then filtering through a $1 \mu \mathrm{m}$ glass-fibre membrane.

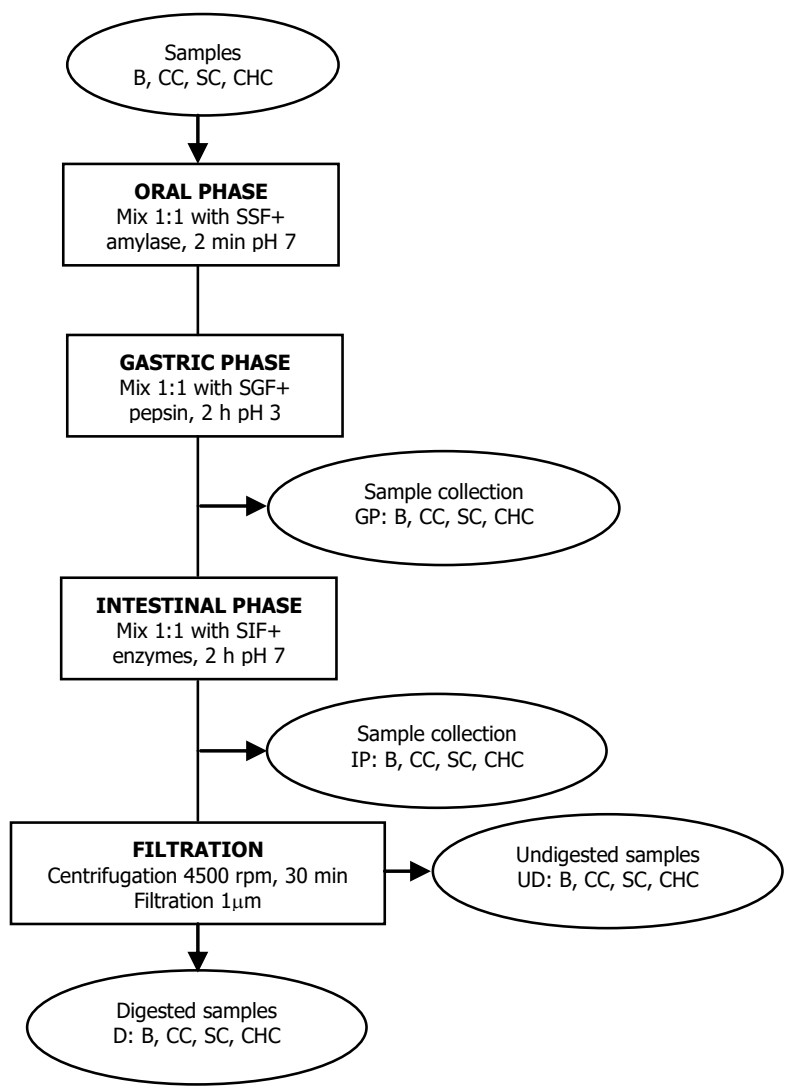

Figure 1. Flow diagram of simulated in vitro digestion method. SSF, SGF, and SIF are Simulated Salivary Fluid, Simulated Gastric Fluid, and Simulated Intestinal Fluid, respectively. B, CC, SC, and CHC are Blank, Control Cookie, Spirulina Cookie, and Chlorella Cookie, respectively. 
The in vitro digestibility (IVD) (\%) was calculated as the difference between the initial mass and the undigested mass (after correcting for the blank assay, B) divided by the initial mass and multiplied by 100 according to Batista et al. (2017). Analyses were repeated in triplicate.

Cookie samples at high level (2\%) of microalgae (SC, $\mathrm{CHC}$ ) and $\mathrm{CC}$ were subjected to in vitro digestion, gastric (GP), intestinal (IP), and in vitro digestion (D) samples were collected according Minekus et al. (2014), and samples were freeze-dried with use of a protease inhibitor when it was necessary.

\section{Analysis}

\section{Water content}

Water content $\left(\mathrm{x}_{\mathrm{w}}\right)$ ( $\mathrm{g}$ water/100 g sample) was determined by vacuum oven drying at 105 ${ }^{\circ} \mathrm{C}$ until constant weight (AOAC, 2005). Cookies were analysed in triplicate.

\section{Ash and mineral content}

Total ash content was determined following method 930.05 of AOAC procedures (AOAC, 2005). A sample of $500 \mathrm{mg}$ was incinerated at high pressure in a microwave oven (Muffle $P$ Selecta Mod.367PE) for $24 \mathrm{~h}$ at $550{ }^{\circ} \mathrm{C}$, and ash was gravimetrically quantified. The residue of incineration was extracted with $\mathrm{HCl}$ (hydrochloric acid) $\left(50 \% \mathrm{v} / \mathrm{v}\right.$ ) and $\mathrm{HNO}_{3}$ (nitric acid) ( $50 \% \mathrm{v} / \mathrm{v}$ ) and made up to an appropriate volume with distilled water (Fernández-Ruiz et al., 2004). Minerals were measured using standard solutions for calibration purposes. The multimineral determination was performed by using an inductively coupled plasma optical emission spectrometer (700 Series ICP-OES; Agilent Technologies, Santa Clara, United States), with an axial viewing and a charge-coupled device detector. The instrumental parameters used for the multi-element determination were with a radiofrequency generator of $40 \mathrm{MHz}$, a power of $1 \mathrm{~kW}$, plasma gas flow rate of $15 \mathrm{~L} \mathrm{~min}^{-1}$, auxiliary gas flow rate of $1.5 \mathrm{~L} \mathrm{~min}^{-1}$, and nebuliser gas (One Neb 2) pressure of $200 \mathrm{kPa}$. The elements and the analytical spectral lines ( $\mathrm{nm}$ ) used were, P (214.914), K (766.491), Ca (317.933), Na (589.592), Mg (285.213), Fe (238.204), Zn (213.857), Cu (327.395), Mn (259.372), and Se (196.026). Mineral composition (macro- and micro-elements) were expressed as mg/100 g. Samples were analysed in triplicate for cookies and for gastric phase, intestinal phase, and final digested samples (Figure 1). 


\section{Statistical analysis}

Analysis of variance (ANOVA) simple or multifactor, with a confidence level of $95 \%$ ( $p<$ 0.05), using Statgraphics (Centurion XVII Software, version 17.2.04) was applied to evaluate the differences among cookies samples, the effect of microalgae concentration, and the type of microalgae. Furthermore, a correlation analysis among microalgae concentration, formulation, and $\mathrm{P}, \mathrm{K}, \mathrm{Ca}, \mathrm{Na}, \mathrm{Mg}, \mathrm{Fe}, \mathrm{Zn}, \mathrm{Cu}, \mathrm{Mn}$, and Se content in the cookies, with a $95 \%$ significance level, was carried out (Statgraphics Centurion XVII).

\section{Results and Discussion}

Water and ash content (mean values and standard deviations) for studied cookies are shown in Table 1. Lower values of water content were observed in samples with Spirulina compared to the rest and higher Spirulina concentrations resulted in lower water content in cookies. However, ash content in Spirulina cookies was significantly $(p<0.05)$ higher than Chlorella and control cookies. Ash content of S1.5C and S2C were high compared to all samples. In general, microalgae mineral ash content is high and can vary between $4 \%$ and 20\% (McDowel, 2003; Fox et al., 2018). Moreover, microalgae biomass has been used as source of proteins and minerals for food and feed purposes (McDowel, 2003; Koller et al., 2014).

Table 1. Mean values (and standard deviations) of water $\left(x_{w}, g / 100 g_{\text {cookie }}\right)$ and ash content $(g / 100$ $g_{\text {cookie) }}$ of cookies.

\begin{tabular}{ccc}
\hline Samples & $\mathbf{x}_{\mathbf{w}}$ & Ash content \\
\hline CC & $5.85(0.07)^{\mathrm{c}}$ & $0.3960(0.0014)^{\mathrm{c}}$ \\
S0.5C & $3.57(0.04)^{\mathrm{g}}$ & $0.586(0.002)^{\mathrm{b}}$ \\
S1C & $5.46(0.15)^{\mathrm{d}}$ & $0.589(0.002)^{\mathrm{b}}$ \\
S1.5C & $4.80(0.10)^{\mathrm{e}}$ & $0.792(0.008)^{\mathrm{a}}$ \\
S2C & $4.23(0.14)^{\mathrm{f}}$ & $0.791(0.003)^{\mathrm{a}}$ \\
CH0.5C & $6.32(0.09)^{\mathrm{a}}$ & $0.396(0.002)^{\mathrm{c}}$ \\
CH1C & $6.02(0.03)^{\mathrm{b}}$ & $0.3868(0.0012)^{\mathrm{c}}$ \\
CH1.5C & $6.01(0.04)^{\mathrm{b}}$ & $0.392(0.005)^{\mathrm{c}}$ \\
CH2C & $5.53(0.03)^{\mathrm{d}}$ & $0.391(0.004)^{\mathrm{c}}$ \\
\hline
\end{tabular}

CC: Control Cookie; S0.5C: Spirulina 0.5\% Cookie; S1C: Spirulina 1\% Cookie; S1.5C: Spirulina 1.5\% Cookie; S2C: Spirulina 2\% Cookie; CH0.5C: Chlorella 0.5\% Cookie; CH1C: Chlorella 1\% Cookie; CH1.5C: Chlorella 1.5\% Cookie; CH2C: Chlorella 2\% Cookie. The same letter in superscript within column indicates homogeneous groups established by ANOVA $(p<0.05)$. 


\section{Mineral content of cookies}

The mineral content of some food products can be increased, specifically, iron and selenium, by the incorporation of Chlorella or Spirulina (Uribe-Wandurraga et al., 2019). Spirulina contains minerals such as iron, magnesium, calcium, and phosphorus (Soni et al., 2017).
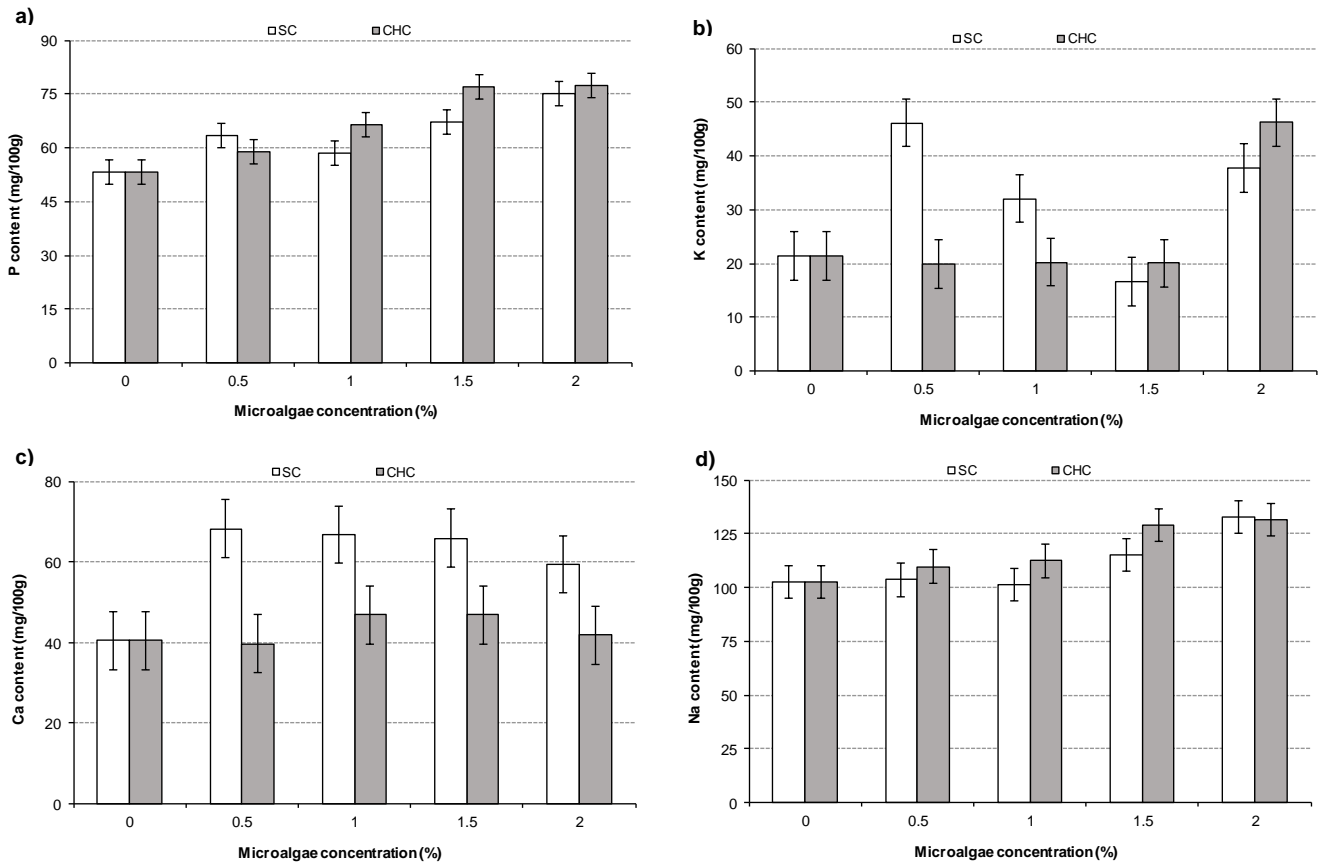

Figure 2. Mean values and Least Significant Difference (LSD) intervals of $P(a), K(b), \mathrm{Ca}(\mathrm{c})$, and $\mathrm{Na}$ (d) content of each formulation ( $\mathrm{SC}$ and $\mathrm{CHC}$ ).

Figure 2 shows $\mathrm{P}(\mathrm{a}), \mathrm{K}(\mathrm{b}), \mathrm{Ca}(\mathrm{c})$, and $\mathrm{Na}$ (d) content of each formulation (SC and CHC) regarding $0-2 \%$ of microalgae. In Figure $2 a$ greater microalgae concentrations in formulation cookies resulted with more $\mathrm{P}$ content in samples. There were significant $(p<$ 0.05) differences between samples with Chlorella and Spirulina in the 1 and $1.5 \%$ concentrations. Nevertheless, increasing microalgae concentration to $2 \%$ in cookies saw no significant $(p>0.05)$ differences between them. The greatest differences were seen in $\mathrm{K}$ content, regarding the control, were observed in cookies with $1.5 \%$ or $2 \%$ of microalgae. Potassium values (Figure $2 \mathrm{~b}$ ) in $\mathrm{CHC}$ were like the control, except for the $2 \%$ concentration cookies; greater than the others. However, SC showed different $\mathrm{K}$ content at different 
Spirulina concentrations, without a definite trend. Calcium content (Figure 2c) did not show significant $(p>0.05)$ differences with added Chlorella, independent of the concentration assay. Similar Ca content of cookies control was obtained by Rao et al. (2018) for wheat flour cookies. However, Spirulina formulation incorporation significantly increased $(p<0.05)$ Ca content. Here it was only the type of microalgae added that presented a significant change $(p<0.05)$ in Ca content of samples when an ANOVA multifactor was applied to the results; microalgae concentration was not significant within the studied range (0.5-2\%). The use of Spirulina in cookies formulation increase Ca content because Spirulina presents in its nutritional value high content in calcium (Soni et al., 2017). The increase of Spirulina from 0.5 to $1.5 \%$ and Chlorella from 0.5 to $1 \%$ did not show significant $(p>0.05)$ differences regarding the control cookie when measuring the Na content (Figure 2d). Nevertheless, the use of $2 \%$ of microalgae in cookies increased the Na content by $25 \%$.

Figure 3 shows Mg (a), Fe (b), Zn (c), and Se (d) content for each formulation (SC and $\mathrm{CHC}$ ) regarding $0-2 \%$ of microalgae addition. $\mathrm{Mg}$ and Fe content of control cookies was similar to wheat flour biscuits developed by Ahmed et al. (2019).

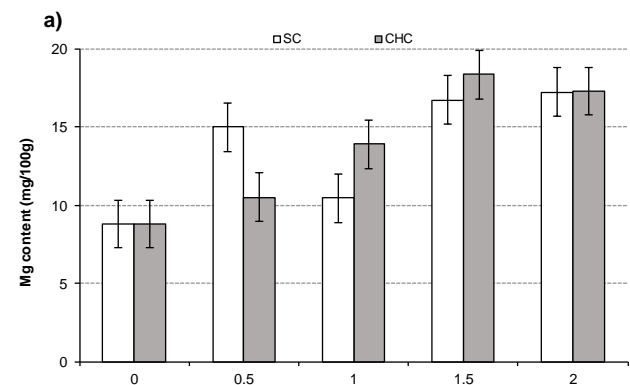

Microalgae concentration(\%)

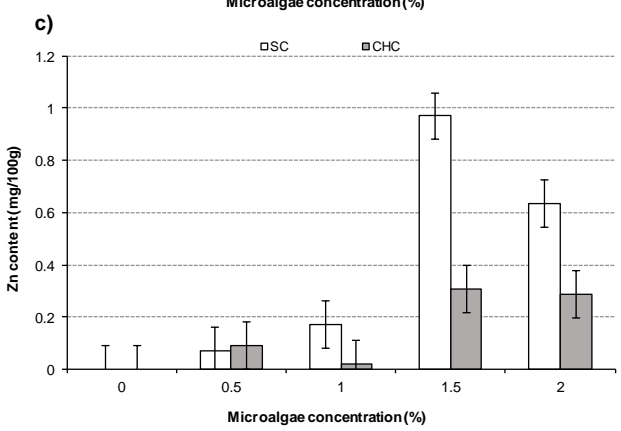

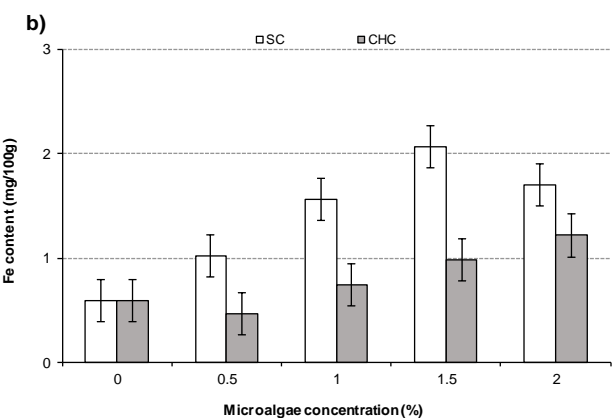

d)

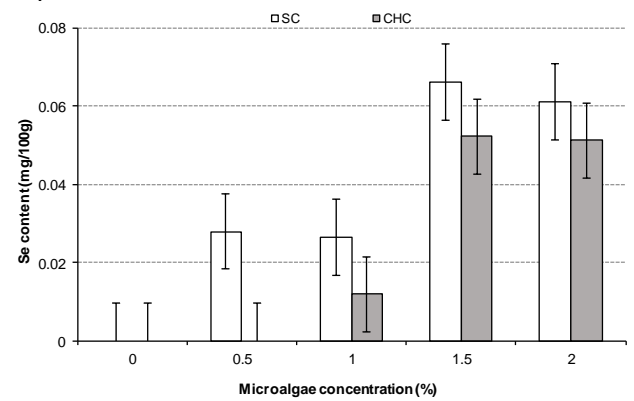

Figure 3. Mean values and Least Significant Difference (LSD) intervals of Mg (a), Fe (b), Zn (c), and Se (d) content of each formulation (SC and $\mathrm{CHC}$ ). 
Microalgae incorporation in the cookie formulation provoked an increase in Mg (Figure 3a), which was statistically significant $(p<0.05)$ at $1 \%$ of Chlorella and, 0.5 and $1.5 \%$ of Spirulina addition. After addition of $1.5 \%$ microalgae there was no further effect on mineral content. Furthermore, the addition of microalgae resulted in a significant increase $(p<$ 0.05 ) in Fe and Se, observed in Figures 3b and 3d, respectively, after 0.5\% Spirulina and $1.5 \%$ Chlorella addition. There were significant differences $(p<0.05)$ between of Spirulina and Chlorella addition when Fe was evaluated but there were no significant differences $(p>$ 0.05 ) in Se content. Moreover, addition of $2 \%$ microalgae did not increase the content of these microminerals in cookies compared with the $1.5 \%$ addition. Likewise, authors have presented that breadsticks enriched with Chlorella and Spirulina showed that Fe and Se content was significantly higher than the control (Uribe-Wandurraga et al., 2019). Figure 3c shows Zn content of each cookie; the control shows no Zn content, however the addition of microalgae provoked an increase of this mineral. With SC showing higher $\mathrm{Zn}$ content than $\mathrm{CHC}$ at 1.5 and $2 \%$ concentrations. Copper and manganese were not detected in any sample.

In general, comparing the mineral content of cookies with microalgae with other works of cookies enriched with other ingredients as baobab pulp (Mounjouenpou et al., 2018), whey protein (Ahmed et al., 2019) or different meals (Rao et al., 2018), the content of iron and calcium was higher. We found that the use of microalgae as an ingredient to enrich cookies with functional minerals was a good alternative because in this study cookies presented with a higher content of minerals. Cookies with Spirulina would be the better choice, as these samples showed the highest mineral levels. Spirulina is a good source of iron with contains 20 times more iron than wheat gram (Soni et al., 2017). The average mineral content of Spirulina was reported by Cuellar-Bermudez et al. (2015). The content of calcium was estimated in $1000 \mathrm{mg} / 100 \mathrm{~g}$; phosphorus $800 \mathrm{mg} / 100 \mathrm{~g}$; magnesium $400 \mathrm{mg} / 100 \mathrm{~g}$; iron 58 $\mathrm{mg} / 100 \mathrm{~g}$; zinc $3 \mathrm{mg} / 100 \mathrm{~g}$; copper $1.2 \mathrm{mg} / 100 \mathrm{~g}$; manganese $0.5 \mathrm{mg} / 100 \mathrm{~g}$; and potassium $1.4 \mathrm{mg} / 100 \mathrm{~g}$ (Cuellar-Bermudez et al., 2015). These quantities justify the high levels of minerals detected in cookies enriched with Spirulina at low quantities (0.5-2\%).

Pearson's statistical correlation analysis established correlations among microalgae concentration in formulations and $\mathrm{P}, \mathrm{K}, \mathrm{Ca}, \mathrm{Na}, \mathrm{Mg}, \mathrm{Fe}, \mathrm{Zn}, \mathrm{Cu}, \mathrm{Mn}$, and Se content in cookies. The results showed that the most significant relation to microalgae concentration was presented by $\mathrm{P}(0.8374, p<0.05)$, followed by Se $(0.8127, p<0.05), \mathrm{Na}(0.7427, p<$ 
0.05), and $\mathrm{Mg}(0.7262, p<0.05)$. When microalgae concentrations increased within the studied range, higher $\mathrm{K}, \mathrm{Se}, \mathrm{Na}$, and $\mathrm{Mg}$ content were observed in cookies.

According to the regulation no. 1924/2006 of the European Parliament and of the Council of 20 December 2006 on nutrition and health claims made in foods (European Parliament and Council of the European Union, 2006), cookies enriched with 1.5 or $2 \%$ of Chlorella or Spirulina are a food "high in selenium", considering that the intake of Se requires concentrations in plasma of $55 \mu \mathrm{g}$ per day for both men and women (Rayman, 2000). Although addition of microalgae increased P, K, Ca, Fe, Mg, and Zn content in cookies, none of them reached the levels of claims.

\section{In vitro digestibility (IVD) and mineral bioaccessibility}

The IVD analysis reproduces the chemical-enzymatic catalysis that occurs in the proximal tract of the monogastric digestive system (Boisen et al., 1997). The IVD differences between the initial mass and the undigested mass results were similar among the three samples. Mean values and standard deviations, in parentheses, were $72 \%$ (3), $73 \%$ (2), and $74 \%$ (4) for CC, CHC, and SC, respectively. No significant difference for IVD between the microalgae cookies and control was observed. Other authors who used a different static in vitro digestion method for cookies observed this trend (Batista et al., 2017).

This study used the term bioaccessibility referring to the fraction of mineral that was released from the examined cookies during in vitro digestion becoming accessible for absorption. Bioaccessibility should be distinguished from the term bioavailability, which is the fraction of nutrients or food components that have been efficiently in vivo digested, assimilated and then absorbed in the body (Fernández-García et al., 2009). Consequently, it could be concluded that bioaccessibility of the studied minerals is a prerequisite for their bioavailability. Total concentrations of $\mathrm{P}, \mathrm{K}, \mathrm{Ca}, \mathrm{Na}, \mathrm{Mg}, \mathrm{Fe}, \mathrm{Zn}$, and Se were quantified in gastric (GP), intestinal (IP), and final digestion (D).

Bioaccessibility was calculated using equation (1) proposed by Khouzam et al. (2011) and Sahuquillo et al. (2003),

$$
\text { Bioaccessibility }=\left(\frac{A}{B}\right) \times 100
$$


where $A$ is the concentration of the element in the bioaccessible fraction following gastric, intestinal, and completed simulated (final) digestion; $B$ is the concentration of the element in the sample before digestion. The minerals present in tap water and the reagents were also analysed and corrected in the final bioaccessible fraction.

Figures 4 and 5 show mean values and standard deviations of mineral bioaccessibility percentages, relative to the total quantity present in cookies of each formulation.
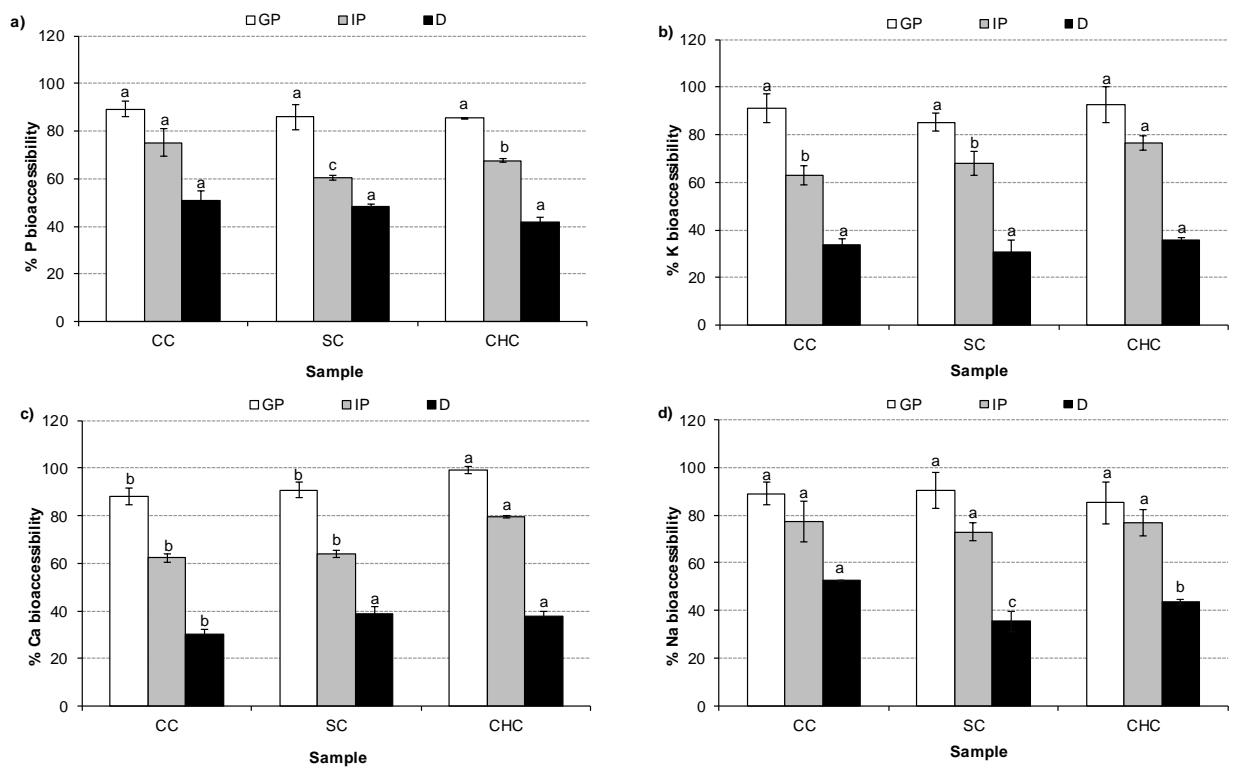

Figure 4. Mean values and standard deviation of $P(a), K(b), C a(c)$, and $\mathrm{Na}$ (d) bioaccessibility percentage relative to total quantity present in samples of each formulation (CC, SC and $\mathrm{CHC}$ ). Letters $\mathrm{a}, \mathrm{b}, \mathrm{c}$ on bars indicate homogeneous groups established by the ANOVA $(p<0.05)$ for each in vitro digestion phase (GP, IP, D). GP: Gastric Phase; IP: Intestinal Phase; D: Digested. CC: Control Cookie; SC: Spirulina Cookie; CHC: Chlorella Cookie.

Mineral biaccessibility in GP ranged from 80 to $100 \%$, IP from 60 to $90 \%$, and D from 16 to $70 \%$, depending on the mineral quantified. Mineral bioavailability in foods can be affected by the presence of the anti-nutritional factors such as phytates, tannins and polyphenols. Anti-nutritional factors are shown to cause complexing, inhibition and binding of minerals, thereby increasing the mineral balance and decreasing their bioaccessibility. Few works were found describing anti-nutritional factors of microalgae. Christ-Ribeiro et al. (2019) reported the phenolic compound profile of Spirulina citing as main phenolic compound gallic and caffeic acids. $\mathrm{K}$ bioaccessibility was similar to values obtained by Vignola et al. (2018) 
for pasta. However, our work presented higher $\mathrm{Mg}$, Fe and $\mathrm{Zn}$ bioaccesibility in comparison with digested pasta.

Magnesium bioaccessibility was higher than the other studied minerals, notably in IP. Vitali et al. (2008) observed this trend in whole grain tea biscuits, showing values of $\mathrm{Mg}$ bioaccessibility $\approx 75 \%$. In contrast, Se bioaccessibility was the lowest among studied minerals at $D$, as food composition affects the ability of enzymes to breakdown solubilised Se. The selenium not solubilised after $D$ might be present in form of undigestible Secontaining polysaccharides, as was observed by Bhatia et al. (2013). These authors indicated that the formation of Se-containing polysaccharides explain the low Se bioaccessibility found in mushrooms. Furthermore, Fe and Zn showed an antagonistic effect on Se absorption (House et al., 1989; Díaz-Castro et al., 2011). The antagonistic effect for $\mathrm{Zn}$ occurred between natural forms of $\mathrm{Zn}$ and Se at concentrations potentially encountered in wheat grain (García-Barrera et al., 2015). K bioaccessibility in was similar to phosphorus, potassium, and magnesium bioaccessibility (Figures $4 a, 4 b$, and $5 a$, respectively) were similar for the three cookies, in each digestion phase. However, $\mathrm{Ca}$ and $\mathrm{Na}$ bioaccessibility (Figures $4 c$ and $4 d$, respectively) presented slight differences among samples. In GP and IP, Ca bioaccessibility of $\mathrm{CHC}$ was higher than the other cookies, but at $\mathrm{D}, \mathrm{Ca}$ bioaccessibility percentages of $\mathrm{SC}$ and $\mathrm{CHC}$ did not show significant differences $(p>0.05)$.

At $\mathrm{D}, \mathrm{Na}$ bioaccessibility percentages of SC and CHC were significantly $(p<0.05)$ lower than the $\mathrm{Na}$ bioaccessibility percentage of $\mathrm{CC}$. Lower bioaccessibility of $\mathrm{Na}$ could be because of the competition of other monovalent competing ions such as K (Kulkarni et al., 2007), since $\mathrm{K}$ content of SC and CHC were double than in CC (Figure 2b). Iron is one of the most studied elements for its bioavailability using in vivo and in vitro methods (House, 1999; Hunt, 2003; Kumari et al., 2004) In this study, SC and CHC showed a significantly ( $p<$ 0.05 ) higher Fe bioaccessibility percentage (Figure $5 b$ ) than CC at the end of gastrointestinal digestion D. Iron bioaccessibility, like Zn (Figure $5 \mathrm{c}$ ) were similar for SC and $\mathrm{CHC}$ and were without significant differences $(p>0.05)$. Calcium can also inhibit iron absorption when fed as inorganic calcium compounds (Akusu et al., 2020).

The iron and zinc bioaccessibility can be affected by the head treatment, which led to a reduction in the bioaccessibility of these minerals (Burgos et al., 2018). Other authors mentioned that $\mathrm{Zn}$ bioaccessibility decreased due the presence of absorption inhibitors, 
especially the phytates. Also, an inhibitory effect of other fiber components on solubility can contribute to bioaccessibility reduction (Burgos et al., 2018). Thus, phytic acid with its phosphate groups, can chelate divalent ions (such as $\mathrm{Ca}, \mathrm{Mg}$ and particularly, Fe and $\mathrm{Zn}$ ) due its strong affinity towards these elements (Ramírez-Ojeda et al., 2018). Figure $5 d$ shows Se bioaccessibility percentage in studied cookies at D of SC was lower than CHC, probably because of the higher Fe content of SC (Figure 3b), and its antagonistic effect on Se absorption (House, 1999; Díaz-Castro et al., 2011).
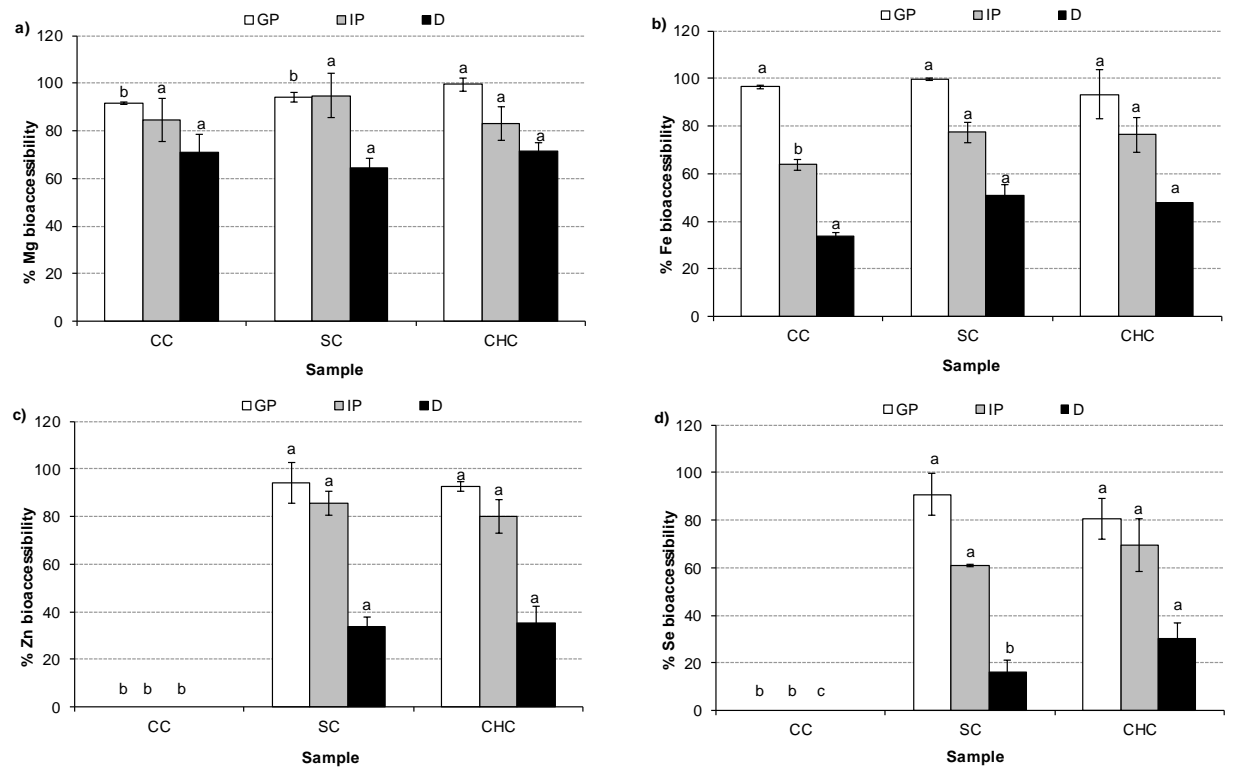

Figure 5. Mean values and standard deviation of percentage $\mathrm{Mg}$ (a), Fe (b), Zn (c), and Se (d) bioaccessibility relative to total quantity present in samples of each formulation ( $\mathrm{CC}, \mathrm{SC}$, and $\mathrm{CHC}$ ). Letters $\mathrm{a}, \mathrm{b}, \mathrm{c}$ on bars indicate homogeneous groups established by the ANOVA $(p<0.05)$ for each in vitro digestion phase (GP, IP, D). GP: Gastric Phase; IP: Intestinal Phase; D: Digested. CC: Control Cookie; SC: Spirulina Cookie; CHC: Chlorella Cookie.

Table 2 shows mean values (and standard deviations) of mineral content (mg/100 $\mathrm{g}_{\text {digested }}$ cookies) in samples after gastrointestinal digestion. Minerals, $\mathrm{P}, \mathrm{K}, \mathrm{Ca}, \mathrm{Mg}, \mathrm{Fe}, \mathrm{Zn}$, and $\mathrm{Se}$ have content in digested SC and CHC that were significantly higher $(p<0.05)$ than CC. Incorporation of Spirulina in cookie formulations allows higher accessibility of calcium, iron, and zinc content for absorption in the body compared to cookies with Chlorella. However, incorporation of Chlorella in cookie formulations allows for higher accessibility of potassium and selenium content for absorption in the body compared to Spirulina cookies. 
Furthermore, Na content in digested SC was significantly lower $(p<0.05)$ than in CC and $\mathrm{CHC}$. This can be a positive aspect to prevent hypertension and reduce blood pressure since the relation of Na serum concentration with blood pressure (Moreda-Piñeiro et al., 2015).

Table 2. Mean values (and standard deviations) of mineral content ( $\mathrm{mg} / 100 \mathrm{~g}_{\text {digested cookies }}$ ) in samples after gastrointestinal digestion.

\begin{tabular}{c|ccc}
\hline \multirow{2}{*}{ Mineral } & \multicolumn{3}{|c}{ Cookies } \\
\cline { 2 - 4 } & CC & SC & CHC \\
\hline \hline P & $27(2)^{\mathrm{b}}$ & $38(3)^{\mathrm{a}}$ & $33.25(1.02)^{\mathrm{a}}$ \\
$\mathrm{K}$ & $7.2(2)^{\mathrm{c}}$ & $11(2)^{\mathrm{b}}$ & $16.1(0.8)^{\mathrm{a}}$ \\
$\mathrm{Ca}$ & $13(2)^{\mathrm{b}}$ & $23(2)^{\mathrm{a}}$ & $15.60(1.13)^{\mathrm{b}}$ \\
$\mathrm{Na}$ & $53.85(0.24)^{\mathrm{a}}$ & $47(6)^{\mathrm{b}}$ & $57.2(1.3)^{\mathrm{a}}$ \\
$\mathrm{Mg}$ & $6.3(0.6)^{\mathrm{b}}$ & $11.1(0.7)^{\mathrm{a}}$ & $12.3(0.6)^{\mathrm{a}}$ \\
$\mathrm{Fe}$ & $0.199(0.009)^{\mathrm{c}}$ & $0.90(0.07)^{\mathrm{a}}$ & $0.5826(0.0008)^{\mathrm{b}}$ \\
$\mathrm{Zn}$ & $-^{\mathrm{c}}$ & $0.22(0.02)^{\mathrm{a}}$ & $0.101(0.020)^{\mathrm{b}}$ \\
$\mathrm{Se}$ & $-^{\mathrm{c}}$ & $0.010(0.003)^{\mathrm{b}}$ & $0.015(0.003)^{\mathrm{a}}$ \\
\hline
\end{tabular}

CC: Control Cookie; SC: Spirulina Cookie; CHC: Chlorella Cookie. The same letter in superscript within rows indicates homogeneous groups established by ANOVA $(p<0.05)$.

\section{Conclusions}

Using microalgae as an ingredient to enrich cookies with functional mineral content was a good alternative, because they presented a greater content of minerals compared to control cookies. Cookies enriched with 1.5 or $2 \%$ of Chlorella or Spirulina are foods classed as "high in selenium". Spirulina and Chlorella incorporation in cookie formulations allowed for greater accessibility of $\mathrm{P}, \mathrm{K}, \mathrm{Ca}, \mathrm{Mg}, \mathrm{Fe}, \mathrm{Zn}$, and Se content for absorption in the body than control cookies. 


\section{References}

Ahmed, H. A. M., Ashraf, S. A., Awadelkareem, A. M., Alam, M. J., \& Mustafa, A. I. (2019). Physico-chemical, textural and sensory characteristics of wheat flour biscuits supplemented with different levels of whey protein concentrate. Current Research in Nutrition and Food Science, 73 ), 761-771. doi: 10.12944/CRNFSJ.7.3.15

Akusu, O. M., Kiin-Kabari, D. B., \& Isah, E. M. (2020). Anti-nutrients , Bioaccessibility and Mineral Balance of Cookies Produced from Processed Sesame Seed Flour Blends. International Journal of Food Science and Nutrition Engineering, 10(1), 1-11. doi: 10.5923/j.food.20201001.01

AOAC. (2005). Official Methods of Analysis of AOAC International. Association of Official Analysis Chemists International.

Batista, A. P., Niccolai, A., Fradinho, P., Fragoso, S., Bursic, I., Rodolfi, L., Biondi, N., Tredici, M. R., Sousa, I., \& Raymundo, A. (2017). Microalgae biomass as an alternative ingredient in cookies: Sensory, physical and chemical properties, antioxidant activity and in vitro digestibility. Algal Research, 26(March), 161-171. doi: 10.1016/j.algal.2017.07.017

Bhatia, P., Aureli, F., D’Amato, M., Prakash, R., Cameotra, S. S., Nagaraja, T. P., \& Cubadda, F. (2013). Selenium bioaccessibility and speciation in biofortified Pleurotus mushrooms grown on selenium-rich agricultural residues. Food Chemistry, 140(1-2), 225-230. doi: 10.1016/j.foodchem.2013.02.054

Boisen, S., \& Fernández, J. A. (1997). Prediction of the total tract digestibility of energy in feedstuffs and pig diets by in vitro analyses. Animal Feed Science and Technology, 68(34), 277-286. doi: 10.1016/S0377-8401(97)00058-8

Burgos, V. E., Binaghi, M. J., de Ferrer, P. A. R., \& Armada, M. (2018). Effect of precooking on antinutritional factors and mineral bioaccessibility in kiwicha grains. Journal of Cereal Science, 80, 9-15. doi: 10.1016/j.jcs.2017.12.014

Christ-Ribeiro, A., Graça, C. S., Kupski, L., Badiale-Furlong, E., \& de Souza-Soares, L. A. (2019). Cytotoxicity, antifungal and anti mycotoxins effects of phenolic compounds from fermented rice bran and Spirulina sp. Process Biochemistry, 80(February), 190-196. doi: 10.1016/j.procbio.2019.02.007

Cuellar-Bermudez, S. P., Garcia-Perez, J. S., Rittmann, B. E., \& Parra-Saldivar, R. (2015). Photosynthetic bioenergy utilizing $\mathrm{CO}_{2}$ : An approach on flue gases utilization for third generation biofuels. In Journal of Cleaner Production (Vol. 98, Issue 2015). Elsevier Ltd. doi: $10.1016 /$ j.jclepro.2014.03.034

Darnton-Hill, I., Webb, P., Harvey, P. W. J., Hunt, J. M., Dalmiya, N., Chopra, M., Ball, M. J., Bloem, M. W., \& De Benoist, B. (2005). Micronutrient deficiencies and gender: Social and 
economic costs. American Journal of Clinical Nutrition, 81(5), 1198-1205. doi: 10.1093/ajen/81.5.1198

Díaz-Castro, J., Ojeda, M. L., Alférez, M. J. M., López-Aliaga, I., Nestares, T., \& Campos, M. S. (2011). Se bioavailability and glutathione peroxidase activity in iron deficient rats. Journal of Trace Elements in Medicine and Biology, 25(1), 42-46. doi: 10.1016/j.jtemb.2010.12.005

European Parliament and Council of the European Union. (2006). Regulation (EC) No 1924/2006 of the Europea Parliament and of the Council of 20 December 2006 on nutrition and health claims made on foods. In Official Journal of the European Union (Issue 404).

Fernández-García, E., Carvajal-Lérida, I., \& Pérez-Gálvez, A. (2009). In vitro bioaccessibility assessment as a prediction tool of nutritional efficiency. Nutrition Research, 29(11), 751760. doi: $10.1016 /$ j.nutres.2009.09.016

Fernández-Ruiz, V., Sánchez-Mata, M. C., Cámara, M., Torija, M. E., Chaya, C., Galiana-Balaguer, L., Roselló, S., \& Nuez, F. (2004). Internal quality characterization of fresh tomato fruits. HortScience, 39(2), 339-345. doi: 10.21273/hortsci.39.2.339

Fox, J. M., \& Zimba, P. V. (2018). Minerals and Trace Elements in Microalgae. Microalgae in Health and Disease Prevention, 177-193. doi: 10.1016/b978-0-12-811405-6.00008-6

Fradique, M., Batista, A. P., Nunes, M. C., Gouveia, L., Bandarra, N. M., \& Raymundo, A. (2010). Incorporation of Chlorella vulgaris and Spirulina maxima biomass in pasta products. Part 1: Preparation and evaluation. Journal of the Science of Food and Agriculture, 90(10), 16561664. doi: 10.1002/jsfa.3999

García-Barrera, T., Gómez-Ariza, J. L., Gómez Jacinto, V., Garbayo Nores, I., Vílchez Lobato, C., \& Gojkovica, Z. (2015). Functional Foods Enriched in Selenium. In Selenium: Chemistry, Analysis, Function and Effects (pp. 273-290). The Royal Society of Chemistry. doi: $10.1039 / 9781782622215-00273$

Hambidge, M. (2000). Zinc and Health: Current status and future directions. J. Nutr., 130, 1344S$1349 S$.

Hemalatha, S., Platel, K., \& Srinivasan, K. (2007). Influence of heat processing on the bioaccessibility of zinc and iron from cereals and pulses consumed in India. Journal of Trace Elements in Medicine and Biology, 21(1), 1-7. doi: 10.1016/j.jtemb.2006.10.002

Hotz, C., \& Gibson, R. S. (2007). Traditional Food-Processing and Preparation Practices to Enhance the Bioavailability of Micronutrients in Plant-Based Diets. The Journal of Nutrition, 1374), 1097-1100. doi: 10.1093/jn/137.4.1097

House, W. A. (1999). Trace element bioavailability as exemplified by iron and zinc. Field Crops Research, 60(1-2), 115-141. doi: 10.1016/S0378-4290(98)00136-1

House, W. A., \& Welch, R. M. (1989). Bioavailability of and Interactions between Zinc and 
Selenium in Rats Fed Wheat Grain Intrinsically Labeled with 65Zn and 75Se. The Journal of Nutrition, 11966), 916-921. doi: 10.1093/jn/119.6.916

Hunt, J. R. (2003). Bioavailability of iron, zinc, and other trace minerals from vegetarian diets. The American Journal of Clinical Nutrition, 78(3), 633S-639S. doi: 10.1093/ajcn/78.3.633S Hurrell, R. (1997). Bioavailability of iron. European Journal of Clinical Nutrition, 51(1), S4-S8.

Khouzam, R. B., Pohl, P., \& Lobinski, R. (2011). Bioaccessibility of essential elements from white cheese, bread, fruit and vegetables. Talanta, 86(1), 425-428. doi: 10.1016/j.talanta.2011.08.049

Koller, M., Muhr, A., \& Braunegg, G. (2014). Microalgae as versatile cellular factories for valued products. Algal Research, 6(PA), 52-63. doi: 10.1016/j.algal.2014.09.002

Kulkarni, S. D., Acharya, R., Rajurkar, N. S., \& Reddy, A. V. R. (2007). Evaluation of bioaccessibility of some essential elements from wheatgrass (Triticum aestivum L.) by in vitro digestion method. Food Chemistry, 103(2), 681-688. doi: 10.1016/j.foodchem.2006.07.057

Kumari, M., Gupta, S., Lakshmi, A, J., \& Prakash, J. (2004). Iron bioavailability in green leafy vegetables cooked in different utensils. Food Chemistry, 86(2), 217-222. Retrieved from https://eurekamag.com/research/004/213/004213902.php

Lachat, C. K., Van Camp, J. H., Mamiro, P. S., Wayua, F. O., Opsomer, A. S., Roberfroid, D. A., \& Kolsteren, P. W. (2006). Processing of complementary food does not increase hair zinc levels and growth of infants in Kilosa district, rural Tanzania. The British Journal of Nutrition, 95(1), 174-180. doi: 10.1079/bjn20051610

Latham, M. C. (2002). Minerales. In Nutrición humana en el mundo en desarrollo. Ithaca, Nueva York: FAO.

McDowel, L. R. (Ed.). (2003). Minerals in Animal and Human Nutrition (2nd ed.). Amsterdam: Elsevier.

Minekus, M., Alminger, M., Alvito, P., Ballance, S., Bohn, T., Bourlieu, C., Carrière, F., Boutrou, R., Corredig, M., Dupont, D., Dufour, C., Egger, L., Golding, M., Karakaya, S., Kirkhus, B., Le Feunteun, S., Lesmes, U., Macierzanka, A., Mackie, A., \& Brodkorb, A. (2014). A standardised static in vitro digestion method suitable for food - an international consensus. Food Funct., 5(6), 1113-1124. doi: 10.1039/C3FO60702]

Moreda-Piñeiro, J., \& Moreda-Piñeiro, A. (2015). Bioavailability of Selenium and Selenium Compounds in Foodstuff by In Vivo Testing. In Selenium: Chemistry, Analysis, Function and Effects (pp. 173-196). The Royal Society of Chemistry. doi: 10.1039/978178262221500173

Mounjouenpou, P., Ngono Eyenga, S. N. N., Kamsu, E. J., Bongseh Kari, P., Ehabe, E. E., \& Ndjouenkeu, R. (2018). Effect of fortification with baobab (Adansonia digitata L.) pulp flour 
on sensorial acceptability and nutrient composition of rice cookies. Scientific African, 1 (November), e00002. doi: 10.1016/j.sciaf.2018.e00002

Parada, J., \& Aguilera, J. M. (2007). Food microstructure affects the bioavailability of several nutrients. Journal of Food Science, 72(2). doi: 10.1111/j.1750-3841.2007.00274.x

Promchan, J., \& Shiowatana, J. (2005). A dynamic continuous-flow dialysis system with on-line electrothermal atomic-absorption spectrometric and $\mathrm{pH}$ measurements for in-vitro determination of iron bioavailability by simulated gastrointestinal digestion. Analytical and Bioanalytical Chemistry, 382(6), 1360-1367. doi: 10.1007/s00216-005-3288-z

Ramírez-Ojeda, A., Moreno-Rojas, R., \& Cámara-Martos, F. (2018). Mineral and trace element content in legumes (lentils, chickpeas and beans): Bioaccesibility and probabilistic assessment of the dietary intake. Subtropical Plant Science, v. 73, 17-28-2018 v.73. doi: 10.1016/j.jfca.2018.07.007

Rao, B. D., Kulkarni, D. B., \& Kavitha, C. (2018). Study on evaluation of starch, dietary fiber and mineral composition of cookies developed from 12 sorghum cultivars. Food Chemistry, 238, 82-86. doi: 10.1016/j.foodchem.2016.12.069

Rayman, M. P. (2000). The importance of selenium to human health. The Lancet, 356(9225), 233-241. doi: 10.1016/S0140-6736(00)02490-9

Rehman, Z. U., \& Shah, W. H. (2005). Thermal heat processing effects on antinutrients, protein and starch digestibility of food legumes. Food Chemistry, 91(2), 327-331. doi: 10.1016/j.foodchem.2004.06.019

Sahuquillo, A., Barberá, R., \& Farré, R. (2003). Bioaccessibility of calcium, iron and zinc from three legume samples. Nahrung/Food, 476), 438-441. doi: 10.1002/food.200390097

Salgueiro, M. J., Zubillaga, M. B., Lysionek, A. E., Caro, R. A., Weill, R., \& Boccio, J. R. (2002). The role of zinc in the growth and development of children. Nutrition, 18(6), 510-519. doi: 10.1016/S0899-9007(01)00812-7

Soni, R. A., Sudhakar, K., \& Rana, R. S. (2017). Spirulina - From growth to nutritional product: A review. Trends in Food Science and Technology, 69, 157-171. doi: 10.1016/j.tifs.2017.09.010

Uribe-Wandurraga, Z. N., Igual, M., García-Segovia, P., \& Martínez-Monzó, J. (2019). Effect of microalgae addition on mineral content, colour and mechanical properties of breadsticks. Food \& Function, 10(8), 4685-4692. doi: 10.1039/c9fo00286c

Vignola, M. B., Bustos, M. C., \& Pérez, G. T. (2018). In vitro dialyzability of essential minerals from white and whole grain pasta. Food Chemistry, 265(November 2017), 128-134. doi: 10.1016/j.foodchem.2018.05.012

Vitali, D., Vedrina Dragojević, I., \& Šebečić, B. (2008). Bioaccessibility of Ca, Mg, Mn and Cu from whole grain tea-biscuits: Impact of proteins, phytic acid and polyphenols. Food Chemistry, 


\section{Chapter 3}

110(1), 62-68. doi: 10.1016/j.foodchem.2008.01.056

Volk, R. B. (2008). A newly developed assay for the quantitative determination of antimicrobial (anticyanobacterial) activity of both hydrophilic and lipophilic test compounds without any restriction. Microbiological Research, 163(2), 161-167. doi: 10.1016/j.micres.2006.03.015 


\title{
Chapter 4
}

\begin{abstract}
Microalgae fortification of low-fat oil-inwater food emulsions: an evaluation of the physicochemical and rheological properties
\end{abstract}

This chapter has been published as:

Uribe-Wandurraga, Z. N., Martínez-Sánchez, I., Savall, C., GarcíaSegovia, P., \& Martínez-Monzó, J. (2020). Microalgae fortification of low-fat oil-in-water food emulsions: an evaluation of the physicochemical and rheological properties. J Food Sci Technol. doi: $10.1007 /$ s13197-020-04828-1 



\section{Abstract}

Reducing the fat content in emulsions can give additional nutritional health benefits. Hence, developing low-fat oil-in-water emulsions, fortified with healthy microalgae providing advantageous properties, is an interesting topic. In this study, the addition of Arthrospira platensis (Spirulina), Chlorella vulgaris (Chlorella), and Dunaliella salina (Dunaliella) microalgae biomass on the physicochemical properties of low-fat oil-in-water emulsion formulations were evaluated. The rheological properties of food emulsions were measured in terms of the viscoelastic, flow behaviour, and textural properties, with all properties studied during 60 days. $\mathrm{pH}$ values of all the emulsions ranged between 3.0 and 3.7 and agreed to the Codex Alimentarius Commission. Moreover, their rheological behaviour may be classified as weak gel-like, a distinguishing characteristic of low-fat emulsion products. Substantial differences in rheological properties were observed between the fortified microalgae emulsions over the storage time (60 days). However, incorporating Spirulina or Dunaliella gave emulsions with stable texture, viscoelastic, and rheological properties. The prepared emulsions displayed good colour stability for Chlorella and Dunaliella. Overall, the fortified microalgae low-fat emulsions are expected to provide a blueprint for the design of low-fat mayonnaise-like food emulsions. 


\section{Introduction}

Food emulsions are systems of two-phase immiscible liquids with restricted stability. An emulsion of oil droplets in water, also called oil-in-water (O/W) emulsion is characterised by a dispersed phase of oil with oil-based ingredients, a combination of emulsifiers, and a continuous phase of water with water-based ingredients (Yang et al., 2003; Morley, 2016). Traditional oil-in-water emulsions, like mayonnaise, containing $70-80 \mathrm{~g}$ per $100 \mathrm{~g}$ of fat is one of the most broadly used examples worldwide. In most western countries, dietary fat ingestion is higher than medical recommendation and it is associated with the prevalence of cardiovascular diseases, obesity and cancer (Mozaffarian, 2017). Studies have been focusing on creating more nutritional and healthier food products, promoting low-fat products formulation to help to prevent and avoid diseases (Chang et al., 2017). Ingredients providing calorie reduction, improving texture or flavour, or functional characteristics are potential targets for emulsions and low-fat food emulsion products (Izidoro et al., 2008; $\mathrm{Ma}$ et al., 2014). Furthermore, there is a considerable demand for health-enhancing, physiologically active supplemented and fortified food products with proven benefits (Hasler et al., 2009).

Microalgae has a great biodiversity, both science and industry have focused the most on Arthrospira platensis (Spirulina), Chlorella vulgaris (Chlorella), and Dunaliella salina (Dunaliella). These types of cyanobacteria and microalgae are cell organisms that can easily grow in either fresh water or sea water. They also provide various other nutrients including proteins (Chlorella, 55 wt\%; Spirulina, 65 wt\%; and Dunaliella; 57 wt\%), fatty acids (very high concentrations of long chain polyunsaturated fatty acids (PUFAs)), pigments (phycobiliproteins from Spirulina; canthaxanthin, astaxanthin, and lutein from Chlorella; and carotenoids from Dunaliella), minerals (iron, calcium, chromium, copper, magnesium, manganese, phosphorus, potassium, sodium, and zinc), vitamins (vitamin A ( $\beta$-carotene), $C$,

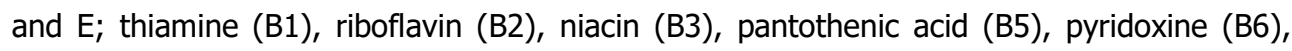
folic acid (B9), and cobalamin (B12)), and antioxidants (Tang et al., 2011; Buono et al., 2014; Uribe-Wandurraga et al., 2019; Sui et al., 2020). These nutritional compounds make the microalgae a valuable and innovative ingredient, improving their quality attributes like colour (Gouveia et al., 2006), emulsifying ability (Raymundo et al., 2005) and rheological characterisation (Batista et al., 2006b) causing significant and interesting physicochemical changes in food products. Besides, to enhance the nutritional value of food products (Uribe- 
Wandurraga et al., 2019). However, to the best of our knowledge, no study has shown the incorporation of microalgae in low-fat oil-in-water food emulsions, despite the high interest of microalgae as a basic food ingredient with great importance in human nutrition (Priyadarshani et al., 2012).

In this study, we focused on the addition of the three microalgae biomasses, Arthrospira platensis, Chlorella vulgaris, and Dunaliella salina, in low-fat oil-in-water food emulsions. The objective was to investigate the effect of microalgae on water activity, $\mathrm{pH}$, colour, texture, and rheological properties of the samples. The formulation was varied with the type of microalgae while retaining the same concentration. The results would provide theoretical guidance to produce low-fat oil-in-water food emulsions with microalgae fortification to enhance their properties, especially their innovative colour and appearance, producing a novel product for the current food market.

\section{Material and methods}

\section{Materials}

Freeze-dried Arthrospira platensis (Spirulina) and Chlorella vulgaris (Chlorella) were supplied from AlgaEnergy S.A. (Madrid, Spain) and Dunaliella salina (Dunaliella), from Algalimento S.L. (Gran Canaria, Spain). Sunflower oil, sugar, vinegar, starch, egg yolk, salt, and potassium sorbate were supplied by Jumel Alimentaria S.A. (Spain).

\section{Emulsions preparation}

The oil-in-water emulsions were prepared according to the procedure by Jumel Alimentaria S.A. (Spain). Three different types of emulsions were formulated replacing $1 \%$ of the quantity of water added to the formulation by freeze-dried microalgae biomass (Table 1).

A control emulsion, without microalgae incorporation, was also prepared. The water phase was first prepared by mixing all the ingredients, apart from the oil and vinegar, with a blender (Braun $\mathrm{GmbH}$, Frankfurt, Germany) at speed one for 2 min. The water phase was transferred to a kitchen appliance (Thermomix, TM31, Vorwerk Corporate Group, Wuppertal, Germany) and the sunflower oil was added dropwise during the blending at speed two. Last, the vinegar was added and blended for another 2 minutes at speed three. The emulsion samples were kept in a $500 \mathrm{ml}$ beaker and stored at $4{ }^{\circ} \mathrm{C}$ for further studies. The samples 
produced were: CM: Control low-fat emulsion, SM: Spirulina low-fat emulsion, CHM: Chlorella low-fat emulsion and, DM: Dunaliella low-fat emulsion.

Table 1. Low-fat oil-in-water emulsion formulations (\%, w/w).

\begin{tabular}{lcccc}
\hline \multicolumn{1}{c}{$\begin{array}{c}\text { Ingredients } \\
(\%)\end{array}$} & CM & SM & CHM & DM \\
\hline Water & 53.5 & 52.5 & 52.5 & 52.5 \\
Sunflower oil & 30 & 30 & 30 & 30 \\
Granulated sugar & 5 & 5 & 5 & 5 \\
Vinegar & 4 & 4 & 4 & 4 \\
Starch & 4 & 4 & 4 & 4 \\
Egg yolk & 2 & 2 & 2 & 2 \\
Salt & 1.4 & 1.4 & 1.4 & 1.4 \\
Microalgae & 0 & 1 & 1 & 1 \\
Potassium sorbate & 0.1 & 0.1 & 0.1 & 0.1 \\
Total & 100 & 100 & 100 & 100 \\
\hline
\end{tabular}

CM: Control low-fat emulsion formulation; SM: Spirulina-fortified low-fat emulsion formulation; CHM: Chlorella-fortified low-fat emulsion formulation; DM: Dunaliella-fortified low-fat emulsion formulation.

\section{Physicochemical analysis}

Water activity $\left(\mathrm{a}_{\mathrm{w}}\right)$ of emulsion samples were determined by an AquaLab Dewpoint Water Activity Meter 4TE (Decagon Devices Inc., Pullman, WA, USA). pH values of samples were measured using a Consort C-830 pH meter (Turnhout, Belgium). Samples were analysed by triplicate at $25^{\circ} \mathrm{C}$ on day $0,15,30,45$, and 60 of storage.

\section{Colour measurement}

Emulsion samples colour was measured using a Konica Minolta CM-700d colorimeter (Konica Minolta CM-700d/600d series, Tokyo, Japan) with the standard illuminant D65 and visual angle of $10^{\circ}$. The emulsion samples were individually placed in a circular glass sample holder of $50 \mathrm{~mm}$ diameter and $10 \mathrm{~mm}$ height and were measured at three equidistant points, on days $0,15,30,45$, and 60 of storage. Colour parameters were determined by: $L^{*}$ lightness ( 0 - black, 100 - white), a* (-a* green, +a* red), and b* (-b* blue, +b* yellow), according to the CIEL*a*b* system. Chroma, $\mathrm{C}^{*}{ }_{\mathrm{ab}}$ (saturation) and hue angle, $\mathrm{h}^{\circ}{ }_{\mathrm{ab}}$, were also calculated, defined by equation 1 and equation 2 , respectively. 


$$
\begin{gathered}
C_{a b}^{*}=\left[\left(a^{*}\right)^{2}+\left(b^{*}\right)^{2}\right]^{1 / 2} \\
\mathrm{~h}^{\circ}{ }_{a b}=\arctan \left(\frac{b^{*}}{a^{*}}\right)
\end{gathered}
$$

The total colour difference $(\Delta \mathrm{E})$ between samples with and without microalgae was determined using $L^{*} a * b *$ values according to equation 3 .

$$
\Delta E=\left[\left(\Delta L^{*}\right)^{2}+\left(\Delta a^{*}\right)^{2}+\left(\Delta b^{*}\right)^{2}\right]^{1 / 2}
$$

The measurements were conducted under constant lighting conditions, at $25^{\circ} \mathrm{C}$.

\section{Textural analysis of emulsions}

The texture was measured using a TA-XT2 Texture Analyser (Stable Micro Systems Ltd, Godalming, UK) with the software Texture Exponent (version 6.1.12.0). A standard size back extrusion container (50 mm diameter) was filled with $60 \mathrm{ml}$ of sample. An extrusion disc (35 mm diameter) attached to a $50 \mathrm{~kg}$ load cell compress was positioned centrally over the container, compressing the sample at pre and test speeds of $1.0 \mathrm{~mm} \mathrm{~s}^{-1}$ and post-test speed of $10 \mathrm{~mm} \mathrm{~s}^{-1}$. Firmness (N), consistency (N.s), cohesiveness (N), and adhesiveness (N.s) were measured in triplicate at $20^{\circ} \mathrm{C}$ on days $0,15,30,45$ and 60 of storage for each blend and the results were averaged.

\section{Rheological and viscoelastic properties of the emulsions}

Flow and oscillatory tests were performed using a Kinexus pro+ rotational rheometer (Malvern Instruments, Worcestershire, UK) and rSpace software; equipped with a $25 \mathrm{~mm}$ diameter parallel-plate geometry (DSR II, Upper Plate) with a $1.5 \mathrm{~mm}$ gap between plates and a heat-controlled sample stage (Peltier Cylinder Cartridge, Malvern Instruments, Worcestershire, UK). Before each measurement samples were loaded onto the geometry plate and rested for $5 \mathrm{~min}$.

Flow tests were used to study the behaviour of shear stress on applied shear rate and viscosity profiles of samples. Shear rate $(\dot{\gamma})$ was increased logarithmically from 0.01 to $10 \mathrm{~s}^{-1}$ over $50 \mathrm{~s}$ at $25^{\circ} \mathrm{C}$. The behaviour parameters were calculated using SigmaPlot Software, version 11.0 (Systat Software Inc., USA). The linear viscoelastic range for all the samples 
was determined with a strain sweep (0.001-100\%) at a fixed frequency of $1.0 \mathrm{~Hz}$, followed by oscillatory stress sweeps with a frequency range of $0.1-10 \mathrm{~Hz}$ for each sample using a constant strain of $0.01 \%$. The mechanical spectra were obtained recording the elastic modulus $\left(\mathrm{G}^{\prime}(\mathrm{Pa})\right)$ and viscous modulus $\left(\mathrm{G}^{\prime \prime}(\mathrm{Pa})\right)$ as a function of the frequency range $(\omega$ $(\mathrm{Hz})) . \mathrm{G}^{\prime}$ is the dynamic elastic or storage modulus, related to the material response as a solid. G" is the dynamic viscous or loss modulus, related to the material response as a fluid. The loss angle $(\tan \delta)$ as a function of frequency $(\omega(\mathrm{Hz}))$ was calculated. Tan $\delta$ is defined as the ratio of $G^{\prime \prime}$ to $G^{\prime}$. For both tests, samples were performed in triplicate on days 0,15 , 30,45 , and 60 of storage and at $25^{\circ} \mathrm{C}$.

\section{Statistical analysis}

Analysis of variance (ANOVA) using Statgraphics Centurion XVII Software, version 17.2.04 with a confidence level of $95 \%(p<0.05)$ was applied to evaluate the differences among emulsion samples. Furthermore, a correlation analysis among rheological and textural properties of the samples, with a $95 \%$ significance level, was conducted (Statgraphics Centurion XVII).

\section{Results and discussion}

\section{Physicochemical properties}

Water activity and $\mathrm{pH}$ of oil-in-water emulsions plays an important role in its structure, stability and food safety (Nout et al., 2000; Su et al., 2010). Table 2 shows the results of $a_{w}$ and $\mathrm{pH}$ of microalgae-fortified emulsions.

Water activity $\left(\mathrm{a}_{\mathrm{w}}\right)$ values were in the range 0.92 to 0.95 with significant $(p<0.05)$ differences between CM, SM, CHM, and DM and during storage time too. The $\mathrm{a}_{\mathrm{w}}$ values are seen to decrease significantly $(p<0.05)$ during the 60 days storage period (Table 2$)$ with DM showing the lowest $a_{w}$ values. Water activity of low-fat emulsions present high $a_{w}$ values, $\approx 0.95$, due to the increased of water holding capacity of the formulations (Su et al., 2010; Alu'datt et al., 2016).

Adding microalgae biomass causes significant differences $(p<0.05)$ in the $\mathrm{pH}$ values of the formulated emulsions than $\mathrm{CM}$ at day 0 and slight differences $(p<0.05)$ when increasing the storage period to 60 days (Table 2 ). The $\mathrm{pH}$ decreasing or increasing rates for different 
samples were affected by each microalgae addition. Table 2 shows a significant increase ( $p$ $<0.05)$ of $\mathrm{pH}$ values for samples CM and DM, with a decrease $(p<0.05)$ for SM during storage time. Furthermore, adding Chlorella led to retardation and the increase of $\mathrm{pH}$ values during storage time. Therefore, CM showed lower $\mathrm{pH}$ values than SM, CHM, and DM among all samples during storage time. Nevertheless, $\mathrm{pH}$ values ranging between 3.0 and 3.7 agreed with the Codex Alimentarius Commission (Joint FAO/WHO Food Standards Programme, 1987). Besides, $\mathrm{pH}$ values of mayonnaise and emulsions are typically between 3.0 and 4.0 because of the presence of acetic acid in formulations, having significant influence on the microbiological stability (Nout et al., 2000).

Table 2. Water activity $\left(\mathrm{a}_{\mathrm{w}}\right)$ and $\mathrm{pH}$ of emulsions during storage time.

\begin{tabular}{|c|c|c|c|c|c|}
\hline Parameters & $\begin{array}{c}\text { Storage period } \\
\text { (days) }\end{array}$ & CM & SM & CHM & DM \\
\hline \multirow{6}{*}{$\mathbf{a}_{\mathbf{w}}$} & 0 & $0.954(0.005)^{\mathrm{aA}}$ & $0.963(0.005)^{\mathrm{aB}}$ & $0.9506(0.0006)^{\mathrm{abc}}$ & $0.930(0.004)^{\mathrm{aA}}$ \\
\hline & 15 & $0.959(0.004)^{\mathrm{aA}}$ & $0.956(0.001)^{\mathrm{bAB}}$ & $0.9527(0.0006)^{\mathrm{ac}}$ & $0.935(0.005)^{\mathrm{aB}}$ \\
\hline & 30 & $0.959(0.004)^{\mathrm{Aa}}$ & $0.954(0.001)^{\mathrm{Ba}}$ & $0.932(0.006)^{\mathrm{bcB}}$ & $0.925(0.001)^{\mathrm{BC}}$ \\
\hline & 45 & $0.942(0.001)^{\mathrm{Ba}}$ & $0.933(0.001)^{\mathrm{Cb}}$ & $0.9287(0.0006)^{\mathrm{bcc}}$ & $0.926(0.003)^{\mathrm{bcc}}$ \\
\hline & 60 & $0.933(0.002)^{\mathrm{CA}}$ & $0.932(0.001)^{\mathrm{cA}}$ & $0.924(0.004)^{\mathrm{CB}}$ & $0.924(0.001)^{C B}$ \\
\hline & $\overline{0}$ & $3(0)^{\mathrm{aA}}$ & $3 . \overline{7}(0.01)^{\mathrm{a}} \overline{\mathrm{B}}$ & $3 . \overline{58}(0.02)^{\mathrm{ac}}$ & $3.54(0.01)^{\mathrm{aD}}$ \\
\hline \multirow{4}{*}{ pH } & 15 & $3.27(0.01)^{\mathrm{bA}}$ & $3.60(0.04)^{\mathrm{bB}}$ & $3.58(0)^{a B}$ & $3.58(0.01)^{\mathrm{bB}}$ \\
\hline & 30 & $3.35(0.02)^{\mathrm{cA}}$ & $3.69(0.02)^{a c}$ & $3.70(0.01)^{\mathrm{bC}}$ & $3.497(0.006)^{\mathrm{CB}}$ \\
\hline & 45 & $3.27(0.01)^{\mathrm{dA}}$ & $3.63(0.01)^{\mathrm{bB}}$ & $3.70(0.01)^{\mathrm{bC}}$ & $3.47(0.02)^{\mathrm{dD}}$ \\
\hline & 60 & $3.46(0.01)^{\mathrm{eA}}$ & $3.62(0.03)^{\mathrm{bB}}$ & $3.70(0.02)^{\mathrm{bC}}$ & $3.62(0.01)^{\mathrm{eB}}$ \\
\hline
\end{tabular}

Results (mean \pm SD) marked for each sample (CM, SM, CHM, and DM) with the same small letter in superscript within column indicates homogeneous groups established by ANOVA $(p<0.05)$ with the storage time $(0,15,30,45$, and 60 days). For each storage time, the same capital letter in superscript within the column indicates homogeneous groups established by ANOVA $(p<0.05)$ comparing to lowfat emulsion formulations. CM: Control low-fat emulsion, SM: Spirulina low-fat emulsion, CHM: Chlorella low-fat emulsion, and DM: Dunaliella low-fat emulsion.

\section{Colour stability}

Colour is an important quality attribute of food products, contributing to its acceptability (Batista et al., 2006). The visual colour perceptions in all samples are attractive as can been observed in Figure 1. 


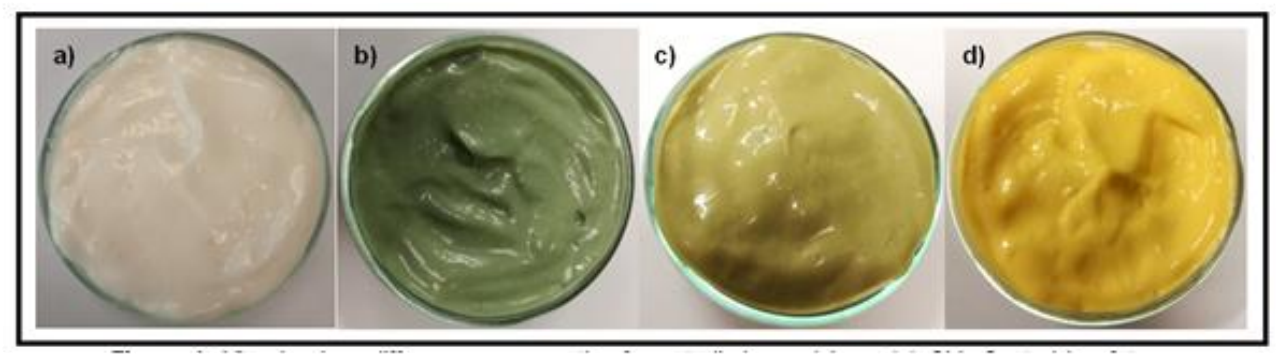

Figure 1. Visual colour differences among the four studied emulsions: a) CM: Control low-fat emulsion, b) SM: Spirulina low-fat emulsion, c) CHM: Chlorella low-fat emulsion and d) DM: Dunaliella low-fat emulsion.

Figure 2 shows the colour changes of the emulsions during 60 days of storage at $5{ }^{\circ} \mathrm{C}$, expressed as lightness $\left(\mathrm{L}^{*}\right)$, redness $\left(\mathrm{a}^{*}\right)$, yellowness $\left(\mathrm{b}^{*}\right)$, hue $\left(\mathrm{h}^{\circ}{ }_{\mathrm{ab}}\right)$, and chroma $\left(\mathrm{C}^{*}{ }_{\mathrm{ab}}\right)$ with a control sample as a reference. $L^{*}, a^{*}$, and $b^{*}$ values of the emulsion products made with microalgae were significantly different $(p<0.05)$ than the control emulsion. The evaluation of parameter $L^{*}$ shows that lightness decreased significantly $(p<0.05)$ with microalgae addition although, slight significant $(p<0.05)$ differences with the SM and CHM are found comparing each storage day, meaning adding Spirulina results in a darker emulsion than Chlorella and Dunaliella. The lightness $\left(L^{*}\right)$ of CM and SM increased during the first 15 days of storage, then consistently increased until the end of the storage period. The DM sample exhibited a slight increase in lightness $\left(L^{*}\right)$ by a range of 0.3-0.8 units at the end of the storage period, comparable behaviour observed by Santipanichwong et al. (2007), in $\beta$-carotene emulsion samples. The CHM sample showed almost unaffected $L^{*}$ values during storage time. These trends were also observed by Gouveia et al. (2006) in emulsions with Chlorella.

The a* values of SM and CHM samples increased rapidly for the first 15 days before reaching a plateau, maintained throughout the remaining storage period. CM and DM were more stable, not showing significant differences $(p>0.05)$ during storage time. No significant differences $(p>0.05)$ are observed for $b^{*}$ of all samples. When Dunaliella was used, high values of $a^{*}$ and $b^{*}$ are observed, meaning that red and yellow hues are intensified, as expected owing to the $\beta$-carotene pigments (Buono et al., 2014). Likewise, when Spirulina and Chlorella are used, low values of $a^{*}$ and $b^{*}$ are observed, meaning that green and blue hues are intensified, due to its phycocyanin pigment contents in Spirulina (Park et al., 2018) and the lutein pigment in Chlorella (Dufossé, 2016). Both microalgae 
were good sources of pigments for oil-in-water food emulsions, proving to impart a stable and appealing colour to them improving the product ranges during storage time (Gouveia et al., 2006). Here the $C^{*}{ }_{a b}$ remains constant for each sample along storage time.
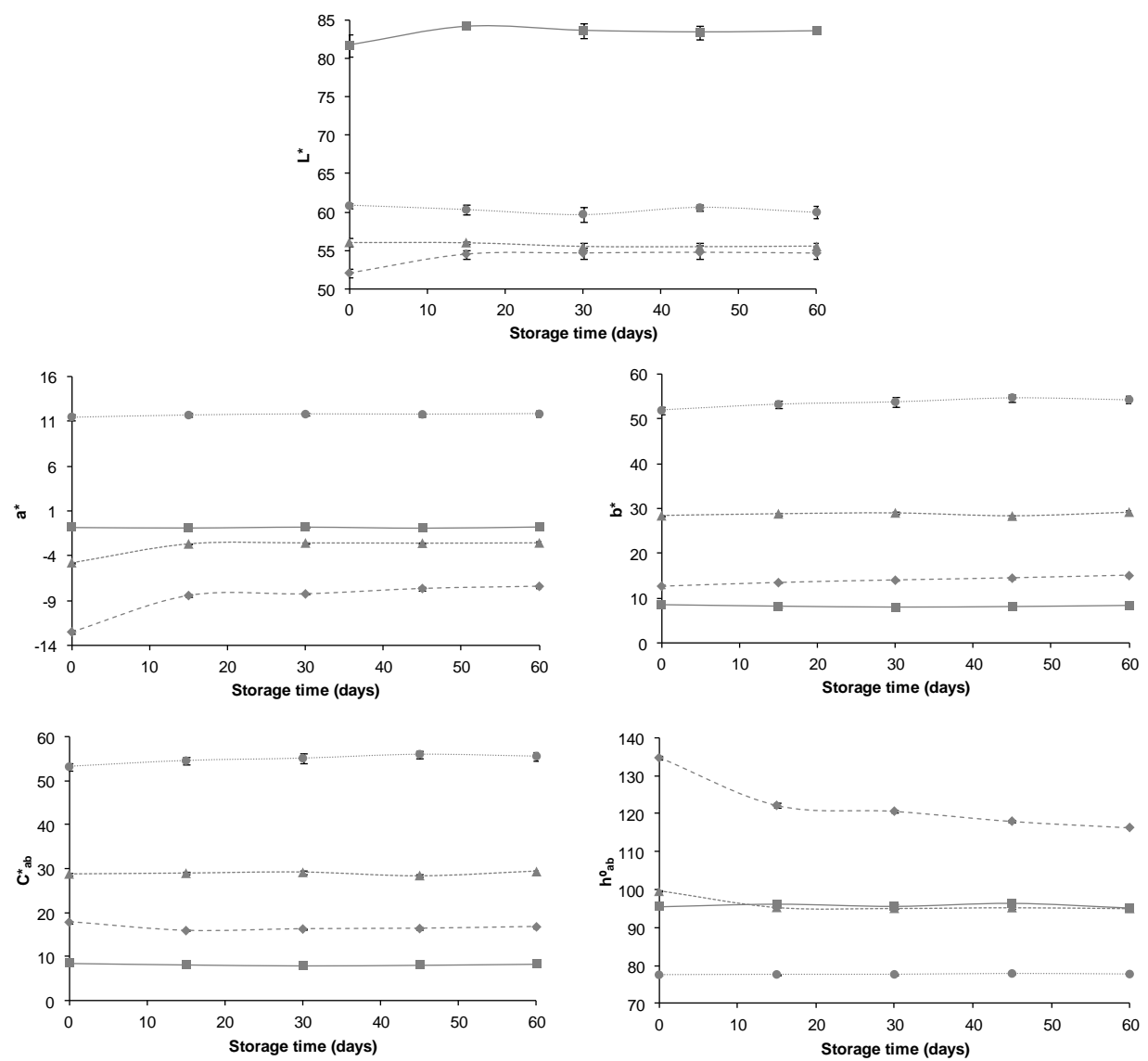

Figure 2. Colour parameters of emulsion samples during storage time. Control low-fat emulsion $(\square)$, Spirulina low-fat emulsion ( $\bullet$ ), Chlorella low-fat emulsion $(\Delta)$ and, Dunaliella low-fat emulsion $(\bullet)$.

Total colour difference, because of storage, were below the perceptible sensory limit by the human eye $(\Delta \mathrm{E}>3)$, according to Bodart et al. (2008). No significant differences $(p>0.05)$ were observed in $\triangle \mathrm{E}$ for $\mathrm{CM}, \mathrm{CHM}$, and $\mathrm{DM}$ among samples at any during storage time (Table 3). Nevertheless, for sample SM, total colour differences caused by storage, were significantly $(p<0.05)$ higher than the other samples with increasing colour differences 
values during storage time. Emulsions with Chlorella or Dunaliella have greater colour stability.

Table 3. Colour stability $(\Delta \mathrm{E})$ along storage time ( $\Delta \mathrm{E}$ in relation to day 0$)$.

\begin{tabular}{ccccc}
\hline $\begin{array}{c}\text { Storage period } \\
\text { (days) }\end{array}$ & CM & SM & CHM & DM \\
\cline { 2 - 5 } & $2.3(1.0)^{\mathrm{aA}}$ & $4.8(0.4)^{\mathrm{aB}}$ & $2.22(0.14)^{\mathrm{aA}}$ & $1.5(0.8)^{\mathrm{aA}}$ \\
\hline Day $15 \mathrm{vs}$. day 0 & $1.9(0.9)^{\mathrm{aA}}$ & $5.2(0.4)^{\mathrm{aBC}}$ & $2.4(0.3)^{\mathrm{aA}}$ & $2.3(1.2)^{\mathrm{aA}}$ \\
Day 30 vs. day 0 & $1.8(1.0)^{\mathrm{aA}}$ & $5.9(0.5)^{\mathrm{bBC}}$ & $2.5(0.2)^{\mathrm{aA}}$ & $2.6(0.8)^{\mathrm{aA}}$ \\
Day 45 vs. day 0 & $1.63(0.9)^{\mathrm{aA}}$ & $6.2(0.4)^{\mathrm{bC}}$ & $2.5(0.3)^{\mathrm{aA}}$ & $2.6(1.2)^{\mathrm{aA}}$ \\
Day 60 vs. day 0 & &
\end{tabular}

Results (mean \pm SD) marked for each sample (CM, SM, CHM, and DM) with the same superscript small letter within the columns indicates homogeneous groups established by ANOVA $(p<0.05)$ comparing to storage time. For each storage time, the same superscript capital letter within the columns indicates homogeneous groups established by ANOVA $(p<0.05)$ comparing to low-fat emulsion formulations. CM: Control low-fat emulsion, SM: Spirulina low-fat emulsion, CHM: Chlorella low-fat emulsion, and DM: Dunaliella low-fat emulsion.

\section{Effect of microalgae addition on textural properties}

The textural properties were determined by firmness $(\mathrm{N})$, consistency (N.s), cohesiveness (N), and adhesiveness (N.s) (Figure 3). Firmness and consistency reveal the solid property of emulsions, while cohesiveness and adhesiveness reveal the liquid properties ( $\mathrm{Li}$ et al., 2014); properties that may affect mouth feel and applicability. For all textural parameters, a significant $(p<0.05)$ difference with Chlorella addition was observed in all samples, with slight significant $(p<0.05)$ differences between CM, SM, and DM. Textural parameters of CM, SM, and CHM did not increase or decrease linearly during storage time, as the oscillatory behaviour stayed between 1 to $1.2(\mathrm{~N})$ for firmness, -0.9 to -0.7 (N.s) for cohesiveness, and -0.85 to -0.65 (N.s) for adhesiveness. The consistency of SM increases during the first 15 days and during the first 45 days for $\mathrm{CM}$, after, decreasing until the end of the storage period. In contrast, the consistency of DM decreases from day 0. For CHM, firmness decreases from 1.29 to $(0.53-0.39)(\mathrm{N})$ and consistency from 5.79 to (3.48-2.74) (N.s), while cohesiveness increases from -0.96 to $((-0.38)-(-0.27)(\mathrm{N})$ and adhesiveness from -0.70 to $((-0.40)-(-0.29))$ (N.s) during storage time.

Considering that some authors have attempted to prepare emulsions without any protein addition, using Chlorella biomass as the sole emulsifier, at concentrations lower than $2 \%$, 
obtaining a very unstable suspension (Raymundo et al., 2005). CHM behaviour after day 15 may be because of physical or chemical emulsion changes where differing interactions with the matrix material (low content of oil ( $30 \% \mathrm{wt}$ ) and microalgae ( $1 \% \mathrm{wt})$ ) resulting in modified stability characteristics during storage.
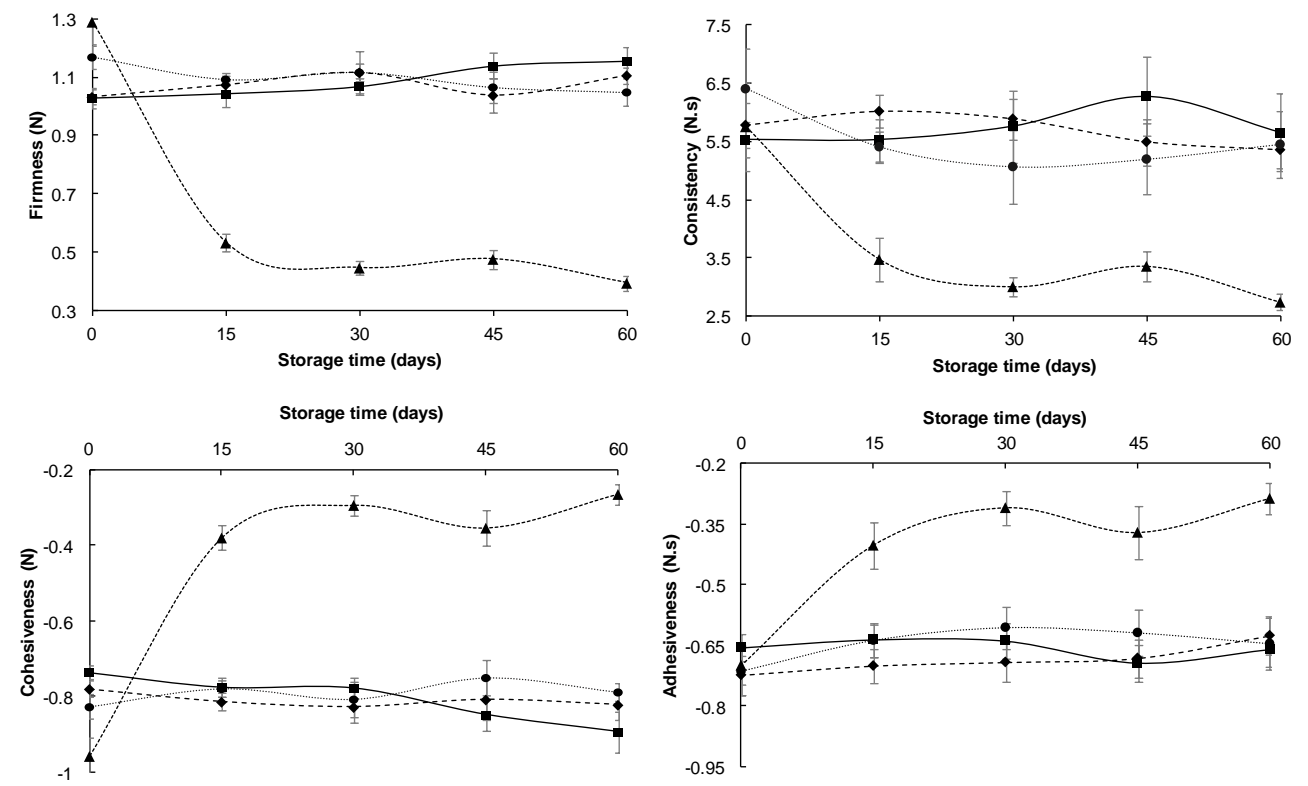

Figure 3. Texture parameters of emulsion samples during storage time. Control low-fat emulsion ( $\mathbf{\bullet})$, Spirulina low-fat emulsion ( $\bullet$ ), Chlorella low-fat emulsion $(\boldsymbol{\Lambda})$, and Dunaliella low-fat emulsion $(\bullet)$.

\section{Rheological and viscoelastic characterisation}

Rheological properties of emulsion samples were investigated by measuring their flow behaviour and dynamic rheological properties, important to determine their long term physical stability (Jain et al., 2019).

The viscosity of emulsion samples was evaluated through flow sweep tests and presented as the viscosity $(\eta)$ as a function of the shear rate $(\dot{\gamma})$. Figure $4 a, 4 b, 4 c$, and $4 d$ show results for CM, SM, CHM, and DM, respectively. Viscosity decreases with shear rate increases, giving shear-thinning behaviour in all cases. When viscosity decreases during shear, the behaviour is said to be thixotropic (Jain et al., 2019). Figure 4 shows all the emulsions have the highest viscosity at day 0 . Nevertheless, the viscosity vs. shear rate curve trend for $\mathrm{CM}$ is higher than other samples, followed by SM, DM, and CHM, subsequently. Under the same 
shear rate, differences with $\mathrm{CHM}$ at day 0 and the other days of storage were pronounced, although viscosity profiles for days $15,30,45$, and 60 showed no significant $(p>0.05)$ differences.
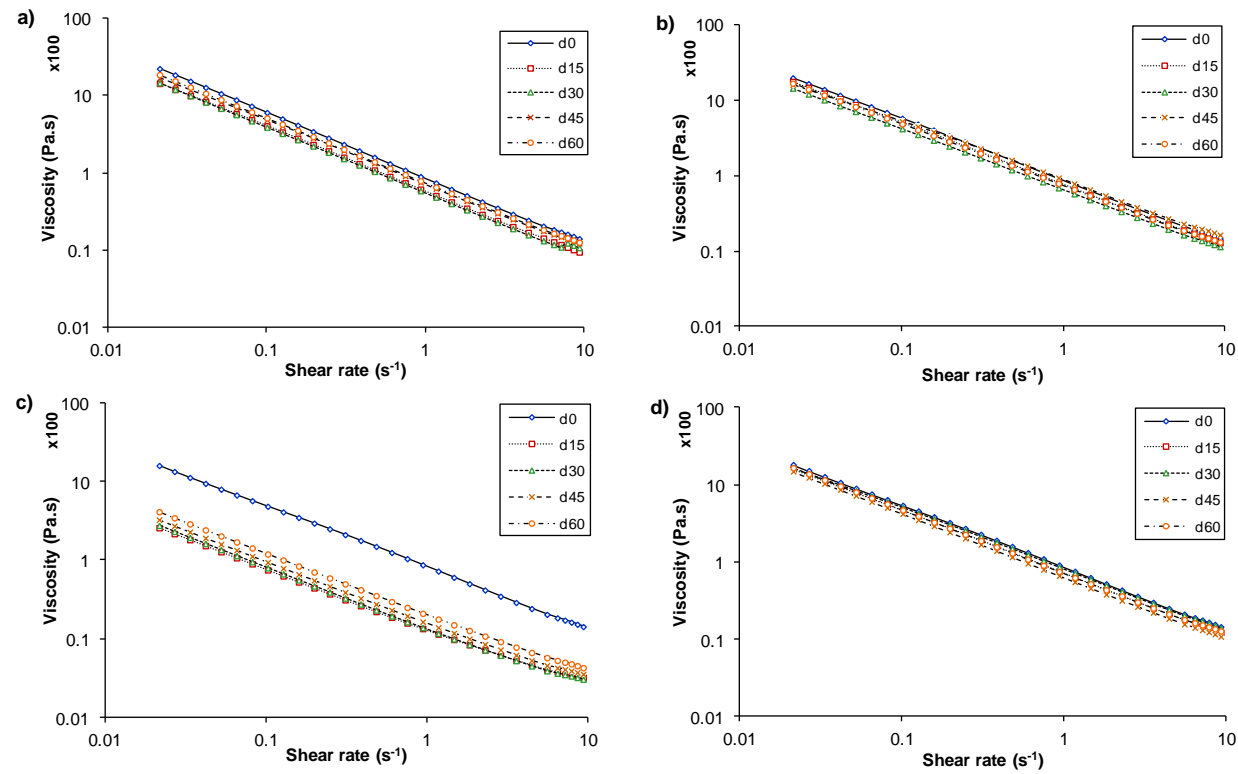

Figure 4. Viscosity profiles of mayonnaise samples during storage time. a) Control low-fat emulsion, b) Spirulina low-fat emulsion c) Chlorella low-fat emulsion, and d) Dunaliella low-fat emulsion.

To evaluate the flow behaviour of the emulsions, the flow curves, plotting the experimental shear stress $(\sigma, \mathrm{Pa})$ as a function of the shear rate $\left(\dot{\gamma}, \mathrm{s}^{-1}\right)$ data, are shown in Figure 5 . In order to perform a quantitative comparison of emulsions, it is generally required fitting the experimental data to some forms of best-fit mathematical equation or model. For the flow tests, the experimental data obtained was well fitted to the Herschel-Bulkley model (equation 4) and the behaviours are showed in Figure 5 too,

$$
\sigma=\sigma_{0}+\mathrm{K} \cdot \dot{\gamma}^{n}
$$

where $\sigma$ is the shear stress $(\mathrm{Pa}), \sigma_{0}$ is the yield stress $(\mathrm{Pa}), \mathrm{K}$ is the consistency coefficient $\left(\mathrm{Pa} \cdot \mathrm{s}^{\mathrm{n}}\right), \dot{\gamma}$ is the shear rate $\left(\mathrm{s}^{-1}\right)$, and $n$ is the flow behaviour index. 
Table 4 summarises the Herschel-Bulkley obtained parameters and the rheological parameters of the different emulsions along the storage time. The behaviour of all samples confirm a non-linear relationship exhibiting a non-Newtonian plastic and time dependent shear-thinning (thixotropic) behaviour between the shear stress over the whole range of shear rate studied $\left(0.01-10 \mathrm{~s}^{-1}\right)$ for all the emulsions (Figure 5).
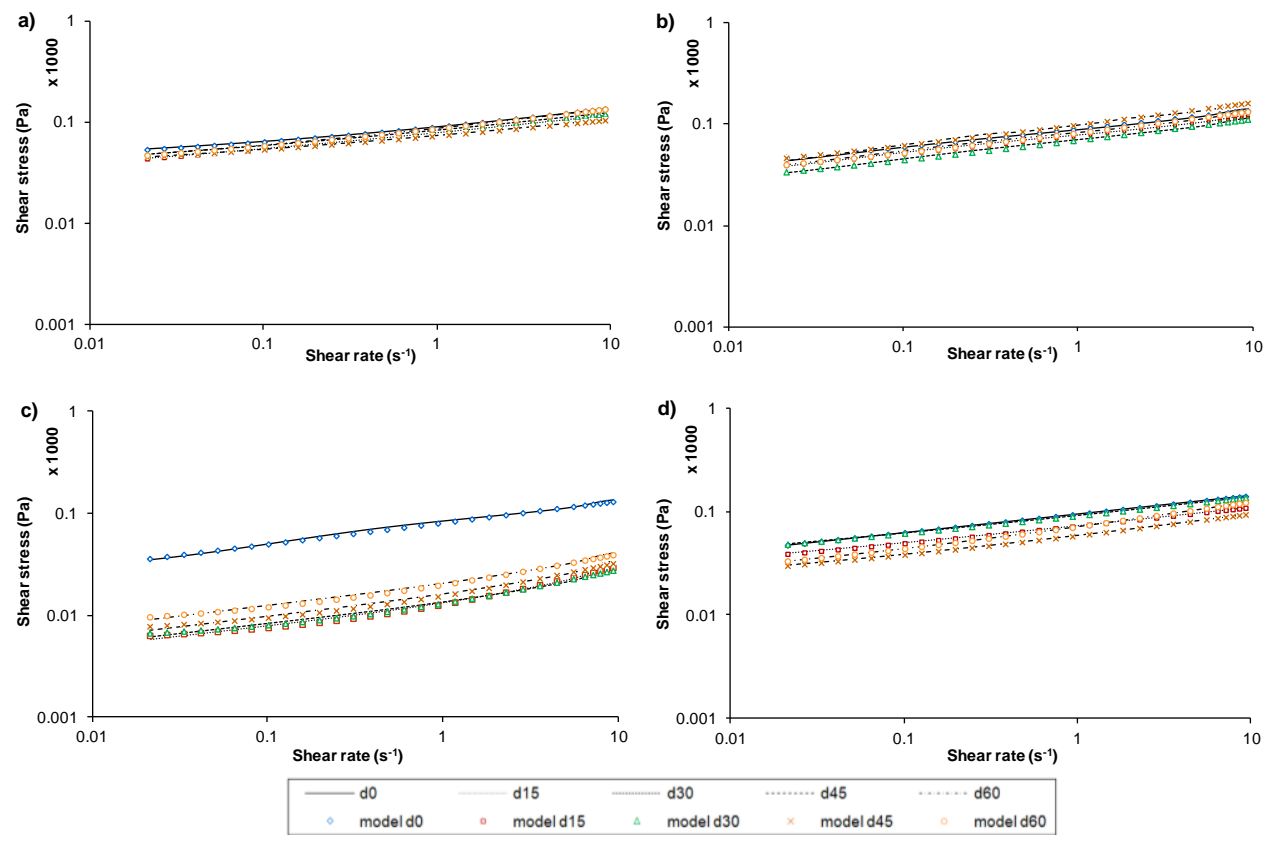

Figure 5. Flow behaviour of the assayed low-fat emulsions. Values obtained from Herschel-Bulkley model (bookmarks) and Shear stress $(\sigma)$ vs. Shear rate $(\dot{\gamma})$ (continuous and dotted lines) of a) Control low-fat emulsion, b) Spirulina low-fat emulsion c) Chlorella low-fat emulsion, and d) Dunaliella low-fat emulsion, during storage time: d0: day 0, d15: day 15, d30: day 30, d45: day 45 and d60: day 60.

Yield stress $\left(\sigma_{0}\right)$ represents the minimum shear stress required to initiate the flow of material, indicating the transition from an elastic form to viscous deformation (Tadros, 2013). Incorporating Spirulina, Chlorella or Dunaliella into emulsion formulations decreased the yield stress significantly $(p<0.05)$ than the control emulsion. Yield stress provides stability to food emulsions in low-stress situations, like those of storage, transportation, mixing, and pumping (Sun et al., 2009). Significant $(p<0.05)$ differences were observed in $\sigma_{0}$ for all samples at day 0 than the whole time under study. Both CM and SM showed a decrease of $\sigma_{0}$ while CHM and DM showed an increase over storage time. However, CM 
shows the highest $\sigma_{0}$ value and CHM the lowest over the long storage time and among all the samples (Table 4). Notably, microalgae-fortified formulations require a lower yield stress to initiate their flow than the control emulsion, also a weaker network structure was seen (i.e., fewer interactions in the sample), which could result in a decreased resistance to flow (Ma et al., 2013). This is seen in all cases due to the Herschel-Bulkley model could interpolate the yield stress of emulsion samples, showing a determination coefficient $\left(R^{2}\right.$ adj $)$ > 0.994 (Table 4).

The consistence coefficients $(K)$ of the emulsions are shown in Table 4 showing a significant difference $(p<0.05)$ in the consistency index of samples with and without microalgae at day $0 . \mathrm{K}$ values of emulsions were higher for both, Chlorella and Dunaliella and lower for the control sample at day 0 . Higher $\mathrm{K}$ values in emulsions indicate a more pronounced viscous characteristic, which corresponds to a sample stronger network structure. Therefore, microalgal biomass can contribute to the reinforcement of the emulsion structure through the formation of physical entanglements (Raymundo et al., 2005). However, slight significant $(p<0.05)$ differences with $\mathrm{K}$ values were observed for long storage times of $\mathrm{CM}$, $\mathrm{SM}$, and DM. Although, a significant $(p<0.05)$ difference between day 0 and the other storage times for $\mathrm{CHM}$, showing low $\mathrm{K}$ values exists.

The flow behaviour indicator $(n)$ is an index to recognise the properties of the liquid product; $n=1$, Newtonian fluid; $n<1$ (a shear-thinning liquid), and shear-thickening or dilatant fluid; $n>1$. All samples show shear-thinning behaviour with a flow behaviour index $n<1$. No significant $(p>0.05)$ differences for $C M$, slight significant $(p<0.05)$ differences for SM and DM, and significant $(p<0.05)$ differences for $\mathrm{CHM}$; with $n$ ranging from 0.53 to 0.19 ; were observed over the long storage time than day 0 . Notably, the data in Table 4 confirmed the shear-thinning liquid behaviour of the emulsions: CHM and DM showed the greatest $\mathrm{K}$ values and the lowest $n$ values at day 0 , confirming CHM and DM have greater consistency and less Newtonian behaviour than samples without microalgae. The addition of a combination of non-fat ingredients like protein, gums, starches, and other fat replacers with different functional roles is necessary to maintain the original viscoelastic properties of reduced-fat dressings and mayonnaise (Yildirim et al., 2016). 


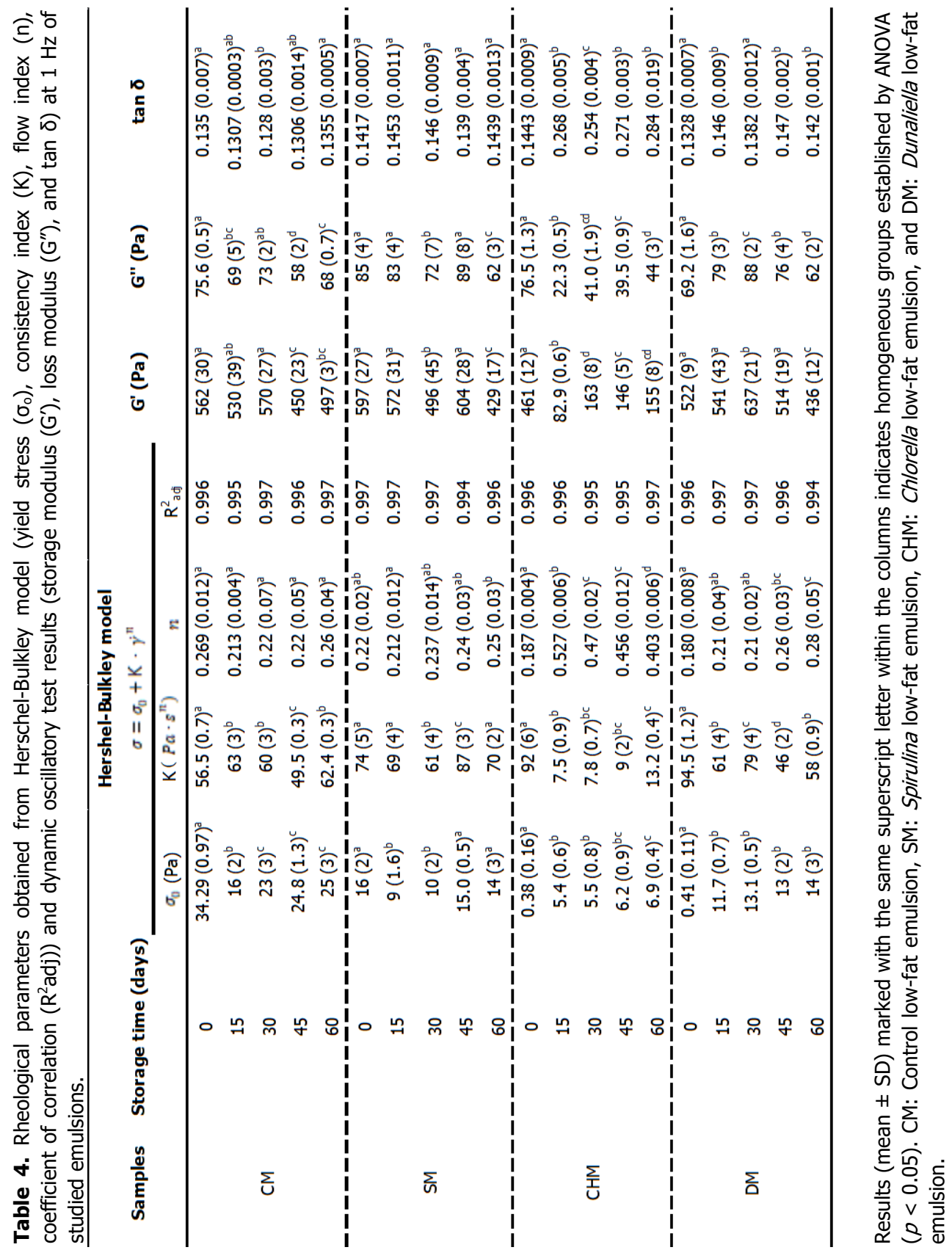


Figure 6 shows the dynamic mechanical spectra of the emulsions during 60 days of storage. The elastic modulus $\left(\mathrm{G}^{\prime}\right)$ was higher than the viscous modulus $\left(\mathrm{G}^{\prime \prime}\right)$ for all samples and both parameters progressively increased, throughout the frequency range. Moreover, loss angle $(\tan \delta$ ) values for all emulsions were larger than 0.1 during the frequency range and storage time (60 days). This behaviour may be classified rheologically as a weak gel-like character (Liu et al., 2007; Ma et al., 2013), which is in good agreement with previous reports in reduced-fat emulsion products (Santipanichwong et al., 2007; Li et al., 2014). In comparison to $\mathrm{CM}, \mathrm{CHM}$, and $\mathrm{DM}$; SM presented the highest $\mathrm{G}^{\prime}$ and $\mathrm{G}^{\prime \prime}$ values at day 0 (Table 4), this can relate to the Spirulina having a high protein content (65\%) (Ejike et al., 2017) giving up a slight reinforcement of the structure (Batista et al., 2011) and forming a flocculated and entangled network (Raymundo et al., 2005). During storage time, significant $(p<0.05)$ differences were seen for all the samples between day 0 and day 60 for $\mathrm{G}^{\prime}$ and $\mathrm{G}^{\prime \prime}$ values (Table 4), especially for CHM; with slight significant $(p<0.05)$ differences with $\mathrm{G}^{\prime}$ and $\mathrm{G}^{\prime \prime}$ values were showed for all the samples from day 15 to day 60 compared to day 0 .
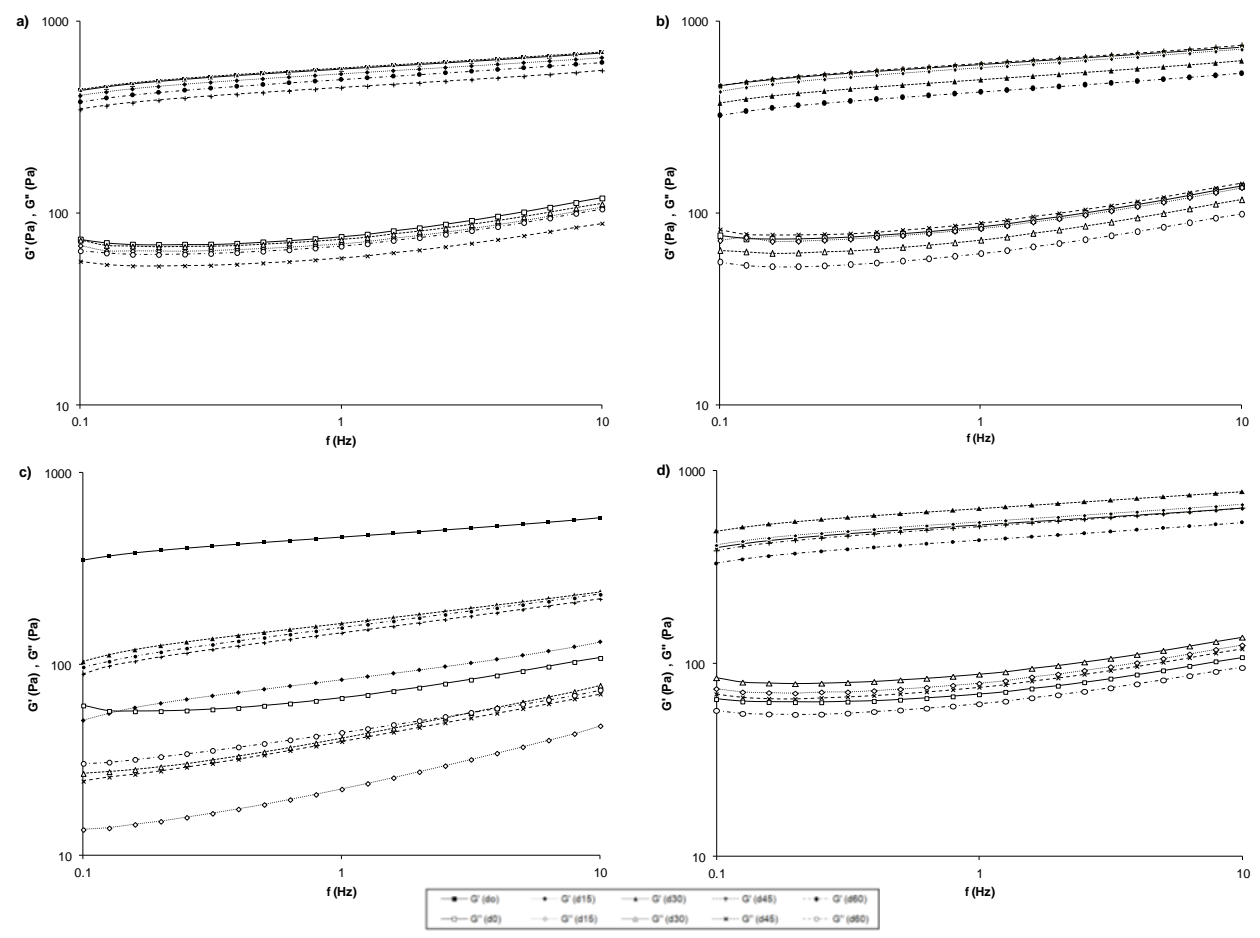

Figure 6. Frequency sweeps of emulsions. Elastic modulus $\left(G^{\prime}\right)$ and viscous modulus $\left(G^{\prime \prime}\right)$ of a) Control low-fat emulsion, b) Spirulina low-fat emulsion c) Chlorella low-fat emulsion, and d) Dunaliella low-fat emulsion, during storage time. d0: day 0, d15: day 15, d30: day 30, d45: day 45 and d60: day 60 . 


\section{Correlation between rheological and viscoelastic properties}

Using Pearson correlation analysis, a range of correlation coefficients ( $r$ ) (from 0.2809 to 0.9888 ) shows the relationships between textural characteristics and dynamic viscoelastic properties. A positive relationship $(r=0.9140)$ was found between the flow behaviour index and loss tangent, fundamental rheological parameters, showing the emulsion has a solid-like viscoelastic behaviour. Other positive correlations were also found between the firmness vs. consistency coefficient $(r=0.8955)$ and cohesiveness vs. flow behaviour index $(r=0.8941)$. The mechanical loss tangent $(r=0.9457 ; r=0.9152)$ were positively correlated with cohesiveness and adhesiveness while negatively correlated ( $r=0.951 ; r=0.9224)$ with firmness and consistency. Emulsions with microalgae have the potential to form solid-like structures giving more resistance to penetration; nevertheless, resulting in an increase of cohesiveness and adhesiveness.

\section{Conclusions}

In this study, the effect of microalgae fortification on the physical and rheological properties of low-fat oil-in-water emulsions was investigated during 60 days of storage. Microalgae addition changed properties such as $\mathrm{a}_{\mathrm{w}}, \mathrm{pH}$, colour, rheological, and textural properties regarding the control emulsion. However, $\mathrm{a}_{\mathrm{w}}$ and $\mathrm{pH}$ values follow the regulations required for these type of products. Microalgae (Spirulina, Chlorella, and Dunaliella) addition proved to give a stable and appealing colour to food emulsions during storage time, with green tonalities for Spirulina and Chlorella and yellow for Dunaliella, which might influence their sensory perception among consumers. However, incorporating Spirulina or Dunaliella in the formulation gives emulsions more stable in textural, viscoelastic, and rheological properties, which can be very useful to determine their shelf life. Future studies should focus on using microalgae biomass at different levels of concentration as an ingredient for emulsions to obtain quality products with good appearance and nutritional value. 


\section{References}

Alu'datt, M. H., Rababah, T., Gammoh, S., Ereifej, K., Al-Mahasneh, M., Kubow, S., \& Tawalbeh, D. (2016). Emulsified protein filaments: types, preparation, nutritional, functional, and biological properties of mayonnaise. In Alexandru Mihai Grumezescu (Ed.), Emulsions. Nanotechnology in the Agri-Food Industry Volume 3 (pp. 557-572). Elsevier Inc. doi: 10.1016/b978-0-12-804306-6.00016-7

Batista, A. P., Nunes, M. C., Raymundo, A., Gouveia, L., Sousa, I., Cordobés, F., Guerrero, A., \& Franco, J. M. (2011). Microalgae biomass interaction in biopolymer gelled systems. Food Hydrocolloids, 25(4), 817-825. doi: 10.1016/j.foodhyd.2010.09.018

Batista, A. P., Raymundo, A., Sousa, I., \& Empis, J. (2006a). Rheological characterization of coloured oil-in-water food emulsions with lutein and phycocyanin added to the oil and aqueous phases. Food Hydrocolloids, 20(1), 44-52. doi: 10.1016/j.foodhyd.2005.02.009

Batista, A. P., Raymundo, A., Sousa, I., Empis, J., \& Franco, J. M. (2006b). Colored food emulsions-implications of pigment addition on the rheological behavior and microstructure. Food Biophysics, 1(4), 216-227. doi: 10.1007/s11483-006-9022-3

Bodart, M., de Peñaranda, R., Deneyer, A., \& Flamant, G. (2008). Photometry and colorimetry characterisation of materials in daylighting evaluation tools. Building and Environment, 43(12), 2046-2058. doi: 10.1016/j.buildenv.2007.12.006

Buono, S., Langellotti, A. L., Martello, A., Rinna, F., \& Fogliano, V. (2014). Functional ingredients from microalgae. Food and Function, 5(8), 1669-1685. doi: 10.1039/c4fo00125g

Chang, C., Li, J., Li, X., Wang, C., Zhou, B., Su, Y., \& Yang, Y. (2017). Effect of protein microparticle and pectin on properties of light mayonnaise. LWT - Food Science and Technology, 82, 8-14. doi: 10.1016/j.Iwt.2017.04.013

Dufossé, L. (2016). Current and Potential Natural Pigments From Microorganisms (Bacteria, Yeasts, Fungi, Microalgae). In R. Carle \& R. M. Schweiggert (Eds.), Handbook on Natural Pigments in Food and Beverages: Industrial Applications for Improving Food Color (pp. 337-354). Elsevier Ltd. doi: 10.1016/B978-0-08-100371-8.00016-6

Ejike, C. E. C. C., Collins, S. A., Balasuriya, N., Swanson, A. K., Mason, B., \& Udenigwe, C. C. (2017). Prospects of microalgae proteins in producing peptide-based functional foods for promoting cardiovascular health. Trends in Food Science and Technology, 59, 30-36. doi: 10.1016/j.tifs.2016.10.026

Gouveia, L., Raymundo, A., Batista, A. P., Sousa, I., \& Empis, J. (2006). Chlorella vulgaris and Haematococcus pluvialis biomass as colouring and antioxidant in food emulsions. European Food Research and Technology, 222(3-4), 362-367. doi: 10.1007/s00217-005-0105-z

Hasler, C. M., \& Brown, A. C. (2009). Position of the American Dietetic Association: Functional 
Foods. Journal of the American Dietetic Association, 109(4), 735-746. doi: 10.1016/J.JADA.2009.02.023

Izidoro, D. R., Scheer, A. P., Sierakowski, M. R., \& Haminiuk, C. W. I. (2008). Influence of green banana pulp on the rheological behaviour and chemical characteristics of emulsions (mayonnaises). LWT - Food Science and Technology, 41(6), 1018-1028. doi: 10.1016/j.Iwt.2007.07.009

Jain, S., Winuprasith, T., \& Suphantharika, M. (2019). Design and synthesis of modified and resistant starch-based oil-in-water emulsions. Food Hydrocolloids, 89(August 2018), 153162. doi: 10.1016/j.foodhyd.2018.10.036

Joint FAO/WHO Food Standards Programme. (1987). Codex Alimentarius Commission Codex Alimentarius Commission. Joint FAO/WHO Food Standars Programme Codex Committee on Food Additives and Contaminansts Thirty-First, July, 1-10. doi: 10.1007/BF02582346

Li, J., Wang, Y., Jin, W., Zhou, B., \& Li, B. (2014). Application of micronized konjac gel for fat analogue in mayonnaise. Food Hydrocolloids, 35, 375-382. doi: 10.1016/j.foodhyd.2013.06.010

Liu, H., Xu, X. M., \& Guo, S. D. (2007). Rheological, texture and sensory properties of low-fat mayonnaise with different fat mimetics. LWT - Food Science and Technology, 40(6), 946954. doi: 10.1016/j.Iwt.2006.11.007

Ma, Z., \& Boye, J. I. (2013). Advances in the Design and Production of Reduced-Fat and Reduced-Cholesterol Salad Dressing and Mayonnaise: A Review. Food and Bioprocess Technology, 6(3), 648-670. doi: 10.1007/s11947-012-1000-9

Ma, Z., \& Boye, J. I. (2014). Novel Health Ingredients and Their Applications in Salad Dressings and Other Food Emulsions. In J. I. Boye (Ed.), Nutraceutical and Functional Food Processing Technologu. Chichester: Wiley Blackwell.

Morley, W. G. (2016). Mayonnaise. In B. Caballero, P. Finglas, \& F. Toldra (Eds.), Encyclopedia of Food and Health (1st ed., pp. 669-676). Academic Press. doi: 10.1016/B978-0-12-3849472.00449-9

Mozaffarian, D. (2017). Dietary and Policy Prioritites for CVD, diabetes and obesity - a comprehensive RV. Circulation, 133(2), 187-225. doi: 10.1161/CIRCULATIONAHA.115.018585.Dietary

Nout, M. J. R., \& Rombouts, F. M. (2000). The Microbiological Safety and Quality of Food. In Fermented and acidified plant foods (Issue vol. 1, pp. 696-701). Gaithersburg, Maryland: Aspen Publishers, Inc.

Park, W. S., Kim, H. J., Li, M., Lim, D. H., Kim, J., Kwak, S. S., Kang, C. M., Ferruzzi, M. G., \& Ahn, M. J. (2018). Two classes of pigments, carotenoids and c-phycocyanin, in Spirulina powder and their antioxidant activities. Molecules, 23(8), 1-11. doi: 
$10.3390 /$ molecules 23082065

Priyadarshani, I., \& Rath, B. (2012). Commercial and industrial applications of micro algae - A review. Journal of Algal Biomass Utilization, 3(4), 89-100.

Raymundo, A., Gouveia, L., Batista, A. P., Empis, J., \& Sousa, I. (2005). Fat mimetic capacity of Chlorella vulgaris biomass in oil-in-water food emulsions stabilized by pea protein. Food Research International, 38(8-9), 961-965. doi: 10.1016/j.foodres.2005.02.016

Santipanichwong, R., \& Suphantharika, M. (2007). Carotenoids as colorants in reduced-fat mayonnaise containing spent brewer's yeast $\beta$-glucan as a fat replacer. Food Hydrocolloids, 21(4), 565-574. doi: 10.1016/j.foodhyd.2006.07.003

Su, H., Lien, C., Lee, T., \& Ho, J. (2010). Development of low-fat mayonnaise containing polysaccharide gums as functional ingredients. Journal of the Science of Food and Agriculture, 90, 806-812. doi: 10.1002/jsfa.3888

Sui, Y., \& Vlaeminck, S. E. (2020). Forum Dunaliella Microalgae for Nutritional Protein: An Undervalued Asset. Trends in Biotechnology, 38(1), 10-12. doi: 10.1016/j.tibtech.2019.07.011

Sun, A., \& Gunasekaran, S. (2009). Yield stress in foods: Measurements and applications. In International Journal of Food Properties (Vol. 12, Issue 1). doi: 10.1080/10942910802308502

Tadros, T. (2013). Rheology. In T. Tadros (Ed.), Encyclopedia of Colloid and Interface Science (pp. 1020-1042). Berlin, Heidelberg: Springer Berlin Heidelberg. doi: 10.1007/978-3-64220665-8_39

Tang, G., \& Suter, P. M. (2011). Vitamin A, nutrition, and health values of Algae: Spirulina, Chlorella, and Dunaliella. Journal of Pharmacy and Nutrition Sciences, 1(2), 111-118. doi: 10.6000/1927-5951.2011.01.02.04

Uribe-Wandurraga, Z. N., Igual, M., García-Segovia, P., \& Martínez-Monzó, J. (2019). Effect of microalgae addition on mineral content, colour and mechanical properties of breadsticks. Food \& Function, 10(8), 4685-4692. doi: 10.1039/c9fo00286c

Yang, S. C., \& Lai, L. S. (2003). Dressings and Mayonnaise. Chemistry of the Products. In B. Caballero, P. Finglas, \& F. Toldra (Eds.), Encyclopedia of Food and Health (2nd ed., pp. 1898-1903). Academic Press. doi: 10.1016/B0-12-227055-X/00364-3

Yildirim, M., Sumnu, G., \& Sahin, S. (2016). Rheology, particle-size distribution, and stability of low-fat mayonnaise produced via double emulsions. Food Science and Biotechnology, 25(6), 1613-1618. doi: 10.1007/s10068-016-0248-7 


\section{Chapter 5}

\section{Influence of microalgae addition in formulation on colour, texture, and extrusion parameters of corn snacks}

This chapter has been published as:

Uribe-Wandurraga, Z. N., Igual, M., García-Segovia, P., \& Martínez-

Monzó, J. (2020). Influence of microalgae addition in formulation on colour, texture, and extrusion parameters of corn snacks. Food Science and Technology International. doi: $10.1177 / 1082013220924178$ 



\section{Abstract}

Extrusion is a more and more popular technique for snack production using interesting raw ingredients, to produce snacks improving their nutritional value. The aim of this study was to obtain corn extrudates enriched with different concentration levels of Arthrospira platensis (Spirulina), Chlorella vulgaris, and Nannochloropsis gaditana biomass and to compare their expansion parameters and physicochemical properties with control corn extrudates. Expansion, physicochemical, and compositional parameters were analysed. Microalgae addition to formulations gave extruded snacks and provoked no major changes compared to control corn extrudate. Addition of microalgae in extrudates formulation implies a slight reduction of water absorption index, swelling index, bulk density and hygroscopicity and a slight increase in water solubility index, expansion index and porosity. Noticeable changes for the addition of microalgae changed the extruded snack from translucent to opaque and total colour difference values of the extrudates were perceptible to the human eye. 


\section{Introduction}

Extrusion processing is a thermally efficient process using high temperature and short time heat treatment and intense shearing under pressure to make a range of food products including expanded snacks, breakfast cereals, and other ready-to-eat textured foods (Chan et al., 2019). The extrusion process, compared with other methods to produce snacks as frying, allows production of low-fat snacks and prompts the formation of resistant starch, which makes no caloric contribution and behaves physiologically like dietary fibre (Larrea et al., 2005). As a result, extrusion is progressively more popular process, using raw materials containing protein, starch, and dietary fibre aids snack creation with increased nutritional value (Šárka et al., 2015). Thus, microalgae can be a good raw material presenting high nutritive and functional value.

Microalgal biomass is an advantageous source of pigments, vitamins, proteins, fatty acids, sterols, polysaccharides, amongst other biologically active compounds presenting potential health benefits (Gouveia et al., 2007). Nowadays, there are many commercial applications for microalgae in food. For example, microalgae can be used to enhance the nutritional value of pasta (Fradique et al., 2010), cookies (Batista et al., 2017) and breadsticks (UribeWandurraga et al., 2019) in which breadsticks enrichment with $1.5 \%$ of Chlorella or Spirulina was classed as foods "high in iron and selenium".

Incorporating microalgae in food formulations offers interesting nutritional and functional insight, it is necessary to evaluate its effect on extruded products under process, because of the impact characteristics of the raw materials can have. Among the most important properties of food products obtained through high temperature and low moisture extrusion cooking is expansion.

Extrudate expansion is a complex phenomenon influenced by food composition and extrusion processing parameters (Patil et al., 2005). Moreover, expansion related parameters (water absorption, water solubility, crispiness and crunchiness) are important to determine the quality of the extruded products and their characteristics (Morales et al., 2015). The main studied parameters of the extrudates are the ratio of diameter square, also known as sectional expansion index, the specific density, bulk density, and porosity (Berrios et al., 2004). Besides, there are other physical properties of extrudates such as swelling 
index, water activity, hygroscopicity, colour, and texture which determinate the extrudates quality.

The aim of this study was to produce corn extrudates enriched with different quantities of Arthrospira platensis (Spirulina), Chlorella vulgaris, and Nannochloropsis gaditana biomass to compare expansion parameters and the physicochemical properties of the extrudates with a control corn extrudate.

\section{Material and methods}

\section{Raw material}

Corn grits were supplied by Molendum Ingredients S.L. (Spain). Freeze-dried Arthrospira platensis (Spirulina), Chlorella vulgaris, and Nannochloropsis gaditana biomass were supplied from AlgaEnergy S.A. (Madrid, Spain).

\section{Formulations and extrusion processing}

Corn grits (CM) were mixed manually using a whisk, with microalgae (Spirulina, Chlorella, and Nannochloropsis) powder at 0.5, 1, and 1.5\%, producing different mixtures. Mixtures obtained (M): CM (Control); S0.5M, S1M, and S1.5M for Spirulina (S) at 0.5, 1, and 1.5\% respectively; $\mathrm{CH} 0.5 \mathrm{M}, \mathrm{CH} 1 \mathrm{M}$ and $\mathrm{CH} 1.5 \mathrm{M}$ for Chlorella $(\mathrm{CH})$ at $0.5,1$, and $1.5 \%$ respectively; and N0.5M, N1M, and N1.5M for Nannochloropsis $(\mathrm{N})$ at $0.5,1$, and $1.5 \%$ respectively.

Extrusion was performed using a single-screw laboratory extruder (Kompaktextruder KE 19/25; Brabender, Duisburg, Germany) with a barrel diameter of $19 \mathrm{~mm}$ and a length:diameter ratio of 25:1. The extruder was operated at a 3:1 compression ratio, loaded with prepared corn samples at a constant dosing speed of $18 \mathrm{rpm}$ (feed rate range, 1.58 $\mathrm{kg} / \mathrm{h}$ ). The screw was rotated at a constant $150 \mathrm{rpm}$, temperatures of barrel sections $1-4$ were set to $25,70,170$, and $175{ }^{\circ} \mathrm{C}$, respectively; and the nozzle diameter was $3 \mathrm{~mm}$. Motor torque, screw speed, barrel temperatures, and melt pressure were monitored using Extruder Winext software (Brabender). Calculated specific mechanical energy (SME) of corn extrusion ranged from 1400 to $1600 \mathrm{~kJ} / \mathrm{kg}$. Extrudates obtained, CE (Control); S0.5E, S1E, and S1.5E for Spirulina; CH0.5E, CH1E and CH1.5E for Chlorella; and N0.5E, N1E, and N1.5E for Nannochloropsis, were cooled at $20^{\circ} \mathrm{C}$ and sealed in plastic bags for further analysis. 


\section{Analysis}

\section{Water content and water activity}

Water content $\left(\mathrm{x}_{\mathrm{w}}\right)$ (g water/100 $\mathrm{g}$ sample), for both mixtures and extruded samples, was determined by vacuum oven drying at $105{ }^{\circ} \mathrm{C}$ until constant weight (AOAC, 2005). Water activity $\left(a_{w}\right)$ of the extruded samples was measured using the AquaLab PRE LabFerrer equipment (Pullman, USA) at $20^{\circ} \mathrm{C}$. Samples were analysed in triplicate.

\section{Particle size distribution}

Formulated flours' particle size distribution was determined by applying the laser diffraction method and Mie theory, following the ISO 13320 standard (ISO, 2009), using a particle size analyser (Malvern Instruments Ltd., Mastersizer 2000, UK) equipped with a dry sample dispersion unit (Malvern Instruments Ltd., Scirocco 2000). Laser diffraction reports the volume of material of a given size since the light energy reported by the detector system is proportional to the volume of material present. The volume (\%) against particle size $(\mu \mathrm{m})$ was recorded and the size distribution was characterised by the volume mean diameter ( $D$ $[4,3])$. The standard percentiles $d(0.1), d(0.5)$, and $d(0.9)$ of the size of particle below which $10 \%, 50 \%$, and $90 \%$ of the sample lies, were also considered for formulated flour characterisation. These parameters were estimated using Mastersizer 2000 software (version 5.6) considering the particle diameter.

\section{Expansion index (SEI)}

Diameter of 20 extruded product pieces $\left(D_{\mathrm{e}}\right)$ were measured for each sample, with an electronic Vernier calliper (Comecta S.A., Spain). The equation 1 was used to obtain the surface expansion index of die (SEI) (Patil et al., 2005),

$$
S E I=\frac{D_{e}{ }^{2}}{D_{d}{ }^{2}}
$$

where $D_{d}$ is die diameter $(3 \mathrm{~mm})$.

\section{Bulk density and porosity}

The porosity $(\varepsilon)$, or percentage of air volume related to the total volume, was calculated from the true $(\rho)$ and bulk $\left(\rho_{b}\right)$ densities according to equation 2 . 


$$
\varepsilon=\frac{\left(\rho-\rho_{b}\right)}{\rho}
$$

The real density of the extruded products was determined using a helium pycnometer (AccPyc 1330, Micromeritics, Norcross, USA). For the purposes of bulk density ( $\left.\rho_{b}\right)$ determination, measurements were taken 15 times where the height and diameter of cylinders were measured with an electronic Vernier calliper (Comecta S.A., Spain) and samples were weighed with a precision scale $( \pm 0.001 \mathrm{~g})$ (Mettler Toledo, Switzerland).

\section{Water absorption index (WSI), water solubility index (WAI), and swelling index (SWE)}

The water solubility index (WSI) and water absorption index (WAI) were determined by the method of Singh et al. (1997). The extrudates were first milled to a mean particle size of 180-250 $\mu \mathrm{m}$. A $2.5 \mathrm{~g}$ sample was dispersed in $25 \mathrm{~g}$ of distilled water, using a rod to break up any lumps. After stirring for 30 min using a magnetic stirrer, the dispersions were rinsed into tared $50 \mathrm{ml}$ centrifuge tubes, made up to $32.5 \mathrm{~g}$ and centrifuged at $3000 \mathrm{~g}$ for $10 \mathrm{~min}$. The supernatant was decanted for determination of its dissolved solids content and the sediment was weighed.

WAI and WSI were calculated according to equation 3 and 4, respectively.

$$
\begin{gathered}
\text { WAI }=\frac{\text { weight of sediment }}{\text { weight of dry solids }} \\
\text { WSI }(\%)=\frac{\text { weight of dissolved solids in supernatant }}{\text { weight of dry solids }} \times 100
\end{gathered}
$$

The swelling index (SWE) was measured using the bed volume technique. Samples were accurately weighed $(1 \mathrm{~g})$ and transferred to a calibrated cylinder and $10 \mathrm{ml}$ of distilled was added. Cylinders were left to stand undisturbed for $18 \mathrm{~h}$ at ambient temperature. The bed volume was recorded and expressed as $\mathrm{mm}$ of swollen sample per $\mathrm{g}$ of dry initial sample (Robertson et al., 2000). 


\section{Hygroscopicity}

Samples (approximately $0.5 \mathrm{~g}$ ) of each extruded sample were placed at $25^{\circ} \mathrm{C}$ in a petri dish, in an airtight plastic container containing with $\mathrm{Na}_{2} \mathrm{SO}_{4}$ saturated solution ( $\left.81 \% \mathrm{RH}\right)$ at the bottom. After 2, 5, and 7 days each sample was weighed and hygroscopicity $(\mathrm{Hg})$ was expressed as $\mathrm{g}$ of water gained per $100 \mathrm{~g}$ dry solids (Cai et al., 2000).

\section{Optical properties}

Translucency and CIE* L*a*b* colour coordinates were determined from the surface reflectance spectra obtained between 400 and $700 \mathrm{~nm}$, when measuring on white and black backgrounds, considering standard light source D65 and a standard observer $10^{\circ}$ (Minolta spectrophotometer CM-3600d, Japan). Measurements were taken 10 times on the extruded samples.

The translucency of the samples was determined by applying the Kubelka-Munk theory for multiple scattering of the reflection spectra (Hutchings, 1999; Talens et al., 2002). This theory assumes that the light flux passing through the sample is related to the ratio of absorbed versus scattered light.

Spectral distribution of Kubelka-Munk coefficient (ratio between light absorption $(\mathrm{K})$ and scattering (S)) was obtained as follows:

$$
\begin{gathered}
\frac{K}{S}=\frac{\left(1-R_{\infty}\right)^{2}}{2 \cdot R_{\infty}} \\
R_{\infty}=a-b \\
a=\frac{1}{2}\left(R+\frac{R_{o}-R+R_{g}}{R_{o} \cdot R_{g}}\right) \\
b=\left(a^{2}-1\right)^{1 / 2}
\end{gathered}
$$

where $R_{\infty}$ is the reflectance of an infinitely thick layer of the material; $R$ and $R_{0}$ are the reflectance of sample over white and ideally black backgrounds, respectively; and $R_{g}$ is the 
reflectance of the white background. For translucent samples, $R$ and $R_{0}$ take different values. In these cases, to obtain CIEL*a*b* colour coordinates, $\mathrm{R}_{\infty}$ was calculated. When no translucency was observed, $\mathrm{R}$ was used to obtain the CIEL*a*b* colour values.

The calculated reflectance of an infinitely thick layer of the material was used to obtain the coordinates $C I E * L^{*} a * b$, the hue $\left(h^{\circ}{ }_{a b}\right)$ and the chroma $\left(C^{*}{ }_{a b}\right)$ colour attributes. The total colour difference $(\Delta \mathrm{E})$ of extrudates was calculated regarding the control sample.

\section{Texture}

The texture of extrudates was measured using a TA-XT2 Texture Analyser (Stable Micro Systems Ltd, Godalming, UK) and software, Texture Exponent (version 6.1.12.0). A puncture test determines the force required to push a cylindrical puncturing device or probe into an extrudate using the texture analyser (Desrumaux et al., 1998). A $2 \mathrm{~mm}$ diameter cylinder was used and the cross-head speed was kept at $0.6 \mathrm{~mm} / \mathrm{s}$ and penetration distance, $3 \mathrm{~cm}$; measurements were taken 10 times. The software recorded and analysed the force-time curve and gave an area under the curve plot, which represented work (S) done for a given time of displacement $(t)$ of the puncturing device. The force drop $(F)$, compared to each peak represented the local resistance of cell walls and the number of peaks $\left(\mathrm{N}_{0}\right)$ were also recorded. These parameters were used to calculate the average puncturing force $\left(F_{\mathrm{mp}}\right)$ (equation 9 ), average specific force of structural ruptures $\left(\mathrm{F}_{\mathrm{sr}}\right)$ (equation 10), spatial frequency of structural ruptures $\left(\mathrm{N}_{\mathrm{sr}}\right)$ (equation 11 ) where $\mathrm{d}$ correspond to the probe travel distance, and crispness work $\left(W_{c}\right)$ (equation 12) according to the following equations.

$$
\begin{gathered}
F_{m p}=\frac{S}{t} \\
F_{s r}=\operatorname{sum} \text { of } \frac{F}{N_{o}} \\
N_{s r}=\frac{N_{o}}{d} \\
W_{c}=\frac{F_{m p}}{N_{s r}}
\end{gathered}
$$




\section{Statistical analysis}

To evaluate the differences between extruded samples, an analysis of variance (ANOVA), with a confidence level of 95\% $(p<0.05)$ (Statgraphics Centurion XVII Software, version 17.2.04) was applied. A correlation analysis among the characteristic parameters of extrudates, the studied parameters of mixture flours, and textural properties of extrudates produced in the study, with a $95 \%$ significance level, was conducted (Statgraphics Centurion XVII).

\section{Results and discussion}

\section{Particle size of mixtures}

There are few published studies on the influence of food particle size and distribution on processing and extrudate characteristics. For example, Mohamed (1990) using a singlescrew extruder on corn grits of $402 \mu \mathrm{m}$ to $618 \mu \mathrm{m}$ average particle sizes found a decrease of melt expansion, and an extrudate hardness with increasing particle size.

Table 1 shows the particle size of mixtures, characterised by the volume mean diameter and standard percentiles values and mixture's water content. All the samples' trends are similar except for S0.5.M, S1M, and S1.5M.

Table 1. Mean values (and standard deviations) of water content $\left(x_{w}, g_{w} / 100 \mathrm{~g}\right)$, volume mean diameter $(\mu \mathrm{m}) \mathrm{D}[4,3]$, standard percentiles $(\mu \mathrm{m}) \mathrm{d}(0.1), \mathrm{d}(0.5)$, and $\mathrm{d}(0.9)$ of used mixture flours.

\begin{tabular}{cccccc}
\hline & $\mathbf{x}_{\mathbf{w}}$ & $\mathbf{D}[\mathbf{4 , 3}]$ & $\mathbf{d}(\mathbf{0 . 1})$ & $\mathbf{d}(\mathbf{0 . 5})$ & $\mathbf{d}(\mathbf{0 . 9})$ \\
\hline CM & $9.4(0.3)^{\mathrm{c}}$ & $503(5)^{\mathrm{c}}$ & $271(14)^{\mathrm{b}}$ & $480(6)^{\mathrm{c}}$ & $784(24)^{\mathrm{c}}$ \\
S0.5M & $9.7(0.2)^{\mathrm{abc}}$ & $509(2)^{\mathrm{bc}}$ & $271(2)^{\mathrm{b}}$ & $485.5(1.5)^{\mathrm{bc}}$ & $798(3)^{\mathrm{bc}}$ \\
S1M & $9.68(0.09)^{\mathrm{abc}}$ & $509(3)^{\mathrm{bc}}$ & $272(3)^{\mathrm{b}}$ & $487(3)^{\mathrm{bc}}$ & $798(4)^{\mathrm{bc}}$ \\
S1.5M & $9.71(0.07)^{\mathrm{ab}}$ & $540(24)^{\mathrm{a}}$ & $305(23)^{\mathrm{a}}$ & $513(19)^{\mathrm{a}}$ & $826(26)^{\mathrm{a}}$ \\
CH0.5M & $9.657(0.103)^{\mathrm{abc}}$ & $509(4)^{\mathrm{bc}}$ & $274(3)^{\mathrm{b}}$ & $486(4)^{\mathrm{bc}}$ & $796(5)^{\mathrm{bc}}$ \\
CH1M & $9.6(0.3)^{\mathrm{abc}}$ & $511(3)^{\mathrm{bc}}$ & $274(2)^{\mathrm{b}}$ & $489(4)^{\mathrm{b}}$ & $799(6)^{\mathrm{b}}$ \\
CH1.5M & $9.71(0.04)^{\mathrm{ab}}$ & $514(3)^{\mathrm{b}}$ & $279(3)^{\mathrm{b}}$ & $491(3)^{\mathrm{b}}$ & $800(4)^{\mathrm{b}}$ \\
N0.5M & $9.604(0.107)^{\mathrm{bc}}$ & $512(2)^{\mathrm{bc}}$ & $281(2)^{\mathrm{b}}$ & $488(2)^{\mathrm{b}}$ & $793(3)^{\mathrm{b}}$ \\
N1M & $9.883(0.108)^{\mathrm{a}}$ & $508(4)^{\mathrm{bc}}$ & $272(5)^{\mathrm{b}}$ & $486(4)^{\mathrm{bc}}$ & $795(4)^{\mathrm{bc}}$ \\
N1.5M & $9.58(0.06)^{\mathrm{bc}}$ & $508(3)^{\mathrm{bc}}$ & $272(3)^{\mathrm{b}}$ & $486(3)^{\mathrm{bc}}$ & $795(4)^{\mathrm{bc}}$ \\
\hline
\end{tabular}

The same letter in superscript within column indicates homogeneous groups established by ANOVA ( $p<$ 0.05). 
Microalgae addition increases significantly $(p<0.05)$ the volume mean diameter (D [4.3]) of mixtures with Spirulina and Chlorella addition at $1.5 \%$. Spirulina addition at $1.5 \%$ provokes a significant displacement of volume particle size distributions to a higher particle size. S1.5M showed a higher percent of volume at $500 \mu \mathrm{m}$ of particle size. However, Nannochloropsis mixtures did not show significant differences $(p>0.05)$ in particle size with respect to control mixtures. $\mathrm{S} 1.5 \mathrm{M}$ showed the highest significant $(p<0.05)$ differences compared with the control, followed by $\mathrm{CH} 1.5 \mathrm{M}$. Values for $d(0.1), d(0.5)$, and $d(0.9)$ presented a similar trend to D[4.3]. Regarding water content (Table 1), CM presented slightly lower values than the other mixtures.

\section{Physicochemical characteristics of extrudates}

The physicochemical properties of the extrudates are direct indicators of the effect on product quality from raw material characteristics and processing variables. Figures 1,2 , and 3 represent water content $\left(x_{w}\right)$, water activity $\left(a_{w}\right)$; water solubility index (WAI), water absorption index (WSI), swelling index (SWE), surface expansion index of die (SEI); bulk density $\left(r_{b}\right)$, porosity $(\varepsilon)$, and hygroscopicity $(\mathrm{Hg})$, respectively.
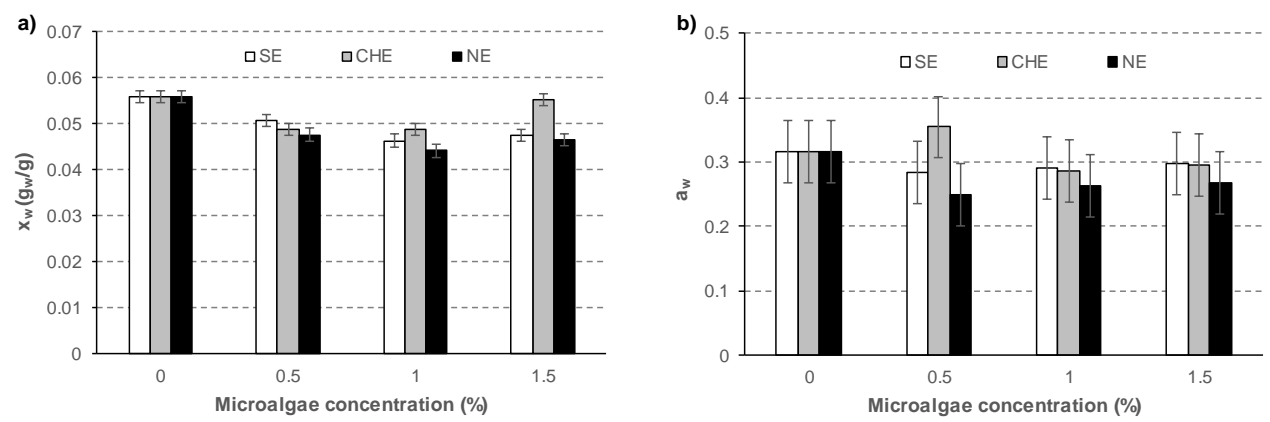

Figure 1. Mean values and LSD (Least Significant Difference) intervals of water content, $x_{w}(a)$ and water activity, $\mathrm{a}_{\mathrm{w}}(\mathrm{b})$ of each extrudate (SE, CHE, and $\mathrm{NE}$ ) according to microalgae concentration (\%).

Water content (Figure 1a) and water activity (Figure 1b) were in the range of low moisture foods. All microalgae formulations showed water content significantly $(p<0.05)$ lower than the control, except to $\mathrm{CH} 1.5 \mathrm{E}$. Moisture losses during extrusion process in samples with microalgae addition were higher that moisture losses in control samples (Table 1). This may be explained by moisture loss at the die is dependent on the vapour pressure inside the air cells and matrix characteristics such as extensibility and water binding, reflecting the degree 
of starch transformation (Karkle et al., 2012). However, there are no significant ( $p>0.05$ ) differences among samples regarding water activity (Figure $1 \mathrm{~b}$ ).

The qualitative characteristics of the extruded products are shown in Figure 2. Water absorption index (WAI) indicates the quantity of water immobilised by the extrudate, while water solubility index (WSI) indicates the quantity of small molecules solubilised in water causing molecular damage in the process (Mezreb et al., 2003). The WAI and WSI can be used to calculate approximately the functional characteristics of foods and predict the behaviour of the materials during processing (De Mesa et al., 2009).

Microalgae addition in formulations in extrudates decreased the WAI (Figure 2a), when the concentrations are high (1.5\%). We believe this trend is because of reduced starch gelatinisation as the starch has depolymerised to some range, consequently losing water absorption capacity (Karkle et al., 2012). Also, these differences could be related to the competition between algae and starch for water during gelatinization, which could be limiting this phenomenon. WSI (Figure $2 b$ ) presented the opposite behaviour to WAI. WSI increased with the addition of microalgae but in NE there were no significant $(p>0.05)$ differences. CHE showed significant differences with respect to the control, and SE only when Spirulina concentrations were 0.5 and $1.5 \%$. Other researchers suggested that increasing WSI is caused by greater shear degradation of starch during extrusion at low moisture conditions (Onyango et al., 2004). WAI and WSI values of control and microalgae extrudates are in the ranges for extrudates food products presented by Oikonomou et al. (2011). The swelling index (Figure 2c), is alike the water holding capacity, determined by the bed volume technique by a static method (Patil et al., 2005). There were no SWE values significantly $(p>0.05)$ higher than the value of the control. S0.5E, N1E and N1.5E showed no significant $(p>0.05)$ differences with the control. However, the rest of the extrudates presented SWE values significantly $(p<0.05)$ lower than the control.

Expansion depends on the food composition, degree of cooking, and melt flow index in the die. Besides, expansion at the die defines the extrudates' final texture (Desrumaux et al., 1998). The expansion ratio and bulk density of extrudates describe the degree of puffing to be put through by the material as it exits the extruder (Keawpeng et al., 2014). Sectional expansion index considers only expansion, in the perpendicular direction to the extrudate flow (Saldanha do Carmo et al., 2019), while bulk density considers expansion in all 
directions (Desta et al., 2019). SEI increased when microalgae were added in the formulations. The effect of concentration was evident in SEI for all concentrations and CHE at 0.5 and $1 \%$; NE was not affected by concentration levels. The extrudate with higher SEI was N0.5E.
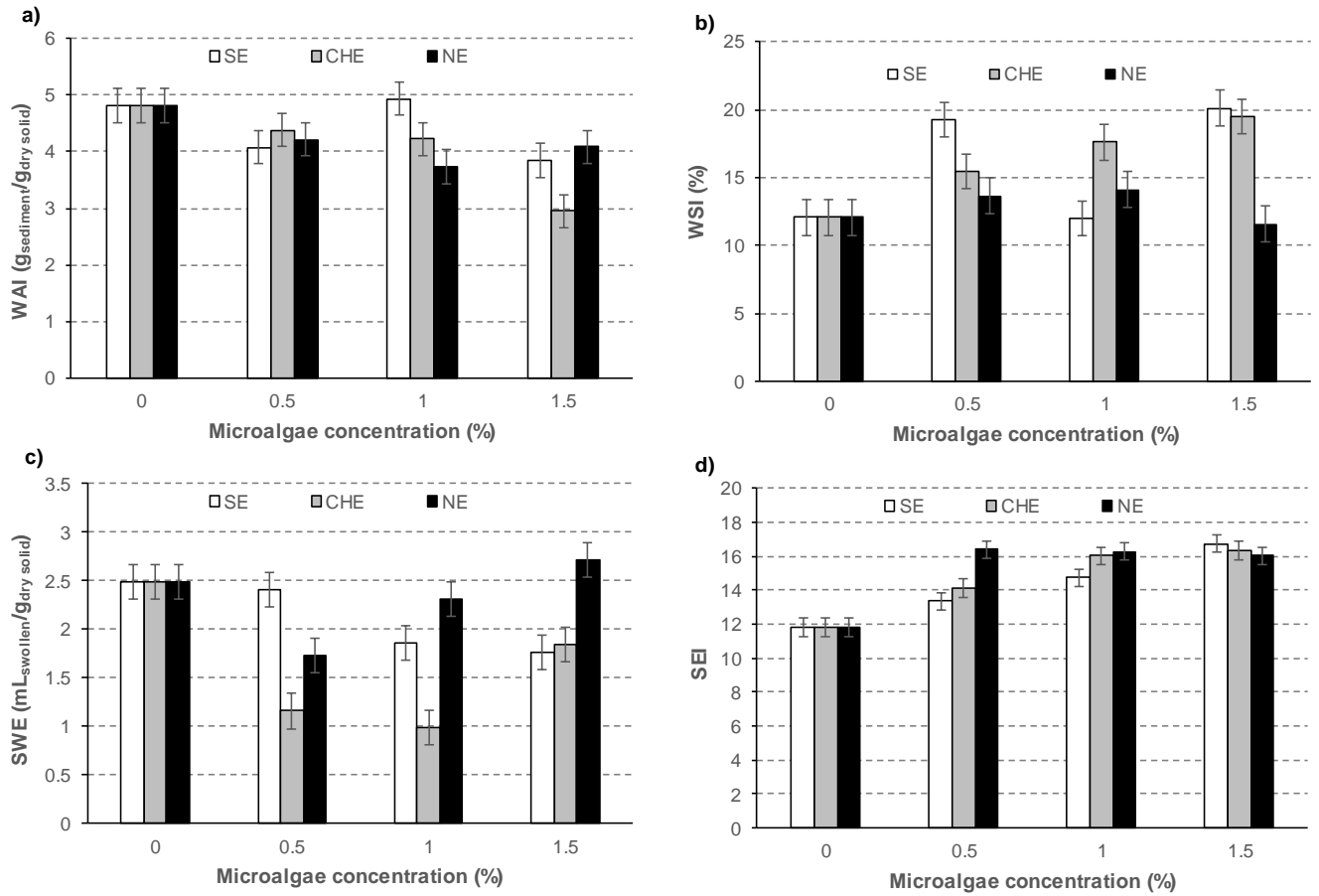

Figure 2. Mean values and LSD (Least Significant Difference) intervals of a) water absorption index, WAI; b) water solubility index, WSI; c) swelling index, SWE; and d) expansion index, SEI of each extrudate ( $\mathrm{SE}, \mathrm{CHE}$, and $\mathrm{NE}$ ) according to microalgae concentration (\%).

Figure 3 shows mean values and LSD intervals of bulk density $\left(\rho_{b}\right)$, porosity $(\varepsilon)$, and hygroscopicity $(\mathrm{Hg})$. Density is a general property of the extrudate, which indicates overall expansion and changes in material parameters plus cell structure, pores, and voids developed as the effect of processing; highly expanded extruded materials show a porous structure. Dullien (1991) reported that the void spaces in extrudates had interconnected pore segments, accessible on both ends; dead-end or blind pore segments, accessible only at one end; and non-interconnected pores, inaccessible pores on the interior of the solid. As a consequence, interconnected and dead-end pores can be observed as open pores whereas non-interconnected pores, as closed pores (Patil et al., 2005). 
The $\rho_{\mathrm{b}}$ decreased significantly $(p<0.05)$ with the use of microalgae in formulations. Furthermore, there was a trend of $\rho_{b}$ decreases with the increase of microalgae concentrations (Figure 3a). The addition of Chlorella or Nannochloropsis in any concentration significantly increased $(p<0.05)$ porosity (Figure $3 b)$. However, the addition of Spirulina at 0.5 and $1 \%$ showed no significant $(p>0.05)$ differences in porosity; at $1.5 \%$ the values increased significantly $(p<0.05)$ (Figure $3 b)$. Seen in Figure 3c, SM hygroscopicity showed no significant $(p<0.05)$ differences in comparison with the control. Nevertheless, CHE and NE presented significant $(p<0.05)$ differences with respect to CE in any microalgae concentration. The less hygroscopic extrudate was $\mathrm{N} 1.5 \mathrm{E}$, with the water gained per $100 \mathrm{~g}$ of dry solid was lower than the rest of the samples.
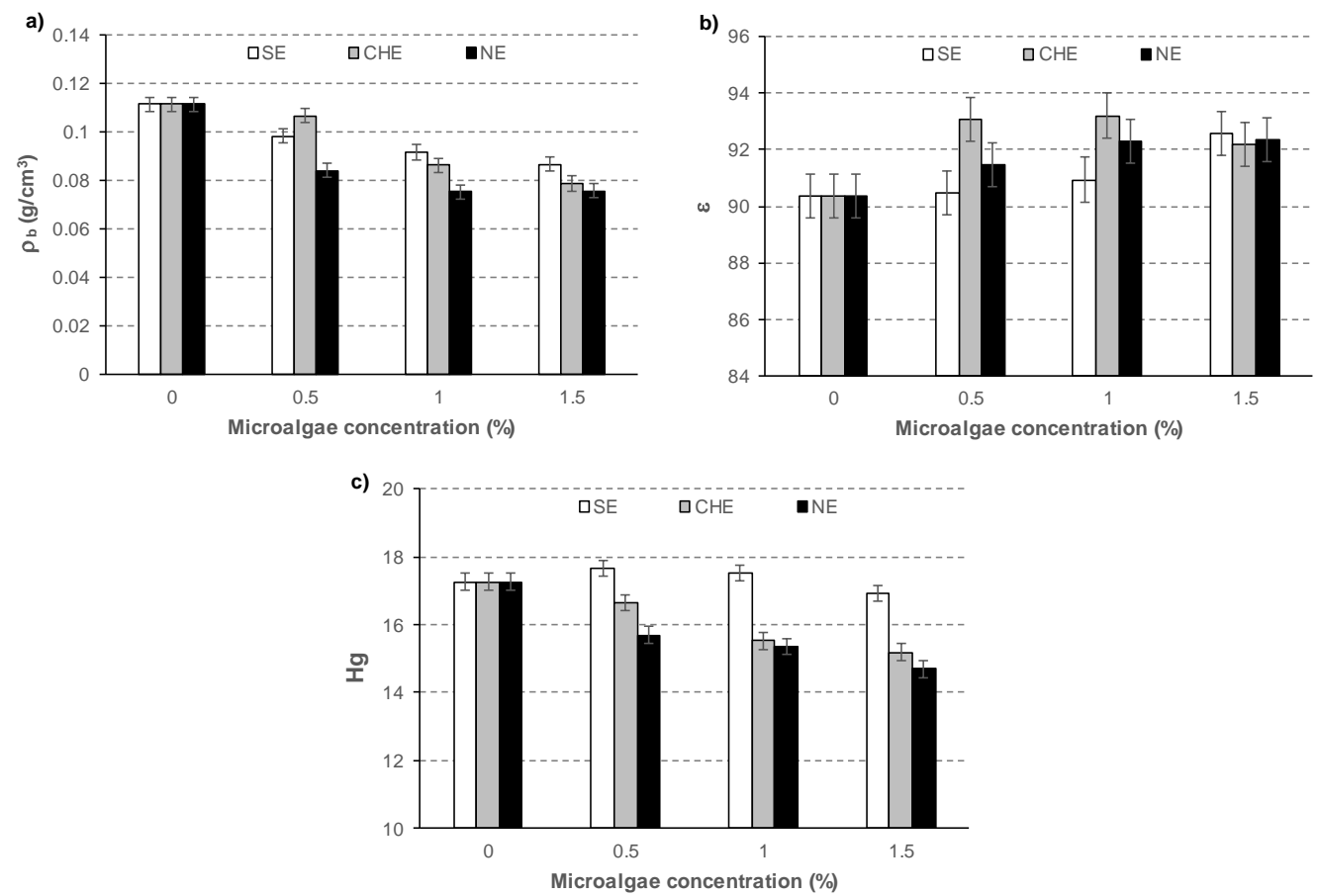

Figure 3. Mean values and LSD (Least Significant Difference) intervals of a) bulk density, $\rho_{b} ; b$ ) porosity, $\varepsilon$; and c) hygroscopicity, $\mathrm{Hg}$ of each extrudate (SE, CHE, and $\mathrm{NE}$ ) according to microalgae concentration (\%).

Pearson correlation coefficients among studied parameters of extruded products were obtained. There were significant $(p<0.05)$ correlations among SEI with $\mathrm{x}_{\mathrm{w}}(-0.5161)$, WAI $(-0.5123)$, hygroscopicity $(-0.6228), \rho_{b}(-0.8172)$, and $\varepsilon(0.6221)$. When the values of SEI are greater, the values of $x_{w}$, WAI, hygroscopicity, $\rho_{b}$ are lower but $\varepsilon$ is greater. Bulk density 
$\left(\rho_{b}\right)$ presented the highest Pearson coefficient with SEI $(-0.8172)$ and showed a high correlation with $\mathrm{Hg}(0.7223)$; porosity showed a reverse correlation with $\mathrm{Hg}(-0.5472)$.

When the corn flour was combined with microalgae, the diameter of extrudates increases but the perimeter of extrudates with microalgae is more irregular. This fact is because of the pore size, which is bigger in snacks with microalgae than those of the control sample (Figure 4).

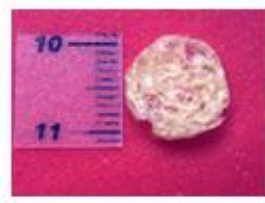

(a)

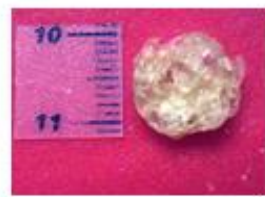

(d)

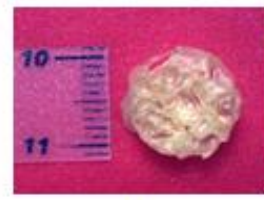

(g)

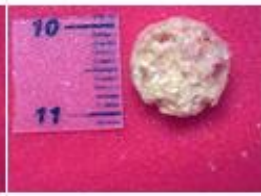

(b)

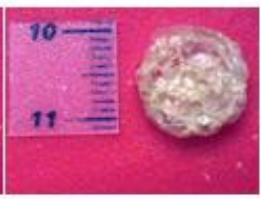

(c)

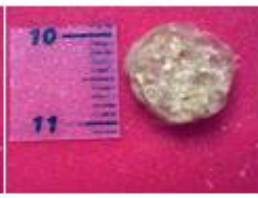

(e)

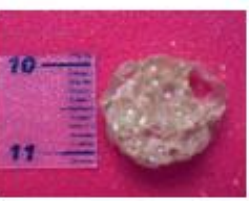

(f)

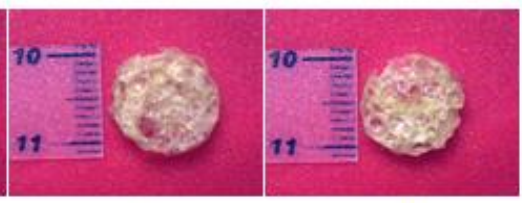

(h)

(i)|

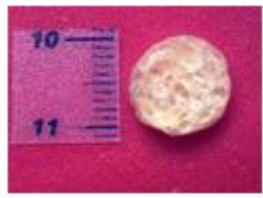

(j)

Figure 4. Transversal section pictures of each extrudate: S0.5E (a), S1E (b), S1.5E (c), CH0.5E (d), CH1E (e), CH1.5E (f), N0.5E (g), N1E (h), N1.5E (i) and CE (j).

\section{Optical properties of extrudates}

To quantify the snack translucency, the analysis of spectral distribution of Kubelka-Munk coefficients obtained from reflectance spectra was conducted; the greater the $\mathrm{K} / \mathrm{S}$ values, the greater the product translucency (Hutchings, 1999). From the reflection spectra in the visible range, the colour coordinates CIE* ${ }^{*} a * b *$ and the values of the chroma $(C * a b)$ and 
tone $\left(\mathrm{h}_{\mathrm{ab}}^{\circ}\right)$ were obtained in control extrudates. Samples with microalgae presented no differences between measurements on white and black backgrounds so they were not translucent. The addition of microalgae changed the extruded snack from translucent to opaque.

Here, the colour coordinates CIE*L*a*b* were obtained directly from the equipment. Table 2 shows $\mathrm{L}^{*}, \mathrm{a}^{*}, \mathrm{~b}^{*}, \mathrm{C}^{*}{ }_{\mathrm{ab}}, \mathrm{h}_{\mathrm{ab}}^{\circ}$, and $\Delta \mathrm{E}$ of studied extrudates. The microalgae addition in extrudate mixtures decreases luminosity $\left(\mathrm{L}^{*}\right)$ of the product. Higher Spirulina or Chlorella concentrations in extrudates provoked lower L* coordinates, however, Nannochloropsis concentration effected no change for $L^{*}$. The incorporation of Nannochloropsis did not significantly $(p>0.05)$ effect $\mathrm{a}^{*}, \mathrm{~b}^{*}$, and $\mathrm{C}^{*}{ }_{\mathrm{ab}}$ parameters, independently of microalgae addition concentration. Extrudates with Spirulina or Chlorella in their composition showed values of $\mathrm{a}^{*}$, significantly $(p<0.05)$ lower than the control, having less reddish colour. When increasing the Spirulina or Chlorella concentration a* decreased but $\mathrm{h}_{\mathrm{ab}}^{\circ}$ increased slightly. The $\mathrm{h}_{\mathrm{ab}}^{\circ}$ values are very near to $90^{\circ}$, so the samples are mainly yellow as can be seen in Figure 4. The higher tone was present in the $\mathrm{CH} 1.5 \mathrm{E}$ sample since its a* value was lower. The values of $\mathrm{C}^{*}{ }_{\mathrm{ab}}$ and $\mathrm{b}^{*}$ are similar because $\mathrm{a}^{*}$ values are approximate to 0 . The total colour difference values of the extrudates are $\Delta \mathrm{E}>3$ and is considered humanly perceptible (Bodart et al., 2008). As the other colour parameters, concentration effects are seen with Spirulina and Chlorella, however, this effect is not evident in NE.

Table 2. Mean values (and standard deviations) of colour coordinates $\left(\mathrm{L}^{*}, \mathrm{a}^{*}, \mathrm{~b}^{*}, \mathrm{C}^{*} \mathrm{ab}\right.$, and $\left.\mathrm{h}_{\mathrm{ab}}^{\circ}\right)$ and total colour differences $(\Delta \mathrm{E})$.

\begin{tabular}{ccccccc}
\hline & $\mathbf{L}^{*}$ & $\mathbf{a}^{*}$ & $\mathbf{b}^{*}$ & $\mathbf{C}_{\text {ab }}$ & $\mathbf{h}_{\mathrm{ab}}$ & $\mathbf{\Delta E}$ \\
\hline CE & $53(4)^{\mathrm{a}}$ & $1.7(0.4)^{\mathrm{a}}$ & $29.1(1.5)^{\mathrm{a}}$ & $29.1(1.5)^{\mathrm{a}}$ & $86.6(0.7)^{\mathrm{d}}$ & - \\
S0.5E & $51(3)^{\mathrm{a}}$ & $1.2(0.5)^{\mathrm{b}}$ & $26(2)^{\mathrm{abc}}$ & $26(2)^{\mathrm{bcd}}$ & $87.5(0.9)^{\mathrm{c}}$ & $5(2)^{\mathrm{e}}$ \\
S1E & $47(5)^{\mathrm{c}}$ & $0.7(0.5)^{\mathrm{c}}$ & $24(2)^{\mathrm{ef}}$ & $24(2)^{\mathrm{fg}}$ & $88.46(1.02)^{\mathrm{b}}$ & $9(4)^{\mathrm{b}}$ \\
S1.5E & $43(3)^{\mathrm{d}}$ & $0.4(0.4)^{\mathrm{c}}$ & $22(2)^{\mathrm{g}}$ & $22(2)^{\mathrm{g}}$ & $89.1(0.9)^{\mathrm{b}}$ & $12(2)^{\mathrm{a}}$ \\
CH0.5E & $49(3)^{\mathrm{b}}$ & $0.6(0.7)^{\mathrm{c}}$ & $25(2)^{\mathrm{bcd}}$ & $25(2)^{\mathrm{cde}}$ & $88.7(1.4)^{\mathrm{b}}$ & $6.5(1.4)^{\mathrm{de}}$ \\
CH1E & $42(4)^{\mathrm{d}}$ & $0.5(0.6)^{\mathrm{c}}$ & $25(3)^{\mathrm{cd}}$ & $25(3)^{\mathrm{de}}$ & $89.0(1.2)^{\mathrm{b}}$ & $12(3)^{\mathrm{a}}$ \\
CH1.5E & $41(5)^{\mathrm{d}}$ & $-0.1(0.6)^{\mathrm{d}}$ & $24(3)^{\mathrm{de}}$ & $24(3)^{\mathrm{ef}}$ & $90.3(1.3)^{\mathrm{a}}$ & $13(5)^{\mathrm{a}}$ \\
N0.5E & $47(5)^{\mathrm{bc}}$ & $1.5(0.5)^{\mathrm{a}}$ & $26(2)^{\mathrm{ab}}$ & $26(2)^{\mathrm{bc}}$ & $86.8(0.9)^{\mathrm{d}}$ & $7(3)^{\mathrm{cd}}$ \\
N1E & $46(6)^{\mathrm{c}}$ & $1.5(0.8)^{\mathrm{a}}$ & $27(3)^{\mathrm{a}}$ & $27(3)^{\mathrm{b}}$ & $86.9(1.3)^{\mathrm{cd}}$ & $8(5)^{\mathrm{bcd}}$ \\
N1.5E & $46(5)^{\mathrm{c}}$ & $1.3(0.7)^{\mathrm{ab}}$ & $26(3)^{\mathrm{abc}}$ & $26(3)^{\mathrm{bcd}}$ & $87.2(1.2)^{\mathrm{cd}}$ & $8(4)^{\mathrm{bc}}$ \\
\hline
\end{tabular}

The same letter in superscript within column indicates homogeneous groups established by ANOVA $(p<$ 0.05). 


\section{Textural characteristics of extrudates}

Texture is very important for ready-to-eat snack products, where crunchiness is a desirable attribute (Patil et al., 2005). Texture parameters studied are showed in Table 3. Crispness work $\left(W_{c}\right)$, describes the work required to fracture one pore or a group of pores and can be interpreted as the sensory parameter of fracturability. Average puncturing force $\left(F_{m p}\right)$ and average specific force of structural ruptures $\left(\mathrm{F}_{\mathrm{sr}}\right)$ of extruded products are usually associated with the sensory perception of hardness during chewing, which is defined as the force to compress a substance between the molar teeth in the case of solids (Azzollini et al., 2018). Spatial frequency of ruptures $\left(\mathrm{N}_{\mathrm{sr}}\right)$ describes the number of fracture events occurring during puncture and $\left(\mathrm{N}_{0}\right)$ is the number of fractures along the assay.

Table 3. Mean values (and standard deviations) of number of peaks $\left(\mathrm{N}_{\mathrm{o}}\right)$, average puncturing force $\left(F_{\mathrm{mp}}\right)$, average specific force of structural ruptures $\left(\mathrm{F}_{\mathrm{s}}\right)$, spatial frequency of structural ruptures $\left(\mathrm{N}_{\mathrm{sr}}\right)$, and crispness work $\left(\mathrm{W}_{\mathrm{c}}\right)$ of extrudates.

\begin{tabular}{cccccc}
\hline & $\mathbf{W}_{\mathbf{c}}(\mathbf{N} \cdot \mathbf{m m})$ & $\mathbf{N}_{\mathbf{s r}}(\mathbf{m} / \mathbf{m})$ & $\mathbf{F}_{\mathbf{s}}(\mathbf{N})$ & $\mathbf{F}_{\mathbf{m p}}(\mathbf{N})$ & $\mathbf{N}_{\mathbf{0}}$ \\
\hline CE & $0.15(0.02)^{\mathrm{a}}$ & $12.070(1.012)^{\mathrm{a}}$ & $2.2(0.2)^{\mathrm{a}}$ & $1.8(0.2)^{\mathrm{a}}$ & $131(11)^{\mathrm{ab}}$ \\
S0.5E & $0.12(0.02)^{\mathrm{bc}}$ & $11.3(0.9)^{\mathrm{ab}}$ & $1.8(0.2)^{\mathrm{bc}}$ & $1.39(0.13)^{\mathrm{bc}}$ & $131(9)^{\mathrm{ab}}$ \\
S1E & $0.13(0.03)^{\mathrm{bc}}$ & $10.83(1.04)^{\mathrm{b}}$ & $2.0(0.5)^{\mathrm{ab}}$ & $1.6(0.4)^{\mathrm{ab}}$ & $129(18)^{\mathrm{ab}}$ \\
S1.5E & $0.12(0.01)^{\mathrm{bcd}}$ & $9.424(1.012)^{\mathrm{cde}}$ & $1.57(0.14)^{\mathrm{cd}}$ & $1.12(0.19)^{\mathrm{de}}$ & $122(17)^{\mathrm{ab}}$ \\
CH0.5E & $0.10(0.01)^{\mathrm{d}}$ & $11.2(0.9)^{\mathrm{ab}}$ & $1.50(0.17)^{\mathrm{cde}}$ & $1.13(0.13)^{\mathrm{de}}$ & $135(11)^{\mathrm{a}}$ \\
CH1E & $0.10(0.02)^{\mathrm{d}}$ & $8.9(1.3)^{\mathrm{de}}$ & $1.30(0.15)^{\mathrm{e}}$ & $0.93(0.17)^{\mathrm{e}}$ & $106(18)^{\mathrm{cd}}$ \\
CH1.5E & $0.14(0.02)^{\mathrm{ab}}$ & $8.6(1.4)^{\mathrm{e}}$ & $1.6(0.2)^{\mathrm{cd}}$ & $1.2(0.2)^{\mathrm{cde}}$ & $101(16)^{\mathrm{d}}$ \\
N0.5E & $0.11(0.02)^{\mathrm{cd}}$ & $9.7(0.9)^{\mathrm{cd}}$ & $1.5(0.2)^{\mathrm{de}}$ & $1.06(0.16)^{\mathrm{de}}$ & $118(12)^{\mathrm{bc}}$ \\
N1E & $0.11(0.02)^{\mathrm{cd}}$ & $11.0(0.6)^{\mathrm{ab}}$ & $1.6(0.4)^{\mathrm{cd}}$ & $1.2(0.3)^{\mathrm{cd}}$ & $128(6)^{\mathrm{ab}}$ \\
N1.5E & $0.10(0.02)^{\mathrm{d}}$ & $10.21(1.06)^{\mathrm{bc}}$ & $1.5(0.3)^{\mathrm{cde}}$ & $1.2(0.3)^{\text {cde }}$ & $124(10)^{\mathrm{ab}}$ \\
\hline
\end{tabular}

The same letter in superscript within column indicates homogeneous groups established by ANOVA $(p<$ 0.05).

Higher Spirulina or Chlorella concentrations in formulation show lower values of studied mechanical parameters. However, higher Nannochloropsis concentration in formulation shows higher values of $\mathrm{W}_{\mathrm{c}}, \mathrm{N}_{\mathrm{sr}}, \mathrm{N}_{0}$, and $\mathrm{F}_{\mathrm{mp}}$. S1E was the most like the control in mechanical parameter terms. There are no significant $(p>0.05)$ differences between them with respect to studied extrudates. The Chlorella addition provoked the highest significant $(p<0.05)$ changes of texture in extrudates samples, at 1 and $1.5 \%$. 
The ingredient composition and moisture content of the mix are main factors that affect the texture of the final extrudate. The extruded materials are highly hygroscopic and hence their texture is affected if they are exposed to a humid atmosphere (Patil et al., 2005).

Pearson's statistical correlation analysis was used to prove correlations between the mechanical parameters and the characteristic parameters of extrudates. $F_{s}$ and $F_{m p}$ showed positive correlations with hygroscopicity, being $0.61(p<0.05)$ and $0.60(p<0.05)$, respectively. However, $\mathrm{N}_{\mathrm{sr}}$ was negatively related to SEI $(-0.72, p<0.05)$; when the expansion index is higher, the number of fracture events occurring during puncture is lower, because the pores size is bigger. Alternatively, samples with lower values of expansion index (SEI) presented higher resistance to fracture $\left(\mathrm{W}_{\mathrm{c},}-0.57, p<0.05\right)$ and hardness $\left(\mathrm{F}_{\mathrm{s}},-0.60, p\right.$ $\left.<0.05 ; F_{m p}-0.65, p<0.05\right)$ according negative Pearson correlations, because of a higher compaction of extrudates. According to Pearson correlations, lower values of porosity are related with higher values of $\mathrm{F}_{\mathrm{s}}$ and $\mathrm{F}_{\mathrm{mp}},-0.67$ and $-0.69(p<0.05)$, respectively. Comparable results were obtained by other authors (Chanvrier et al., 2014; Azzollini et al., 2018), showing that force is negatively correlated with porosity fraction when they studied extruded snacks.

\section{Conclusions}

Microalgae addition to formulations for production of extruded snacks provoked no major changes with respect to control corn extrudates. Produced snacks showed expansion parameters and physicochemical properties suitable for this kind of process. The addition of microalgae changed the extruded snack from translucent to opaque. The total colour difference values of extrudates were perceptible to the consumer. In general, addition of microalgae in extrudates formulation implies a reduction of bulk density and hygroscopicity and an increase in porosity. The total colour difference values of extrudates were perceptible to the human eye, producing samples with less luminosity and reddish colour. This effect was less evident in samples with Nannochloropsis. Extrudates with Spirulina or Chlorella in their composition showed greater greenish tone than the control. Higher Spirulina or Chlorella concentrations in formulation show lower values of studied mechanical parameters. Produced snacks showed expansion parameters and physicochemical properties suitable for this kind of process. 


\section{References}

AOAC (2005) Official Methods of Analysis. 18th ed. Association of Official Analytical Chemists; Arlington, VA, USA.

Azzollini, D., Derossi, A., Fogliano, V., Lakemond, C. M. M., \& Severini, C. (2018). Effects of formulation and process conditions on microstructure, texture and digestibility of extruded insect-riched snacks. Innovative Food Science and Emerging Technologies, 45(December 2017), 344-353. doi: 10.1016/j.ifset.2017.11.017

Batista, A. P., Niccolai, A., Fradinho, P., Fragoso, S., Bursic, I., Rodolfi, L., Biondi, N., Tredici, M. R., Sousa, I., \& Raymundo, A. (2017). Microalgae biomass as an alternative ingredient in cookies: Sensory, physical and chemical properties, antioxidant activity and in vitro digestibility. Algal Research, 26(March), 161-171. doi: 10.1016/j.algal.2017.07.017

Berrios, J. de J., Wood, D. F., Whitehand, L., \& Pan, J. (2004). Sodium Bicarbonate and the microestructure, expansion and color of extruded black beans. Journal of Food Processing and Preservation, 28, 321-335. doi: 10.1111/j.1745-4549.2004.24008.x

Bodart, M., de Peñaranda, R., Deneyer, A., \& Flamant, G. (2008). Photometry and colorimetry characterisation of materials in daylighting evaluation tools. Building and Environment. doi: 10.1016/j.buildenv.2007.12.006

Cai, Y. Z., \& Corke, H. (2000). Production and Properties of Spray-dried Amaranthus Betacyanin Pigments E. Journal of Food Science, 65(6), 1248-1252. doi: 10.22323/1.166.0002

Chan, E., Masatcioglu, T. M., \& Koksel, F. (2019). Effects of different blowing agents on physical properties of extruded puffed snacks made from yellow pea and red lentil flours. Journal of Food Process Engineering, 42(3), 1-8. doi: 10.1111/jfpe.12989

Chanvrier, H., Jakubczyk, E., Gondek, E., \& Gumy, J.-C. (2014). Insights into the texture of extruded cereals: Structure and acoustic properties. Innovative Food Science \& Emerging Technologies, 24, 61-68. doi: 10.1016/J.IFSET.2013.11.013

De Mesa, N. J. E., Alavi, S., Singh, N., Shi, Y. C., Dogan, H., \& Sang, Y. (2009). Soy proteinfortified expanded extrudates: Baseline study using normal corn starch. Journal of Food Engineering, 90(2), 262-270. doi: 10.1016/J.JFOODENG.2008.06.032

Desrumaux, A., Bouvier, J. M., \& Burri, J. (1998). Corn grits particle size and distribution effects on the characteristics of expanded extrudates. Journal of Food Science, 63(5), 857-863. doi: 10.1111/j.1365-2621.1998.tb17914.x

Desta, Y., Gabbiye, N., \& Alemu, A. (2019). Advances of Science and Technology. 6th EAI International Conference, ICAST 2018. (Vol. 274). Springer International Publishing. doi: 
10.1007/978-3-030-15357-1

Dullien, F. A. L. (1991). Pore Structure. In Porous Media. Fluid Transport and Pore Structure (Second Ed, pp. 5-115). San Diego, California: Academic Press, INC. doi: 10.1016/b978-012-223651-8.50007-9

Fradique, M., Batista, A. P., Nunes, M. C., Gouveia, L., Bandarra, N. M., \& Raymundo, A. (2010). Incorporation of Chlorella vulgaris and Spirulina maxima biomass in pasta products. Part 1: Preparation and evaluation. Journal of the Science of Food and Agriculture, 90(10), 16561664. doi: $10.1002 /$ jsfa.3999

Gouveia, L., Batista, A. P., Miranda, A., Empis, J., \& Raymundo, A. (2007). Chlorella vulgaris biomass used as colouring source in traditional butter cookies. Innovative Food Science and Emerging Technologies, 8(3), 433-436. doi: 10.1016/j.ifset.2007.03.026

Hutchings, J. B. (1999). Food Color Mechanisms. In Food Colour and Appearance (pp. 453-592). Gaithersburg, Maryland: Aspen Publishers, Inc. doi: 10.1007/978-1-4615-2373-4

ISO, S. I. (2009). ISO 13320. Particle size analysis-laser diffraction methods. ISO Standard International.

Karkle, E. L., Keller, L., Dogan, H., \& Alavi, S. (2012). Matrix transformation in fiber-added extruded products: Impact of different hydration regimens on texture, microstructure and digestibility. Journal of Food Engineering, 108(1), 171-182. doi: 10.1016/J.JFOODENG.2011.06.020

Keawpeng, I., Charunuch, C., Roudaut, G., \& Meenune, M. (2014). The optimization of extrusion condition of phatthalung sungyod rice extrudate: A preliminary study. International Food Research Journal, 21(6), 2299-2304.

Larrea, M., Chang, Y., \& Martínez Bustos, F. (2005). Effect of some operational extrusion parameters on the constituents of orange pulp. Food Chemistry, 89(2), 301-308. doi: 10.1016/J.FOODCHEM.2004.02.037

Mezreb, K., Goullieux, A., Ralainirina, R., \& Queneudec, M. (2003). Application of image analysis to measure screw speed influence on physical properties of corn and wheat extrudates. Journal of Food Engineering, 572), 145-152. doi: 10.1016/S0260-8774(02)00292-3

Mohamed, S. (1990). Factors affecting extrusion characteristics of expanded starch-based products. Journal of Food Processing and Preservation, 14(6), 437-452. doi: 10.1111/j.1745-4549.1990.tb00145.x

Morales, P., Berrios, J. D. J., Varela, A., Burbano, C., Cuadrado, C., Muzquiz, M., \& Pedrosa, M. M. (2015). Novel fiber-rich lentil flours as snack-type functional foods: An extrusion cooking effect on bioactive compounds. Food and Function, 6(9), 3135-3143. doi: 


\subsection{9/c5fo00729a}

Oikonomou, N. A., \& Krokida, M. K. (2011). Literature data compilation of WAI and WSI of extrudate food products. International Journal of Food Properties, 14(1), 199-240. doi: $10.1080 / 10942910903160422$

Onyango, C., Noetzold, H., Bley, T., \& Henle, T. (2004). Proximate composition and digestibility of fermented and extruded uji from maize-finger millet blend. LWT - Food Science and Technology, 378), 827-832. doi: 10.1016/J.LWT.2004.03.008

Patil, R. T., De J. Berrios, J., Tang, J., Pan, J., \& Swanson, B. (2005). Physical Characteristics of Food Extrudates - $A$ Review. St. Joseph, MI: ASAE. doi: https://doi.org/10.13031/2013.19680

Robertson, J. A., de Monredon, F. D., Dysseler, P., Guillon, F., Amado, R., \& Thibault, J.-F. (2000). Hydration Properties of Dietary Fibre and Resistant Starch: a European Collaborative Study. LWT - Food Science and Technology, 33(2), 72-79. doi: 10.1006/FSTL.1999.0595

Saldanha do Carmo, C., Varela, P., Poudroux, C., Dessev, T., Myhrer, K., Rieder, A., Zobel, H., Sahlstrøm, S., \& Knutsen, S. H. (2019). The impact of extrusion parameters on physicochemical, nutritional and sensorial properties of expanded snacks from pea and oat fractions. $L W T, 112$ (January), 108252. doi: 10.1016/j.Iwt.2019.108252

Šárka, E., Smrčková, P., Chena Aldao, D. A., Sałlamtaş, M., Koláček, J., \& Pour, V. (2015). Influence of process parameters and added starches on resistant starch content and sensory properties of maize extrudates. Starch/Staerke, 679-10), 737-744. doi: 10.1002/star.201500059

Singh, N., \& Smith, A. C. (1997). A comparison of wheat starch, whole wheat meal and oat flour in the extrusion cooking process. Journal of Food Engineering, 34(1), 15-32. doi: 10.1016/S0260-8774(97)00069-1

Talens, P., Martínez-Navarrete, N., Fito, P., \& Chiralt, A. (2002). Changes in optical and mechanical properties during osmodehydrofreezing of kiwi fruit. Innovative Food Science \& Emerging Technologies, 3(2), 191-199. doi: 10.1016/S1466-8564(02)00027-9

Uribe-Wandurraga, Z. N., Igual, M., García-Segovia, P., \& Martínez-Monzó, J. (2019). Effect of microalgae addition on mineral content, colour and mechanical properties of breadsticks. Food \& Function, 10(8), 4685-4692. doi: 10.1039/c9fo00286c 



\section{Chapter 6}

\section{Effect of microalgae (Arthrospira platensis and Chlorella vulgaris) addition on 3D printed cookies}

This chapter has been published as:

Uribe-Wandurraga, Z. N., Igual, M., Reino-Moyón, J., García-

Segovia, P., \& Martínez-Monzó, J. (2020). Effect of Microalgae (Arthrospira platensis and Chlorella vulgaris) Addition on 3D Printed Cookies. Food Biophysics. doi: 10.1007/s11483-020-09642-y 



\section{Abstract}

Rheological and textural characteristics of cookie doughs were measured to characterise the effect of two microalgae biomasses additions (Arthrospira platensis and Chlorella vulgaris) in 3D printed cookies. The rheological characteristics determined the addition of microalgae lead to a greater mechanical resistance and a predominance of the elastic component ahead of the viscous component, this behaviour was confirmed by the textural analysis that showed a greater force for the extrusion of microalgae-enriched doughs. Besides, the influence of processing parameters, including filament diameter $(26$ and $27 \mathrm{~mm}$ ) and layer height (1.3 and $1.5 \mathrm{~mm}$ ), on the geometric accuracy of a 3D printed food structure made of cookie dough before and after baking process, was evaluated. The addition of microalgae biomass in dough, for 3D printed cookies, improves the printability in terms of dimensional properties, achieving 3D structures more stable and resistant to baking. 


\section{Introduction}

Additive manufacturing may be considered among the most important emerging technologies since the early 2000s. Its potential for research and industrial applications is an object of daily discussion and debate. Jiang et al. (2017) reported the first results of a prediction of the most likely scenario of emerging technologies in 2030; communicating additive manufacturing will be involved in production systems such as spare parts and on supply chains. 3D printing provides the possibility to print complex objects and users have a substantial liberty of design or can download their favourite models using CAD systems. A huge variety of commercial but also freeware and open-source software packages, available to download from websites, providing the opportunity to create their own food 3D models (Junk et al., 2016; Jiang et al., 2017).

3D printing has opened new perspectives in several areas such as food processing and manufacturing (Bhattacharjee et al., 2016; Pallottino et al., 2016; Schniederjans, 2017; Brunner et al., 2018), and it is expected to be a breakthrough in the popularisation of the 3D printing industry (Sun et al., 2015). As reported by Ringquist et al. (2016), consumer's choice to purchase food is guided by the criterion: taste, cost, experience, convenience, and nutrition. 3D food printing is a technique that satisfies all these criteria for manufacturing personalised/customised food and for specific consumer groups (children, elderly, pregnant women, teenagers, and athletes, among others) both in terms of sensorial and nutritional properties (Dankar et al., 2018a). For instance, the application of 3D printing in food manufacturing can exceed our expectation on traditional foods by obtaining smooth food for those affected by mastication or swallowing problems, providing a personalised nutrition or innovative food in terms of shape, consistency, colour and flavour (Sun et al., 2015; Dankar et al., 2018a).

The properties and composition of materials have are the most important factors in 3D printing process (Lipton, 2017; Kim et al., 2017; Liu et al., 2019a; Liu et al., 2019b). These materials should be homogenous with appropriate flow properties for extrusion to support its structure during and after the printing process (Dankar et al., 2018b). However, the printing of a complex food formula with desired 3D structure is difficult. If attention is only paid on the reproducibility of the 3D structure, analysing their dimensional properties, related to printability, the knowledge of rheological properties of food formula and the 
optimisation of printing variables are the key factors (Liu et al., 2018a; Severini et al., 2018).

For these structuring methods, traditional ingredients or materials have been being used (Ricci et al., 2019; Lanaro et al., 2019). Nevertheless, researchers have been looking for the creation of novel 3D food structures using alternative ingredients which are gaining interest as potential supplements towards custom and balanced nutrition, complementing traditional food sources (Dick et al., 2019). Despite the fact that the origin of microalgae as a food ingredient is not a recent phenomenon, its use as an ingredient in western countries is (van der Weele et al., 2019). Microalgae have been commercially available worldwide and can be considering a novel ingredient because of its high nutritive and functional value (Matos et al., 2017; Khan et al., 2018).

Microalgae biomass is a valuable source of several nutrients, such as carotenoid pigments, vitamins, proteins, fatty acids, sterols, and polysaccharides, among other biologically active compounds presenting potential health benefits. Microalgae have demonstrated the potential to meet the population's needs for a more sustainable food supply, specifically with respect to protein, for years to come. Depend on the type of microalgae; the protein content is around $50-70 \%$, slightly higher than the protein present in traditional meat products (Plaza et al., 2009; Guedes et al., 2011; Batista et al., 2013; Koller et al., 2014; Uribe-Wandurraga et al., 2020). Furthermore, protein is one of the macronutrients required for the human body (Wang et al., 2020). Research has been conducted regarding the attractive and functional foods prepared using microalgae biomass (Lafarga et al., 2019), although most of these have been foods obtained in a conventional way. One of the matrices that are being widely studied in 3D food printing is cereal base dough (Severini et al., 2016).

Cookies are enjoyed worldwide by consumers who select their favourites based on flavour and appearance. Their consumption is considerable, with about 40 packets per person per year consumed (Zydenbos et al., 2003). Following the trend of ready-to-eat and easy-to-eat products (Contini et al., 2016), and taking advantage of adding an ingredient with high protein content into a cereal base mix, microalgae allows a reinforcement of the viscoelastic protein matrix (Uribe-Wandurraga et al., 2019) which is beneficial to be extruded through a syringe and a nozzle using a 3D food printer system (Dankar et al., 2018a). Considering 
previous studies of 3D printable wheat flour-based products like cookie dough (Vancauwenberghe et al., 2017; Uribe-Wandurraga et al., 2019; Kim et al., 2019), microalgae-enriched cookie dough could be a good and convenient alternative for printing material, affecting significantly the printability of the food and the shape stability post printing, maintaining the complex structure of printable products, giving a nutritive novel product.

The aim of this study was to investigate the printability in terms of dimensional properties (variation in width, height and internal diameter) of 3D printed cookie doughs containing different microalgae concentration levels of Spirulina and Chlorella. The effect of microalgae biomass on rheology and texture of doughs plus colour of the final product was studied. Furthermore, cookie doughs and cookies were evaluated for changes in shape and dimensions of the 3D printed structures based on layer height and filament diameter, with increasing microalgae incorporation. In addition, the results acquired from this study can give us knowledge regarding the effect of microalgae-enriched cookie dough in 3D printing and their effects on post-processing of 3D printed foods.

\section{Material and methods}

\section{Raw materials}

Wheat pastry flour $(75 \mathrm{~g} / 100 \mathrm{~g}$ starch, $10 \mathrm{~g} / 100 \mathrm{~g}$ protein and $2 \mathrm{~g} / 100 \mathrm{~g}$ lipids), salt, granulated sugar, and butter were purchased from a local supermarket (Alcampo, Valencia, Spain). Freeze dried Arthrospira platensis (Spirulina) and Chlorella vulgaris (Chlorella) were supplied from Alga Energy S.A. (Madrid, Spain).

\section{Dough preparation}

Three types of cookie dough samples were formulated, Spirulina (SD), Chlorella (CHD), and a control sample without microalgae biomass addition (CD). Cookie doughs were preparing using $43.8 \%$ wheat pastry flour, $25 \%$ water, $18 \%$ butter, $13 \%$ granulated sugar, and $0.2 \%$ salt. For formulations containing microalgae-wheat pastry flour (SD or CHD) binomial combinations were produced at different levels of concentrations: $0.5 \%: 43.3 \%$; 1.0\%:42.8\%; 1.5\%:42.3\%, and 2.0\%:41.8\%, respectively. Butter and granulated sugar were manually mixing, using a whisk for 5 min, until obtaining a creamy and lump-free texture. Salt, microalgae biomass, and wheat pastry flour or microalgae-wheat pastry flour 
binomial combinations were gradually added to the mix in a food processor (Kenwood chef classic, KM400/99 plus, Kenwood Corporation, Tokyo, Japan) and blended for 5 min at speed 1 obtaining an uniform cookie dough. After mixing, each cookie dough sample was transferred to a syringe for the 3D printing.

\section{Rheological and mechanical properties of doughs}

The rheological behaviour of cookie dough was studied using a Kinexus pro+ rotational rheometer (Malvern Instruments, Worcestershire, UK) equipped with a $25 \mathrm{~mm}$ plate-plate geometry (DSR II, Upper Plate) set $3 \mathrm{~mm}$ gap between the plates and a heat-controlled sample stage (Peltier Cylinder Cartridge, Malvern Instruments, Worcestershire, UK). Dough samples were loaded onto the geometry plate and rested for $300 \mathrm{~s}$ before each measurement. First, a strain sweep test, at $25^{\circ} \mathrm{C}$ and a frequency of $1 \mathrm{~Hz}$, was conducted to identify the linear viscoelastic region. Based on the obtained results, dynamic rheological characterisation was performed, by applying a constant strain of $0.05 \%$ at $25{ }^{\circ} \mathrm{C}$ with a frequency range between $0.1-10 \mathrm{~Hz}$. Values of elastic modulus $\left(G^{\prime}\right)$, viscous modulus $\left(G^{\prime \prime}\right)$, loss factor $(\tan \delta)$, and complex viscosity $\left(\eta^{*}\right)$ were obtained as a function of frequency values $(\omega)$ by rSpace software. To compare $\mathrm{G}^{\prime}, \mathrm{G}^{\prime \prime}$ and $\tan \delta$ values between the investigated dough samples an oscillatory frequency of $1 \mathrm{~Hz}$ was chosen as a reference. Samples were analysed in triplicate.

Before the 3D printing process, doughs were characterised in a Texture Analyser TA-XT2 (Stable Micro Systems Ltd, Godalming, UK) equipped with a load cell of $50 \mathrm{~kg}$ (Stable Micro Systems Ltd, Godalming, UK) using the software, Texture Exponent (version 6.1.12.0) and the forward extrusion test. The syringe used in the printing process (cylindrical measurement chamber of $35 \mathrm{~mm}$ diameter $\times 100 \mathrm{~mm}$ height and $100 \mathrm{ml}$ volume) was filled with cookie dough avoiding air bubbles formation. An extrusion piston disc (35 mm diameter) was positioned centrally over the syringe. The extrusion piston was placed at 100 $\mathrm{mm}$ height, in contact with the sample, compressing slightly to pack the dough more tightly. The sample was compressed at pre-test, test, and post-test speed of $0.04 \mathrm{~mm} \mathrm{~s}^{-1}$ and was extruded through a $2.0 \mathrm{~mm}$ diameter aperture. The measurements were made at a controlled temperature of $25^{\circ} \mathrm{C}$ using a cooling coil to cover the syringe, connected to a water bath recirculation (Heidolph rotacool chiller, Heildolph, Illinois, USA). The curve gradient (stiffness $(\mathrm{N} / \mathrm{s})$ ) during the first 25 seconds, the maximum force required to continue the extrusion (hardness $(\mathrm{N})$ ), the mean force applied in the observed plateau 
during $150 \mathrm{~s}$ (extrusion force (N)), and the area under the curve (extrusion area (N.s)) were measured as the characterising parameters. Doughs were measured in triplicate, and the results were averaged.

\section{D printing experiment}

The printing of dough structures was performed using a 3D food printer (BCN 3D+, BCN3D Technologies, Barcelona, Spain) equipped with a pasta extruder nozzle designed for food materials (BCN3D Technologies, Barcelona, Spain). The 3D printing system comprised of: an extrusion system (syringe) and an X-Y-Z positioning system using stepper motors (MartínezMonzó et al., 2019). The printing process was performed at $25^{\circ} \mathrm{C}$ using a cooling coil to cover the pasta extruder nozzle connected to a circulating water bath (Heidolph rotacool chiller, Heildolph, Illinois, USA).

A cylinder structure was modelled in Thinkercad (Thinkercad, free software, Autodesk, Inc., San Rafael, California, USA.). The printing route of the 3D structure was constructed by using Slic3r software (Slic3r, free software, USA), and exported as a Gcode, a software extension that allows the movement, positioning, and control of the printing process. The dough in the syringe was extruded at a speed of $8 \mathrm{~mm} \mathrm{~s}^{-1}$ through a $2.0 \mathrm{~mm}$ diameter hole and the 3D object was printed layer-by-layer on a stainless steel plate covered with baking paper to facilitate the baking process.

Two variable printing conditions, layer height; $1.3 \mathrm{~mm}$ and $1.5 \mathrm{~mm}$, and filament diameter; $26 \mathrm{~mm}$ and $27 \mathrm{~mm}$, were tested in this study. The structure dimensions are $50 \mathrm{~mm}$ height, $15 \mathrm{~mm}$ external diameter (width), $42.2 \mathrm{~mm}$ and $41 \mathrm{~mm}$ internal diameter for $1.3 \mathrm{~mm}$ and $1.5 \mathrm{~mm}$ layer height, respectively. Filament diameter depends on several factors such as the printing speed which is related to the volumetric flow rate of the dough during printing process and, on the type of printer too (Yang et al., 2018). Layer height is a parameter related to the thickness of each deposited layers which directly affects the visual aspect (e.g., surface's smoother) of the printed object as the fineness of the details. The thinner is the layer height, the greater the number of layers printed per millimetre, increasing significantly the printing time as well as the amount of food material used to print the whole 3D structure (Yang et al., 2018; Martínez-Monzó et al., 2019). 


\section{Post-processing of 3D printed structures}

The printed structures were first quick-frozen at $-18{ }^{\circ} \mathrm{C}$ for $90 \mathrm{~min}$ in a fast freezer (SINCOLD, A.T.O. SRL, Treviso, Italy) to minimise the collapse of the printed structures during baking process and, then baked in a steamer oven (Convotherm OES 6.06 mini CC, Convotherm Elektrogeräte GMBH, Eglfing, Germany) at $140{ }^{\circ} \mathrm{C}$ for 55 min on a stainless steel plate covered with baking paper. The tray with samples was placed in the central zone of the steamer oven. All baking tests were conducted in triplicate. After baking, printed cookies were cooled at room temperature $\left(25^{\circ} \mathrm{C}\right)$ before further analyses.

\section{Physical properties of 3D printed structures}

\section{Image analysis}

Digital pictures of top and lateral views of each 3D printed cookie were taken immediately after printing and once the samples were baked, using a digital colour camera (mod Alpha 330, Sony, Tokyo, Japan). The pictures were taken using a semi-professional kit to control illumination. The digital camera was positioned on a support placed at fixed distance from the sample to take pictures. A reference scale was used in each picture but in the final table was positioned only on the top. Pictures were taken in triplicate for each sample.

The Image J software (Image], NIH, USA) was used for processing the images. For the top view, the internal diameter was measured and; for the lateral view, the width and height were measured (Figure 1). Three measurements were performed after printing of each sample and post-processing (baking). The differences between the dimensions (height, width and internal diameter) after printing process comparing with the design cylindrical structure and after baking process comparing with the freshly printing cylindrical structure were used as a metric of variation of each dimension.

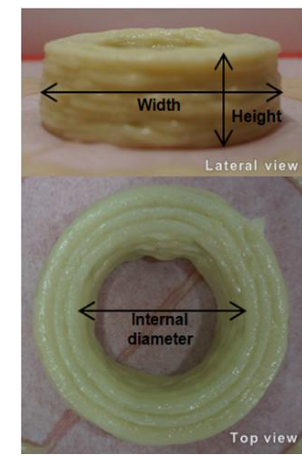

Figure 1. Studied dimensions of the printed structure.

\section{Colour measurement}

The colour of the 3D printed cookies was measured instrumentally using a Konica Minolta CM-700d colourimeter (Konica Minolta CM-700d/600d series, Tokyo, Japan) with a visual angle of $10^{\circ}$ and standard illuminant D65. The cookies' colour was measured at six 
equidistant points for each printed cookie after baking. The results were express in terms of L* (brightness), a* (greenness/redness), and b* (blueness/yellowness), according to the CIE*L*a*b* system. Chroma, $\mathrm{C}^{*}{ }_{\mathrm{ab}}$ (saturation) and hue angle, $\mathrm{h}^{\circ}{ }_{\mathrm{ab}}$, were also calculated, using equations 1 and 2, respectively:

$$
\begin{gathered}
C^{*}{ }_{a b}=\left[\left(a^{* 2}+b^{* 2}\right)\right]^{1 / 2} \\
\mathrm{~h}^{\circ}{ }_{\mathrm{ab}}=\arctan \left(\frac{b^{*}}{a^{*}}\right)
\end{gathered}
$$

The total colour difference $(\Delta \mathrm{E})$ between samples, with and without microalgae addition at different concentration levels, was determined using $L^{*} a * b *$ values according to equation 3 .

$$
\Delta E=\left[\left(\Delta L^{*}\right)^{2}+\left(\Delta a^{*}\right)^{2}+\left(\Delta b^{*}\right)^{2}\right]^{1 / 2}
$$

The measurements were conducted under constant lighting conditions, at $25^{\circ} \mathrm{C}$.

\section{Experimental design and statistical analysis}

Minitab 18 Statistical Software (Minitab Inc., USA) was used for the experimental design of mixtures (extreme vertices), where 120 impressions for each type of microalgae (Spirulina and Chlorella) was generated for the two process variables (layer height (1.3 $\mathrm{mm}$ and 1.5 $\mathrm{mm})$ and filament diameter $(26 \mathrm{~mm}$ and $27 \mathrm{~mm}))$, and microalgae concentrations $(0,0.5$, $1.0,1.5$, and $2.0 \%)$.

Analysis of the variance (ANOVA) using Statgraphics Centurion XVII Software, version 17.2.04 was performed to evaluate differences among control and microalgae-enriched dough samples and for all the 3D printed cookies. The level of significance was set at $95 \%$ $(p<0.05)$.

\section{Results and discussion}

\section{Rheological characterisation of dough}

In cookie production, rheological behaviour of dough is important because it impacts the processability and quality of cookie (Devi et al., 2016). The rheological behaviour of foods 
can be expressed by the parameters elastic modulus $\left(G^{\prime}, P a\right)$ and viscous modulus ( $\left.G^{\prime \prime}, P a\right)$. The $G^{\prime}$ modulus is a measurement for elastic behaviour and can be an indicator of mechanical strength of the structure and shape retention ability of 3D printed products. The $\mathrm{G}^{\prime \prime}$ modulus is a measurement for viscous behaviour and can be an indicator of the dough extrusion capacity (Huang et al., 2019a). Both properties play an important role during 3D food printing (Yang et al., 2018). Furthermore, the loss factor ( $\tan \delta=\mathrm{G}^{\prime \prime} / \mathrm{G}^{\prime}$ ) is often used to measure the ratio of viscous and elastic response of the tested material, where values < 1 indicate predominantly elastic behaviour, and $>1$ predominantly viscous behaviour (Liu et al., 2018b).

Figure 2 shows the dynamic mechanical spectra of enriched doughs with increasing concentrations of Spirulina (Figures 2a and 2c) and, Chlorella (Figures 2b and 2d). G' was greater than $G^{\prime \prime}$ throughout the studied frequency range for all samples, suggesting that all the cookie doughs exhibited dominant elastic behaviour. $G^{\prime}$ and $G^{\prime \prime}$ values of microalgaeenriched doughs were higher than the control dough sample, which indicated that the viscoelastic behaviour of doughs was modified by microalgae addition, where the elastic behaviour was improved predominately (Uribe-Wandurraga et al., 2019). Since wheat flour dough presents viscoelastic behaviour with non-linear shear thinning and thixotropic behaviour (Lefebvre, 2009). Therefore, microalgae-enriched doughs can recover energy from deformation more easily, an important behaviour for 3D food printing.

The green microalgae Chlorella and especially the cyanobacteria Spirulina are preferred for the use in human food, because of their high nutritional value molecules such as carbohydrates, lipids and, secondary metabolites with bioactive compounds as vitamins, carotenoids, chlorophylls, and phycobiliproteins. Moreover, due to their high protein content, $50-60 \%$ and $60-70 \%$ (dry weight), respectively (Lefebvre, 2009; Nova et al., 2020).

Comparing microalgae-enriched doughs, higher values of $\mathrm{G}^{\prime}$ and $\mathrm{G}^{\prime \prime}$ through the frequency range $(0.1$ to $10 \mathrm{~Hz})$ were observed when Spirulina addition was $>0.5 \%$, which may be because of its protein content, changing significantly their rheological behaviour $(p<0.05)$, higher than Chlorella enriched doughs. Besides, this can be because the higher protein content favoured the formation of a continuous gluten network (Zhang et al., 2018). UribeWandurraga et al. (2019) indicated that the addition of microalgae (Spirulina and Chlorella) significantly changed the rheological behaviour of doughs compared to control dough. 
Comparable results were found by other authors (Bair et al., 2014; Mancebo et al., 2016). Thus, the addition of both types of microalgal biomass led to a significant increase ( $p<$ 0.05 ) in $G^{\prime}$ and $G^{\prime \prime}$, which could indicate greater mechanical resistance, an important property in 3D food printing (Kim et al., 2019).
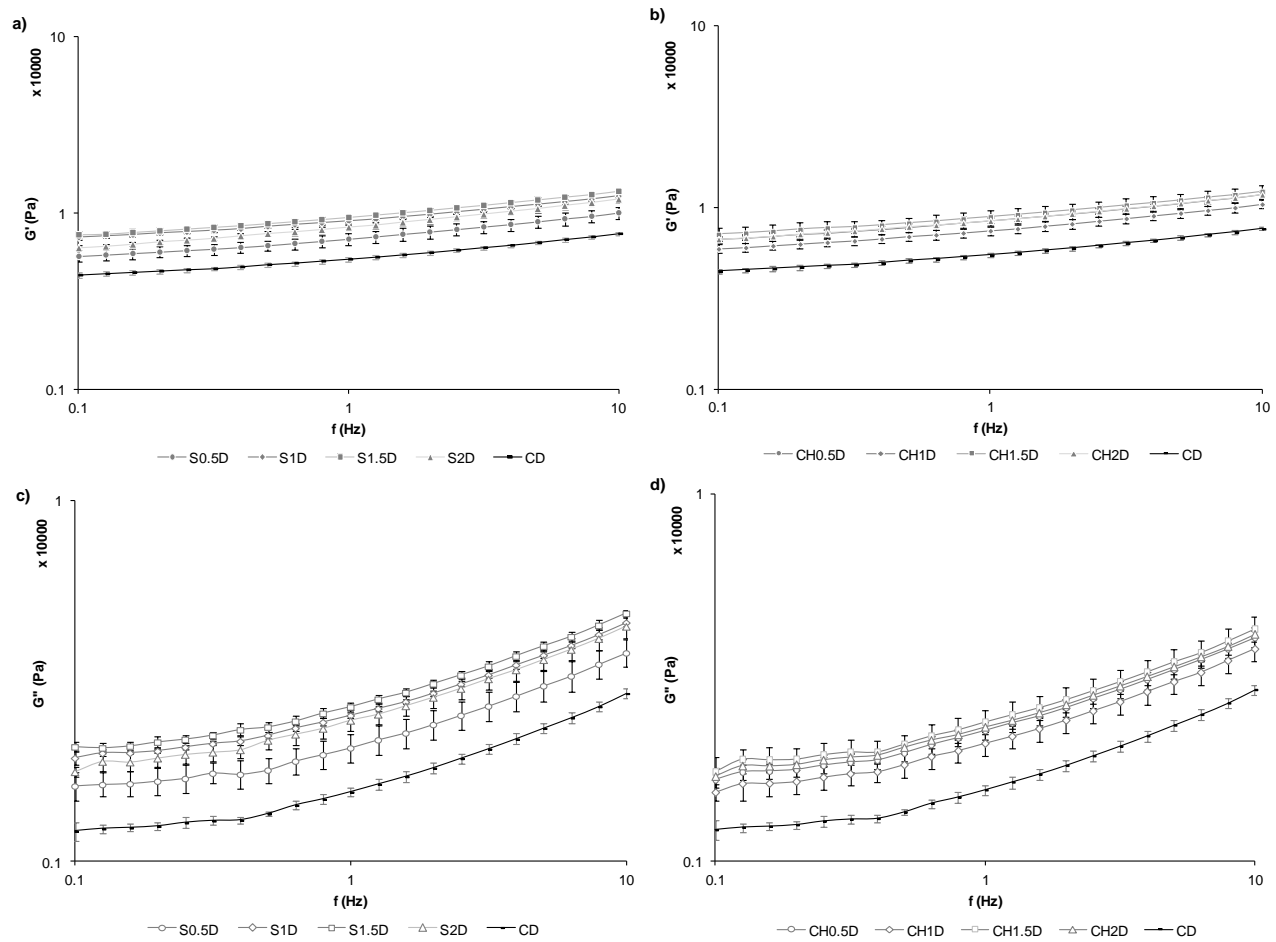

Figure 2. Elastic modulus $\left(\mathrm{G}^{\prime}\right)$ and viscous modulus $\left(\mathrm{G}^{\prime \prime}\right)$ of doughs enriched with increasing concentrations (0, 0.5, 1, 1.5 and $2 \%$ ) of Spirulina (a and c) and Chlorella (b and d). CD: Control cookie dough; SD: Spirulina cookie dough; CHD: Chlorella cookie dough.

Another fundamental property obtained from rheological measurements is the complex viscosity $\left(\eta^{*}, \mathrm{~Pa} \cdot \mathrm{s}\right)$, defined as the resistance to flow of the material in the structured state, originating as viscous or elastic flow resistance to the oscillating movement (Kasapis et al., 2017). According Godoi et al. (2016), the viscosity of the material must be low enough, at high shear rate, to allow flow through a small nozzle, but the material has to quickly recover a high viscosity after deposition, to support the structure.

Figure 3 shows the complex viscosity $\left(\eta^{*}\right)$ of microalgae-enriched doughs at different microalgae concentrations. All the samples showed a decrease in the $\eta^{*}$ values with 
frequency on a log scale. Microalgae-enriched doughs showed significant higher $(p<0.05)$ complex viscosity values than the control dough for both Spirulina and Chlorella, with increasing concentration ( $1 \%$ and $1.5 \%$ ) over the experimental shear frequency range, thus, indicating shear thinning characteristics (Kasapis et al., 2017). This behaviour of samples is a key parameter for a successful 3D printing, allowing easier extrusion and shape retention after the material deposition (Huang et al., 2019b).
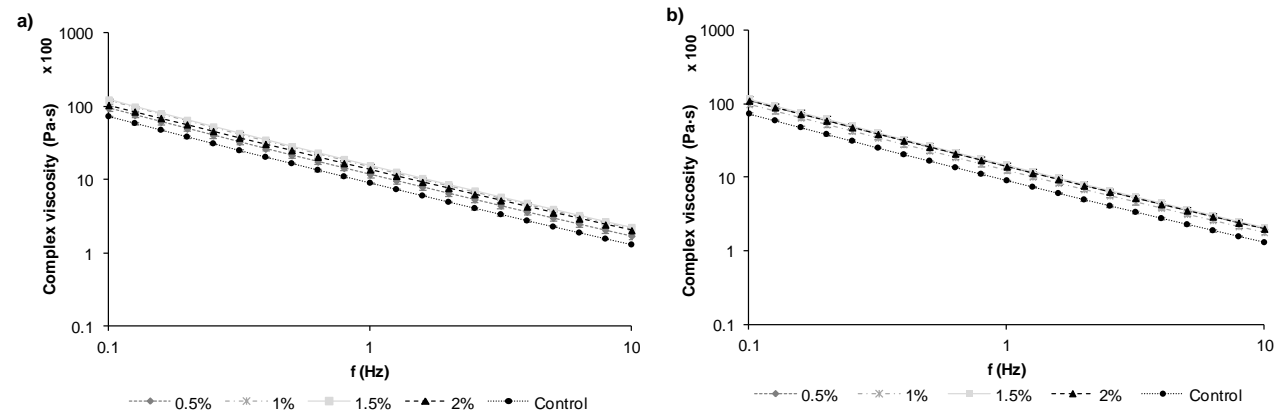

Figure 3. Complex viscosity $\left(\eta^{*}\right)$ of doughs enriched with increasing concentrations $(0,0.5,1,1.5$ and $2 \%$ ) of Spirulina (a) and Chlorella (b).

According to the results obtained (Figure 2), the frequency of $1 \mathrm{~Hz}$ can be taken as a reference in the frequency range analysed to compare $G^{\prime}$ and $G^{\prime \prime}$ values. The different lines of $\mathrm{G}^{\prime}$ and $\mathrm{G}^{\prime \prime}$ do not cross each other and the distance between curves is very similar. Thus, the difference between samples for $\mathrm{G}^{\prime}, \mathrm{G}^{\prime \prime}$ and $\tan \delta$ was quantified at $1 \mathrm{~Hz}$ (Table 1 ).

Table 1 shows the mean values of $\mathrm{G}^{\prime}, \mathrm{G}^{\prime \prime}$, and $\tan \delta$ at a frequency of $1 \mathrm{~Hz}$, for $\mathrm{CD}, \mathrm{SD}$, and CHD at different concentration $(0.5,1,1.5$ and $2 \%)$. The effect of the microalgae concentration from 0.5 to $2 \%$ does not show an increasing or decreasing pattern of mean values. However, higher values of $\mathrm{G}^{\prime}$ and $\mathrm{G}^{\prime \prime}$ were obtained for microalgae concentration level $>1 \%$ showing not significantly differences $(p>0.05)$ for both SD and CHD, while the lowest values were for $C D$, showing a greater elastic behaviour than the control sample. The values of $\tan \delta$ were lower than 1 for all cookie doughs which indicates that all of them behave more like elastic material too. Although, SD at $2 \%$, showed a higher $\tan \delta$ value compared to the other samples, showing less elastic-like behaviour, especially with respect to control sample. 
Table 1. Mean values (and standard deviations) of storage modulus $\left(G^{\prime}\right)$ and loss modulus ( $\left.G^{\prime \prime}\right)$ at $1 \mathrm{~Hz}$ obtained from rheological measurements of studied doughs. CD: Control dough; SD: Spirulina dough; CHD: Chlorella dough.

\begin{tabular}{|c|c|c|c|c|}
\hline Sample & $\begin{array}{c}\text { Microalgae } \\
\text { concentration (\%) }\end{array}$ & $\mathbf{G}^{\prime}(\mathbf{P a})$ & G" (Pa) & $\tan \delta$ \\
\hline$C D$ & 0 & $5481(150)^{d}$ & $1560(46)^{\mathrm{e}}$ & $0.285(0.006)^{\mathrm{bc}}$ \\
\hline \multirow{4}{*}{ SD } & 0.5 & $7135(536)^{c}$ & $2067(185)^{d}$ & $0.289(0.004)^{\mathrm{ab}}$ \\
\hline & 1 & $9005(155)^{\mathrm{ab}}$ & $2542(48)^{\mathrm{ab}}$ & $0.2823(0.0013)^{\mathrm{bc}}$ \\
\hline & 1.5 & $9462(355)^{\mathrm{a}}$ & $2684(70)^{a}$ & $0.284(0.007)^{\mathrm{bc}}$ \\
\hline & 2 & $8322(342)^{b}$ & $2463(162)^{\mathrm{abc}}$ & $0.296(0.008)^{\mathrm{a}}$ \\
\hline \multirow{4}{*}{$\mathrm{CHD}$} & 0.5 & $8405(462)^{b}$ & $2266(121)^{\mathrm{cd}}$ & $0.2696(0.0009)^{\mathrm{e}}$ \\
\hline & 1 & $7463(422)^{c}$ & $2090(157)^{d}$ & $0.280(0.007)^{\mathrm{cd}}$ \\
\hline & 1.5 & $8900(725)^{\mathrm{ab}}$ & $2390(182)^{\mathrm{bc}}$ & $0.269(0.003)^{\mathrm{e}}$ \\
\hline & 2 & $8477(279)^{b}$ & $2315(65)^{c}$ & $0.273(0.003)^{\mathrm{de}}$ \\
\hline
\end{tabular}

The same letter in superscript within column indicates homogeneous groups established by ANOVA $(p<$ 0.05).

\section{Extrusion behaviour of doughs}

A forward extrusion assay was used to analyse the extrusion behaviour of the doughs (Martínez-Monzó et al., 2019), where the force curves vs. time showed the different periods doughs go through in the extrusion process. During the first stage, the force increased steeply until a maximum force, where the extrusion initiated. Once the force reached its peak, a plateau was observed; the mean value of the plateau force was determined as the force needed to continue the extrusion process (Ares et al., 2006), and the area under the plateau was extrusion area. The maximum extrusion force may be considered as the force that can be achieved by the 3D printer during the printing process (Zhu et al., 2019).

By examining dough extrusion behaviour (Table 2), stiffness, hardness, extrusion force, and extrusion area parameters showed $2 \%$ SD had significantly higher values among all samples $(p<0.05)$. Microalgae-enriched doughs showed an overall greater hardness than the $\mathrm{CD}$, with $2 \%$ SD the hardest sample. These results can be related to the high protein content in Spirulina (Singh et al., 2015). Still, slight differences in the parameters among CD and SD at $0.5,1$, and $1.5 \%$ were observed. Besides, a decrease in the parameters for CHD at $0.5,1$, and $1.5 \%$ was observed. 
Table 2. Mean values (and standard deviations) of extrusion parameters of studied doughs. CD: Control dough; SD: Spirulina dough; CHD: Chlorella dough.

\begin{tabular}{|c|c|c|c|c|c|}
\hline Sample & $\begin{array}{c}\text { Microalgae } \\
\text { concentration (\%) }\end{array}$ & $\begin{array}{c}\text { Stiffness } \\
\left(\mathrm{N} \mathrm{s}^{-1}\right)\end{array}$ & $\begin{array}{c}\text { Hardness } \\
\text { (N) }\end{array}$ & $\begin{array}{c}\text { Extrusion } \\
\text { force } \\
\text { (N) }\end{array}$ & $\begin{array}{c}\text { Extrusion } \\
\text { area } \\
\text { (Ns) } \\
\end{array}$ \\
\hline$C D$ & 0 & $0.29(0.03)^{d}$ & $17.9(1.7)^{\text {de }}$ & $15.1(1.7)^{\text {de }}$ & $3375(384)^{\mathrm{de}}$ \\
\hline \multirow{4}{*}{ SD } & 0.5 & $0.26(0.02)^{\mathrm{de}}$ & $22(3)^{d}$ & $14.9(1.6)^{\mathrm{de}}$ & $3342(356)^{\mathrm{de}}$ \\
\hline & 1 & $0.154(0.011)^{f}$ & $20(3)^{\mathrm{de}}$ & $15.9(1.7)^{\text {de }}$ & $3592(387)^{\mathrm{de}}$ \\
\hline & 1.5 & $0.25(0.05)^{\mathrm{e}}$ & $17.3(1.9)^{\mathrm{e}}$ & $13(3)^{\mathrm{e}}$ & $3017(615)^{\mathrm{e}}$ \\
\hline & 2 & $0.477(0.017)^{a}$ & $45.8(2.6)^{\mathrm{a}}$ & $41.63(1.18)^{a}$ & $9367(267)^{\mathrm{a}}$ \\
\hline \multirow{4}{*}{$\mathrm{CHD}$} & 0.5 & $0.45(0.03)^{\mathrm{a}}$ & $33.2(1.6)^{b}$ & $29(2)^{b}$ & $6610(527)^{b}$ \\
\hline & 1 & $0.39(0.02)^{b}$ & $28(2)^{c}$ & $26(2)^{c}$ & $5759(549)^{\mathrm{c}}$ \\
\hline & 1.5 & $0.347(0.02)^{c}$ & $20(3)^{\mathrm{de}}$ & $18(3)^{d}$ & $4071(636)^{d}$ \\
\hline & 2 & $0.36(0.03)^{\mathrm{bc}}$ & $30(4)^{b c}$ & $27(4)^{b c}$ & $6157(938)^{\mathrm{bc}}$ \\
\hline
\end{tabular}

The same letter in superscript within column indicates homogeneous groups established by ANOVA ( $p<$ 0.05).

\section{Printing process and post-processing of 3D printed samples}

According the classification system proposed by Kim et al. (2017) for food printability, cookie dough is a good additive manufacturing food material (Yang et al., 2019), and can be classified as grade $\mathrm{C}$. Grade $\mathrm{C}$ foods are materials that require high output for extrusion and can fabricate simple structures with low height, such as customised cookies. Figure 4 shows images of printed cookies (layer height $1.3 \mathrm{~mm}$ and filament diameter $26 \mathrm{~mm}$ ) before and after the baking process. In order to perform a good printing process for a new product, researchers have found that parameters like filament diameter and layer height can affect printing precision and the quality of the 3D printed end-product (e.g., shape) (Pérez et al., 2019).

Besides doughs' formulation effects, this study investigated two printer parameters, layer height (1.3 mm and $1.5 \mathrm{~mm}$ ) and filament diameter (26 mm and $27 \mathrm{~mm}$ ) (Figure 5). In our printer, equipped with a pasta extruder nozzle (syringe) and designed for food materials, the parameter filament diameter is used to control the flow of deposition and it is also related to the diameter of the syringe. Thus, the filament diameters $26 \mathrm{~mm}$ and $27 \mathrm{~mm}$, correspond to a flow rate of $40 \mathrm{~mm}^{3} / \mathrm{s}$ and, $35 \mathrm{~mm}^{3} / \mathrm{s}$, respectively. Figure 5 shows the appearance of the printed microalgae cookies had high definition layering, higher than the control sample. It is possible that when microalgae are added to the cookie dough, they 
absorb more water and oil/fat, reinforcing the cookie dough internal structure (Batista et al., 2017).

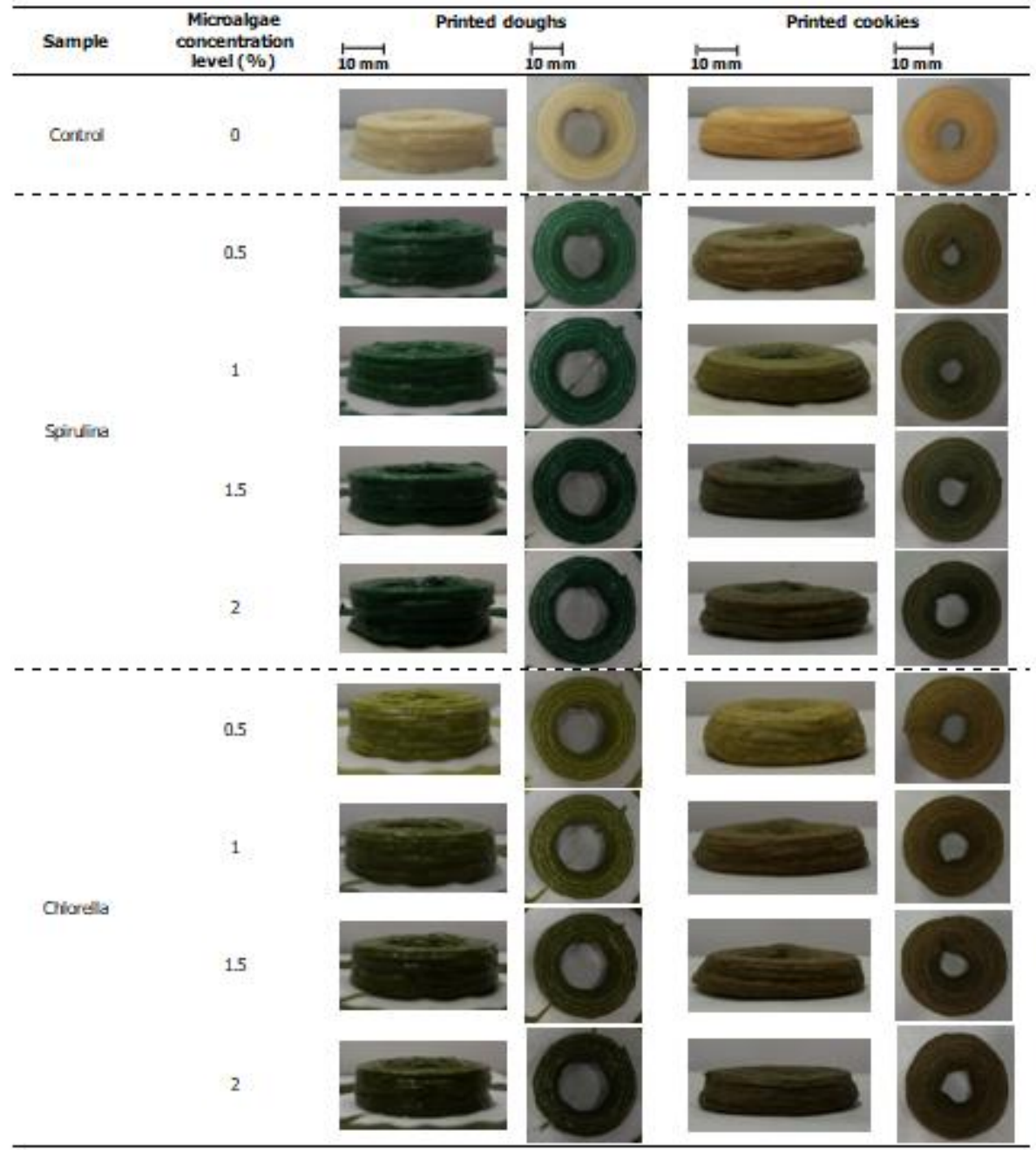

Figure 4. Example of 3D printed samples (layer height $1.3 \mathrm{~mm}$ and filament diameter $26 \mathrm{~mm}$ ) before and after baking process.

To explain the effect of layer height and filament diameter studied, microalgae concentration, height, width, and internal diameter of variations of principal dimension of printed cylinders respect to model a multifactor ANOVA was conducted. 
First, it was only applied to $C D$, evaluating layer height and filament diameter. Here, when the filament diameter was $27 \mathrm{~mm}$, an increase of layer height provoked a significant increase of cylinder height ( $p<0.05$ ). However, when using $26 \mathrm{~mm}$ as filament diameter, there were no significant differences $(p>0.05)$ in cylinder height variation. The filament diameter is correlated with printing speed. Thus, since the printing speed for $27 \mathrm{~mm}$ is less than that of $26 \mathrm{~mm}$, it takes more time to deposit the layer of dough, which would cause the structure to slightly start to collapse (Yang et al., 2018).

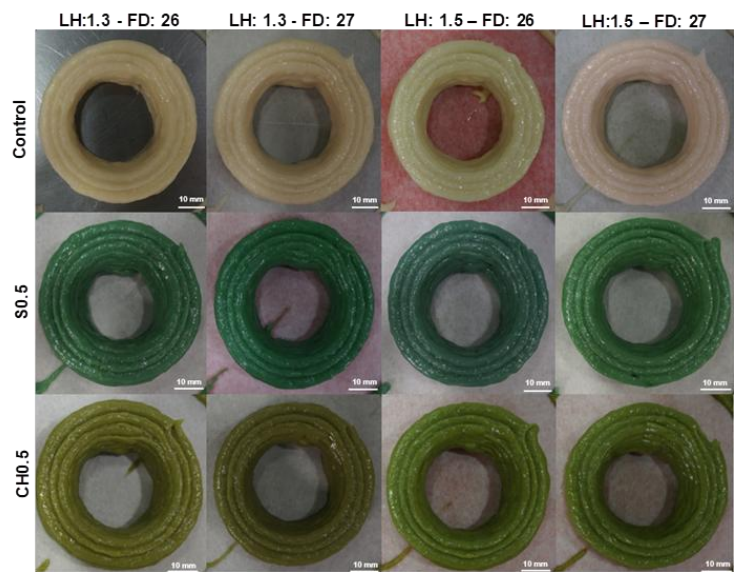

Figure 5. Example of 3D printed cookies before baking process at different printing conditions. LH: Layer height $(\mathrm{mm})$ and FD: Filament diameter ( $\mathrm{mm}$ ) for Control sample, S0.5: Spirulina-enriched sample at $0.5 \%$ and $\mathrm{CHO} .5$ : Chlorella-enriched sample at $0.5 \%$.

In relation to cylinder width variation, using lower values of layer height and filament diameter showed a significant increase $(p<0.05)$. By using a small layer height, the printing time and the amount of food material used to print the whole 3D structure increases. This effect could makes the structures begin to change their dimensions during the printing process (Derossi et al., 2019). The internal diameter variation of cylinder was significantly affected $(p<0.05)$ by layer height, showing higher layer heights leading to higher internal cylinder diameters variation. This can be attributed to when layer heights are high, the printing nozzle is further from the previous layer of dough and the new layer deposited falls toward the external face of the shell. Hence, reducing the expected increase in height of the samples (Severini et al., 2016).

Height variation of printed SD cookies was significantly higher $(p<0.05)$ when a $1.5 \mathrm{~mm}$ layer height was used, while microalgae concentration and filament diameter do not cause significant changes $(p>0.05)$ in height. However, the effect of studied parameters on width 
and internal diameter variation of microalgae-enriched doughs showed an interaction among them. Therefore, changes in layer height, filament diameter or/and microalgae concentration cause changes in width and internal diameter of the printed cookie. Likewise, CHD cookies were significantly higher $(p<0.05)$ when $1.5 \mathrm{~mm}$ of layer height was used. Cookie dough studies have shown a structural reinforcement because of microalgae addition and its increasing concentration (Batista et al., 2017). The two other studied parameters did not show significant changes in cylinder height variation $(p>0.05)$. Width variation of the printed cylinder decreased significantly $(p<0.05)$ with increasing concentration of microalgae, higher layer height, and filament diameter. Besides, filament diameter had a significant effect $(p<0.05)$ on the internal diameter variation of CHD cookies, being lower when a lower filament diameter was used.

Figure 6 shows the effect of the different microalgae concentration on the variation in dimensions of printed cookies compared to the designed structure. Printed cookies resulted with a significant difference $(p<0.05)$ between the CHD and SD or CD cookies in height variation. However, there was no significant difference $(p>0.05)$ between $\mathrm{CD}$ and SD cylinder width variation.

When all samples were baked (Figure 7), there was an increase in width resulting from the decrease in height. This behaviour was also shown by Severini et al. (2016) on cereal-based products, attributing this effect to the water evaporation during the cooking process which induced the reduction of sample dimensions. The most relevant significant difference is between SD and CHD cookies width variation, with the mean width variation being greater for CHD cookies. For the internal diameter variation, there were no significant differences ( $p$ $<0.05$ ) among studied groups after the samples had been printed or baked.

Although no great differences in the geometric characteristics of the samples according to the printing parameters existed, the best parameters for these doughs are with a layer height of $1.5 \mathrm{~mm}$ and a filament diameter of $27 \mathrm{~mm}$. This gives greater defined cookies in terms of height and width proportions than the designed structure. Thus, measurement of height, width and internal diameter are essential to determine the accuracy of the 3D food printer in the object's construction (Yang et al., 2019). 

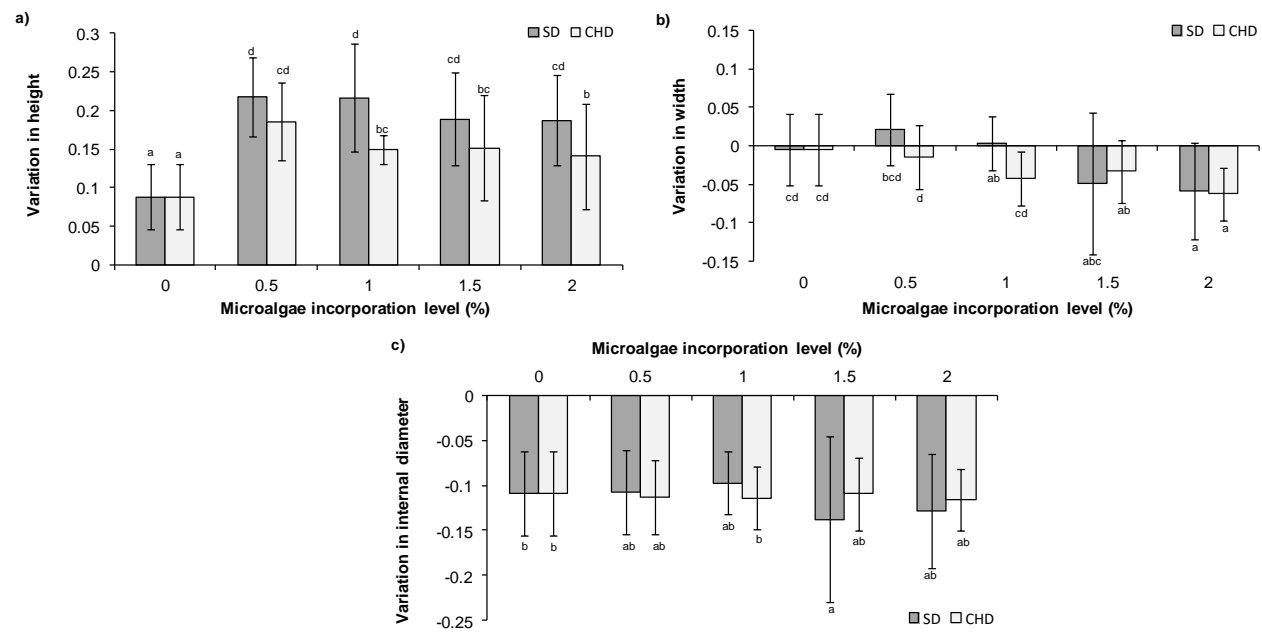

Figure 6. Variation in height (a), width (b) and internal diameter (c) of 3D printed cylinder-shaped dough cookies with addition of Spirulina (SD) and Ch/orella (CHD). Letters a, b, c and d on bars indicate homogeneous groups established by the ANOVA $(p<0.05)$ for microalgae level concentrations $(0,0.5$, $1,1.5$ and $2 \%)$.
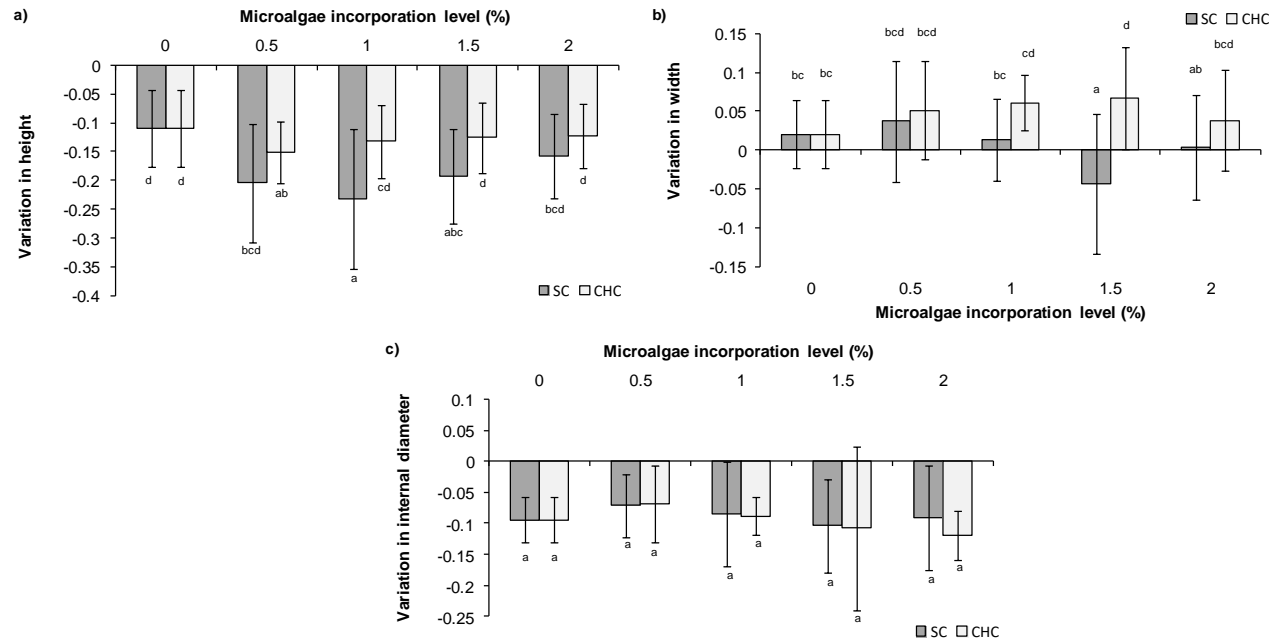

Figure 7. Variation in height (a), width (b) and internal diameter (c) of 3D printed cylinder-shaped baked cookies with addition of Spirulina (SC) and Chlorella (CHC). Letters a, b, c and d on bars indicate homogeneous groups established by the ANOVA $(p<0.05)$ for microalgae level concentrations $(0,0.5$, $1,1.5$ and $2 \%)$. 


\section{Colour changes of 3D printed cookies}

The printing parameters (layer and filament diameter) do not affect the cookie colour; therefore 3D printed cookies were grouped by type of microalgae (Spirulina and Chlorella) and levels of concentration $(0,0.5,1,1.5$ and $2 \%)$.

Colour of food is considered the most important intrinsic sensory cue of a product, since it governs the sensations and hedonic expectations defining the consumer's acceptability of baked products (Gouveia et al., 2007; Casales-Garcia et al., 2020). The colour of cookies with microalgae (Figure 4) was typical of samples enriched with Spirulina or Chlorella, as previous studies have shown (Gouveia et al., 2007).

Figure 8 shows coordinates of $\mathrm{L}^{*}, \mathrm{a}^{*}, \mathrm{~b}^{*}, \mathrm{~h}_{\mathrm{ab}}^{\circ}$, and $\mathrm{C}_{\mathrm{ab}}^{*}$ for all the samples after the baking process. The results indicate greater luminosity in formulations with Spirulina than those containing Chlorella, with increasing microalgae concentration, while a reduction in this parameter is seen, as the increases resulted in darker cookies than the control (Figure 4). This effect may be associated to a higher pigment degradation with the baking process or with a pigment saturation effect above certain microalgae concentrations, leading to the formation of brown-coloured chlorophyll degradation products (Gouveia et al., 2007).

An increase in microalgae concentration has also led to lower values of the chromatic parameters a* and b*. As an increase in microalgae concentration causes a greener colour, while control cookies are redder. Spirulina-enriched cookies at microalgae concentration of $0.5 \%$ show the green chromaticity decreased, reaching an a* positive value; while negative a* values in the green domain for those samples with concentration higher that $1 \%$. Nevertheless, for Spirulina and Chlorella concentrations higher than $1.5 \%(\mathrm{w} / \mathrm{w})$, the differences in $\mathrm{a}^{*}$ are not significant $(p<0.05)$. Hence, cookies enriched with Spirulina concentration higher than $1 \%$ denote a greener colour compared to Chlorella-enriched cookies. These results agree with other authors (Batista et al., 2017; Onacik-Gür et al., 2018), where a reduction in $a^{*}$ and $b^{*}$ parameters upon increasing microalgae biomass concentration in the products was observed. Regarding the hue, it remains almost constant $\left(83^{\circ}\right.$ to $\left.85^{\circ}\right)$ for Chlorella-enriched cookies with increasing concentration and slight differences were found among concentration levels of Spirulina-enriched cookies. 

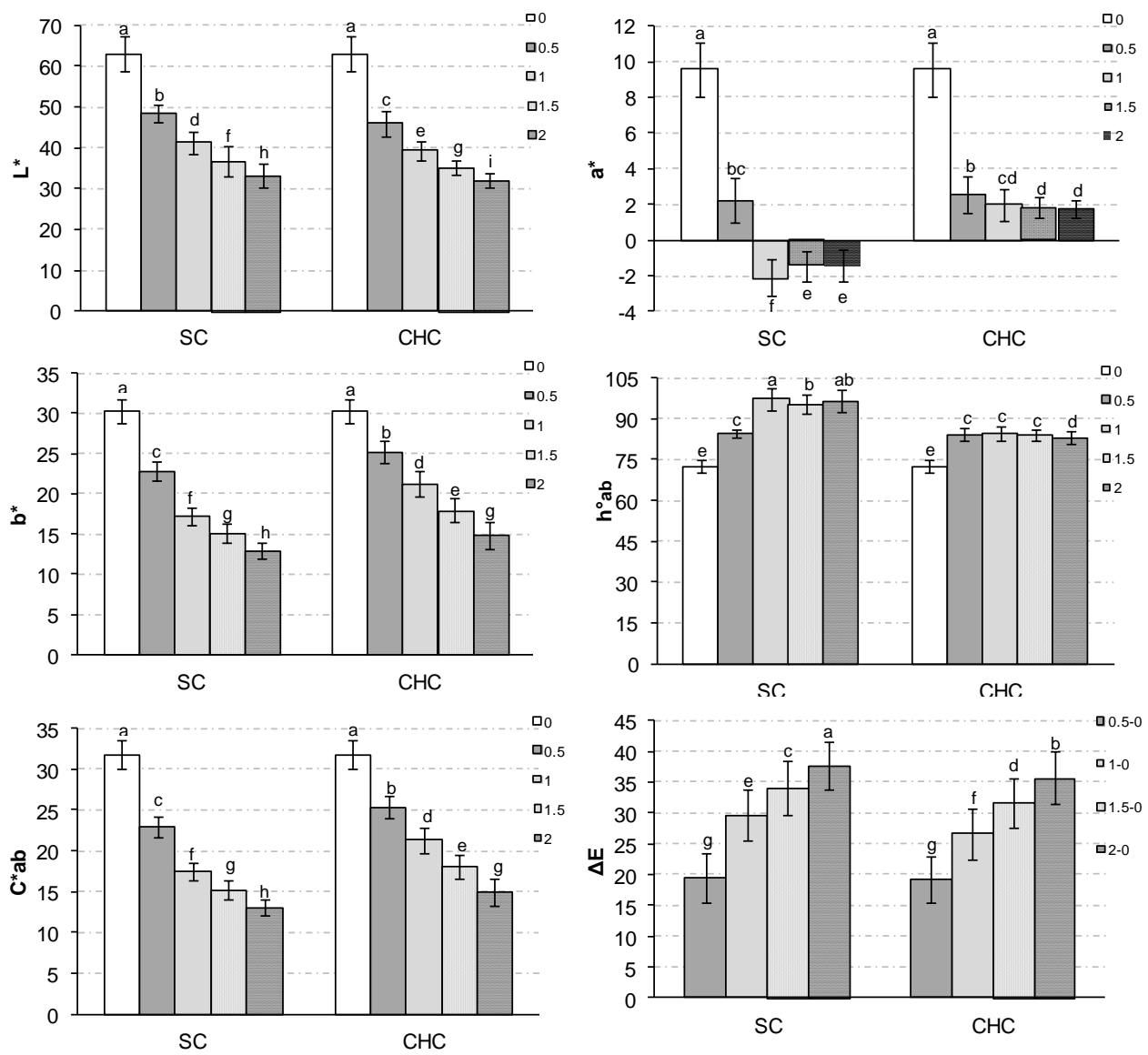

Figure 8. Colour parameters $\left(\mathrm{L}^{*}, \mathrm{a}^{*}, \mathrm{~b}^{*}, \mathrm{~h}_{\mathrm{ab}}^{\circ}\right.$, and $\left.\mathrm{C}^{*} \mathrm{ab}\right)$ and colour differences $(\Delta \mathrm{E})$ compared to control sample of 3D Printed cookies enriched with Spirulina (SC) and Chlorella (CHC) at different concentrations.

For SC and $\mathrm{CHC}$ a similar concentration-dependent colour intensity $\left(\mathrm{C}^{*}{ }_{\mathrm{ab}}\right)$ pattern is observed, with cookies without microalgae addition having higher colour intensity value. By incorporation of microalgae into cookies formulation, $\mathrm{C}^{*}{ }_{\mathrm{ab}}$ decreases with both microalgae, which suggests a loss of colour intensity after microalgae addition in cookies, although it is higher with Chlorella. The difference in colour after the baking process was evaluated taking as reference control baked cookies. As expected, the difference in colour is higher in all cases and is perceptible to the human eye with $\Delta \mathrm{E}$ values $>3$ (Bodart et al., 2008).

To explore the relationship between colour coordinates and microalgae concentration Pearson correlation analysis was conducted. Pearson's coefficients establish the statistically 
significant linear relationship $(p<0.05)$ between the variables analysed and range from -1 to 1 . All studied colour coordinates showed significant correlations $(p<0.05)$ related to microalgae concentration. For with Spirulina cookies, Pearson coefficients were -0.9192, 0.8219, -0.9487, 0.8424, -0.9402 , and 0.8377 for $\mathrm{L}^{*}, \mathrm{a}^{*}, \mathrm{~b}^{*}, \mathrm{~h}_{\mathrm{ab}}^{\circ} \mathrm{C}^{*} \mathrm{ab}$, and $\Delta \mathrm{E}$, respectively. Therefore, higher Spirulina concentration in cookies lowers values of $L *$, a*, $\mathrm{b}^{*}$, and $\mathrm{C}^{*}{ }_{\mathrm{ab}}$ (cookies were darker and more green-blue) while $\mathrm{h}_{\mathrm{ab}}^{\circ}$, and $\Delta \mathrm{E}$ values were higher. The same trend was observed in Chlorella cookies, As Pearson coefficients were 0.9097, -0.7424, -0.9585, 0.5957, -0.9555, and 0.8239 for $\mathrm{L}^{*}, \mathrm{a}^{*}, \mathrm{~b}^{*}, \mathrm{~h}_{\mathrm{ab}}^{\circ} \mathrm{C}_{\mathrm{ab}}$, and $\Delta \mathrm{E}$, respectively. As can be observed, the Pearson coefficient of $\mathrm{C}^{*}{ }_{\mathrm{ab}}$ was notably higher for Spirulina (0.8424) cookies than in the case of Chlorella cookies (0.5957). Therefore, the relationship between microalgae concentration and $\mathrm{C}^{*}{ }_{\mathrm{ab}}$ was more fitted when Spirulina was added.

\section{Conclusions}

In this study, the printability in terms of dimensional properties (height, width and internal diameter) and physicochemical properties of 3D printed cookies and textural and rheological characteristics of doughs containing different microalgae concentration levels of Spirulina and Chlorella was evaluated.

The addition of the two microalgae in dough led to a greater mechanical resistance during the 3D printing process, with a dominant elastic component versus viscous in all cases. An increase in force required for extrusion was clear at the time of adding microalgae, in almost all cases. The sample that required a greater force was the formulation containing $2 \%$ of Spirulina followed by all formulations with Chlorella, while the smallest was the formulation containing $1 \%$ of Spirulina. The best printing parameters for microalgae-enriched doughs are with a layer height of $1.5 \mathrm{~mm}$ and a filament diameter of $27 \mathrm{~mm}$. This gives greater defined cookies in terms of height and width proportions than the designed structure. Spirulina cookies at all concentrations, showing a yellow tonality with slight green while Chlorella cookies showed a yellowish colour with slight red at all concentrations.

In summary, the addition of microalgae biomass in doughs, to obtain 3D printed cookies, improves the printability in terms of dimensional properties, achieving 3D structures with more stability and resistance to baking. In addition, the results acquired from this study can 
give us knowledge regarding the role of microalgae biomasses as ingredient for food-inks. Understanding the effects of microalgae on 3D printed food and on post-processing of 3D printed foods in order to broadening its applications. 


\section{References}

Ares, G., Giménez, A., \& Gámbaro, A. (2006). Instrumental methods to characterize nonoral texture of dulce de leche. Journal of Texture Studies, 37(5), 553-567. doi: 10.1111/j.17454603.2006.00068.x

Bair, S., Yamaguchi, T., Brouwer, L., Schwarze, H., Vergne, P., \& Poll, G. (2014). Oscillatory and steady shear viscosity: The Cox - Merz rule, superposition, and application to EHL friction. Tribiology International, 79, 126-131. doi: 10.1016/j.triboint.2014.06.001

Batista, A. P., Gouveia, L., Bandarra, N. M., Franco, J. M., \& Raymundo, A. (2013). Comparison of microalgal biomass profiles as novel functional ingredient for food products. Algal Research, 2(2), 164-173. doi: 10.1016/j.algal.2013.01.004

Batista, A. P., Niccolai, A., Fradinho, P., Fragoso, S., Bursic, I., Rodolfi, L., Biondi, N., Tredici, M. R., Sousa, I., \& Raymundo, A. (2017). Microalgae biomass as an alternative ingredient in cookies: Sensory, physical and chemical properties, antioxidant activity and in vitro digestibility. Algal Research, 26(March), 161-171. doi: 10.1016/j.algal.2017.07.017

Bhattacharjee, N., Urrios, A., Kang, S., \& Folch, A. (2016). The upcoming 3D-printing revolution in microfluidics. Lab Chip, 16(10), 1720-1742. doi: 10.1039/C6LC00163G

Bodart, M., de Peñaranda, R., Deneyer, A., \& Flamant, G. (2008). Photometry and colorimetry characterisation of materials in daylighting evaluation tools. Building and Environment. doi: 10.1016/j.buildenv.2007.12.006

Brunner, T. A., Delley, M., \& Denkel, C. (2018). Consumers' attitudes and change of attitude toward 3D-printed food. Food Quality and Preference, 68(December 2017), 389-396. doi: 10.1016/j.foodqual.2017.12.010

Casales-Garcia, V., Museros, L., Sanz, I., Falomir, Z., \& Gonzalez-Abril, L. (2020). Extracting Feeling from Food Colour. In Microalgae Biotechnology for Food, Health and High Value Products (171st ed., pp. 15-24). Springer Singapur. doi: 10.1007/978-981-15-0169-2

Contini, C., Romano, C., Scozzafava, G., \& Casini, L. (2016). Food habits and the increase in ready-to-eat and easy-to-prepare products. In Food Hygiene and Toxicology in Ready-toEat Foods (pp. 3-14). Academic Press. doi: 10.1016/B978-0-12-801916-0.00001-7

Dankar, I., Haddarah, A., Omar, F. E. L., Sepulcre, F., \& Pujolà, M. (2018a). 3D printing technology: The new era for food customization and elaboration. Trends in Food Science and Technology, 75(July 2017), 231-242. doi: 10.1016/j.tifs.2018.03.018

Dankar, I., Pujolà, M., Omar, F. El, Sepulcre, F., \& Haddarah, A. (2018b). Impact of Mechanical and Microstructural Properties of Potato Puree-Food Additive Complexes on ExtrusionBased 3D Printing. Food and Bioprocess Technology, 11(11), 2021-2031. doi: $10.1007 / \mathrm{s} 11947-018-2159-5$ 
Derossi, A., Caporizzi, R., Ricci, I., \& Severini, C. (2019). Critical Variables in 3D Food Printing. In Fundamentals of 3D Food Printing and Applications. Elsevier Inc. doi: 10.1016/b978-0-12814564-7.00003-1

Devi, A., \& Khatkar, B. S. (2016). Physicochemical, rheological and functional properties of fats and oils in relation to cookie quality: a review. Journal of Food Science and Technology, 53(10), 3633-3641. doi: 10.1007/s13197-016-2355-0

Dick, A., Bhandari, B., \& Prakash, S. (2019). 3D printing of meat. Meat Science, 153(September 2018), 35-44. doi: 10.1016/j.meatsci.2019.03.005

Godoi, F. C., Prakash, S., \& Bhandari, B. R. (2016). 3d printing technologies applied for food design: Status and prospects. Journal of Food Engineering, 179, 44-54. doi: 10.1016/j.jfoodeng.2016.01.025

Gouveia, L., Batista, A. P., Miranda, A., Empis, J., \& Raymundo, A. (2007). Chlorella vulgaris biomass used as colouring source in traditional butter cookies. Innovative Food Science and Emerging Technologies, 8(3), 433-436. doi: 10.1016/j.ifset.2007.03.026

Guedes, A. C., Amaro, H. M., \& Malcata, F. X. (2011). Microalgae as sources of high added-value compounds-a brief review of recent work. Biotechnology Progress, 27(3), 597-613. doi: 10.1002/btpr.575

Huang, M., Zhang, M., \& Bhandari, B. (2019a). Assessing the 3D Printing Precision and Texture Properties of Brown Rice Induced by Infill Levels and Printing Variables. Food and Bioprocess Technology, 12(7), 1185-1196. doi: 10.1007/s11947-019-02287-x

Huang, M., Zhang, M., Bhandari, B., \& Liu, Y. (2019b). Improving the three-dimensional printability of taro paste by the addition of additives. Journal of Food Process Engineering, April, e13090. doi: 10.1111/jfpe.13090

Jiang, R., Kleer, R., \& Piller, F. T. (2017). Predicting the future of additive manufacturing: A Delphi study on economic and societal implications of 3D printing for 2030. Technological Forecasting and Social Change, 117, 84-97. doi: 10.1016/j.techfore.2017.01.006

Junk, S., \& Kuen, C. (2016). Review of Open Source and Freeware CAD Systems for Use with 3DPrinting. Procedia CIRP, 50, 430-435. doi: 10.1016/j.procir.2016.04.174

Kasapis, S., \& Bannikova, A. (2017). Rheology and Food Microstructure. In J. Ahmed, P. Ptaszek, \& S. B. T. Basu (Eds.), Advances in Food Rheology and Its Applications (pp. 7-46). Elsevier Ltd. doi: 10.1016/B978-0-08-100431-9.00002-4

Khan, M. I., Shin, J. H., \& Kim, J. D. (2018). The promising future of microalgae: Current status, challenges, and optimization of a sustainable and renewable industry for biofuels, feed, and other products. Microbial Cell Factories, 17(1), 1-21. doi: 10.1186/s12934-018-0879-x

Kim, H. W., Bae, H., \& Park, H. J. (2017). Classification of the printability of selected food for 3D printing: Development of an assessment method using hydrocolloids as reference material. 
Journal of Food Engineering, 215, 23-32. doi: 10.1016/J.JFOODENG.2017.07.017

Kim, H. W., Lee, I. J., Park, S. M., Lee, J. H., Nguyen, M. H., \& Park, H. J. (2019). Effect of hydrocolloid addition on dimensional stability in post-processing of 3D printable cookie dough. LWT - Food Science and Technology, 101(November 2018), 69-75. doi: 10.1016/j.Iwt.2018.11.019

Koller, M., Muhr, A., \& Braunegg, G. (2014). Microalgae as versatile cellular factories for valued products. Algal Research, 6(PA), 52-63. doi: 10.1016/j.algal.2014.09.002

Lafarga, T., Mayre, E., Echeverria, G., Viñas, I., Villaró, S., Acién-Fernández, F. G., Castellari, M., \& Aguiló-Aguayo, I. (2019). Potential of the microalgae Nannochloropsis and Tetraselmis for being used as innovative ingredients in baked goods. LWT - Food Science and Technology, 115(May), 108439. doi: 10.1016/j.lwt.2019.108439

Lanaro, M., Desselle, M. R., \& Woodruff, M. A. (2019). 3D Printing Chocolate: Properties of Formulations for Extrusion, Sintering, Binding and Ink Jetting. In F. C. Godoi, B. R. Bhandari, S. Prakash, \& M. Zhang (Eds.), Fundamentals of 3D Food Printing and Applications (pp. 151-173). Elsevier Inc. doi: 10.1016/B978-0-12-814564-7.00006-7

Lefebvre, J. (2009). Nonlinear, time-dependent shear flow behaviour, and shear-induced effects in wheat flour dough rheology. Journal of Cereal Science, 49(2), 262-271. doi: 10.1016/j.jcs.2008.10.010

Lipton, J. I. (2017). Printable food: the technology and its application in human health. Current Opinion in Biotechnology, 44, 198-201. doi: 10.1016/j.copbio.2016.11.015

Liu, Y., Liang, X., Saeed, A., Lan, W., \& Qin, W. (2019a). Properties of 3D printed dough and optimization of printing parameters. Innovative Food Science \& Emerging Technologies, 54(October 2018), 9-18. doi: 10.1016/J.IFSET.2019.03.008

Liu, Z., Bhandari, B., Prakash, S., Mantihal, S., \& Zhang, M. (2019b). Linking rheology and printability of a multicomponent gel system of carrageenan-xanthan-starch in extrusion based additive manufacturing. Food Hydrocolloids, 87(August 2018), 413-424. doi: 10.1016/j.foodhyd.2018.08.026

Liu, Z., Zhang, M., Bhandari, B., \& Yang, C. (2018a). Impact of rheological properties of mashed potatoes on 3D printing. Journal of Food Engineering, 220, 76-82. doi: 10.1016/j.jfoodeng.2017.04.017

Liu, Z., Zhang, M., \& Yang, C. (2018b). Dual extrusion 3D printing of mashed potatoes/strawberry juice gel. LWT - Food Science and Technology, 96(February), 589-596. doi: 10.1016/j.Iwt.2018.06.014

Mancebo, C. M., Rodriguez, P., \& Gómez, M. (2016). Assessing rice flour-starch-protein mixtures to produce gluten free sugar-snap cookies. LWT - Food Science and Technology, 67, 127132. doi: $10.1016 /$ j.Iwt.2015.11.045 
Martínez-Monzó, J., Cárdenas, J., \& García-Segovia, P. (2019). Effect of Temperature on 3D Printing of Commercial Potato Puree. Food Biophysics, 1-10. doi: 10.1007/s11483-01909576-0

Matos, J., Cardoso, C., Bandarra, N. M., \& Afonso, C. (2017). Microalgae as healthy ingredients for functional food: A review. Food and Function, 8(8), 2672-2685. doi: 10.1039/c7fo00409e

Nova, P., Martins, A. P., Teixeira, C., Abreu, H., Silva, J. G., Silva, A. M., Freitas, A. C., \& Gomes, A. M. (2020). Foods with microalgae and seaweeds fostering consumers health: a review on scientific and market innovations. Journal of Applied Phycology, 32(3), 1789-1802. doi: 10.1007/s10811-020-02129-w

Onacik-Gür, S., Zbikowska, A., \& Majewska, B. (2018). Effect of Spirulina (Spirulina platensis) addition on textural and quality properties of cookies. Italian Journal of Food Science, $30(1), 1-12$.

Pallottino, F., Hakola, L., Costa, C., Antonucci, F., Figorilli, S., Seisto, A., \& Menesatti, P. (2016). Printing on Food or Food Printing: a Review. In Food and Bioprocess Technology (Vol. 9, Issue 5, pp. 725-733). doi: 10.1007/s11947-016-1692-3

Pérez, B., Nykvist, H., Brøgger, A. F., Larsen, M. B., \& Falkeborg, M. F. (2019). Impact of macronutrients printability and 3D-printer parameters on 3D-food printing: A review. Food Chemistry, 287(October 2018), 249-257. doi: 10.1016/j.foodchem.2019.02.090

Plaza, M., Herrero, M., Alejandro Cifuentes, A., \& Ibáñez, E. (2009). Innovative natural functional ingredients from microalgae. Journal of Agricultural and Food Chemistry, 57(16), 71597170. doi: $10.1021 / \mathrm{jf} 901070 \mathrm{~g}$

Ricci, I., Derossi, A., \& Severini, C. (2019). 3D Printed Food From Fruits and Vegetables. In F. C. Godoi, B. R. Bhandari, S. Prakash, \& M. Zhang (Eds.), Fundamentals of 3D Food Printing and Applications (pp. 117-149). Elsevier Inc. doi: 10.1016/b978-0-12-814564-7.00005-5

Ringquist, J., Flannery, J., Stuart, K., Baum, M., Phillips, T., Renner, B. and Sides, R., Capitalizing on the shifting consumer food value equation", London, UK: Deloitte Development LLC, 2016. [Online] Available at: https://www2.deloitte.com/content/dam/Deloitte/us/Documents/consumer-business/us-fmi-gma-report.pdf. [Accessed, April 12, 2020]

Schniederjans, D. G. (2017). Adoption of 3D-printing technologies in manufacturing: A survey analysis. International Journal of Production Economics, 183, 287-298. doi: 10.1016/j.ijpe.2016.11.008

Severini, C., Azzollini, D., Albenzio, M., \& Derossi, A. (2018). On printability, quality and nutritional properties of 3D printed cereal based snacks enriched with edible insects. Food Research International, 106(November 2017), 666-676. doi: 10.1016/j.foodres.2018.01.034 
Severini, C., Derossi, A., \& Azzollini, D. (2016). Variables affecting the printability of foods: Preliminary tests on cereal-based products. Innovative Food Science and Emerging Technologies, 38, 281-291. doi: 10.1016/j.ifset.2016.10.001

Singh, P., Singh, R., Jha, A., \& Rasane, P. (2015). Optimization of a process for high fibre and high protein biscuit. Journal of Food Science and Technology, 52(3), 1394-1403. doi: $10.1007 / \mathrm{s} 13197-013-1139-z$

Sun, J., Zhou, W., Huang, D., Fuh, J. Y. H., \& Hong, G. S. (2015). An Overview of 3D Printing Technologies for Food Fabrication. Food and Bioprocess Technology, 8, 1605-1615. doi: $10.1007 / \mathrm{s} 11947-015-1528-6$

Uribe-Wandurraga, Z. N., Igual, M., García-Segovia, P., \& Martínez-Monzó, J. (2019). Effect of microalgae addition on mineral content, colour and mechanical properties of breadsticks. Food \& Function, 10(8), 4685-4692. doi: 10.1039/c9fo00286c

Uribe-Wandurraga, Z. N., Igual, M., García-Segovia, P., \& Martínez-Monzó, J. (2020). In vitro bioaccessibility of minerals from microalgae-enriched cookies. Food \& Function, 11, 21862194. doi: $10.1039 / \mathrm{c} 9 f 002603 \mathrm{~g}$

van der Weele, C., Feindt, P., van der Goot, A. J., van Mierlo, B., \& van Boekel, M. (2019). Meat alternatives: an integrative comparison. Trends in Food Science and Technology, 88(November 2018), 505-512. doi: 10.1016/j.tifs.2019.04.018

Vancauwenberghe, V., Delele, M. A., Aregawi, W., Verboven, P., Bongaers, E., Noort, M. W. J., de Schipper, M., Van den Eijnden, E., Van Bommel, K., \& Nicolai, B. (2017). Characterization and model-based design validation of 3D printed cookies. 7th Conference on Industrial Computed Tomography, iCT, 1-9. Retrieved from http://www.ndt.net/search/docs.php3?showForm=off\&id=20855

Wang, A., Yan, K., Chu, D., Nazer, M., Lin, N. T., Samaranayake, E., \& Chang, J. (2020). Microalgae as a Mainstream Food Ingredient: Demand and Supply Perspective. In M. A. Alam, J.-L. Xu, \& Z. Wang (Eds.), Microalgae Biotechnology for Food, Health and High Value Products (pp. 29-80). Singapore: Springer Nature Singapore Pte Ltd. doi: 10.1007/978-981-15-0169-2

Yang, F., Zhang, M., Fang, Z., \& Liu, Y. (2019). Impact of processing parameters and posttreatment on the shape accuracy of 3D-printed baking dough. International Journal of Food Science and Technology, 54(1), 68-74. doi: 10.1111/ijfs.13904

Yang, F., Zhang, M., Prakash, S., \& Liu, Y. (2018). Physical properties of 3D printed baking dough as affected by different compositions. Innovative Food Science \& Emerging Technologies, 49, 202-210. doi: 10.1016/J.IFSET.2018.01.001

Zhang, L., Lou, Y., \& Schutyser, M. A. I. (2018). 3D printing of cereal-based food structures containing probiotics. Food Structure, 18(August), 14-22. doi: 
10.1016/j.foostr.2018.10.002

Zhu, S., Stieger, M. A., van der Goot, A. J., \& Schutyser, M. A. I. (2019). Extrusion-based 3D printing of food pastes: Correlating rheological properties with printing behaviour. Innovative Food Science \& Emerging Technologies, 58(July), 102214. doi: 10.1016/j.ifset.2019.102214

Zydenbos, S., \& Humphrey-Taylor, V. (2003). Biscuits, Cookies, and Crackers. In Encyclopedia of Food Sciences and Nutrition (2nd ed., pp. 524-528). Academic Press. doi: 10.1016/B0-12227055-X/00103-6 



\section{Chapter 7}

\section{Printability and physicochemical properties of microalgae-enriched 3D-printed snacks}

This chapter has been published as:

Uribe-Wandurraga, Z. N., Zhang, L., Noort, M. W. J., Schutyser, M. A. I., García-Segovia, P., \& Martínez-Monzó, J. (2020). Printability and Physicochemical Properties of MicroalgaeEnriched 3D-Printed Snacks. Food and Bioprocess Technology. doi: 10.1007/s11947-020-02544-4 



\section{Abstract}

Microalgal biomass is a promising functional ingredient for innovative food products due to its potential health benefits given by its composition (protein, minerals, vitamins, pigments, fatty acids, sterol, and antioxidants). However, in practice the level of incorporation of microalgae in many products is limited due to amongst others the strong green colour. In this study, we investigated the potential of 3D food printing to incorporate microalgae in cereal snacks. Chlorella vulgaris and Arthrospira platensis were the microalgae evaluated. First, the effect of microalgae fortification on both the rheological properties and printability of batters and on the properties of snacks (i.e., shape, texture, and colour) were studied. Microalgae fortification improved the printability of batters using extrusion-based 3D printing, which was concluded from the increased extrusion force and shear modulus in comparison to those for the batter without microalgae. Subsequently, snacks enriched with $3 \%$ and $4 \%$ Chlorella provided most accurate printed structures. However, snacks with the latter levels of microalgae addition are probably not well accepted by consumers due to the strong green \& dark colour of the cereal snacks after baking. The next logical step could be to use co-axial food printing to hide the microalgae inside the snack. First co-axial printing experiments showed that this could be a feasible approach. 


\section{Introduction}

Microalgae are considered a promising ingredient for food application, which have many compounds with potential health benefits for humans like antioxidative, antihypertensive, immunomodulatory, anticancerogenic, hepato-protective, and anticoagulant (Caporgno et al., 2018). Chlorella vulgaris (Chlorella) and Arthrospira platensis (Spirulina) are two of the most well-known microalgae species. Chlorella is a unicellular organism and Spirulina is a filamentous multicellular cyanobacterium. They both live in fresh water and produce bioactive compounds like protein, minerals, vitamins, pigments, long chain polyunsaturated fatty acids, sterols, and antioxidants (Andrade, 2018). Availability of microalgae has led to the production of novel food products (Buono et al., 2014). In most studies microalgal biomass is added to traditionally baked-foods such as biscuits (Gouveia et al., 2008), bread (García-Segovia et al., 2017), breadsticks (Uribe-Wandurraga et al., 2019) and crackers (Batista et al., 2019). However, to the best of our knowledge, addition of microalgal biomass has not been thoroughly investigated to fabricate 3D printed foods (UribeWandurraga et al., 2020b; Vieira et al., 2020). In spite of their nutritional value, one of the main factors limiting the application of microalgae in wheat-based baked goods is their sensory colour perception (dark green colour), which is not generally associated with bakedfood products (Lafarga, 2019). In addition, visual appearance and acceptance and also, purchase intention for some products as yogurt (Barkallah et al., 2017), snacks (Lucas et al., 2018), cookies (Sahni et al., 2019) and broccoli soup (Lafarga et al., 2019) were affected by microalgae addition.

3D food printing is a promising technology to design and manufacture personalised foods, based on specific nutritional needs of individuals or of special consumer groups (e.g., hospital patients, school children, and athletes). Extrusion-based 3D food printing (3DFP) technique, is the most commonly used method for novel food fabrication (Sun et al., 2015; Pallottino et al., 2016; Pérez et al., 2019). For example, 3DFP has been used to obtain 3Dprinted cereal-based products (Noort et al., 2017) containing probiotics as a novel ingredient (Zhang et al., 2018) and to investigate the printing behaviour of other food materials such as mashed potato and milk protein paste (Martínez-Monzó et al., 2019) and gels based on xanthan/konjac gums (García-Segovia et al., 2020a). In addition, 3DFP could be an interesting technology to create novel food containing microalgae with better sensory perception by spatially distributing the ingredients (Schutyser et al., 2018). Thus, 3DFP 
using a coaxial extrusion nozzle (Vancauwenberghe et al., 2018) allows to design structures where the dark colour of microalgae in baked products is hidden.

Rheological and viscoelastic properties are critical to the printability of food materials in extrusion-based printing processes (Zhu et al., 2019). The food material used for extrusion printing should ideally be a pseudoplastic fluid with shear-thinning behaviour and rapid structural recovery ability, thereby facilitating that the material is easily extrudable and selfsupporting after deposition (Liu et al., 2017). However, how the addition of microalgae biomass influences the rheology and printability of batters is not fully understood yet. Moreover, little attention has been paid to the behaviour of the printed structures after postprocessing (e.g., baking) which is however a crucial step for products made with dough and batters. Other research has already showed that structures printed with dough or batters may rapidly deform after baking, leading to unacceptable quality changes (e.g., shape deformation) in the final product (Lipton et al., 2015). Therefore, improvement is needed for increasing the stability of 3D-printed structures after post-processing by modifying the formulation of printing materials or applying an intermediate process before baking (e.g., dehydration, refrigeration or freezing).

Snacks are small portions of food, generally eaten between typical meals, which have gained great popularity among consumers because of changes in lifestyles over recent years, with people spending less time preparing and consuming their food (Pedreschi et al., 2018). Therefore, snacks are chosen due to they could be considered interesting products to fortify with microalgae in order to improve their quality factors like texture, shape, colour, flavour, and nutritional content (Uribe-Wandurraga et al., 2020a).

The aim of our study was to investigate the printability (in terms of extrusion behaviour (via analysis of extrusion force) and shear modulus (via rheological assessment of 3D-printed snack batters containing microalgal biomass (Chlorella vulgaris and Arthrospira platensis). The effect of microalgal biomass addition on rheological properties of snack batters and texture of the final product was also studied. Furthermore, snacks were evaluated for changes in colour and dimensions (variations in width and height) of the 3D printed structures before and after post processing (i.e., baking). In addition, it was evaluated if 3DFP using a coaxial nozzle can be a method to hide microalgae fortified batter in the interior of the product. Wheat flour in the original recipe of the batter was partially replaced 
by different levels of freeze-dried microalgal biomass. The results of this study allow development of innovative food products containing microalgae which are attractive to consumers by means on 3D food printing technology.

\section{Materials and methods}

\section{Batter materials}

Freeze-dried Arthrospira platensis (Spirulina) and Chlorella vulgaris (Chlorella) were supplied from AlgaEnergy (S.A., Madrid, Spain). The biochemical composition of the different microalgae biomasses, which were provided by the supplier company, is presented in Table 1. Pure whole egg powder was purchased from Proteinvital (Landgold Fresh $\mathrm{GmbH}$, Ried im Traunkreis, Austria); pastry wheat flour, crystal sugar, sunflower oil, baking powder, and fat-free milk powder were purchased from a local supermarket (Alcampo, Valencia, Spain).

Table 1. Biochemical composition of the two microalgae biomasses used in the experiments ( $\mathrm{g}$ component /100 g biomass, dry weight).

\begin{tabular}{lcc}
\hline $\begin{array}{l}\text { Biochemical component } \\
\text { (g /100 g) }\end{array}$ & $\begin{array}{c}\text { Arthrospira platensis } \\
\text { (Spirulina) }\end{array}$ & $\begin{array}{c}\text { Chlorella vulgaris } \\
\text { (Chlorella) }\end{array}$ \\
\hline Lipid & 5 & 7.5 \\
Carbohydrate & 2.5 & 5 \\
Fibre & 13.5 & 20 \\
Protein & 67.5 & 55 \\
Salt & 1.5 & 0.5 \\
Minerals & 1.1 & 0.9 \\
\hline
\end{tabular}

\section{Batter preparation}

The batters were prepared according to procedure of Topkaya et al. (2019), with some modifications (Table 2). Two different types of batters were formulated replacing pastry wheat flour with different levels $(1,2,3$, and 4\%) of freeze-dried microalgal biomass (Spirulina and Chlorella); a control batter was also prepared without microalgae. Egg powder, granulated sugar, and water were whisked light and creamy with a blender (Braun $\mathrm{GmbH}$, Frankfurt, Germany) for 2 min at slow speed (speed 1). Subsequently, sunflower oil 
was added and blended in for 1 min at intermediate speed (speed 2.) Finally, freeze-dried microalgae, pastry wheat flour, baking powder, and milk powder were added to the mixture and further whisked at speed 2, until a creamy and lump-free texture was obtained. After mixing, each batter batch was transferred to a plastic syringe and was let to rest for 5 min at room temperature before the 3D printing experiment and further analysis.

Table 2. Ingredients of snack batters where pastry wheat flour was partially replaced with microalgae (Spirulina or Chlorella).

\begin{tabular}{lccccc}
\hline \multicolumn{1}{c}{ Ingredients } & \multicolumn{5}{c}{ Microalgae in snack batter (\%) } \\
\cline { 2 - 6 } & Control & $\mathbf{1}$ & $\mathbf{2}$ & $\mathbf{3}$ & $\mathbf{4}$ \\
\hline Wheat pastry flour & 38.45 & 37.45 & 36.45 & 35.45 & 34.45 \\
Water & 25 & 25 & 25 & 25 & 25 \\
Granulated sugar & 16 & 16 & 16 & 16 & 16 \\
Sunflower oil & 14 & 14 & 14 & 14 & 14 \\
Egg powder & 6 & 6 & 6 & 6 & 6 \\
Milk powder & 0.5 & 0.5 & 0.5 & 0.5 & 0.5 \\
Baking powder & 0.05 & 0.05 & 0.05 & 0.05 & 0.05 \\
Microalgae & 0 & 1 & 2 & 3 & 4 \\
\hline Total & 100 & 100 & 100 & 100 & 100 \\
\hline
\end{tabular}

\section{Snack preparation}

\section{D printing process}

The printing of batter structures was performed using a 3D food printer (ByFlow, The Netherlands) at room temperature. The 3D printing system is composed of two major components: an extrusion system (a syringe, mount piston, and nozzle) and a printhead, with a motored $X-Y-Z$ positioning system (Zhang et al., 2018). A structure comprised in a cylinder with a diameter of $35 \mathrm{~mm}$ and a height of $8 \mathrm{~mm}$ was chosen for printing the batter and was designed using Thinkercad (Thinkercad, free software, Autodesk, Inc., San Rafael, California, USA). The printing route of the 3D structure was constructed by using Slic3r software (Slic3r, free software, USA) and was exported as a g-code, which was sent to the printer to perform the required movements, positioning, and control of the printing process. 
The batter in the syringe was extruded mechanically through a nozzle (diameter $1.2 \mathrm{~mm}$, Nordson, USA) at a control speed of $8 \mathrm{~mm} / \mathrm{s}$, and the 3D cylinders (35 x $8 \mathrm{~mm}$ ) were printed layer-by-layer. Samples were printed in quadruplicate on baking paper.

\section{Processing of 3D-printed samples}

To minimise the collapse of the printed structures during baking process, the 3D-printed structures were first frozen at $-20^{\circ} \mathrm{C}$ for $90 \mathrm{~min}$ in a freezer (LCexv 4010 MEDLine, Liebherr, Germany). Then, the structures were baked at $105^{\circ} \mathrm{C}$ for $30 \mathrm{~min}$ on a stainless steel plate in a convection oven (Function Line T6, Heraeus Hanau, Germany). The internal temperature of the structure was measured using K-type thermocouples (Maxtermo-Gita, Taiwan). The tray with samples was placed in the central zone of the oven. All baking tests were conducted in quadruplicate. After baking, the cylindrical structures were cooled for $2 \mathrm{~h}$ before further analyses.

\section{Analyses of physicochemical properties}

\section{Rheological properties of batters}

Flow and oscillatory tests of snack batters were performed using a Kinexus pro+ rotational rheometer (Malvern Instruments, Worcestershire, UK) and rSpace software; equipped with a $25 \mathrm{~mm}$ diameter parallel-plate geometry (DSR II, Upper Plate) with a $2 \mathrm{~mm}$ gap between plates and a heat-controlled sample stage (Peltier Cylinder Cartridge, Malvern Instruments, Worcestershire, UK).

Flow tests were used to study the behaviour of shear stress with varying shear rate and viscosity profiles of batter samples. Shear rate $(\dot{\gamma})$ was ramped from 0.1 to $10 \mathrm{~s}^{-1}$ during 45 $\mathrm{S}$ at $25^{\circ} \mathrm{C}$. The behaviour parameters were calculated using SigmaPlot Software, version 11.0 (Systat Software Inc., USA). Before rheological measurements, batter samples were put in the rheometer and rested for $5 \mathrm{~min}$ before each measurement. Dynamic rheological characterisation of the samples was subsequently performed. First, strain sweep tests were conducted to identify the linear viscoelastic region at the fixed frequency of $1 \mathrm{~Hz}$, followed by oscillatory stress sweeps at $25{ }^{\circ} \mathrm{C}$ with a frequency range of $0.1-10 \mathrm{~Hz}$ for each sample using a constant strain of $0.01 \%$. Values of elastic modulus $\left(\mathrm{G}^{\prime}, \mathrm{Pa}\right)$ and viscous modulus $\left(G^{\prime \prime}, P a\right)$, indicating the dimensional stability of the materials, and $\tan \delta\left(G^{\prime \prime} / G^{\prime}\right)$ were 
obtained for different frequency values $(\omega, \mathrm{Hz})$. For all tests, samples were analysed in quadruplicate.

\section{Printability of batters}

The printability of the batters was assessed by measuring the shear modulus and extrusion hardness, which is the required force to extrude the material.

Shear modulus measurements were conducted using the same equipment and settings as described in rheological properties of batters section. The shear strain sweep ranged from 0.001 to $1 \%$ for $200 \mathrm{~s}$ at $25^{\circ} \mathrm{C}$. The measurements were conducted in quadruplicate and the average value was analysed.

The extrusion hardness of batters was performed using a TA-XT2 Texture Analyser (Stable Micro Systems Ltd, Godalming, UK) and software Texture Exponent (version 6.1.12.0) following a slightly modified procedure of Kim et al. (2019). The syringe, used in the 3D food printer (cylindrical chamber of $23 \mathrm{~mm}$ diameter x $100 \mathrm{~mm}$ height and $41.5 \mathrm{ml}$ volume), was fully filled with snack batter and extruded through a nozzle (1.2 mm aperture). An extrusion disc (23 mm diameter) attached to a $50 \mathrm{~kg}$ load cell was positioned centrally over the syringe and was placed at $100 \mathrm{~mm}$ height (in contact with the sample) and moved 10 $\mathrm{mm}$. The samples were extruded under the condition of the compression test mode with a pre-test and test speed of $0.02 \mathrm{~mm} / \mathrm{s}$, and post-test speed of $2 \mathrm{~mm} / \mathrm{s}$, calculated considering the $3 \mathrm{D}$ printing process conditions. The force during compression was recorded and the maximum load on the graph was taken as the extruded hardness. Four samples were measured in duplicate from each mixture and the results were present as the mean value.

\section{Water activity, water loss and moisture content}

Water activity $\left(\mathrm{a}_{\mathrm{w}}\right)$, for both batter and snack samples, was measured using an Aqua Lab water activity meter (Decagon Devices Inc., Pullman, WA, USA) at $25^{\circ} \mathrm{C}$. Water loss during baking was measured by the difference in weight before and after the baking process. Moisture content $\left(g_{w} / 100 \mathrm{~g}\right)$ of the final products was determined by vacuum oven drying at $105^{\circ} \mathrm{C}$ until achieving a constant snack sample weight (AOAC, 2005). Determinations were conducted in quadruplicate. 


\section{Colour measurement}

Batter and snack surface colour were measured using a Konica Minolta CR-400 colourimeter (Konica Minolta Chroma Meter CR-400, Tokyo, Japan) with the standard illuminant D65 and a visual angle of $10^{\circ}$. For batter colour, four batter samples were placed in a circular glass sample holder of $50 \mathrm{~mm}$ diameter and $10 \mathrm{~mm}$ height and were measured at three equidistant points, for each formulation. For snack colour, four snacks of each formulation were measured at three equidistant points on the same baking day. The measurement was taken at $8 \mathrm{~mm}$ in diameter. The results were expressed in terms of $\mathrm{L}^{*}$, brightness (increasing from 0 to 100 ); $a^{*}$, greenness to redness (negative to positive values, respectively); and $b^{*}$, blueness to yellowness (negative to positive values, respectively) according to the CIE*L*a*b* system (CIE, 1986). Chroma, C* ${ }_{a b}$ (saturation) and hue angle, $\mathrm{h}_{\mathrm{ab}}^{\circ}$, were also calculated, defined by equations 1 and 2, respectively.

$$
\begin{gathered}
C^{*}{ }_{a b}=\left[\left(a^{* 2}+b^{* 2}\right)\right]^{1 / 2} \\
\mathrm{~h}^{\circ}{ }_{a b}=\arctan \left(\frac{b^{*}}{a^{*}}\right)
\end{gathered}
$$

The total colour difference $(\Delta \mathrm{E})$ between samples with and without microalgae addition (control sample), for both batters and snacks, was determined using $L^{*} a * b *$ values according to equation 3 .

$$
\Delta E=\left[\left(\Delta L^{*}\right)^{2}+\left(\Delta a^{*}\right)^{2}+\left(\Delta b^{*}\right)^{2}\right]^{1 / 2}
$$

The measurements were conducted under constant lighting conditions, at $25^{\circ} \mathrm{C}$.

\section{Image analysis of 3D-printed samples}

Here the accuracy of the snack structures was compared to the original design. Digital photos of lateral and top views of each printed structure were taken using a digital colour camera Canon, mod. EOS30D (Canon, NY, USA), immediately after printing and baking the samples. The pictures were taken using a semi-professional kit to control illumination. The digital camera was positioned on a support placed at fixed distance from the sample to take pictures. A reference scale was used in each picture but in the final table was positioned 
only on the top. Photos were taken in quadruplicate for each sample. Images were processed using Image] software (Image], NIH, USA). Width and height of the samples were measured for the lateral view. Three measurements of each dimensional parameter were performed after printing each sample and after post-processing (baking). The difference between the dimensions (width and height) after printing and baking process comparing with the design cylindrical structure was used as a metric of variation of each dimension.

\section{Texture analysis of 3D-printed snacks}

The texture of the snacks was measured using an Instron Texture Analyser (3380 Series Universal, Instron, Norwood, Massachusetts, USA) and software Bluehill ${ }^{\circledR}$ Universal, in penetration mode with a cylinder of $1.7 \mathrm{~mm}$ diameter and probe plunged $2 \mathrm{~mm}$ at $1 \mathrm{~mm} / \mathrm{s}$. Four snacks of each formulation were measured at four equidistant points in the top view of the walls of the baked cylinder-shaped snacks on the same baking day. The resistance to penetration, or hardness, was determined by the total area below the force vs. time curve, corresponding to the penetration work (N.S) (Batista et al., 2017). Values were calculated using SigmaPlot Software, version 11.0. (Systat Software Inc., USA). Measurements were conducted in quadruplicate at $25^{\circ} \mathrm{C}$.

\section{Coaxial extrusion printing process}

A dual printhead (Supreme, TNO, The Netherlands) was used to deposit simultaneously two food-inks through a coaxial extrusion nozzle (outer diameter: 3mm; inner diameter: 1.6 $\mathrm{mm}$ ), in which the inner flow was the microalgae-enriched batter and the outer, the control batter, at volume ratio $80: 20$, respectively.

A structure comprised in a cylinder with a diameter of $50 \mathrm{~mm}$ and a height of $3 \mathrm{~mm}$ was chosen for printing the batter and was designed using G-code creator (version 5.0). The printing route of the 3D structure was constructed using the same software and was exported as a g-code, which was sent to the printer through Pronterface (Open-source software, version 3) to perform the required movements, positioning, and control of the printing process. This analysis was performed for the purpose of studying visually the printing behaviour of microalgae-enriched batters and control batter using a coaxial extrusion nozzle. 


\section{Statistical analysis}

An experimental design was used, with four replacement levels (1, 2, 3 and, 4\%) and two types of microalgae (Spirulina and Chlorella). The total quantity of samples with the experiment was replicated three times $(n=40)$. Analysis of variance (ANOVA) using Statgraphics Centurion XVII Software, version 17.2.04 with a confidence level of $95 \%$ ( $p<$ 0.05) applied to evaluate the differences among batter and snack samples. Furthermore, a correlation analysis for measured rheological, viscoelastic, and printability properties of batters, with a 95\% significance level, was conducted (Statgraphics Centurion XVII).

\section{Results and discussion}

\section{Physicochemical properties of batters}

Table 3 shows the results of $\mathrm{a}_{\mathrm{w}}$ and colour of batters with various fortification levels of microalgal biomass. The $\mathrm{a}_{\mathrm{w}}$ values of batter samples are between 0.89 to 0.93 . Compared to the control batter, the water activity slightly decreases $(p<0.05)$ in samples with added Spirulina and Chlorella, indicating that addition of microalgae could reduce the water absorption capacity due to the ability to compete for water with other constituents (proteins, fibres, lipids) in the batter system.

Colour of batters changed significantly $(p<0.05)$ upon addition of microalgae (Table 3 ). The lightness $L^{*}$ of the batters decreased significantly $(p<0.05)$ when the replacement level of microalgae increased. In addition, at the same replacement level of microalgae (1, $2,3$, and $4 \%)$, significant $(p<0.05)$ differences were found between batters enriched with Chlorella and Spirulina, resulting in a darker Spirulina batter. Furthermore, when comparing the control batter to microalgae-enriched batters, colour parameters $a^{*}$ and $b^{*}$ showed significant differences $(p<0.05)$. Higher replacement levels of Chlorella and Spirulina significantly $(p<0.05)$ increased the batters' green colour (negative $\mathrm{a}^{*}$ values) leading to green hues $\left(h_{\mathrm{ab}}^{\circ}=104-160\right)$ because of the chlorophyll content of both microalgae (Buono et al., 2014). Despite Spirulina content of 3-4\%, the differences in b* were not significant ( $p$ $>0.05$ ). However, at a microalgae addition of $4 \%$, for both microalgae, batters showed low chroma values. Overall, the values of $\Delta \mathrm{E}$ show significant colour differences $(p<0.05)$ when comparing the control batter to enriched batters. It is noted that values of $\Delta \mathrm{E}>3$ are perceived by the human eye (Bodart et al., 2008). 


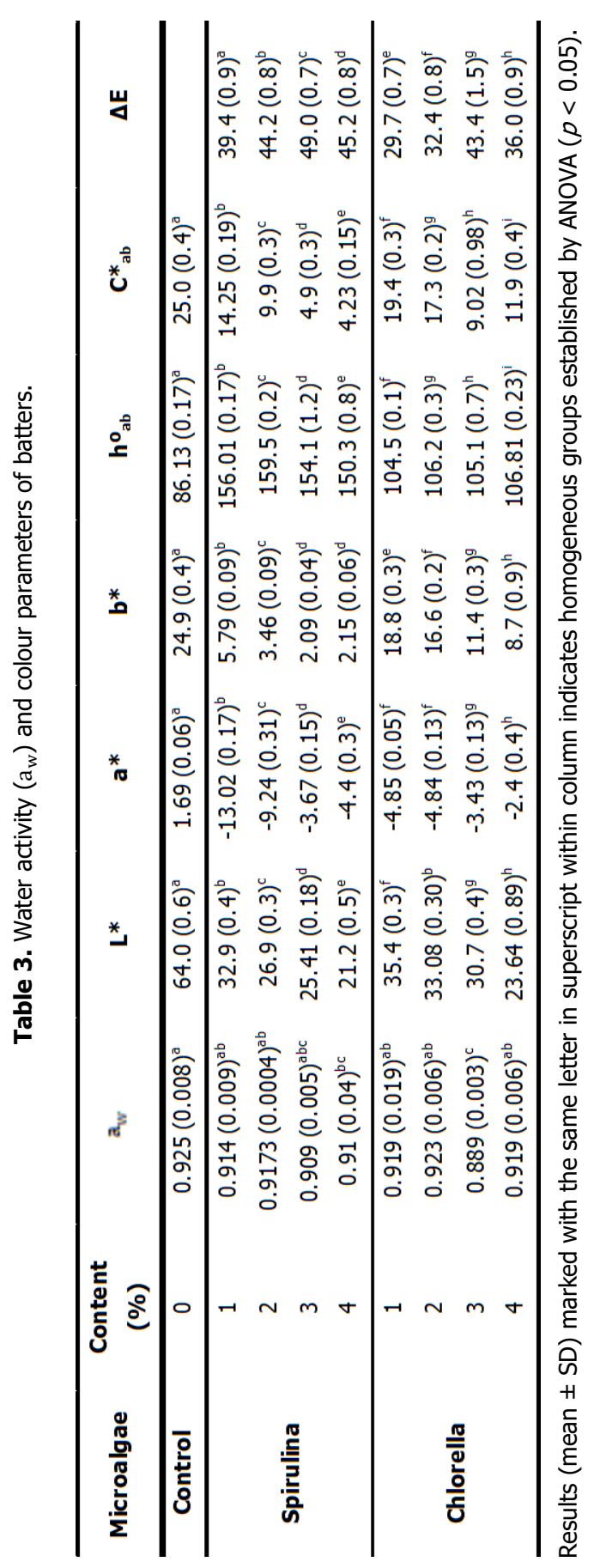




\section{Rheological and viscoelastic behaviour of batters}

Rheological behaviour of the batters is complex as the different added ingredients influence rheological and viscoelastic properties (Yang et al., 2018). To evaluate the flow behaviour of batters enriched with microalgae, the flow curves, plotting the experimental shear stress ( $\sigma$, Pa) as a function of the shear rate $\left(\gamma, \mathrm{s}^{-1}\right)$ data, are shown in Figures $1 \mathrm{a}$ and $1 \mathrm{~b}$. The Herschel-Bulkley model was fitted to the experimental obtained data to characterise the rheological behaviour of suspensions, emulsion, and pastes indicating non-Newtonian behaviour of the batters after yielding (Mantihal et al., 2019) (equation 4),

$$
\sigma=\sigma_{0}+\mathrm{K} \cdot \dot{\gamma}^{n}
$$

where $\sigma$ is the shear stress $(\mathrm{Pa}), \sigma_{0}$ is the yield stress $(\mathrm{Pa}), \mathrm{K}$ is the consistency coefficient $\left(\mathrm{Pa} \cdot \mathrm{s}^{\mathrm{n}}\right), \dot{\gamma}$ is the shear rate $\left(\mathrm{s}^{-1}\right)$, and $\mathrm{n}$ is the flow behaviour index.

The behaviour of all samples confirm a non-linear relationship exhibiting a non-Newtonian plastic and time dependent shear-thinning (thixotropic) behaviour between the shear stress over the whole range of shear rate studied $\left(0.01-10 \mathrm{~s}^{-1}\right)$ for all the emulsions (Figures $1 \mathrm{a}$ and $1 b)$. Viscosity $(\eta)$ profiles of all batters are obtained as a function of the shear rate $(\dot{\gamma})$ (Figures $1 \mathrm{c}$ and $1 \mathrm{~d}$ ). Figures $1 \mathrm{c}$ and $1 \mathrm{~d}$ show that the viscosity of batters decreased with increasing shear rate for all samples, indicating that the batters produced in this study are pseudoplastic fluids.

Figures 1a and 1c show that Spirulina-enriched batters at 4\% presented a higher shear stress vs. shear rate and also, viscosity vs. shear rate curve trend than the samples at different levels of Spirulina addition. Under the same rate, differences with respect to the Spirulima addition at 0, 1, 2 and 3\% were pronounced, although shear stress profiles for Spirulina-enriched batters at $1 \%$ and $3 \%$ and viscosity profiles, at $1 \%$ and $2 \%$ showed no significant $(p>0.05)$ differences. For Chlorella (Figures $1 \mathrm{~b}$ and $1 \mathrm{~d})$, enriched batters at 3\% presented a higher shear stress vs. shear rate and also, viscosity vs. shear rate curve trend than Chlorella-enriched batters at 0,1,2 and 4\%. However, under the same rate, samples with Chlorella addition at 0, 1, 2 and $4 \%$ showed no significant $(p>0.05)$ differences for shear stress profiles. The combination of proteins and polysaccharides and their interactions can be the responsible for significant changes in batter samples. 

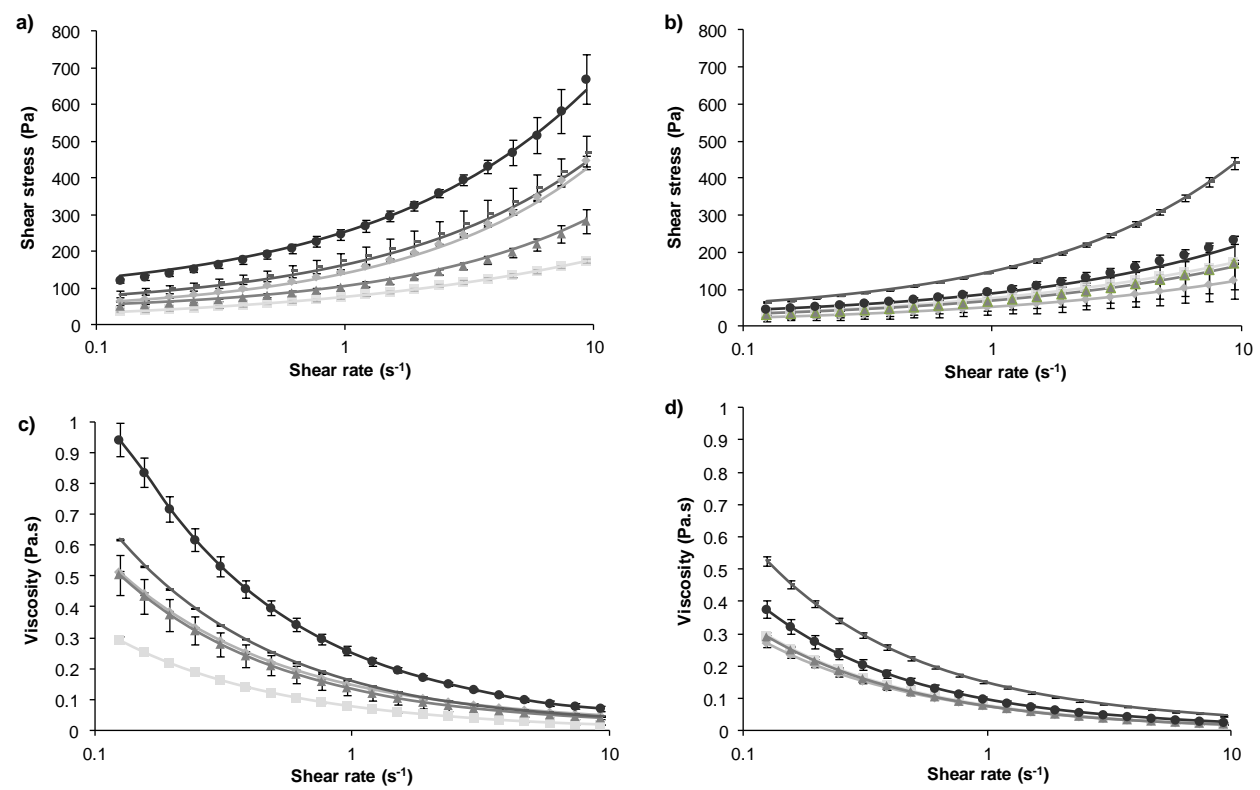

Figure 1. Flow behaviour of the assayed batters. Values obtained from Herschel-Bulkley model (bookmarks) and Shear stress $(\sigma)$ vs. Shear rate $(\dot{\gamma})$ (continuous lines) of a) Spirulina batter and b) Chlorella batter. Viscosity profiles of c) Spirulina batter and d) Chlorella batter at different microalgae

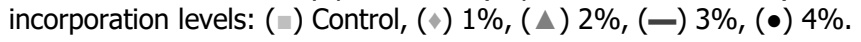

Table 4 summarises the rheological parameters of the batters with different microalgaeenriched replacement levels. Pseudoplasticity was confirmed by the flow behaviour indexes (n) of the Hershel-Bulkley model presented in Table 4, where an $n<1$ is characteristic of pseudoplastic materials. This is significant behaviour related to the ability of the material to extrude through the nozzle (Theagarajan et al., 2020). Here, batters fortified with Spirulina presented higher $\mathrm{n}$ values, without significant $(p>0.05)$ differences between content levels, comparing to the control and Chlorella batter samples (Table 4).

Incorporating microalgae in batter formulations increased the yield stress $\left(\sigma_{0}\right)$ compared to the control sample $(p<0.05)$, being more significant at higher replacement levels for both microalgae. Besides, the results indicated that the batters enriched with microalgae require a higher shear stress (i.e., a higher energy input) to induce flow (i.e., transition from elastic to viscous deformation) than the control batter. The consistency coefficient $(K)$ is an indicator of viscosity of the batter and is shown in Table 4. There was a significant difference $(p<0.05)$ in the consistency index of batters with and without microalgae. The $\mathrm{K}$ values of the batter increased as both microalgae incorporation levels increased, consistent 
with the results presented in Figures $1 \mathrm{c}$ and $1 \mathrm{~d}$. This was probably related to the high water holding capacity of polysaccharides, fibres and protein in microalgae, making the product more viscous.

Frequency sweep tests show for all the frequency range studied that the elastic modulus $\left(\mathrm{G}^{\prime}\right)$ was higher than the viscous modulus $\left(\mathrm{G}^{\prime \prime}\right)$ in batters with Spirulina (Figure 2a) and Chlorella (Figure 2b) biomass addition. This indicates solid-elastic like behaviour of all batters studied, being an important parameter for materials used for 3D food printing (Liu et al., 2019; Liu et al., 2020). Both $\mathrm{G}^{\prime}$ and $\mathrm{G}^{\prime \prime}$ progressively increased with the increasing angle frequency in all samples. Compared to the control sample, both microalgae $4 \%$ batters have significantly $(p<0.05)$ higher $\mathrm{G}^{\prime}$ and $\mathrm{G}^{\prime \prime}$ values at $1 \mathrm{~Hz}$ (Table 4 ). From Table 4 it can be derived that samples with microalgae at different levels of addition have significantly lower $\tan \delta(p<0.05)$, indicating a greater elastic behaviour. This may be explained by the high dry weight protein content of Spirulina and Chlorella biomass, $67 \%$ dry wt and 55\% dry wt, respectively (see Table 1) (Buono et al., 2014). Similar observation was reported for Spirulina and Chlorella addition at $1.5 \%$ in breadstick doughs (Uribe-Wandurraga et al., 2019).
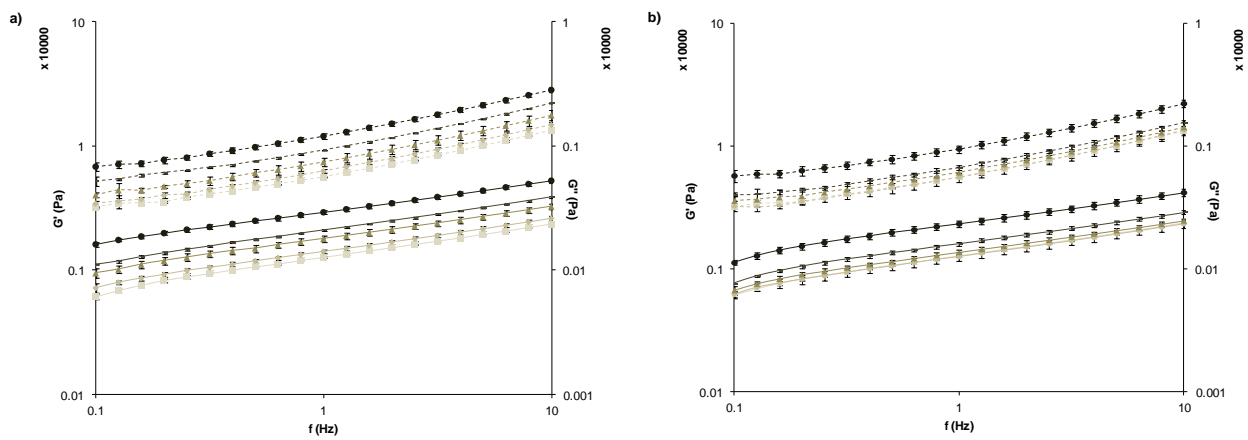

Figure 2. Frequency sweeps of a) Spirulina batter and b) Chlorella batter. Storage modulus ( $\left.\mathrm{G}^{\prime}\right)$ with continuous lines; loss modulus $\left(\mathrm{G}^{\prime \prime}\right)$ with dashed lines of studied batters at different microalgae incorporation level: ( $($ ) Control, (†) $1 \%,(\Delta) 2 \%,(-) 3 \%,(\bullet) 4 \%$. 


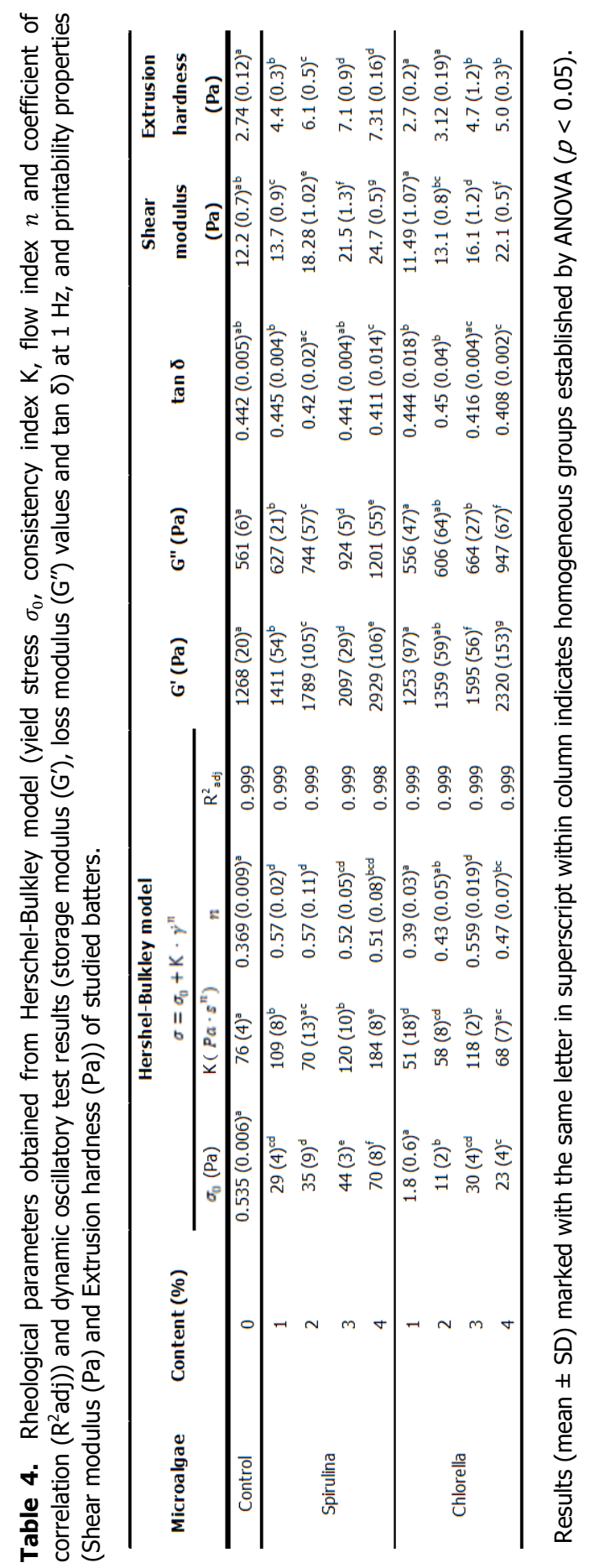




\section{Printability of batters}

Table 4 shows the printability of batters evaluated in terms of shear modulus ( $\mathrm{Pa}$ ) and extrusion hardness $(\mathrm{Pa})$. Shear modulus values can predict and quantify the deformation behaviour of samples after the 3D printing process (Kim et al., 2018). The addition of microalgal biomass contributed to a significant increase $(p<0.05)$ in the shear modulus of the batters than with the control batter. All samples show the shear modulus increased significantly when $4 \%$ microalgae is added. This increase in shear modulus indicates the incorporation of microalgae significantly improves the shape retention after deposition. The force required for extruding Spirulina batters significant increased $(p<0.05)$ when the replacement level of Spirulina biomass increased, whereas the extrusion hardness of Chlorella batters showed no significant differences at $1 \%$ and $2 \%$ and a slight increase at $3 \%$ and $4 \%$ of Chlorella biomass addition, compared with control sample. Although, there were no significant $(p>0.05)$ differences between extrusion hardness parameters with the addition of $3 \%$ and $4 \%$ of both microalgae, extrusion hardness values of Spirulina batters were greater than Chlorella batters reducing their extrudability. Thus, it makes difficult the uniform extrusion of the layers, which can result in to fatal defects in the resolution of the 3D printed products (Kim et al., 2019).

Spirulina is well recognised as a potential food supplement for humans because of its high levels of protein (60-70\% of dry weight) (Buono et al., 2014). Chlorella, also contains elevated levels of protein; however, less than Spirulina (Batista et al., 2013). In addition, microalgae show interesting polysaccharide fractions and are used as dietary supplements (Beheshtipour et al., 2013). The printability is an important parameter in 3D printing, which is related to the viscosity and the rheological properties of the food matrix. As the shear modulus is also a rheological parameter, the deformation behaviour of samples can be affected by the matrix composition (Caporizzi et al., 2019). Higher shear modulus can be indicating a possible strengthening effect of the batter structure due to a reinforcement of the viscoelastic protein matrix from the addition of microalgae, with high protein content compared to the control samples (Graça et al., 2018; Uribe-Wandurraga et al., 2019). Likewise, the combination of proteins and polysaccharides and their interactions can be the responsible for significant changes in hardness extrusion of Spirulina-enriched batter samples (Kim et al., 2018). 


\section{Correlation between rheological, viscoelastic, and printability properties}

The relationship between flow behaviour, rheological, and printability properties was analysed by statistics (Table 5). The results show there are strong correlations between microalgae content, $G^{\prime}, G^{\prime \prime}$, shear modulus, $\sigma_{0}$, and extrusion hardness. Positive relationships were found between the concentration of microalgae and $G^{\prime}(r=0.8459)$ and between the concentration and shear modulus $(r=0.8677)$. This could indicate that higher microalgae content in batters results in increased elastic like behaviour. Besides, the shear modulus ( $r=0.9400 ; r=0.9323$ ) was positively correlated with elastic and viscous modulus, indicating the system can flow and be extruded.

Table 5. Pearson correlation coefficients among rheological and printability parameters of batter samples.

\begin{tabular}{|c|c|c|c|c|c|c|c|c|}
\hline & $\begin{array}{r}b_{a} \\
(\mathrm{~Pa}) \\
\end{array}$ & $\begin{array}{c}\mathrm{K} \\
\left(\mathrm{Pa} \cdot \mathrm{s}^{\mathrm{n}}\right) \\
\end{array}$ & $n$ & $\begin{array}{c}\mathbf{G}^{\prime} \\
(\mathrm{Pa})\end{array}$ & $\begin{array}{c}\text { G" } \\
(\mathrm{Pa})\end{array}$ & Tan $\delta$ & $\begin{array}{c}\text { Shear } \\
\text { modulus } \\
(\mathrm{Pa}) \\
\end{array}$ & $\begin{array}{c}\text { Extrusion } \\
\text { hardness } \\
(\mathrm{Pa})\end{array}$ \\
\hline Microalgae content (\%) & $0.6939^{*}$ & $0.4976^{*}$ & $0.3636^{*}$ & $0.8459^{*}$ & $0.8241^{*}$ & $-0.5227^{*}$ & $0.8677^{*}$ & $0.6966^{*}$ \\
\hline$\sigma_{0}(\mathrm{~Pa})$ & & $0.8168^{*}$ & $0.6286^{*}$ & $0.8212^{*}$ & $0.8226^{*}$ & $-0.3776^{*}$ & $0.8043^{*}$ & $0.8849 *$ \\
\hline$K\left(\mathrm{~Pa} \cdot \mathrm{s}^{\mathrm{n}}\right)$ & & & $0.3473^{*}$ & $0.6668^{*}$ & $0.6802^{*}$ & $-0,2339$ & $0.6162^{*}$ & $0.6795^{*}$ \\
\hline$n$ & & & & 0,3129 & 0,2856 & $-0.3772^{*}$ & $0.3419^{*}$ & $0.5788^{*}$ \\
\hline$G^{\prime}(\mathrm{Pa})$ & & & & & $0.9887^{*}$ & $-0.5037^{*}$ & $0.9400^{*}$ & $0.7964^{*}$ \\
\hline G" (Pa) & & & & & & $-0.3736^{*}$ & $0.9323^{*}$ & $0.7960^{*}$ \\
\hline $\operatorname{Tan} \delta$ & & & & & & & $-0.4921^{*}$ & $-0.4222^{*}$ \\
\hline Shear modulus $(\mathrm{Pa})$ & & & & & & & & $0.8449^{*}$ \\
\hline
\end{tabular}

* Correlation is significant at $p<0.05$.

Furthermore, the extrusion hardness presented a high Pearson coefficient value with the yield stress $\left(\sigma_{0}\right)$. Positive correlation $(r=0.8449)$ was also seen between shear modulus and extrusion hardness, allowing us to explain the relationship between both parameters in terms of printability. Though properties of printing material can be affected by many factors, such as type of microalgae, their composition and addition level into the mixture (Caporizzi et al., 2019), the correlation between rheological, viscoelastic, and printability properties can be established so far.

\section{D printing and post-processing}

The 3D-printed and baked microalgae-enriched batters were smoothly extruded and the freshly printed exhibiting good shape retention than the control sample (Figure 3). However, the top layers of the printed cylinders with 1 and $2 \%$ microalgae-enriched batters differed 
from the original geometric design. Batters with 3 and 4\% Spirulina showed a predominant elastic batter behaviour comparing with other formulations, which probably explains the elastic thread and distortion of the structure during the final stage of 3D printing process (i.e., the upper part of the structure). Nevertheless, snacks enriched with 3 and $4 \%$ Chlorella resulted in more accurately printed structures.

Figure 4 shows the variation in width (structures' diameter) and height of the microalgae snacks compared to the design cylindrical structure after printing and baking process (postprocessing). Width and height of microalgae-enriched snacks after printing and baking changed $(p<0.05)$ compared to the design cylindrical structure. When the same printing setting was applied, the control printed snack showed a remarkable deformed structure, with increasing width $(0.46 \mathrm{~mm})$ and decreasing height $(-0.28 \mathrm{~mm})$ after the printing process (Figure 4a). Meanwhile, the microalgae-enriched printed snacks showed small variations of length, decreasing for Spirulina and increasing for Chlorella, independent of the microalgae replacement levels $(p>0.05)$. In contrast, 3 and $4 \%$ microalgae samples showed less variation in height of the structures; especially $4 \%$ Chlorella $(0.003 \mathrm{~mm})$. Graça et al. (2018) indicated that samples with the addition of up to $3 \mathrm{~g} / 100 \mathrm{~g}$ Ch/orella changed the rheological properties of doughs, observing an increase of the viscoelastic parameters which can be attributed to the reinforcement of the viscoelastic protein network.

Figure 3 shows the effect of baking on the deformation behaviour of printed baked snacks. Figure $4 \mathrm{~b}$ shows a negative variation in width $(-0.1 \mathrm{~mm})$ and height $(-0.3 \mathrm{~mm})$ for the control sample compared with the designed structure. Although Chlorella exhibited better printability than Spirulina, greater deviation from the designed structure in terms of width and height was seen after baking samples enriched with Chlorella $(p<0.05)$. However, no significant $(p>0.05)$ differences for deviation in width for Spirulina were observed. The variation in width of baked samples was slightly higher than the unbaked printed samples, with a variation of $0.01 \mathrm{~mm}$ to $0.1 \mathrm{~mm}$ for Spirulina and $0.04 \mathrm{~mm}$ to $0.1 \mathrm{~mm}$ for Chlorella. This may be caused by the baking powder in the formulation, which induced expansion of the structures during baking. 


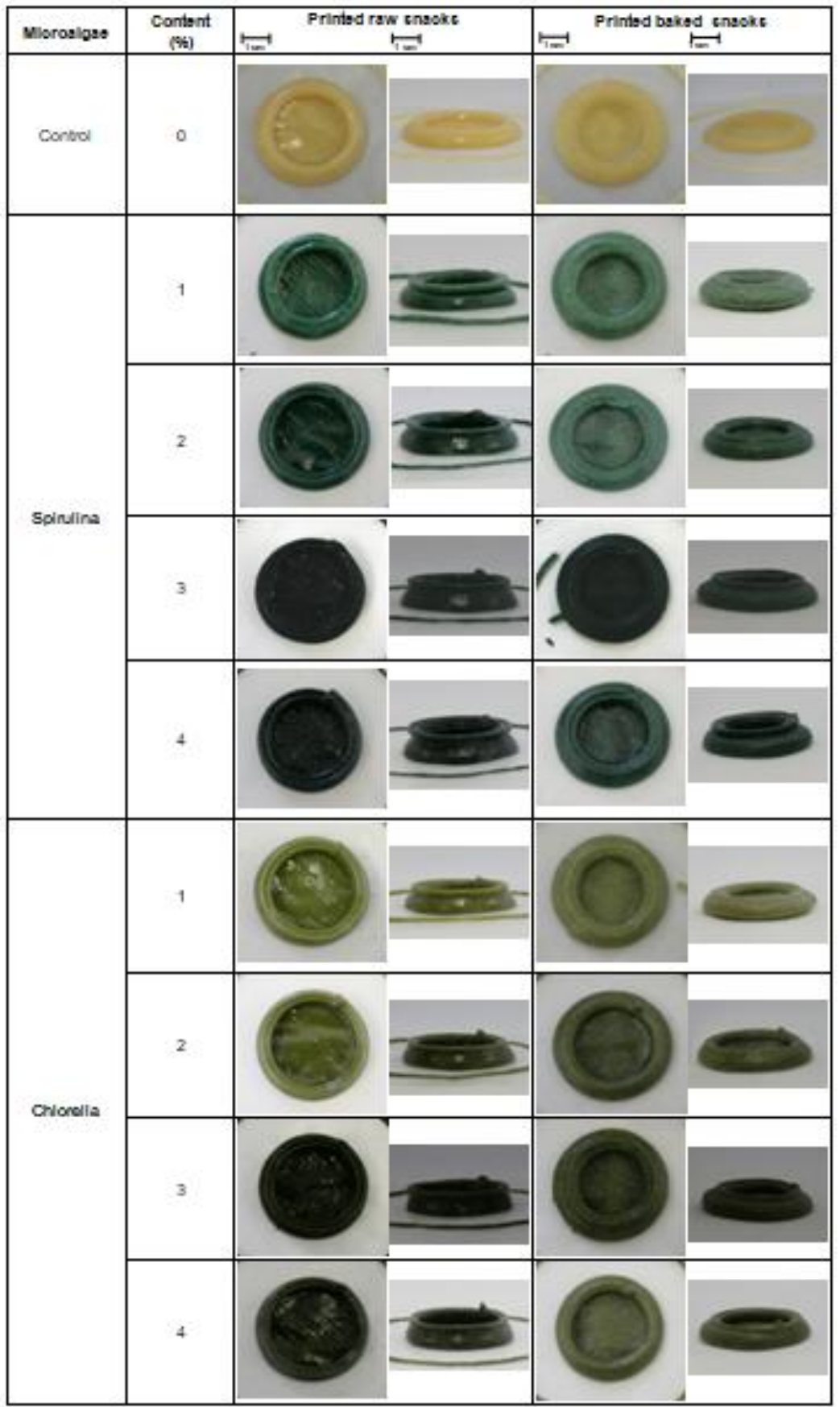

Figure 3. Three-dimensional printed and baked snacks photos obtained at different microalgae incorporation levels. 

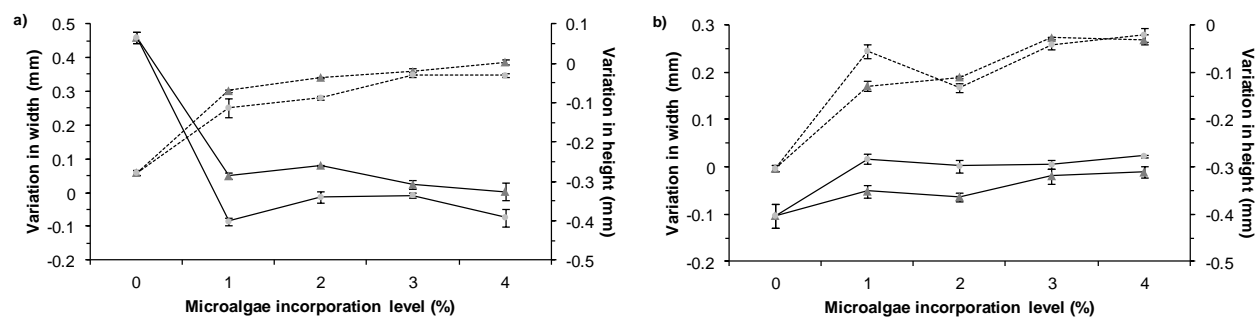

Figure 4. Variation in width (continuous lines) and in height (dashed lines) of cylinder-shaped snack with addition of Spirulina (circle symbol) and Chlorella (triangular symbol). a) After 3D printing and b) After baking, compared to the design cylindrical structure.

\section{Evaluation of 3D-printed snacks}

\section{Water content}

3D-printed microalgae-enriched snacks were evaluated in terms of $\mathrm{a}_{\mathrm{w}}$, water loss, moisture content, optical, and textural properties (Table 6). Moisture content of cereal baked products is important for quality and influences retrogradation during storage (Cai et al., 2014). The water activity of 3D-printed snacks tested in this study ranged from 0.69 to 0.81 with significant differences $(p<0.05)$ between microalgae-enriched snacks and the control snack samples existing. The mass transfer characteristics associated to baking include an evaporation front moving from the surface towards the product core (Ureta et al., 2014). Microalgae incorporation in snacks resulted in a significant $(p<0.05)$ decrease in water loss compared to the control sample during the baking process. This was probably because of the higher water holding capacity of polysaccharides in microalgae, especially Chlorella (Fradique et al., 2010). All snacks presented moisture content values ranging from 15.9 to $19.2\left(g_{\mathrm{w}} / 100 \mathrm{~g}\right)$ with slight significant $(p<0.05)$ differences, typical for this type of muffinbase baked goods formulation. All microalgae formulations showed moisture content significantly $(p<0.05)$ lower than the control.

\section{Colour}

Microalgae-enriched snacks presented green tonalities (Figure 3). Colour is a very important property defining the consumer acceptability of baked products (Kohajdová et al., 2011). Mean values of colour parameters of 3D-printed snacks are shown in Table 6. Regarding the lightness parameter $L^{*}$ significantly $(p<0.05)$ reduces after baking with the addition and increasing amounts of microalgae incorporation for both species compared with the control, 
causing darkening of the snacks. This effect may be associated to a higher pigment degradation of chlorophyll and carotenoids because of the baking process; or with a pigment saturation effect above certain microalgae concentrations, contributing to colour changes in microalgae-enriched snacks (Batista et al., 2019). It may be questionable if such dark green colours are acceptable for consumers.

Water loss and changes in the dimension of structure occurring upon baking can also greatly influence the appearance of snacks (Batista et al., 2019). As expected, the addition of microalgae with increasing levels from 1 to $4 \%$ decreased $a^{*}$ and $b^{*}$ values of microalgae-enriched snacks colours significantly $(p<0.05)$ (Table 6$)$.

The same phenomena were observed in other studies about cookies (Batista et al., 2017) and breadsticks (Uribe-Wandurraga et al., 2019) with added Spirulina and Chlorella biomass. However, no significant $(p>0.05)$ differences for $\mathrm{a}^{*}, \mathrm{~b}^{*}, \mathrm{~h}_{\mathrm{ab}}^{\circ}$, and $\mathrm{C}^{*}{ }_{\mathrm{ab}}$ values for 3 and $4 \%$ of Chlorella snacks were observed. Table 6 also presents the total colour differences $(\Delta \mathrm{E})$ between microalgae-enriched snacks; 3D-printed snacks with microalgae showed significant $(p<0.05)$ colour differences compared to the control snacks, because of the baking process.

\section{Texture}

The texture of the baked snacks was evaluated by a penetration test. The hardness of the sample, expressed by the resistance to penetration work, was presented in Figure 5. Snacks enriched with microalgae showed greater hardness than the control snack, regardless of the type of microalgae incorporated. This was probably due to the decreased moisture content in the microalgae-enriched snacks after baking (Table 6). In addition, increasing microalgae concentration from 3 to $4 \%$ causes significant $(p<0.05)$ hardness increases, from 1.6 to $2.4 \mathrm{~N} \cdot \mathrm{s}$ for Spirulina and 1.5 to $2.3 \mathrm{~N} \cdot \mathrm{s}$ for Chlorella snacks. These results agree with studies conducted where an increase in cookie hardness with Spirulina and Chlorella addition was observed (Batista et al., 2017) and in cookies with Chlorella concentrations from 0.5 to 3.0\% (Gouveia et al., 2007). Microalgae protein and carbohydrate molecules play key roles in the water absorption process in batters. They can increase snack hardness and relates to the control snack having higher water loss than both the microalgae-enriched snacks models. The positive effect of the microalgae to maintain the structure of the snacks is shown in this study. 


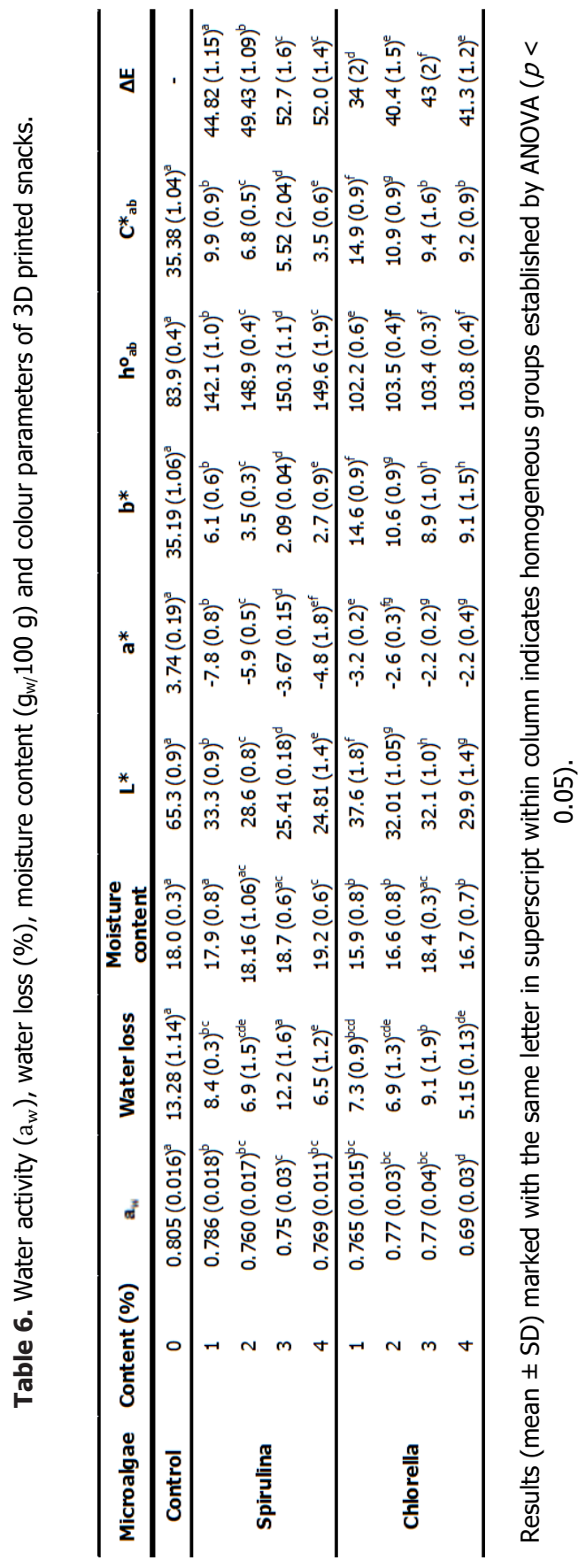




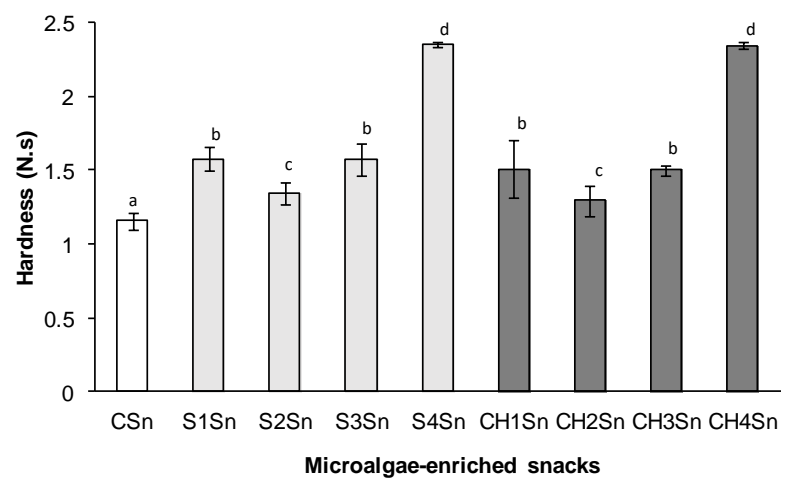

Figure 5. Texture profile expressed by penetration work (hardness) of microalgae-enriched baked snacks with different incorporation levels. The same small letter within bars indicates homogeneous groups established by ANOVA $(p<0.05)$. Sn: Snacks samples; C: Control; S: Spirulina; $\mathrm{CH}$ : Chlorella; $1,2,3$ and, 4: Microalgae incorporation levels (\%).

To summarize, 3D microalgae-enriched printed snacks presenting an innovative and attractive aspect to food product manufacture. Microalgae enrichment, greater than $1.5 \%$, of baked cereal-based food increases potassium, sodium, calcium, iron, and selenium, important minerals in human nutrition (Uribe-Wandurraga et al., 2019). However, the increase of the green colour hues and low $L^{*}$ values, as microalgae incorporation increase can affect the consumer perception, probably resulting in a lower acceptability of the product (Cervejeira Bolanho et al., 2014). We showed that microalgae-enriched batters may be well used for 3D printing.

\section{Coaxial extrusion printing experiment}

One of the sensorial challenges of microalgae-enriched foods is the dark colour, especially when the concentration of microalgae increases in their formulations (Figure 3). Some authors have found that baked-foods enriched with Chlorella and Spirulina at concentration levels higher than $2.6 \%(\mathrm{w} / \mathrm{w})$ showed low scores in colour perception, appearance, overall acceptability and purchase intention using a 5-point and 9-point hedonic scale (Lucas et al., 2018; Sahni et al., 2019). In order to obtain more attractive baked products, hiding the dark colour of microalgae in snacks, but considering the microalgae based breadstick is just as acceptable as the breadstick without microalgae addition (García-Segovia et al., 2020b); a good alternative would be to use a dual coaxial nozzle printing (Figures $6 a$ and $6 \mathrm{~b}$ ). 

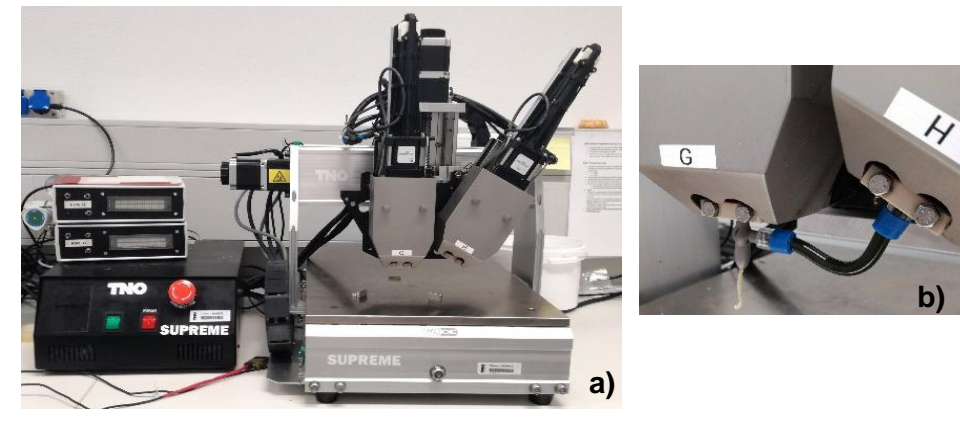

Figure 6. Supreme

TNO 3D food printer:

a) Dual printhead;

b) Coaxial extrusion nozzle.

b)

a)

Therefore, once 3D microalgae-enriched printed batters and snacks were analysed and the printing behaviour was studied, coaxial extrusion was used for printing new cylinder-shaped batter samples. Using a coaxial nozzle allowed us to deposit two batters at the same time (inner layer: microalgae-enriched batter; outer layer: control batter without microalgal biomass). In this way, we created a structure in which the green colour of microalgae batter was hidden because the control batter is covering it in the final structure (Figure 7). Thus, formulating new batter batches with higher microalgae incorporation levels (greater than the levels described in this study) to be use as inner ink-food in coaxial extrusion can provide an improved appearance that could be better accepted by consumers.

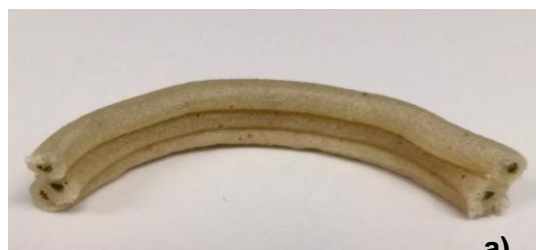

a)

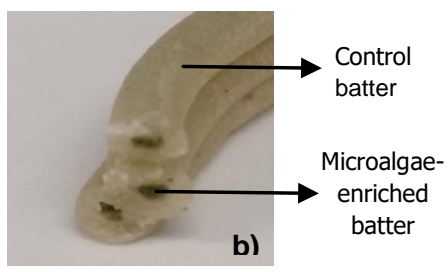

b)

Figure 7. Photos of the structure printed by Fused Deposit Modelling (FDM) through a coaxial extrusion nozzle. Inner batter: microalgae-enriched batter; Outer batter: control batter without microalgal biomass. a) Perpendicular cut to the base and b) Crossection, of the 3D printed structure. 


\section{Conclusions}

In this study, the effect of microalgae addition on the printability of batters and physicochemical properties of 3D-printed snacks were investigated after printing and baking. Microalgae addition changed properties such as $\mathrm{a}_{\mathrm{w}}$, water loss, moisture content, optical, rheological, and texture properties compared to the control batter and 3D control snacks. Batters showed rheological and viscoelastic behaviour suitable for the printing process. The snack batters with 3 and $4 \%$ of microalgae provided most accurate printed structures. Microalgae-enriched snacks showed greener tones than the control with the total colour difference values of snacks perceptible by the consumer. However, the effects of baking cause changes in colour increasing brown tones. These colour changes at 1 and $2 \%$ microalgae addition are small in comparison with the nutritive benefits reported for incorporating microalgae, up to $3 \mathrm{~g} / 100 \mathrm{~g}$ sample. To obtain quality snacks with more acceptable colour future studies could employ coaxial extrusion-based food printing. 


\section{References}

Andrade, L. M. (2018). Chlorella and Spirulina Microalgae as Sources of Functional Foods, Nutraceuticals, and Food Supplements; an Overview. MOJ Food Processing \& Technology, 6(1), 45-58. doi: 10.15406/mojfpt.2018.06.00144

AOAC. (2005). Official Methods of Analysis of AOAC International. Association of Official Analysis Chemists International.

Barkallah, M., Dammak, M., Louati, I., Hentati, F., Hadrich, B., Mechichi, T., Ayadi, M. A., Fendri, I., Attia, H., \& Abdelkafi, S. (2017). Effect of Spirulina platensis fortification on physicochemical, textural, antioxidant and sensory properties of yogurt during fermentation and storage. LWT - Food Science and Technology, 84, 323-330. doi: 10.1016/j.Iwt.2017.05.071

Batista, A. P., Gouveia, L., Bandarra, N. M., Franco, J. M., \& Raymundo, A. (2013). Comparison of microalgal biomass profiles as novel functional ingredient for food products. Algal Research, 2(2), 164-173. doi: 10.1016/j.algal.2013.01.004

Batista, A. P., Niccolai, A., Bursic, I., Sousa, I., Raymundo, A., Rodolfi, L., Biondi, N., \& Tredici, M. R. (2019). Microalgae as Functional Ingredients in Savory Food Products: Application to Wheat Crackers. Foods, 8(611), 1-22. doi: 10.3390/foods8120611

Batista, A. P., Niccolai, A., Fradinho, P., Fragoso, S., Bursic, I., Rodolfi, L., Biondi, N., Tredici, M. R., Sousa, I., \& Raymundo, A. (2017). Microalgae biomass as an alternative ingredient in cookies: Sensory, physical and chemical properties, antioxidant activity and in vitro digestibility. Algal Research, 26(March), 161-171. doi: 10.1016/j.algal.2017.07.017

Beheshtipour, H., Mortazavian, A. M., Mohammadi, R., Sohrabvandi, S., \& Khosravi-Darani, K. (2013). Supplementation of Spirulina platensis and Chlorella vulgaris algae into probiotic fermented milks. Comprehensive Reviews in Food Science and Food Safety, 12(2), 144154. doi: $10.1111 / 1541-4337.12004$

Bodart, M., de Peñaranda, R., Deneyer, A., \& Flamant, G. (2008). Photometry and colorimetry characterisation of materials in daylighting evaluation tools. Building and Environment. doi: 10.1016/j.buildenv.2007.12.006

Buono, S., Langellotti, A. L., Martello, A., Rinna, F., \& Fogliano, V. (2014). Functional ingredients from microalgae. Food and Function, 5(8), 1669-1685. doi: 10.1039/c4fo00125g

Cai, L., Choi, I., Hyun, J. N., Jeong, Y. K., \& Baik, B. K. (2014). Influence of bran particle size on bread-baking quality of whole grain wheat flour and starch retrogradation. Cereal Chemistry, 91(1), 65-71. doi: 10.1094/CCHEM-02-13-0026-R

Caporgno, M. P., \& Mathys, A. (2018). Trends in Microalgae Incorporation Into Innovative Food Products With Potential Health Benefits. Frontiers in Nutrition, 5(July), 1-10. doi: 
10.3389/fnut.2018.00058

Caporizzi, R., Derossi, A., \& Severini, C. (2019). Cereal-Based and Insect-Enriched Printable Food. In Fundamentals of 3D Food Printing and Applications. Elsevier Inc. doi: 10.1016/b978-012-814564-7.00004-3

Cervejeira Bolanho, B., Buranelo Egea, M., Morocho Jácome, A. L., Campos, I., Monteiro de Carvalho, J. C., \& Godoy Danesi, E. D. (2014). Antioxidant and nutritional potential of cookies enriched with Spirulina platensis and sources of fibre. Journal of Food and Nutrition Research, 53(2), 171-179. doi: 10.1093/humrep/deq166

Fradique, M., Batista, A. P., Nunes, M. C., Gouveia, L., Bandarra, N. M., \& Raymundo, A. (2010). Incorporation of Chlorella vulgaris and Spirulina maxima biomass in pasta products. Part 1: Preparation and evaluation. Journal of the Science of Food and Agriculture, 90(10), 16561664. doi: 10.1002/jsfa.3999

García-Segovia, P., García-Alcaraz, V., Balasch-Parisi, S., \& Martínez-Monzó, J. (2020a). 3D printing of gels based on xanthan/konjac gums. Innovative Food Science \& Emerging Technologies, 102343. doi: https://doi.org/10.1016/j.ifset.2020.102343

García-Segovia, P., García-Alcaraz, V., Tárrega, A., \& Martínez-Monzó, J. (2020b). Consumer perception and acceptability of microalgae based breadstick. Food Science and Technology International. doi: 10.1177/1082013220906235

García-Segovia, P., Pagán-Moreno, M., Lara, I., \& Martínez-Monzó, J. (2017). Effect of microalgae incorporation on physicochemical and textural properties in wheat bread formulation. Food Science and Technology International, 23(5), 437-447. doi: 10.1177/1082013217700259

Gouveia, L., Batista, A. P., Miranda, A., Empis, J., \& Raymundo, A. (2007). Chlorella vulgaris biomass used as colouring source in traditional butter cookies. Innovative Food Science \& Emerging Technologies, 8(3), 433-436. doi: 10.1016/J.IFSET.2007.03.026

Gouveia, L., Batista, A. P., Sousa, I., Raymundo, A., \& Bandarra, N. M. (2008). Microalgae in novel food products. In K. N. Papadopoulos (Ed.), Food Chemistry Research Developments (pp. 1-36). Nova Science Publishers, Inc.

Graça, C., Fradinho, P., Sousa, I., \& Raymundo, A. (2018). Impact of Chlorella vulgaris on the rheology of wheat flour dough and bread texture. LWT - Food Science and Technology, 89 (July 2017), 466-474. doi: 10.1016/j.Iwt.2017.11.024

Huang, M., Zhang, M., \& Bhandari, B. (2019). Assessing the 3D Printing Precision and Texture Properties of Brown Rice Induced by Infill Levels and Printing Variables. Food and Bioprocess Technology, 12(7), 1185-1196. doi: 10.1007/s11947-019-02287-x

Kim, H. W., Lee, I. J., Park, S. M., Lee, J. H., Nguyen, M. H., \& Park, H. J. (2019). Effect of hydrocolloid addition on dimensional stability in post-processing of 3D printable cookie dough. LWT - Food Science and Technology, 101(November 2018), 69-75. doi: 
10.1016/j.Iwt.2018.11.019

Kim, H. W., Lee, J. H., Park, S. M., Lee, M. H., Lee, I. W., Doh, H. S., \& Park, H. J. (2018). Effect of Hydrocolloids on Rheological Properties and Printability of Vegetable Inks for 3D Food Printing. Journal of Food Science, 83(12), 2923-2932. doi: 10.1111/1750-3841.14391

Kohajdová, Z., Karovičacová, J., Jurasová, M., \& Kukurová, K. (2011). Application of citrus dietary fibre preparations in biscuit production. Journal of Food and Nutrition Research, 50(3), 182-190.

Lafarga, T. (2019). Effect of microalgal biomass incorporation into foods: Nutritional and sensorial attributes of the end products. Algal Research, 41(101566). doi: 10.1016/j.algal.2019.101566

Lafarga, T., Acién-Fernández, F. G., Castellari, M., Villaró, S., Bobo, G., \& Aguiló-Aguayo, I. (2019). Effect of microalgae incorporation on the physicochemical, nutritional, and sensorial properties of an innovative broccoli soup. LWT - Food Science and Technology, 111, 167-174. doi: 10.1016/J.LWT.2019.05.037

Lipton, J. I., Cutler, M., Nigl, F., Cohen, D., \& Lipson, H. (2015). Additive manufacturing for the food industry. Trends in Food Science and Technology, 43(1), 114-123. doi: 10.1016/j.tifs.2015.02.004

Liu, Y., Zhang, W., Wang, K., Bao, Y., Regenstein, J. Mac, \& Zhou, P. (2019). Fabrication of Gellike Emulsions with Whey Protein Isolate Using Microfluidization: Rheological Properties and 3D Printing Performance (Food and Bioprocess Technology, (2019), 12, 12, (1967-1979), 10.1007/s11947-019-02344-5). Food and Bioprocess Technology, 12(12), 1980-1981. doi: 10.1007/s11947-019-02356-1

Liu, Z., Dick, A., Prakash, S., Bhandari, B., \& Zhang, M. (2020). Texture Modification of 3D Printed Air-Fried Potato Snack by Varying Its Internal Structure with the Potential to Reduce Oil Content. Food and Bioprocess Technology, 13(3), 564-576. doi: 10.1007/s11947-020-02408-x

Liu, Z., Zhang, M., Bhandari, B., \& Wang, Y. (2017). 3D printing: Printing precision and application in food sector. Trends in Food Science \& Technology, 69, 83-94. doi: 10.1016/J.TIFS.2017.08.018

Lucas, B. F., Morais, M. G. de, Santos, T. D., \& Costa, J. A. V. (2018). Spirulina for snack enrichment: Nutritional, physical and sensory evaluations. LWT - Food Science and Technology. doi: 10.1016/j.lwt.2017.12.032

Mantihal, S., Prakash, S., Godoi, F. C., \& Bhandari, B. (2019). Effect of additives on thermal, rheological and tribological properties of 3D printed dark chocolate. Food Research International, 119(January), 161-169. doi: 10.1016/j.foodres.2019.01.056

Martínez-Monzó, J., Cárdenas, J., \& García-Segovia, P. (2019). Effect of Temperature on 3D 
Printing of Commercial Potato Puree. Food Biophysics, 1-10. doi: 10.1007/s11483-01909576-0

Noort, M. W. J., Van Bommel, K., \& Renzetti, S. (2017). 3D-Printed Cereal Foods. Cereal Foods World, 62(November), 272-277. doi: 10.1094/CFW-62-6-0272

Pallottino, F., Hakola, L., Costa, C., Antonucci, F., Figorilli, S., Seisto, A., \& Menesatti, P. (2016). Printing on Food or Food Printing: a Review. In Food and Bioprocess Technology (Vol. 9, Issue 5, pp. 725-733). doi: 10.1007/s11947-016-1692-3

Pedreschi, F., Cortés, P., \& Mariotti, M. S. (2018). Potato Crisps and Snack Foods. In Reference Module in Food Science. Elsevier. doi: 10.1016/B978-0-08-100596-5.21137-2

Pérez, B., Nykvist, H., Brøgger, A. F., Larsen, M. B., \& Falkeborg, M. F. (2019). Impact of macronutrients printability and 3D-printer parameters on 3D-food printing: A review. Food Chemistry, 287(October 2018), 249-257. doi: 10.1016/j.foodchem.2019.02.090

Sahni, P., Sharma, S., \& Singh, B. (2019). Evaluation and quality assessment of defatted microalgae meal of Chlorella as an alternative food ingredient in cookies. Nutrition and Food Science, 49(2), 221-231. doi: 10.1108/NFS-06-2018-0171

Schutyser, M. A. I., Houlder, S., de Wit, M., Buijsse, C. A. P., \& Alting, A. C. (2018). Fused deposition modelling of sodium caseinate dispersions. Journal of Food Engineering, 220, 49-55. doi: 10.1016/j.jfoodeng.2017.02.004

Sun, J., Zhou, W., Huang, D., Fuh, J. Y. H., \& Hong, G. S. (2015). An Overview of 3D Printing Technologies for Food Fabrication. Food and Bioprocess Technology, 8, 1605-1615. doi: 10.1007/s11947-015-1528-6

Theagarajan, R., Moses, J. A., \& Anandharamakrishnan, C. (2020). 3D Extrusion Printability of Rice Starch and Optimization of Process Variables. Food and Bioprocess Technology, 10481062. doi: $10.1007 / \mathrm{s} 11947-020-02453-6$

Topkaya, C., \& Isik, F. (2019). Effects of pomegranate peel supplementation on chemical, physical, and nutritional properties of muffin cakes. Journal of Food Processing and Preservation, December 2018, 1-11. doi: 10.1111/jfpp.13868

Ureta, M. M., Olivera, D. F., \& Salvadori, V. O. (2014). Quality Attributes of Muffins: Effect of Baking Operative Conditions. Food and Bioprocess Technology, $7(2), 463-470$. doi: 10.1007/s11947-012-1047-7

Uribe-Wandurraga, Z. N., Igual, M., García-Segovia, P., \& Martínez-Monzó, J. (2019). Effect of microalgae addition on mineral content, colour and mechanical properties of breadsticks. Food \& Function, 10(8), 4685-4692. doi: 10.1039/c9fo00286c

Uribe-Wandurraga, Z. N., Igual, M., García-Segovia, P., \& Martínez-Monzó, J. (2020a). In vitro bioaccessibility of minerals from microalgae-enriched cookies. Food \& Function, 11, 21862194. doi: $10.1039 / \mathrm{c} 9$ fo02603g 
Uribe-Wandurraga, Z. N., Igual, M., Reino-Moyón, J., García-Segovia, P., \& Martínez-Monzó, J. (2020b). Effect of Microalgae (Arthrospira platensis and Chlorella vulgaris) Addition on 3D Printed Cookies. Food Biophysics. doi: 10.1007/s11483-020-09642-y

Vancauwenberghe, V., Verboven, P., Lammertyn, J., \& Nicolaï, B. (2018). Development of a coaxial extrusion deposition for 3D printing of customizable pectin-based food simulant. Journal of Food Engineering, 225, 42-52. doi: 10.1016/j.jfoodeng.2018.01.008

Vieira, M. V., Oliveira, S. M., Amado, I. R., Fasolin, L. H., Vicente, A. A., Pastrana, L. M., \& Fuciños, P. (2020). 3D printed functional cookies fortified with Arthrospira platensis: Evaluation of its antioxidant potential and physical-chemical characterization. Food Hydrocolloids, 107(March). doi: 10.1016/j.foodhyd.2020.105893

Yang, F., Zhang, M., Prakash, S., \& Liu, Y. (2018). Physical properties of 3D printed baking dough as affected by different compositions. Innovative Food Science \& Emerging Technologies, 49, 202-210. doi: 10.1016/J.IFSET.2018.01.001

Zhang, L., Lou, Y., \& Schutyser, M. A. I. (2018). 3D printing of cereal-based food structures containing probiotics. Food Structure, 18(August), 14-22. doi: 10.1016/j.foostr.2018.10.002

Zhu, S., Stieger, M. A., van der Goot, A. J., \& Schutyser, M. A. I. (2019). Extrusion-based 3D printing of food pastes: Correlating rheological properties with printing behaviour. Innovative Food Science \& Emerging Technologies, 58(July), 102214. doi: 10.1016/j.ifset.2019.102214 


\section{Chapter 8}

Q
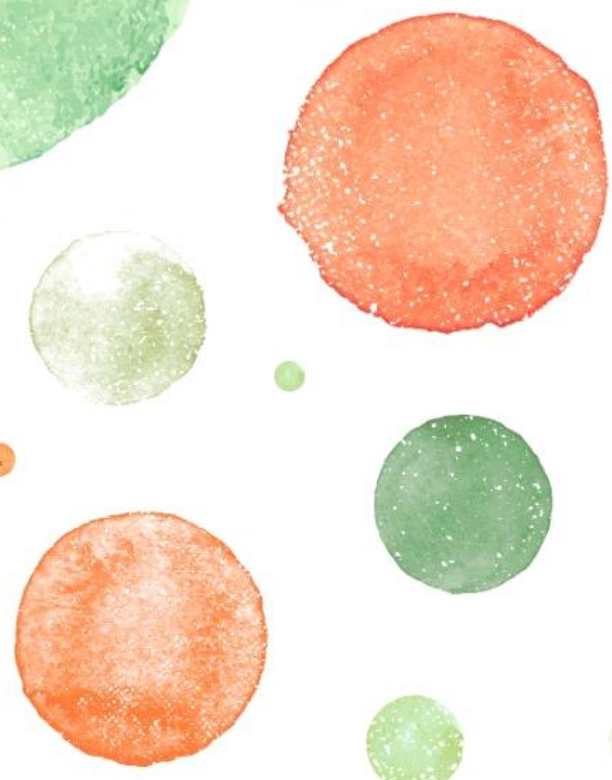

General Discussion 



\section{Outlook}

Microalgae and cyanobacteria are currently of interest to scientific and research communities among the world owing to their infinite availability and promising role in biotechnological prospects. They can be found in almost all environments and habitats on earth from the polar regions to the equator becoming visible in water bodies, when they grow out rapidly and in large quantities. They are a group of relatively basic plant-like organisms, which depend on light as the energy source for their metabolic processes (Enzing et al., 2014; Deviram et al., 2020). Although cyanobacteria belong to the domain of bacteria, being photosynthetic prokaryotes, often they are considered microalgae (Brodie et al., 2007). Microalgae are well-known for their unique chemical composition, including components with proven health benefits, making them valuable as nutrient-enhancing ingredients for foods (Borowitzka, 2018; Wang et al., 2020). Microalgal compounds such as protein, fatty acids, minerals, fibres, vitamins, polyphenols, starch and pigments are, depending on the species, accumulated under stress conditions including nutrient deprivation and changes in $\mathrm{pH}$, light intensity, temperature and salinity (Hamed, 2016; Batista et al., 2017).

The use of microalgae as an ingredient in the formulation of food products has been studied throughout this PhD Thesis, and it has been shown that their incorporation fortifies different food matrices allowing the development of functional foods. Functional foods are highly nutritious and associated with a number of powerful health benefits, which makes it a highly interesting research topic (Villarruel-López et al., 2017). Thus, in addition that we studied the mineral content and mineral bioaccessibility of some of microalgae-enriched studied products, we aimed at understanding the effect of the addition of microalgae on the viscoelastic, textural and physicochemical properties of different food matrices using different production processing techniques.

Based on the findings in this thesis it can be concluded that microalgae could be a novel ingredient for making food products which have a more appealing appearance to consumers. Moreover, rheological, textural and physicochemical properties of the microalgae-enriched food products have been improved in the majority of the cases. However, it is clear that the ingredients compounds, the interaction between microalgae and the other ingredients in the different product matrices and food production processes is 
complex and it is a field in which more research would be useful and interesting for the food industry.

\section{Improvement of food products}

Rheological parameters are essential elements in the food industry for designing formulations for achieving a targeted structure, predicting the physical shelf life and sensory attributes of food products (Zheng, 2019). Therefore, rheological parameters were studied to analyse the viscoelastic behaviour of microalgae-enriched doughs or batters (Chapters 2, 6 and 7).

In Chapters 2, 6 and 7, microalgae-enriched doughs/batters rheological properties ( $\mathrm{G}^{\prime}$ and $\mathrm{G}^{\prime \prime}$ ) increased greatly in comparison with control, which indicated that the viscoelastic behaviour of doughs was modified by microalgae addition, showing solid-like characteristics. This may be explained by the high dry weight protein content of microalgae, around 55$70 \%$ and its interaction into the network (Buono et al., 2014; Mancebo et al., 2016; Sui et al., 2020). Furthermore, in Chapters 6 and 7, doughs/batters with microalgae addition showed higher shear-thinning characteristics, indicating that they are pseudoplastic fluids (Kasapis et al., 2017). This behaviour of samples is a key parameter for different processes such as a successful 3D food printing for easier extrusion and a later shape retention (Huang et al., 2019; Theagarajan et al., 2020).

Food texture is one of the attributes used by consumers to assess the food quality, playing an important role in their perception (Day et al., 2016). For baked goods, the addition of microalgae in breadsticks (Chapter 2) provoked a decrease in the breadsticks hardness compared with control samples. Consistently, Shahbazizadeh et al. (2015) reported that the firmness of cookies generally decreased by increasing microalgal biomass addition. This behaviour could be due to microalgae's particles imprinting discontinuities in the dough network, resulting in a softer structure(Batista et al., 2011). However, after 15 storage days, microalgae-enriched breadsticks were harder than the control sample. This could be due to storage conditions such as storage temperature and packaging, a topic that could be interesting for further study. On the other hand, 3D-printed snacks enriched with microalgae (Chapter 7) showed greater hardness compared to control samples. This was probably due to the microalgae protein content which allows a reinforcement of the batter system during 
the production process time, since microalgae protein and carbohydrate molecules play key roles in the water absorption process in batters (Gouveia et al., 2007). It should be noted that although both breadsticks and snacks are baked goods, their food matrices are different and a further study could be interesting for an in depth understanding (i.e., scanning electron microscopy). However, for snacks (Chapter 7) greater hardness is a positive effect showing that microalgae addition could enhance the structure of the snacks for techniques like 3D food printing.

Minerals have many key functions in the human body, from structural to metabolic functions and acting as cofactor for many enzymatic processes. Therefore, ingesting sufficient amounts of mineral is crucial for human health (Mohammad et al., 2017). Reinforcing the mineral content of food products is one of the ways that microalgae can contribute to their enrichment. This was studied in Chapters $\mathbf{2}$ and $\mathbf{3}$ in which we showed that mineral enrichment depends on the type of food product, type of microalgae and on microalgae concentration. In Chapter 2, all breadsticks samples, without and with microalgae-addition, presented similar macro and micronutrient composition ( $\mathrm{P}, \mathrm{Ca}, \mathrm{Na}, \mathrm{Mg}, \mathrm{Zn}, \mathrm{Cu}$ and $\mathrm{Mn}$ ). However, $\mathrm{K}$ content in breadsticks with Chlorella was higher than the rest of the samples. Also, the addition of microalgae resulted in a significant increase in Fe and Se which was similar between Spirulina and Chlorella. Researching on another food product, in Chapter 3, the mineral content in microalgae-enriched cookies was studied. An increase in $\mathrm{P}, \mathrm{K}, \mathrm{Ca}$, $\mathrm{Na}, \mathrm{Mg}, \mathrm{Fe}$ and Se was observed with the addition of both microalgae along the increase of concentration of microalgae addition. It should be noted that control cookies did not show detectable amounts of $\mathrm{Zn}$ whereas after the addition of microalgae $\mathrm{Zn}$ was detected. In contrast to breadsticks, $\mathrm{Cu}$ in Spirulina-enriched cookies and $\mathrm{Mn}$ in both Spirulina and Chlorella-enriched cookies were not detected, which could be due to the detection range of the equipment used for this purpose.

The ingredients that each food matrix contains are an outstanding topic considering that both products are different. Hence, their initial mineral content may vary. Nevertheless, we showed that the use of microalgae as an ingredient to enrich baking goods with functional minerals was a good alternative because in Chapter 2 and Chapter 3, studying breadsticks and cookies, respectively, presented higher content of minerals. Thus, some of them can be claimed in the package labelling information. Following the regulations on nutrition labelling for food stuffs (Council of the European Union, 1990) and on nutrition and 
health claims made in foods (European Parliament and Council of the European Union, 2006), breadstick enrichment with Chlorella or Spirulina are a food "high in iron (Fe)" (Chapter 2). In the same way, breadsticks (Chapter 2) and cookies (Chapter 3) enriched with microalgae can be considered a "high in selenium (Se)" food. It must be considered that the concentrations of microalgae added should be $1.5 \%$ and higher in order to claim these statements on the label packaging.

It is clear that the baking temperatures do not affect the mineral content in baked products like breadsticks and cookies. Fortification with minerals does not pose any risk of substantial losses or any deteriorative effects during baking on native mineral contents in wheat flour, a highly preferred food carrier for fortification of minerals (Akhtar et al., 2009). Therefore, microalgae can be added to different food products regardless of whether the use of temperatures is required in any of the processes involved in their production, since the mineral content is not affected by them.

Going a step further, Spirulina and Chlorella incorporation in cookie formulations allowed for greater bioaccessibility of $\mathrm{P}, \mathrm{K}, \mathrm{Ca}, \mathrm{Mg}, \mathrm{Fe}, \mathrm{Zn}$, and Se content for absorption in the body than control cookies (Chapter 3). Thus, in addition to showing that mineral contents increase by microalgae-enrichment, the results in Chapter 3 provide evidence that those minerals are accessible for uptake by the human body.

During the development of the thesis, we showed that the addition of microalgae biomass as natural ingredient resulted in all the products (breadsticks, cookies, snacks, emulsions and extrudates) with innovative and appealing colours and appearance. We showed that doughs/batters/low-fat emulsions (Chapters 2, 4, 6 and 7) presented greater luminosity and stable green tonalities for Spirulina and Chlorella and yellow for Dunaliella. In Chapters 2, 6 and 7, the typical green colour of microalgae doughs/batters was lost after the baking process and the addition of microalgae decreased the luminosity causing darkening of the samples. During baking, Maillard and browning reactions, and also dough/batter expansion resulted from water evaporation affected the samples colours (Lara et al., 2011). For low-fat emulsions (Chapter 4), samples with Chlorella or Dunaliella had greater colour stability during storage time. In the case of extruded snacks (Chapter 5) we noticed that the addition of microalgae (Spirulina, Chlorella and Nannochloropsis) changed them from translucent to opaque, producing samples, in the case of Spirulina and Chlorella, with 
slightly less luminosity compared to control samples. Regarding to the difference in colour between all the samples and their controls, that is clearly evident and perceptible by the consumer when control is taken as standard (Bodart et al., 2008).

\section{Food processing}

Nowadays, the food sector faces major challenges in seeking to produce new food products reducing salt, sugar and monounsaturated fats and increasing vitamins, minerals, protein, fibres, among others (FAO, 2018). That can be possible with the incorporation of interesting and novel ingredients that allow fortifying it and simultaneously having attributes similar to the regular products (Chapter 4 and $\mathbf{5}$ ).

In the same way as microalgae-enriched doughs/batters, microalgae-enriched (Spirulina, Chlorella and Dunaliella) low-fat emulsions (Chapter 4) are pseudoplastic fluids and they presented similar rheological behaviour indicating a more pronounced viscous characteristic, which corresponds to a stronger network structure. Therefore, microalgal biomass can contribute to the reinforcement of the emulsion structure through the formation of physical entanglements (Riscardo et al., 2003; Raymundo et al., 2005). Microalgae addition proved to give a stable texture to food emulsions during storage time, which might influence their perception among consumers. Nevertheless, Chlorella-enriched low-fat emulsion showed a different rheological behaviour compared to other samples. Some authors have attempted to prepare emulsions without any protein addition, using microalgae as the sole emulsifier, at concentrations lower than $2 \%$, obtaining a very unstable suspension (Raymundo et al., 2005). This may be because of physical or chemical emulsion changes where differing interactions with the matrix material resulting in modified stability characteristics (McClements, 2016). Thus, to maximally evaluate the functionality of the microalgae as an ingredient in the rheological properties of low-fat emulsions, the process should be optimized without influencing the type of microalgae to any great extent.

On the other hand, extrusion has been investigated for producing snacks using a mixture of starchy raw materials with other ingredients. Consequently, microalgae addition (Arthrospira platensis (Spirulina), Chlorella vulgaris and Nannochloropsis gaditana) is an alternative for obtaining extruded snacks with better sensory, physicochemical and nutritional characteristics. Moreover, their production can be customized to meet the dietary 
requirements of particular groups of the population (Reddy et al., 2014). Spirulina and Chlorella addition to formulations gave extruded snacks with slight changes in their physicochemical and expansion parameters compared to control. Although, Nannochloropsis extruded snacks showed similar parameters as the control sample (Chapter 5). In short, produced microalgae snacks showed expansion parameters and physicochemical properties suitable for this kind of process.

\section{Innovative food processing technology}

The addition of both Spirulina and Chlorella enhanced food matrices properties by improving the viscoelastic behaviour of the dough towards a strong gel, characteristic suitable for baking process (Chapter 2). Moreover, quality and nutritional content of the product upon the incorporation of microalgae was shown as well (Chapters 2 and 3). Thus, making doughs enriched with microalgae and using different technology for obtaining baked products was an interesting topic of study in this research.

3D food printing is a technique that allows personalised/customised food for specific consumer groups (children, elderly, pregnant women, teenagers, and athletes, among others) both in terms of sensorial and nutritional properties (Dankar et al., 2018). For instance, the application of 3D printing in food manufacturing can exceed our expectation on traditional foods by obtaining smooth food for those affected by mastication or swallowing problems, providing a personalised nutrition or innovative food in terms of shape, consistency, colour and flavour (Sun et al., 2015). In this regard, wheat flour-based food structures with same shape but different dimensions were created by using threedimensional (3D) Food Printing which offers a customisable structure at maximal convenience compared to the conventional methods (Chapters 6 and 7).

In both Chapters 6 and 7, the addition of the two types of microalgae, Spirulina and Chlorella, led to a greater mechanical resistance during the 3D printing process meaning doughs/batters possess minimal fluidity, an important characteristic for 3D food printing. We found that samples which required a greater extrusion force were formulations containing increasing concentrations of microalgae but at the same time provided the most accurately printed structures. After printing, freezing was carried out to minimise the collapse of the printed structures during baking process. Afterward, samples were baking as a post- 
processing to obtain the final product, cookies or snacks. For baked cookies and snacks differences compared to control samples were found because of greater compression in microalgae-enriched samples, which resulted in an increase in the external diameter or width and finally a lower height. However, for an even better completion of the baking process may also be judged by the moisture content of the structure in order to find the best conditions (temperature and time) for improving and achieving 3D structures with more stability and resistance to baking (Zhang et al., 2018).

In Chapter 7, a dual printhead was used to deposit simultaneously two food-inks through a coaxial extrusion nozzle, in which the inner flow was the microalgae-enriched batter and the outer, the control batter. This analysis was performed for the purpose of studying visually the printing behaviour of microalgae-enriched batters and control batter using a coaxial extrusion nozzle. In this way, we created structures in which the green colour of microalgae batter is hidden because the control batter is covering it in the final structure resulting in an interesting and innovative way to present 3D food printing structures. In turn, obtaining food samples showing different colours and textures but with the same levels of nutrients and health benefits.

\section{Future perspectives and research}

The microalgae production industry is looking for technologies to introduce microalgae as innovative ingredients to improve the product quality (e.g., nutritional value, longer shelflife, better sensory properties), and to develop products using different technologies (e.g., extrusion, baking, 3D food printing) for specific market segments (e.g. children, elderly people, gluten-free products). The development of functional foods is increasing by the products demand among consumers; they want novel but at the same time, healthier products.

As we have seen during the development of this $\mathrm{PhD}$ thesis, microalgae biomass as an ingredient is a versatile product, since it can be easily incorporated into the different food matrices when mixed with other ingredients. In addition, microalgae addition could improve the properties of the products obtained. However, one of the properties for further investigation is the general perception of the obtained products. 
Some studies have shown that considering minor differences, microalgae breadsticks $(1.5 \%$ $\mathrm{w} / \mathrm{w}$ ) have different colour, flavour and odour characteristics because of the presence of microalgae, but they are just as acceptable as breadsticks without microalgae (GarcíaSegovia et al., 2020). On the other hand, other authors have found that baked-foods enriched with Chlorella and Spirulina at concentration levels higher than $2.6 \%(\mathrm{w} / \mathrm{w})$ showed low scores in colour perception, appearance, overall acceptability and purchase intention using a 5-point and 9-point hedonic scale (Lucas et al., 2018; Sahni et al., 2019). In any case, it is considered advisable to carry out an exhaustive study where different products, different types of microalgae and, at the same time, different concentrations of addition can be compared. Thus, assess the general perception that the consumer could have for the purchase and/or intake of these types of microalgae-enriched products.

Regarding 3D Food Printing, further experiments will be necessary to print edible objects using microalgae as ingredients that perfectly fit the designed structure. Particularly, the precise knowledge of the rheological properties of food formula and a better understanding of the differences between the expected and real behaviour of the printer during printing of complex food formula will be the main issues of future research. Moreover, the evaluation of nutritional changes of 3D printed food if more steps during the processing are added (i.e., IR dehydration, freezing) will be of utmost importance for industrial application of 3D food printing or innovative home appliance to prepare customised food at home.

A good alternative in 3D-printed food products is the use of the coaxial nozzle (Chapter 7). In addition to creating structures in which the green colour of microalgae batter is hidden in the obtained structures, this technique could also be interesting if higher levels of microalgae incorporation are added or required than those that in Chapter $\mathbf{7}$ were described. Using an inner ink-food in coaxial extrusion can provide and improved the appearance of samples that could be better accepted by consumers. Coaxial food printing could be the next logical step in the development of microalgae-enriched foods with better sensory perception, where experiments showed that this could be a feasible approach.

The results of this study provide ideas for improving the use of microalgae biomass as novel ingredient for food products. Likewise, we advise the study of those species of microalgae that their use has not yet been approved by the different regulations, but that their composition also makes them a potential ingredient in the elaboration of future functional 
foods. Therefore, we recommend that another interesting way to optimise and take advantage of the components of microalgae could be the extraction of their compounds in order to evaluate the properties that they can provide into different food matrices. 


\section{References}

Akhtar, S., Anjum, F. M., Rehman, S.-U., \& Sheikh, M. A. (2009). Effect of storage and baking on mineral contents of fortified whole wheat flour. Journal of Food Processing and Preservation, 34(2010), 335-349. doi: 10.1111/j.1745-4549.2009.00405.x

Batista, A. P., Nunes, M. C., Raymundo, A., Gouveia, L., Sousa, I., Cordobés, F., Guerrero, A., \& Franco, J. M. (2011). Microalgae biomass interaction in biopolymer gelled systems. Food Hydrocolloids, 25(4), 817-825. doi: 10.1016/j.foodhyd.2010.09.018

Batista, A. P., Niccolai, A., Fradinho, P., Fragoso, S., Bursic, I., Rodolfi, L., Biondi, N., Tredici, M. R., Sousa, I., \& Raymundo, A. (2017). Microalgae biomass as an alternative ingredient in cookies: Sensory, physical and chemical properties, antioxidant activity and in vitro digestibility. Algal Research, 26(March), 161-171. doi: 10.1016/j.algal.2017.07.017

Bodart, M., de Peñaranda, R., Deneyer, A., \& Flamant, G. (2008). Photometry and colorimetry characterisation of materials in daylighting evaluation tools. Building and Environment. doi: 10.1016/j.buildenv.2007.12.006

Borowitzka, M. A. (2018). Biology of Microalgae. In I. A. Levine \& J. B. T. Fleurence (Eds.), Microalgae in Health and Disease Prevention (pp. 23-72). Academic Press. doi: https://doi.org/10.1016/B978-0-12-811405-6.00003-7

Brodie, J., \& Lewis, J. (Eds.). (2007). Unravelling the algae: the past, present, and future of algal systematics (Systematic). Boca raton: CRC Press.

Buono, S., Langellotti, A. L., Martello, A., Rinna, F., \& Fogliano, V. (2014). Functional ingredients from microalgae. Food and Function, 5(8), 1669-1685. doi: 10.1039/c4fo00125g

Council of the European Union. (1990). Council Directive of 24 September 1990 on nutrition labelling for foodstuffs. In Official Journal of the European Communities (Vol. 276, Issue (90/496/EEC)).

Dankar, I., Haddarah, A., Omar, F. E. L., Sepulcre, F., \& Pujolà, M. (2018). 3D printing technology: The new era for food customization and elaboration. Trends in Food Science and Technology, 75(July 2017), 231-242. doi: 10.1016/j.tifs.2018.03.018

Day, L., \& Golding, M. (2016). Food Structure, Rheology, and Texture. In L. Melton, F. Shahidi, \& P. B. T., Varelis (Eds.), Encyclopedia of Food Chemistry (pp. 125-129). Oxford: Academic Press. doi: https://doi.org/10.1016/B978-0-08-100596-5.03412-0

Deviram, G., Mathimani, T., Anto, S., Ahamed, T. S., Ananth, D. A., \& Pugazhendhi, A. (2020). Applications of microalgal and cyanobacterial biomass on a way to safe, cleaner and a sustainable environment. Journal of Cleaner Production, 253, 119770.

Enzing, C., Ploeg, M., Barbosa, M., \& Sijtsma, L. (2014). Microalgae-based products for the food and feed sector: an outlook for Europe. In JRC Scientific and Policy Reports. European 
Comission. doi: 10.2791/3339

European Parliament and Council of the European Union. (2006). Regulation (EC) No 1924/2006 of the European Parliament and of the Council of 20 December 2006 on nutrition and health claims made on foods. In Official Journal of the European Union (Issue 404).

FAO. (2018). The future of food and agriculture - Alternative pathways to 2050. Rome: License: CC BY-NC-SA 3.0 IGO. Retrieved from http://www.fao.org/3/I8429EN/i8429en.pdf

García-Segovia, P., García-Alcaraz, V., Tárrega, A., \& Martínez-Monzó, J. (2020). Consumer perception and acceptability of microalgae based breadstick. Food Science and Technology International. doi: 10.1177/1082013220906235

Gouveia, L., Batista, A. P., Miranda, A., Empis, J., \& Raymundo, A. (2007). Chlorella vulgaris biomass used as colouring source in traditional butter cookies. Innovative Food Science $\&$ Emerging Technologies, 8(3), 433-436. doi: 10.1016/J.IFSET.2007.03.026

Hamed, I. (2016). The Evolution and Versatility of Microalgal Biotechnology: A Review. Comprehensive Reviews in Food Science and Food Safety, 15(6), 1104-1123. doi: $10.1111 / 1541-4337.12227$

Huang, M., Zhang, M., \& Bhandari, B. (2019). Assessing the 3D Printing Precision and Texture Properties of Brown Rice Induced by Infill Levels and Printing Variables. Food and Bioprocess Technology, 12(7), 1185-1196. doi: 10.1007/s11947-019-02287-x

Kasapis, S., \& Bannikova, A. (2017). Rheology and Food Microstructure. In J. Ahmed, P. Ptaszek, \& S. B. T. Basu (Eds.), Advances in Food Rheology and Its Applications (pp. 7-46). Elsevier Ltd. doi: 10.1016/B978-0-08-100431-9.00002-4

Lara, E., Cortés, P., Briones, V., \& Perez, M. (2011). Structural and physical modifications of corn biscuits during baking process. LWT - Food Science and Technology, 44(3), 622-630. doi: 10.1016/j.Iwt.2010.10.007

Lucas, B. F., Morais, M. G. de, Santos, T. D., \& Costa, J. A. V. (2018). Spirulina for snack enrichment: Nutritional, physical and sensory evaluations. LWT - Food Science and Technology. doi: 10.1016/j.Iwt.2017.12.032

Mancebo, C. M., Rodriguez, P., \& Gómez, M. (2016). Assessing rice flour-starch-protein mixtures to produce gluten free sugar-snap cookies. LWT - Food Science and Technology, 67, 127132. doi: $10.1016 /$ j.lwt.2015.11.045

McClements, D. (2016). Food Emulsions (3rd ed.). Boca Raton: CRC Press. doi: 10.1201/b18868

Mohammad, S., Gharibzahedi, T., \& Mahdi, S. (2017). Trends in Food Science \& Technology The importance of minerals in human nutrition: Bioavailability, food forti fi cation, processing effects and nanoencapsulation. Trends in Food Science \& Technology, 62, 119-132. doi: 10.1016/j.tifs.2017.02.017

Raymundo, A., Gouveia, L., Batista, A. P., Empis, J., \& Sousa, I. (2005). Fat mimetic capacity of 
Chlorella vulgaris biomass in oil-in-water food emulsions stabilized by pea protein. Food Research International, 38(8-9), 961-965. doi: 10.1016/j.foodres.2005.02.016

Reddy, M. K., Kuna, A., \& Devi, N. L. (2014). Development of extruded Ready-To-Eat ( RTE ) snacks using corn , black gram, roots and tuber flour blends. Journal of Food Science and Technology, 51(September), 1929-1937. doi: 10.1007/s13197-013-1251-0

Riscardo, M. A., Franco, J. M., \& Gallegos, C. (2003). Influence of Composition of Emulsifier Blends on the Rheological Properties of Salad Dressing-Type Emulsions. Food Science and Technology International, 9(1), 53-63. doi: 10.1177/1082013203009001008

Sahni, P., Sharma, S., \& Singh, B. (2019). Evaluation and quality assessment of defatted microalgae meal of Chlorella as an alternative food ingredient in cookies. Nutrition and Food Science, 49(2), 221-231. doi: 10.1108/NFS-06-2018-0171

Shahbazizadeh, S., Khosravi-Darani, K., \& Sohrabvandi, S. (2015). Fortification of Iranian Traditional Cookies with Spirulina platensis. Annual Research \& Review in Biology, 73), 144-154. doi: 10.9734/ARRB/2015/13492

Sui, Y., \& Vlaeminck, S. E. (2020). Dunaliella Microalgae for Nutritional Protein: An Undervalued Asset. Trends in Biotechnology, 38(1), 10-12. doi: 10.1016/j.tibtech.2019.07.011

Sun, J., Zhou, W., Huang, D., Fuh, J. Y. H., \& Hong, G. S. (2015). An Overview of 3D Printing Technologies for Food Fabrication. Food and Bioprocess Technology, 8, 1605-1615. doi: $10.1007 / \mathrm{s} 11947-015-1528-6$

Theagarajan, R., Moses, J. A., \& Anandharamakrishnan, C. (2020). 3D Extrusion Printability of Rice Starch and Optimization of Process Variables. Food and Bioprocess Technology, 10481062. doi: $10.1007 / \mathrm{s} 11947-020-02453-6$

Villarruel-López, A., Ascencio, F., \& Nunõ, K. (2017). Microalgae, a Potential Natural Functional Food Source- A Review. Polish Journal of Food and Nutrition Sciences, 674), 251-263. doi: 10.1515/pjfns-2017-0017

Wang, A., Yan, K., Chu, D., Nazer, M., Lin, N. T., Samaranayake, E., \& Chang, J. (2020). Microalgae as a Mainstream Food Ingredient: Demand and Supply Perspective. In M. A. Alam, J.-L. Xu, \& Z. Wang (Eds.), Microalgae Biotechnology for Food, Health and High Value Products (pp. 29-80). Singapore: Springer Nature Singapore Pte Ltd. doi: $10.1007 / 978-981-15-0169-2$

Zhang, L., Lou, Y., \& Schutyser, M. A. I. (2018). 3D printing of cereal-based food structures containing probiotics. Food Structure, 18(August), 14-22. doi: 10.1016/j.foostr.2018.10.002

Zheng, H. (2019). Introduction: Measuring Rheological Properties of Foods BT - Rheology of Semisolid Foods. In H. S. Joyner (Ed.), Rheology of Semisolid Foods (pp. 3-30). Cham: Springer International Publishing. doi: 10.1007/978-3-030-27134-3_1 


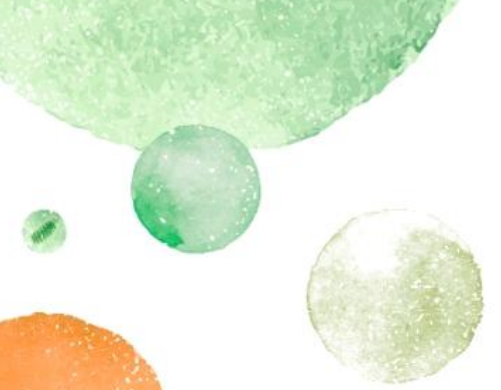

Q

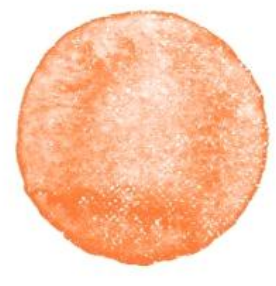

(9)

\section{Chapter 9}

Conclusions 

The studies developed in the context of this $\mathrm{PhD}$ Thesis have provided more insight about how microalgae can be an useful ingredient for enhancing the rheological, textural and physicochemical properties of food products. Furthermore, microalgae can increase the content of minerals (i.e., iron and selenium) of them. More specifically, the findings showed interesting results for breadsticks (Chapter 2), cookies (Chapter 3), low-fat oil-in-water emulsions (Chapter 4), corn extrudates (Chapter 5), 3D-printed cookies (Chapter 6) and 3D-printed snacks (Chapter 7), which will be described in this Concluding chapter.

The effect of the addition of two types of microalgae biomass, Arthrospira platensis (Spirulina) and Chlorella vulgaris (Chlorella) on the colour, texture and rheology of doughs and mineral content, colour, textural and rheological properties of breadsticks was investigated in Chapter 2. The study has proven that in terms of textural and rheological dough properties, doughs with microalgae addition showed a greater hardness and also a greater elastic behaviour in comparison with control doughs. Doughs appeared more attractive and innovative as shown by distinguished green colour tones. Consequently, the study confirmed that the effect of baking induced changes in colour towards brown tonalities. Although, during storage time breadsticks showed colour stability, textural parameters continued showing greater hardness values. Moreover, the mineral content of breadsticks increased, specifically, potassium for Chlorella samples and iron and selenium for both microalgae samples. Thus, the incorporation of Chlorella or Spirulina in the formulation allows for the production of breadsticks classed as "high in iron and selenium food" according to current regulations.

The study in Chapter 3 evaluated the mineral content of cookies enriched with Arthrospira platensis (Spirulina) and Chlorella vulgaris (Chlorella) and also, the mineral bioaccessibility using in vitro static systems that simulate digestive processes. It was shown that microalgae can be useful for increasing the nutritional value of cookies with minerals such as $\mathrm{P}, \mathrm{K}, \mathrm{Ca}$, $\mathrm{Na}, \mathrm{Mg}$, Fe and Se compared to control cookies. It should be noted that control cookies did not show detectable amounts of $\mathrm{Zn}$ whereas after the addition of microalgae $\mathrm{Zn}$ was detected. In addition, the bioaccesibility test showed that, Spirulina and Chlorella incorporation in cookie formulations allowed for greater accessibility of $\mathrm{P}, \mathrm{K}, \mathrm{Ca}, \mathrm{Mg}, \mathrm{Fe}, \mathrm{Zn}$ and Se content for absorption in the body than control cookies. Thus, cookies enriched with 1.5 or $2 \%$ of Chlorella or Spirulina reached 'high in selenium' claim according to current regulations. 
Chapter 4 described the effect of the addition of Arthrospira platensis (Spirulina), Chlorella vulgaris and Dunaliella salina microalgae biomass on the physicochemical properties of lowfat oil-in-water emulsion formulations. The study showed that the rheological behaviour of all samples (with and without microalgae addition) can be classified as weak gel-like, a distinguishing characteristic of low-fat emulsion products. Moreover, the addition of Spirulina or Dunaliella provided emulsions with stable textural, viscoelastic, and rheological properties over the tested storage time (60 days) than control sample. Finally, it was shown that microalgae (Spirulina, Chlorella, and Dunaliella) addition to low-fat emulsions yielded a stable and appealing colour to food emulsions during storage time, with green tonalities for Spirulina and Chlorella and yellow for Dunaliella.

Expansion parameters and physicochemical properties of corn extrudates enriched with Arthrospira platensis, Chlorella vulgaris and Nannochloropsis gaditana biomass were studied in Chapter 5. The use of microalgae in extruded snacks is a good and innovative proposal from a physicochemical and nutritive point of view. The research showed that the addition of microalgae changed the extruded snack from translucent to opaque producing samples with less luminosity. However, Spirulina and Chlorella extruded snacks showed slight differences in their parameters compared to control sample while Nannochloropsis extruded snacks showed similar characteristics. Thus, produced microalgae snacks showed expansion parameters and physicochemical properties suitable for this type of process.

The research in Chapter 6 and Chapter $\mathbf{7}$ showed the potential of incorporating Arthrospira platensis (Spirulina) and Chlorella vulgaris (Chlorella) in baked goods by making use of 3D food printing.

The study in Chapter 6 showed the printability in terms of dimensional properties and rheological, textural and physicochemical characteristics of 3D-printed cookies containing Spirulina and Chlorella. The addition of the two types of microalgae led to a greater mechanical resistance during the 3D printing process, especially for Spirulina. Although no great differences in the geometric characteristics of the samples according to the printing parameters existed, the best parameters for these doughs are with a layer height of $1.5 \mathrm{~mm}$ and a filament diameter of $27 \mathrm{~mm}$. This yields better defined cookies in terms of height and width proportions than the designed control structure. 
The study in Chapter $\mathbf{7}$ showed the effect of microalgae addition on the printability of batters and physicochemical properties of 3D-printed snacks containing Spirulina and Chlorella after printing and baking processes. Microalgae-enriched batters showed rheological and viscoelastic behaviour suitable for the printing process. Snack batters with 3 or $4 \%$ of microalgae yielded the most accurate printed structures. Although microalgaeenriched snacks showed green tones baking caused a change towards more brown tones. However, these colour changes due to microalgae addition are small in comparison with the nutritive benefits reported for incorporating microalgae in food products. The findings showed the feasibility of using a coaxial nozzle during 3D food printing process to hide the green colour inside of each printing layer. Therefore, this technique could be a promising method for improve the consumer preferences.

Thus, the addition of microalgae biomass to doughs/batters, used for 3D printing of cookies and snacks, improves the printability in terms of dimensional properties, achieving 3D structures with more stability and resistance to baking respect to printing accuracy.

\section{Concluding remarks}

Microalgae is a source of natural compounds with high value, including pigments, PUFA's, carbohydrates, proteins and others, which have a wide range of applications as functional ingredients. They can be incorporated into different food products showing high physicochemical, nutritional, and sensorial quality. Combined, the results in this PhD thesis further our understanding of microalgae and suggest that microalgae biomass may be seen as a trendy ingredient, eventually contributing to they could have the potential to become an essential ingredient for food products for consumers all over the planet. 


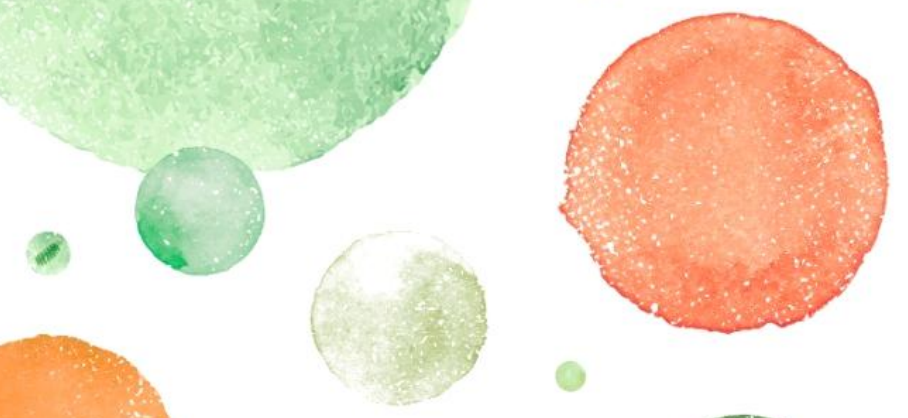

C
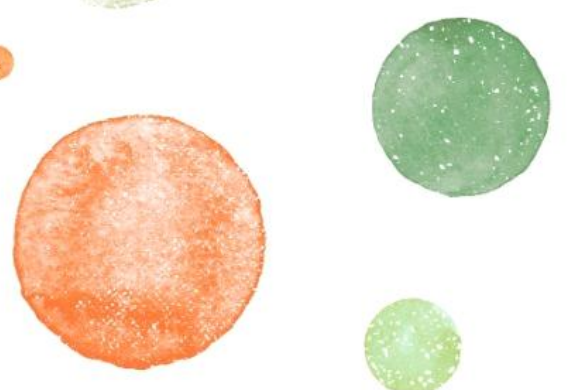

(9) 

Esta historia que hoy concluye, no comenzó el primer día del doctorado. Se remota a unos años atrás, en la primavera del 2013, cuando Chus en un pasillo de la CPI me preguntó si estaría interesada en hacer el trabajo final de máster con ella y su en aquel entonces doctorando, Carlos. El aceptar, fue el inicio de toda esta aventura.

Gracias a Carlos, porque aparte de formular y crear nuevos productos alimentarios, aprendí a hacer microbiología. Una tarea un poco ardua, pero de quién aprendí bastante y tuve la oportunidad de discutir cuanto evento científico o de la vida pudiera ocurrírsenos.

Como resultado del trabajo con el grupo de investigación, mi relación con Puri y Javi, mis supervisores, fue creciendo, ya que hasta ese momento solo habíamos compartido en el aula de clase y en la preparación de nuestro producto para Ecotrophelia, 2013, y gracias a Carlos, quién hizo posible la comunicación constante con ellos, el camino doctoral comenzó a hacerse realidad a finales del 2016.

A Puri y Javi, les agradezco por darme la oportunidad y la confianza de haber podido desarrollar el tema de esta tesis doctoral y los proyectos en paralelo, y por permitirme explorar en el laboratorio, en la cocina y con los estudiantes sobre este mundo tan interesante, el cual ha permitido mi crecimiento profesional. A Chus, gracias por haber sido la artífice de la conexión de todo esto y por su sentir de madre. Gracias a los tres por todo el cariño y las recomendaciones que me han dado durante todos estos años.

I would like to thank my doctoral stay supervisor in Wageningen University \& Research, Maarten Schutyser and my mentor, Lu Zhang for the opportunity to work with you at Food Process Engineering (FPE) group. I am grateful for the nice discussions and the insights about my work there. I thank you Lu for the patient and to give me the chance to learn more every day. I also thank you for starting the contact with Martijn Noort from Wageningen Food \& Biobased Research (WFBR) group, which resulted in one part of this PhD Project. I would like to thank to Martijn for allowing me to develop a part of this work in his lab. Thank you all for your collaboration in chapter 7.

La vida en el laboratorio es bastante extenuante pero a su vez divertida, las largas jornadas para poder alcanzar a hacer lo planeado y programado, la limpieza al finalizar y las repeticiones, hacen que los días no vayan como uno quisiera. Pero gracias a cada uno de los que he conocido y han estado conmigo en el laboratorio, en la salita de becarios, en la salita de comer, en el Departamento de Tecnología de Alimentos y en general, en la Universidad, el trabajo doctoral fue más ameno. 
Totalmente agradecida con Ana, mi compañerita de tesis doctoral, quien ha estado desde mi primer día como doctoranda a mi derecha, literalmente, a mi derecha. Su nombre solo está aquí, en las últimas páginas, pero esta tesis también lleva su esfuerzo. Muchas gracias por los días de ayuda en el laboratorio, por la mano extra que siempre se necesita o por solo estar presente haciéndome compañía, por los análisis del porqué de las cosas, las charlas en los ordenadores, las convocatorias al café, comida y cenas, por haberme dejado entrar en su vida y enseñarme a ser un poquito Murciana, por las actividades extraescolares como danza y pintura, los momentos con sus padres y los jueves de Jose, por escuchar mis mil historias, alentarme en los momentos complicados y lo mejor quizás, haber podido crear ese mundo paralelo de conversaciones no verbales.

Mil gracias,

A Amparo, por el tiempo compartido de charlas y risas y por contarme sus labores diarias entre el laboratorio, el despacho y su rol de mamá; pero en especial, por la sonrisa y el abrazo cuando volví al laboratorio a comenzar el doctorado.

A Virginia, quién me ayudó con las primeras pruebas y me acompañó en los días calurosos del calorímetro. Gracias también, por las charlas sobre senderismo y los momentos de tartas y café.

A Víctor, quién desde el primer día fue como si le conociéramos de toda la vida. Gracias por ayudarme a formular mientras estaba en el reómetro, escuchar mis historias, llevarnos regañás, contarnos de su vida, el pueblo y las festividades, por enseñarme Valencià y a entender a la impresora 3D. Gracias también, porque aunque haya cambiado de trabajo sigue estando por ahí, para Ana y para mí.

A JuanVi, nuestro técnico del DTA. Gracias por tener siempre una respuesta de ayuda para todo, por enseñarme y guiarme con el reómetro y por nuestras conversaciones de running y de viajes. El tiempo se pasa muy bien charlando de carreras y de lugares a donde viajar.

A Gloria, a quién conocí por el proyecto CDTi con Jumel. Gracias por los lunes de laboratorio, por enseñarnos junto con los estudiantes de trabajo final de grado, sobre el mundo de las salsas y mermeladas, como formular y como prepararlas, por las catas y las recomendaciones y por la gestión de lo relacionado al proyecto. $Y$ es también, quién hace parte de unos de los capítulos de esta tesis, el de emulsiones con microalgas. 
A mis estudiantes,

Rafa, mil gracias por los cafés y tés matcha para Ana y para mí, directamente del Starbucks, calientitos y a domicilio sobre las $10 \mathrm{~h}$. Gracias por las charlas, la genialidad a la hora de ponerle nombre a los productos, la cena de celebración de finalización del grado, por su último día de trabajo en Starbucks y por ende, bebidas gratis y mezclas exóticas. Irene, la persona perfecta para programar y organizar algo, desde el primer día nos pusimos a trabajar y la ayuda mutua fue evidente y exitosa desde ese mismo instante. Gracias por las visitas a la CPI y por los constantes mensajes de saludo y de cariño. Nuestro trabajo hace parte de un capítulo de esta tesis. María, gracias por las ideas espontáneas en la formulación de las mermeladas, por las charlas sobre cine y las recomendaciones de películas y también, por contarme toda su historia de vida. Alicia, gracias al trabajo juntas, aprendí bastante sobre un tema totalmente nuevo para mí y de extensa lectura y resolución. Gracias por la soltura día a día durante las jornadas y por el compartir de su familia conmigo. Javi, gracias por pertenecer al 3D-printed cookies team, una total aventura formulando y ejecutando. Gracias por contarnos sobre Riobamba y sus alrededores, por contarme todos aquellos detalles de su vida y por la paciencia que se requiere cuando se trabaja en impresión 3D. Otro capítulo de la tesis, refleja esta parte del trabajo.

A Marta, nuestra Postdoc, gracias por las enseñanzas, la estadística, las discusiones, las recomendaciones, la resolución para prácticamente todo, su entera paciencia y el responder cuánta pregunta se me ocurría. Gracias también, por compartirnos las aventuras de sus niños y de Teruel.

A Vico, gracias por su positivismo y la energía diaria que nos irradiaba. Por contarnos de su vida en Gualeguaychú, por haber estado siempre dispuesta a ayudarnos en nuestras tareas sin importar lo que fuera, y por los alfajores. Gracias también por la comunicación constante y por vivir desde lejos mi vida personal y doctoral.

A Luis, el técnico de Producción Animal, y a su grupo de trabajo, por permitirnos utilizar las muflas. Gracias también, por su alegre saludo cada vez que iba a su laboratorio y por compartir mi emoción cuando le contaba sobre los avances que tenía en la tesis. Aún le debo las galletas impresas en 3D con microalgas.

I would like to thank the technicians and secretary from FPE group in Wageningen University \& Research. Jos, Jarno and Maurice, thank you for the help in the general labs and for being prompt to answer any of my questions. Martin, thank for the help in the Dry 
Food Processing lab, especially with the 3D Food Printer. Marjan and Ilona, thank you for dealing with administrative stuff relating to my doctoral stay. Sophie, the internship student, and Jolanda, the technician from WFBR group, thanks for their technical supports with the coaxial extrusion printing experiment.

I would like to thank to the FPE colleagues to have collaborated with me. Sicong, Qinhui and Joanne, I am very grateful for your kindness and help especially during the first weeks in the lab. To my officemates Anouk, Sten and Silvia, thank you for helping me to get through the three months in the lab. Anouk, thank you for being so kind to me, for the Wageningen tips, for coffee breaks and lunch time and for making my days enjoyable.

I would like to thank to Fiona, Wanqing, Raisa, Claudine, Paty, Ondino, Konstantina, Luo Qi, Davide, Juli y Elvi for all the conversations, borrel, parties, drinks and food we shared. Thank you for being so warm with me. Juli, gracias por compartir tu buena vibra conmigo, por contarme de Orizaba y tu familia, por nuestros saludos de pasillo, los cafés en Impulse, las cenas mexicanas y tus tortas en el parque. Elvi, totalmente agradecida por todos los momentos compartidos. Gracias por recibirme en su apartamento, por las charlas sobre España, las fiestas, comida y cuanto plan apareciera con todo y carro incluido. Muchas gracias a las dos por todo el cariño, por integrarme al grupo, por los momentos en la coffee corner y por las celebraciones por mi cumpleaños.

A los chicos de CUINA, Cris, muchas veces mi primer saludo en la mañana y el último en la tarde, gracias por el saludo de cariño cuando volví a la salita de becarios y por todas las conversaciones en medio de la jornada; Nataly, mi Colombiana en la salita de becarios, mil gracias por todos los envíos para mi mamá y por compartirme lo que pasaba en su familia, charlando de lado a lado del asiento; Damián, gracias porque el día a día era como estar jugando, carreras por no cerrar la puerta y las mil veces que nos saludábamos al día, gracias también por las dedicatorias de los libros y las recomendaciones para el formato de la tesis; Susana, gracias por las convocatorias al café y a comer, por nuestras conversaciones matinales y aquellas que teníamos con solo miradas. iMil gracias a ustedes, a quienes veía diariamente, especialmente por el ánimo en la última fase de la tesis!

Y porque no todo lo que pasa durante este recorrido ocurre dentro del laboratorio o del entorno universitario, agradezco enormemente a mi familia y amigos por el apoyo, palabras, mensajes, llamadas, por ser quienes en Valencia y desde la distancia, en muchas partes del mundo, han contribuido granito a granito en este proceso. 
A mi familia en San Gil, especialmente a mi prima Johanna, a quién desde siempre he considerado como mi hermana, quién siempre está pendiente de nosotras y me ayuda en todo momento, y a mis primos Wilmar y Rubier, quienes siempre están disponibles para todo durante mis visitas decembrinas; a mis primas Alix y Sofía en Floridablanca, quienes siempre me reciben con buena comida y bebida; y a mi primo Edu en Bogotá, quién hace que su casa sea mi casa cada vez que voy; gracias también, por compartir conmigo su sabiduría. Siempre es bueno contar con personas que tengan tanta paz espiritual.

A mi familia putativa repartida por todos lados, al tío Alejandro en Pereira, por sus constantes mensajes de cariño; a Pipe y Mayi, por siempre recibirme en su casa en Bogotá y estar al pendiente de mi; a David y Natalia, por todo el apoyo en este lado del mundo y por nuestro tiempo compartido y ser mi familia en Barcelona y a Lili, por las serenatas cada vez que voy a San Gil.

A mis amigos de San Gil, Jenny, Silvis, Pao, Cayita y Chisco, y de Bogotá, Adri, María y Di, a quienes conozco prácticamente de toda la vida, con quienes he compartido multitudes de aventuras y día a día estamos en constante comunicación. Jenny, Silvis, Cayita, Chisco y Adri, gracias también por todas las diligencias, mandados, conexiones, paseos, recogidas y llevadas al aeropuerto y la buena vibra ante cualquier mensaje y emergencia. Di, gracias por el cariño extendido con la mami, nuestros desayunos Bogotanos y los regalitos, especialmente el último súper regalo, al ayudarme a diseñar la cubierta de la tesis. Gracias a todos ustedes por estar viviendo conmigo desde la distancia, todas estas etapas y momentos de mi vida.

A mis amigos en Valencia, Cris y Temo, por el cariño en cada mensaje y encuentro, nuestras citas a merendar y nuestros viajes a Lille; Bren, por brindarme su casa y por mantener nuestras tradiciones latinas y celebrar conmigo todos los buenos momentos; Elen, por estar para cualquier plan, en especial, los viajes y nuestras salidas de trekking y cine, y a Marthica, ahora radicada en Barcelona, por nuestras charlas, planes de cine, el tiempo en Popayán y por compartir las comilonas colombianas.

A Nuri, nuestra madrileña en Lille, gracias por todo el apoyo en los momentos difíciles y por todas las veces que he estado en su casa; a Vale, mi mexicana en Bruselas, quién ha sido mi soporte en muchos momentos y por ayudarme con tips durante mi estancia en Wageningen y a Anita, mi hermanita venezolana en Santiago de Chile, gracias por el apoyo, soporte, cariño y ayuda desde la distancia, en realidad por absolutamente todo. 
To Kristel, my Estonian ex-roomie, thank you for helping me during my stay in Bennekom, for our shared meals and desserts and for our long conversations around the apartment.

Arthur, thank you very much for the patient, care, support and help especially in the last few months. Thanks for all the moments we have shared, for the ideas and advices for my thesis and our PhD life and travel talks, in particular about San Gil. It was good to have met someone on this side of the world who has been over there.

Mi infinito agradecimiento para mi mamá. Ella es quién ha hecho posible que yo haya llegado hasta aquí, quién con su cariño, apoyo y compañía desde San Gil, ha alentado cada paso y decisión que he tomado; y quién con su forma de ver y aceptar la vida, hace que los momentos difíciles sean vistos de la mejor manera posible.

Tan solo me queda por darle las gracias al COVID-19. El terminar el doctorado con la pandemia andando, quizás ha sido lo más difícil del recorrido por la incertidumbre que genera, pero le doy gracias también, porque me ha ayudado a reflexionar aún más sobre el poder que tenemos en nuestras manos como humanos. Primero con la gente que está a nuestro alrededor, no solo nuestra familia, también nuestros amigos, compañeros del día a día y a quienes nos encontramos en nuestro andar; y luego, con los recursos que el planeta nos provee. Podré ser soñadora, pero espero que esto nos ayude a aprender a ser mejores personas y a utilizar de una mejor forma todos los recursos que el planeta nos provee. El doctorado me ha dejado amigos, enseñanzas, experiencias pero sobre todo, lecciones. 

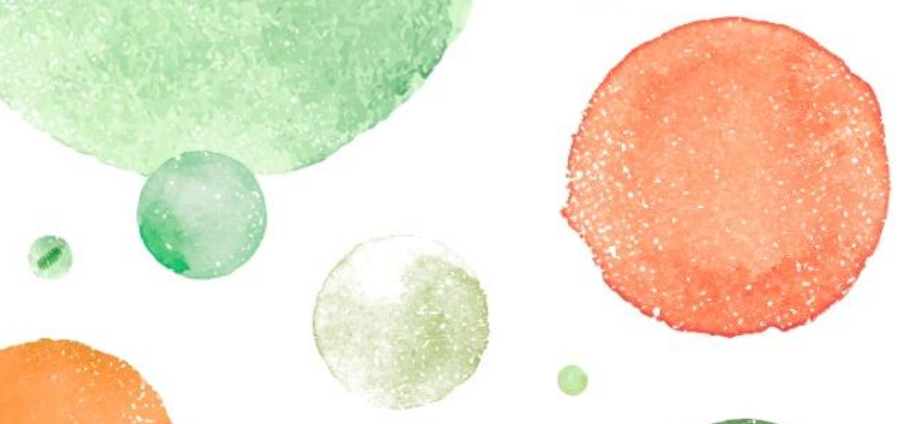

?
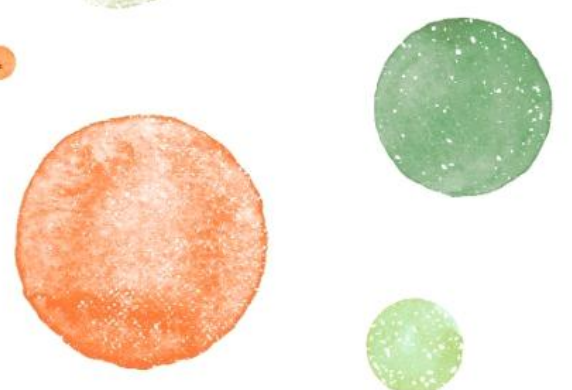

(8)

C

\section{About the author}





\section{Curriculum Vitae}

Zaida Natalia Uribe Wandurraga was born on 24 June 1985 in San Gil, Colombia. She attended her secondary education at Colegio Nuestra Señora de la Presentación in San Gil, where she graduated obtaining an IT Science Diploma. She obtained a Bachelor degree in Chemical Engineering at the Universidad Industrial de Santander in Bucaramanga, Colombia. During her Bachelor, she studied the use of expanded polystyrene postconsumption as an additive to piroxiline lacquer-like paints in

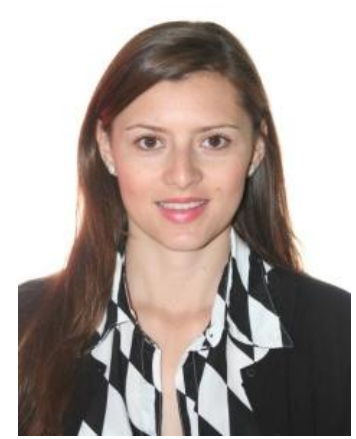
the Industrial Chemistry Laboratory. After her Bacherlor, she earned a Specialist diploma in Food Science and Technology at Universidad Nacional de Colombia in Bogotá, Colombia, where her research focused on obtaining fish protein hydrolyzate from red tilapia residues.

She has worked in the Research, Development and Innovation area in the Food Sector in Bogotá, Colombia, where she obtained experience in the development and formulation of different food products. She has also participated in the planning, implementation and kickstart of new production processes, while working closely together with supply chain, marketing and sales departments. In addition, she has experience in personnel management, administration and business organization.

Coming from coffee origins where her family still produces coffee in their farm in San Gil, she also has experience with coffee planting and harvesting, the production process to obtain the dry grain of Colombian Coffee and its subsequent sale.

After working in the Food Industry, she went on to earn her MSc degree in Food Science and Engineering with a specialisation in Processes and Products Engineering at the Universitat Politécnica de Valéncia in Valencia, Spain. As part of her MSc thesis work at the Food Innovation and Investigation (CUINA) group of Universitat Politécnica de Valéncia, she evaluated the antimicrobial capacity of a bioconservative powder obtained from starter cultures for meat products.

She started her PhD research at the CUINA group of Universitat Politécnica de Valéncia in 2016 where she has been working on formulating new food products using microalgae biomass as an ingredient. Moreover, while performing a Pre-doctoral Stay at the Food and Process Engineering (FPE) Group at Wageningen University and Research in The 
Netherlands, she worked on the formulation and study of the effects of microalgae addition to 3 D-Printed Snacks.

Additionally, she has been participating in the PhD Student Council since 2018 and she is one of $10 \mathrm{PhD}$ representative students in the Doctoral School committee during the academic year 2019-2020. The results of her PhD research are described in this thesis.

Contact: zaidanuw@hotmail.com 


\section{List of Publications}

\section{Journal articles}

Uribe-Wandurraga, Z. N., Igual, M., García-Segovia, P., \& Martínez-Monzó, J. (2019). Effect of microalgae addition on mineral content, colour and mechanical properties of breadsticks. Food \& Function, 10(8), 4685-4692. doi: 10.1039/c9fo00286c

Uribe-Wandurraga, Z. N., Igual, M., García-Segovia, P., \& Martínez-Monzó, J. (2020). In vitro bioaccessibility of minerals from microalgae-enriched cookies. Food \& Function, 11, 2186-2194. doi: 10.1039/c9fo02603g

Uribe-Wandurraga, Z. N., Igual, M., García-Segovia, P., \& Martínez-Monzó, J. (2020). Influence of microalgae addition in formulation on colour, texture, and extrusion parameters of corn snacks. Food Science and Technology International. doi: $10.1177 / 1082013220924178$

Uribe-Wandurraga, Z. N., Igual, M., Reino-Moyón, J., García-Segovia, P., \& MartínezMonzó, J. (2020). Effect of Microalgae (Arthrospira platensis and Chlorella vulgaris) Addition on 3D Printed Cookies. Food Biophysics. doi: 10.1007/s11483-020-09642-y

Uribe-Wandurraga, Z. N., Martínez-Sánchez, I., Savall, C., García-Segovia, P., \& Martínez-Monzó, J. (2020). Microalgae fortification of low-fat oil-in-water food emulsions : an evaluation of the physicochemical and rheological properties. J Food Sci Technol. doi: 10.1007/s13197-020-04828-1

Uribe-Wandurraga, Z. N., Zhang, L., Noort, M. W. J., Schutyser, M. A. I., García-Segovia, P., \& Martínez-Monzó, J. (2020). Printability and Physicochemical Properties of MicroalgaeEnriched 3D-Printed Snacks. Food and Bioprocess Technology. doi: 10.1007/s11947-02002544-4 


\section{Conferences proceedings}

García-Segovia, P., Pagán-Moreno, M.J., Uribe-Wandurraga, Z.N., \& Martínez-Monzó, J. (2017). Efecto de la Incongruencia visual en la percepción del sabor en helados. II Congreso de la Asociación Española de Profesionales del Análisis Sensorial (AEPAS 2017). Universitat Politècnica de València. Valencia, Spain. 18-20 October 2017. Poster

Uribe-Wandurraga, Z.N., García-Segovia, P., Pagán-Moreno, M.J., \& Martínez-Monzó, J. (2018). Effect of the addition of microalgae biomass on bread dough physical, textural and rheological properties. 4th International \& 5th National Student Congress of Food Science and Technology. Asociación Valenciana de Estudiantes y Profesionales en Ciencia y Tecnología de los Alimentos. Valencia, Spain. 22-23 February 2018. Poster

Uribe-Wandurraga, Z.N., García-Segovia, P., \& Martínez-Monzó, J. (2018). Uso de microalgas en la formulación de nuevos alimentos. V Meeting of PhD Students UPV 2018. Universitat Politècnica de València. 5 July 2018. Valencia, Spain. Poster

Uribe-Wandurraga, Z.N., García-Segovia, P., \& Martínez-Monzó, J. (2018). Use of microalgae biomass in novel food formulations. 3rd International PhD Summer School. Kaunas University of Technology. Palanga, Lithuania. 20-24 August 2018. Oral Presentation

Uribe-Wandurraga, Z.N., Igual, M., Noguerol, A.T., García-Segovia, P., \& MartínezMonzó, J. (2019). Microalgae for breadsticks enrichment: Mineral Content and Color Evaluation. VI International Student Congress of Food Science and Technology. Asociación Valenciana de Estudiantes y Profesionales en Ciencia y Tecnología de los Alimentos. Valencia, Spain. 21-22 February 2019. Poster

Noguerol, A.T., Igual, M., Uribe-Wandurraga, Z.N., \& Pagán-Moreno, M.J. (2019). Obtaining powder products from a fermentation broth of Pediococcus acidilactici. VI International Student Congress of Food Science and Technology. Asociación Valenciana de Estudiantes y Profesionales en Ciencia y Tecnología de los Alimentos. Valencia, Spain. 21-22 February 2019. Poster 


\section{Overview of completed training activities}

\section{General Courses}

Re-writing science. How to avoid mistakes in written and spoken scientific English

Research dissemination strategies for researchers

Universitat Politècnica de València. Spain. 2018

Oral Presentation and Communication skills development

Research grant proposal development

Research Ethics, Integrity and Responsibility

Entrepreneurship and Innovations

Kaunas University of Technology. Lithuania. 2018

Time Management

Teamwork

Nonverbal communication

Universitat Politècnica de València. Spain. 2019

Coaching Skills for Learner-Centred Conversations

Imperial College London

Effective Communication for Today's Leader

Critical thinking: reasoned decision making

Tecnológico de Monterrey

edX. 2020

\section{Conflict Resolution}

Universitat Politècnica de València. Spain. 2020 


\section{Optional activities}

\section{Assistance in the organization}

II Congreso de la Asociación Española de Profesionales del Análisis Sensorial (AEPAS 2017) Universitat Politècnica de València. Spain. October 2017

\section{Ecotrophelia Spain 2018}

Finalist of the IX National Spanish Food Innovation Award- Ecotrophelia 2018

Product: "UMITASTE". A new concept of sushi wrappers developed from microalgae Fundación Alicia. Barcelona. Spain

\section{Pre-doctoral Stay at Foreign Institution}

Food Process Engineering Group

Wageningen University \& Research

Under the supervision of Dr. Maarten Schutyser and Dr. Lu Zhang

The Netherlands. April 2019 - July 2019

\section{Weekly group meetings}

Food Process Engineering Group

Wageningen University \& Research

The Netherlands. 3 months. 2019

\section{Teaching}

Supervision of 4 BSc and 1 MSc thesis students

Universitat Politècnica de València. Spain. 2017 - 2019 





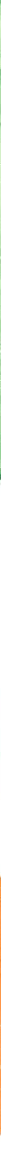

